Runoff and Sediment Yield Model

for Predicting Nuclide Transport

in Watersheds Using BIOTRAN
A. F. Gallegos
W. J. Wenzel 


\section{CONTENTS}

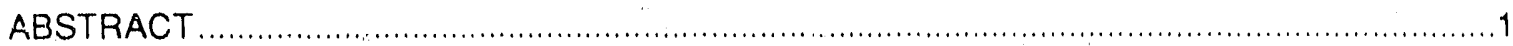

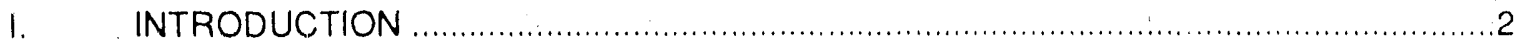

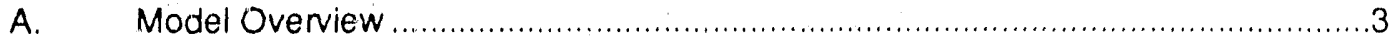

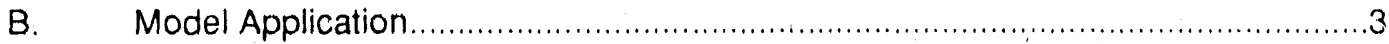

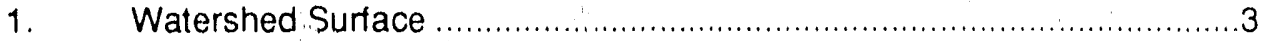

2. Watershed Aquifer and Alluvial Plain ........................................... 7

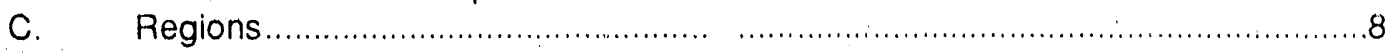

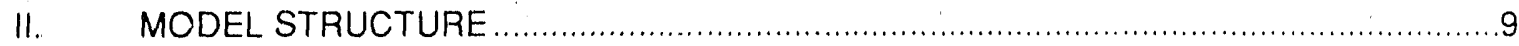

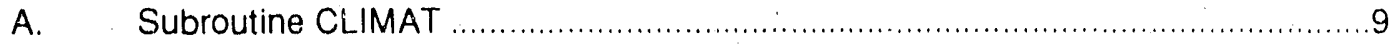

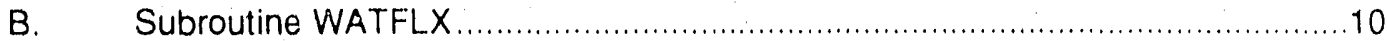

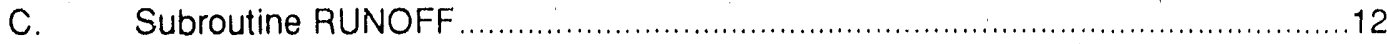

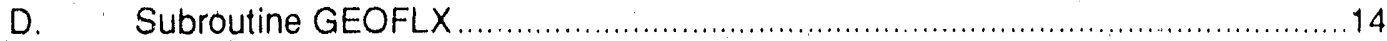

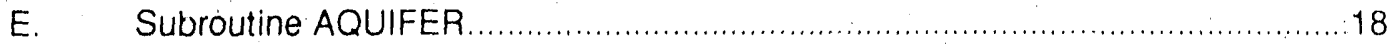

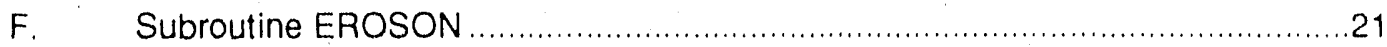

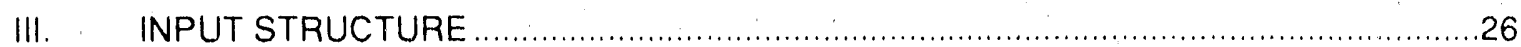

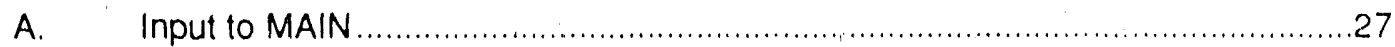

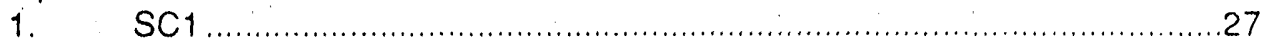

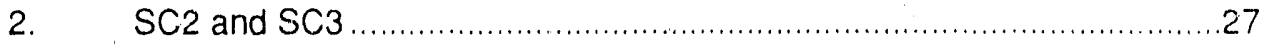

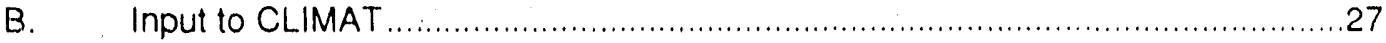

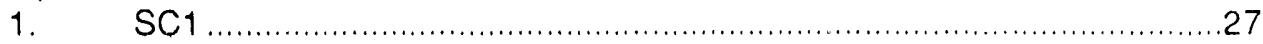

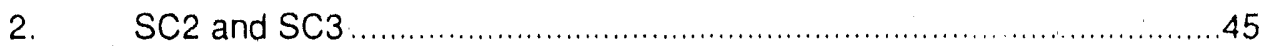

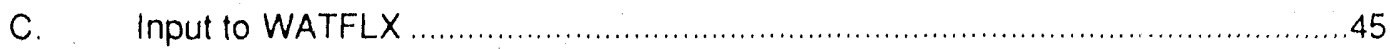

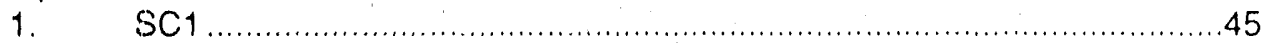

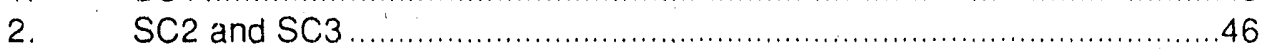

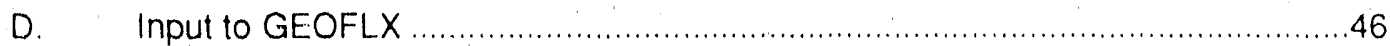

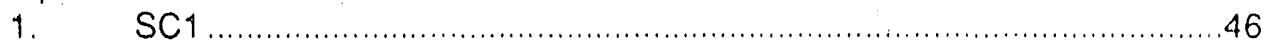

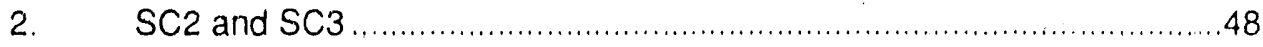

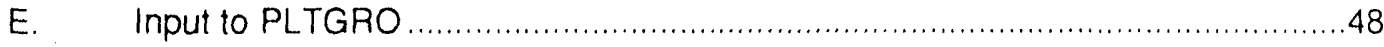

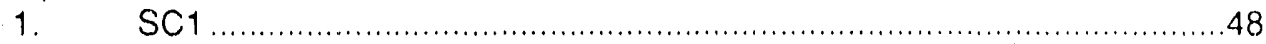

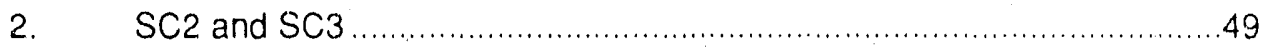

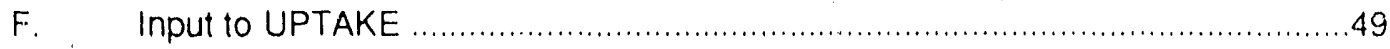

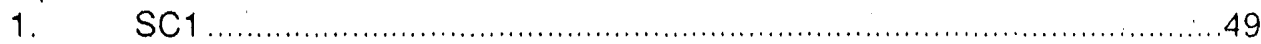

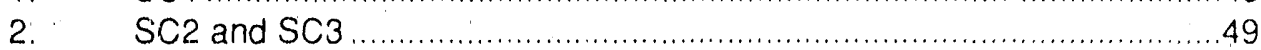

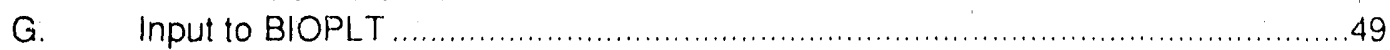

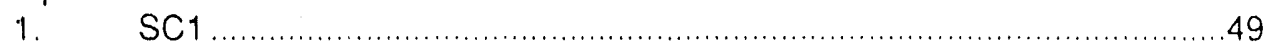

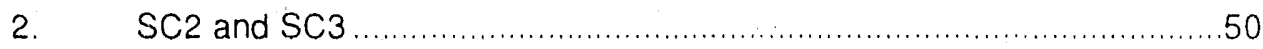

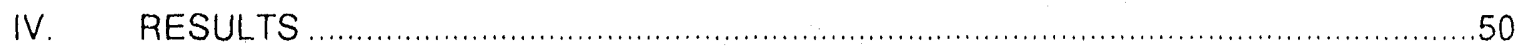

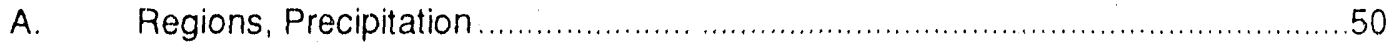

B. Regions, Mean Daily Temperature …..................................................... 50

C. Regions, Total Above Ground Biomass ...................................................102

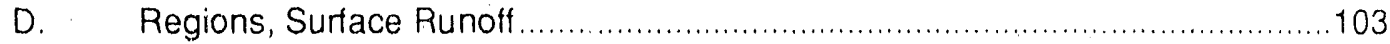

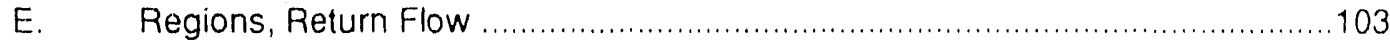

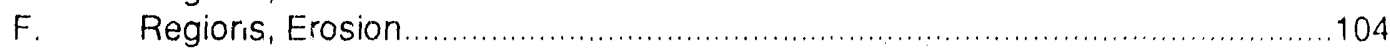

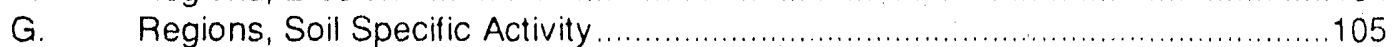

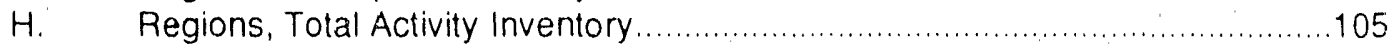

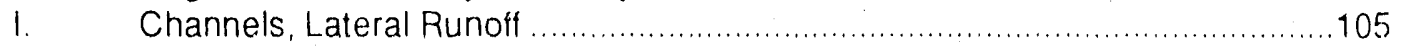

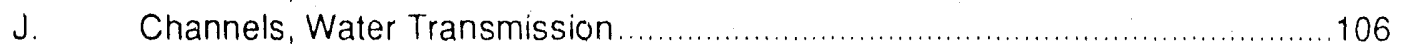




\section{Contents (cont)}

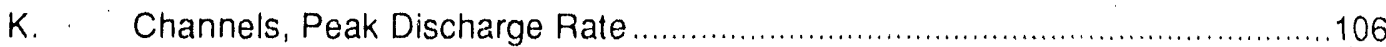

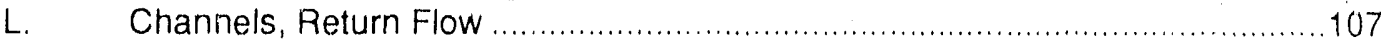

M. Channels, Aquifer Transport Losses and Aquifer Heights ..........................107

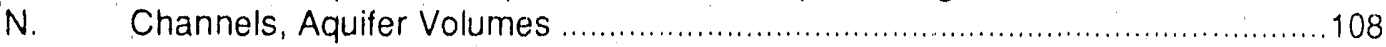

O. Channels, Sediment Discharges ....................................................... 107

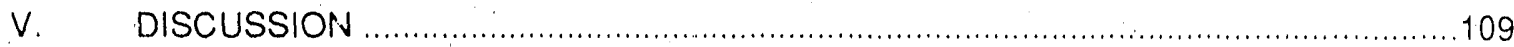

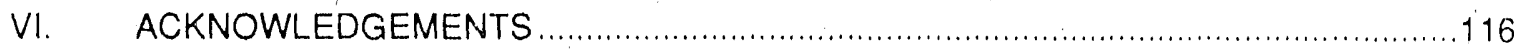

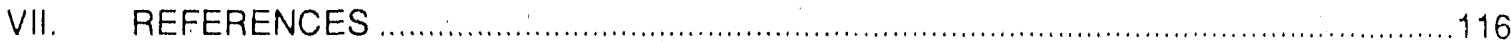

\section{FIGURES}

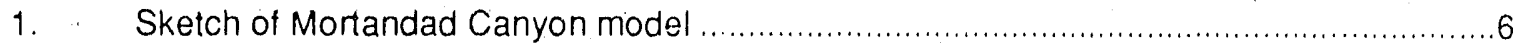

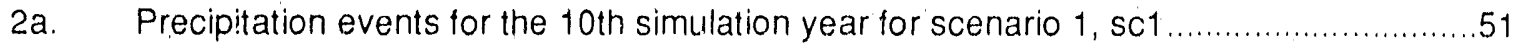

2b. Precipitation events for the 10th simulation year for scenario 2, sc2 ...........................52

2c. Precipitation events for the 100th simulation year for scenario $3, \operatorname{sc} 3 \ldots \ldots \ldots \ldots \ldots \ldots \ldots . \ldots . \ldots 3$

3a. Mean daily temperature for the 10th.simulation year for scenario $1, \mathrm{sc1} \ldots \ldots \ldots \ldots \ldots \ldots . \ldots 54$

3b. Mean daily temperature for the 10 th simulation year for scenario $2, \mathrm{sc2} \ldots \ldots \ldots \ldots \ldots \ldots . \ldots 5$

3c. Mean daily temperature for the 100 th simulation year for scenario $3,5 c 3 \ldots \ldots \ldots \ldots \ldots \ldots . . .56$

4a. Total above ground live biomass for scenario 1, sc1, for annual and perennial grasses and herbs on the 10th simulation year ....................................................5. 57

4b. Total above ground live biomass for scenario 2, sc2, for grasses, shrubs, and trees in niche competition and succession on the 10 th simulation year .......................58

4c. Total above ground live biomass for scenario 3, sc3, for grasses, shrubs, and trees in niche competition and succession on the 100th simulation year .....................59

5a. Regional surface runoff events for the 10th simulation year in scenario 1, Sc1.

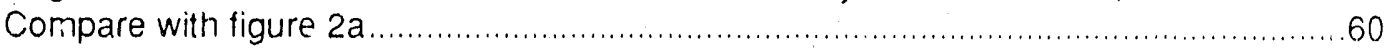

5b. Regional surface runoff events for the 10th simulation year in scenario 2, sc2.

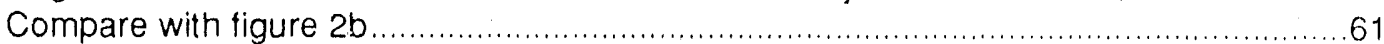

5c. Regional surface runoff events for the 100th simulation year in scenario 3, sc3.

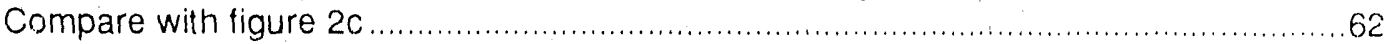

6a. Subsurface return flow for the 10 th simulation year for scenario 1, sc $1 \ldots \ldots \ldots \ldots \ldots \ldots . . \ldots 3$

6b. Subsurtace return flow for the 10th simulation year for scenario 2, sc2 $\ldots \ldots \ldots \ldots \ldots \ldots \ldots \ldots . \ldots 4$

ic. Subsurtace return flow for the 100th simulation year for scenario 3, sc $3 \ldots \ldots \ldots \ldots \ldots \ldots . .65$

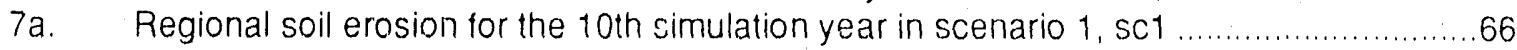

7b. Regional soil erosion for the 10th simulation year in scenario 2, sc2 _.....................67

7c. Regional soil erosion for the 100 th simulation year in scenario $3, \mathrm{sc3} \ldots \ldots \ldots \ldots \ldots \ldots \ldots \ldots . . . . . . . . . .68$

8a. Mass of soil removed by erosion from regions in 10 th simulation year for

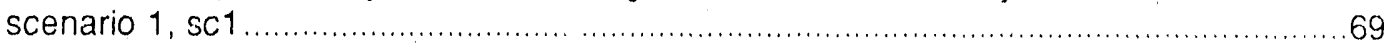

8b. Mass of soil removed by erosion from regions in 10 th simulation year for scenario 2 ,

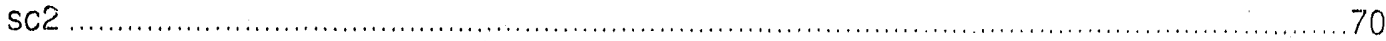

8c. Mass of soil removed by erosion from regions in 100 th simulation year for

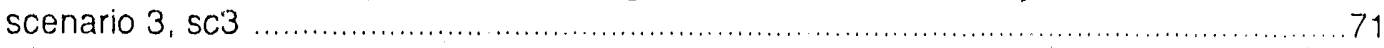

9a. Regional soil uranium specific radioactivity for 10 th simulation year in scenario $1, \mathrm{sc} 1$ 


\section{Colitents (cont)}

9b. Regional soil uranium specific radioactivity for 10 th simulation year in scenario 2, sc2.

9c. Regional soil uranium specific radioactivity for the 100 th simulation year in scenario 3, sc3.

10a. Regional total soil uranium radioactivity for 10 th simulation year for

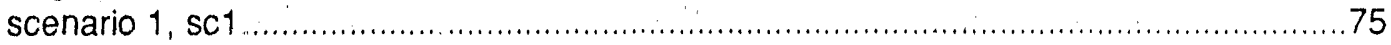

10b. Regional total soil radioactivity for 10 th simulation year for

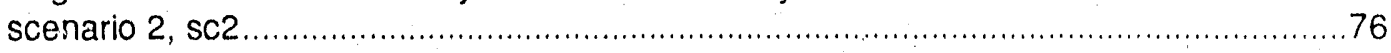

10c. Regional total soil uranium radioactivity for 100 th simulation year for

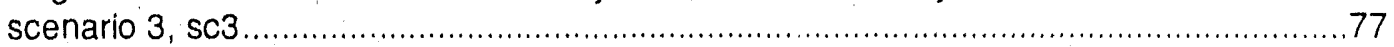

11a. Lateral runoff into charinels from adjacent regions for 10 th simulation year for

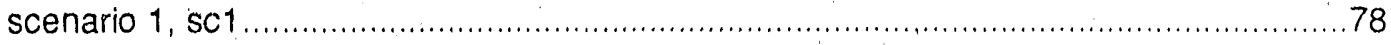

11b. Lateral runoff into channels from adjacent regions for 10 th simulation year for

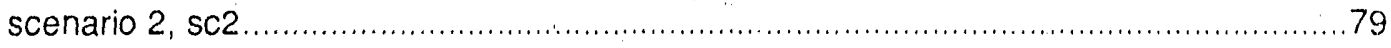

11c. Lateral runoff into channels from adjacent regions for 100 th simulation year for

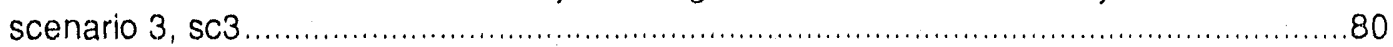

12a. Water transmission at end of channel on 10th simulation year for scenario $1, \mathrm{sc} 1 \ldots \ldots . . .81$

12b. Water transmission at end of channel on 10th simulation year for scenario $2, \operatorname{sc2} \ldots \ldots \ldots .82$

12c. Water transmission at end of channel on 100th simulation year for scenario $3, \operatorname{sc} 3 \ldots \ldots . .83$

13a. Peak channel discharge rates for runoff events in 10th simulation year in

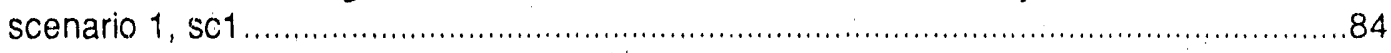

13b. Peak channel discharge rates for runoff events in 10 th simulation year in

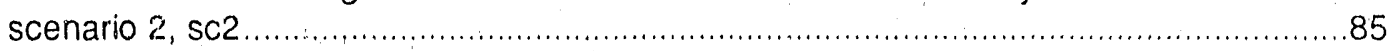

13c. Peak channel discharge rates for runoff events in 100 th simulation year in scenaiio 3, sc3.....

14a. Return flow volume entering a channel from adjacent regions on 10tri simulation

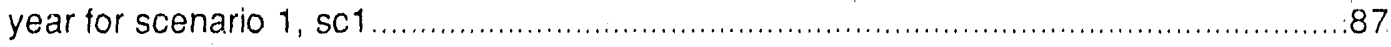

14b. Return flow volume entering a channel from adjacent regions on 10 th simulation

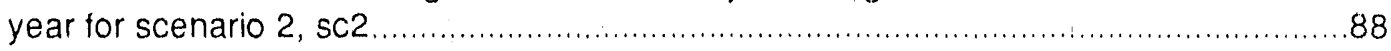

14c. Return flow volume entering a channel from adjacent regions on 100 th simulation year for scenario $3, \mathrm{sc} 3$.

15a. Aquifer transport losses at distal face below channels for 10th simulation

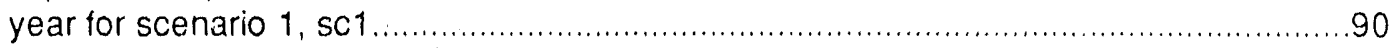

15b. Aquifer transport losses at distal face below channels for 10 th simulation

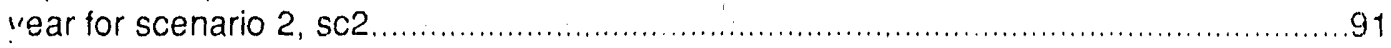

15c. Aquifer transport losses at distal face below channels for 100 th simulation

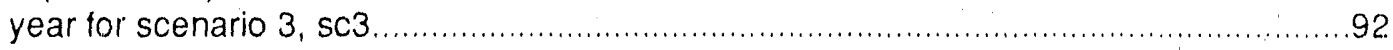

16a. Aquifer height below channel for 10 th simulation year for scenario $1, \mathrm{sc1} \ldots \ldots \ldots \ldots \ldots \ldots . . . . . . .33$

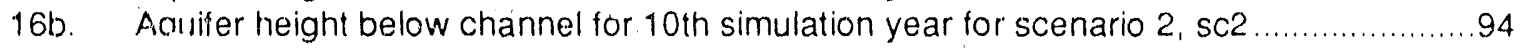

16c. Aquifer height below channel for 100 th simulation year for scenario $3, \operatorname{sc} 3 \ldots \ldots \ldots \ldots \ldots . . . . . .55$

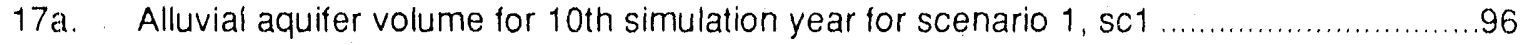

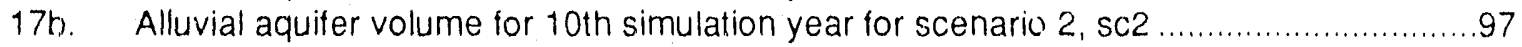

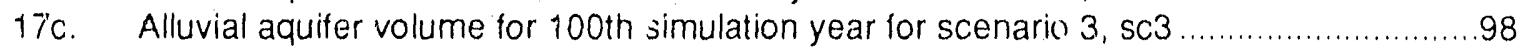

18a. Sediment discharge from chanriels in 10th simulation year for scenario 1, sc1 ............99

18b. Sediment discharge from channeis in 10th simulation year for scenario $2, \mathrm{sc2} \ldots \ldots \ldots \ldots 100$

18c. Sediment discharge from channels in 100th simulation year for scenario $3, \operatorname{sc} 3 \ldots \ldots \ldots 101$ 


\section{Contents (cont)}

\section{TABLES}

1. Listing of BIOTRAN Subroutines and Their Functions .......................................

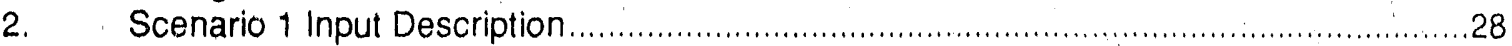

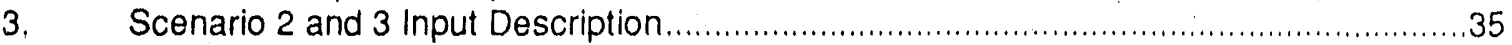

4. Observed Precipitation Near Mortandad Canyon at Three LANL Sites .......................110

5. Observed and Simulated Precipitation and Runoff Evenis in Mortandad

Canyon: Above Upper Weir (GS-1) .....................................................111

6. Simulated Moisture Runoff from Surface and Return Flow. Events............................112

7. Simulated Discharge Rates and Other Related Parameters for Mortandad Canyon......113

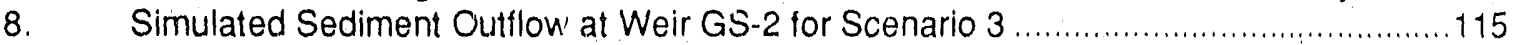

9. Annual Water and Sediment Outflows from GS-Z .........................................115 


\title{
RUNOFF AND SEDIMENT YIELD MODEL FOR PREDICTING NUCLIDE TRANSPORT IN WATERSHEDS USING BIOTRAN
}

by

A. F. Gallegos and W. J. Wenzel

\begin{abstract}
The environmental risk simulation model BIOTRAN was interfaced with a series of new subroutines (RUNOFF, GEOFLX, EROSON, and AQUIFER) to predict the movement of nuclldes, elements, and pertinent chemical compounds in association with sediments through lateral and channel flow of runoff water. In addition, the movement of water into and out of segmented portions of runoff channels was modeled to simulate the dynamics of moisture flow through specified aquifers within the watershed. The BIOTRAN soil water flux subroutine, WATFLX, was modifled to interface the relationships found in the. SPUR model (Wight 1984) for runoff and sediment transport into channeis with the particle sorting relationships utilized by Lane (1985) to predict radionuclide enrichment and movement in watersheds. The new subroutines were applied specifically to Mortandad Canyon within Los Alamos National Laboratory by simultaneous simulation of eight surface vegetational subdivisions and associated channel and aquifer segments of this watershed. This report focuses on descriptions of the construction and rationale for the new subroutines and on discussing both input characteristics and output relationships to known runoff events; from Mortandad Canyon. Limitations of the simplified input on model behavior are also discussed. Uranium-238 was selected as the nuclide for demonstration of the model because it could be assumed to be homogeneously distributed over the watershed surface.
\end{abstract}




\section{INTRODUCTION}

The simulation model BIOTRAN has been used in previous health risk assessments and contaminant migration studies by constructing complex scenarios to estimate the movement of nuclides and nutrients in diverse environments through specified plant and animal pathways to man. The plant pathways simulated by BIOTRAN have involved both natural and irrigated plants used as food by both humans and livestock to predict cancer mortality in a given human population. There is an equal need to predict the surtace and subsurtace transport of radionuclides and hazardous chemiçals within a watershed. Contaminated particles and solutes may ultimately be transported from areas of minimal risk to humans to environments which may pose a health hazard to man by entering his drinking water and foodchain in significant quantities.

A number of factors such as climate, vegetation type and standing crop, soil characteristics, and slope of watershed surtaces and channels all affect erosion processes. A simulation model which can integrate these processes with those involving human landscape mudifications such as surface paving and agricultural tillage can become a valuable tool in assessing health risks to man from runoff-generated events. BIOTRAN has the capability of estimating surticial contamination of plant surfaces from global fallout and resuspension of soil particles. In its present version, it is capable of integrating these process with scouring and sediment deposition events. The integration has been possible by use of the relationships developed in the SPUR model (Wight 1984) for overland runoff and sediment yield predictions with the simulation model particle size sorting and channel transport processes developed by Lane (1985) for application in the Los Alamos environment. The development of an aquifer component in BIOTRAN to simulate the subsurface movement of water is complementary to channel transport processes mentioned earlier. The simulation of a riparian ecosystem along the channel segments is also a new feature of the model. As with many sirnulation models, BIOTRAN previously modeled only one site or region of variable area. In its present version, multiregional simulations are possible to characterize different parts of a watershed to correspond to topographic plant associations and slope effects, thus a wide variety of vegetational zones for the steep E-W trending canyon and mesa watersheds at Los Alamos can be simulated simultaneously. It is also possible to perform simultaneous multinuclide and multinutrient simulations in one run of BIOTRAN.

BIOTRAN has incorporated well-known, validated portions of other ecosystem models such as RANGE (Gilberi 1974). ELM (Cole 1978), and CREAMS (Knisel 1980) in addition to SPUR (Wight 1984) over the last 14 yr. BIOTRAN is internally consistent with units. The units shown in this report retain the English or metric units from the references used to derive input or develop code. BIOTRAN functions primarily in daily time increments and operates generally with difference equations involving regression equations when required. The version presented in this report is limited to modeling physical transport of contaminants and solutes by erosion and excludes adsorption-desorption or chemical processes involving contact by surlace or infiltrating water. However, plant uptake and soil leaching of nuclides by these last processes have been modeled previously for other applications, and it is expected that future model development will interface them with runoff simulations. 


\section{A. Model Overview}

The simulation model BIOTRAN contains a menu program called MAIN to allow the user to set up the scenario sequencing the 16 subroutines listed in Table 1 with an abbreviated function. A detailed description for each subroutine and its intended applications are described in the BIOTRAN User's Manual (Gallegos et al. 1990). The asterisked subroutines in Table 1 are described using FORTRAN algorithms in this report. All or part of the 16 subroutines could be used in any given simulation, depending on the scenarios defined by the user in MAIN. The subroutines used in this report were limited to CLIMAT, WATFLX, GEOFLX, RUNOFF, EROSON, AQUIFER, PLTGRO, and UPTAKE: The subroutines CLIMAT, PLTGRO, UPTAKE, AND BIOPLT will be described in this report in general terms as they relate to those subroutines of inter est. Additional information on these subroutines may be found in another report (Wenzel ef al. 1987). The subroutine WATFLX will be described primarily in reference to its importance as an interface to the new subroutines and not as the soil moisture movement simulator, which is its major function.

\section{B. Model Application}

1. Watershed Surface. The site for the application of the runoff and sediment transport sirnulations involved the upper portion of Mortandad Canyon within the confines of the Los Alamos National Laboratory (LANL.). Figure 1 shows a sketch of the simulated area. The simulated segments are outlined on the figure. The portion of the canyon simulated extends from its farthest reach at 7300-ft elevation near Diamond Drive to about 6800-ft elevation at the intersection of the main channel with the tributary channel that originates about $1.5 \mathrm{mi}$ west; this channel was not included in the simulation. The main channel segment extends about $2.43 \mathrm{mi}$ and ras ari average slope of about 0.04 between the markers set for the scenario. About $1.15 \mathrm{mi}$ downstream from the main channel, another tributary channel intersects at about 7100 -ft elevation; the channel originates about $0.46 \mathrm{mi}$ up-channel in a westerly direction near the L_ANL facilities TA-50 and TA-55. This channel is included in the scenario because low-lovel radioactive effluent is dis. posed into it from the LANL liquid waste processing facility. TA-50. The main channel segment also receives sanitary and cooling water effluents a short distance above this junction, which is also included in the scenario construct. The total watershed area modeled is approximately 500 acres, consisting of ponderosa pine forest with an admixture of pinyon-juniper and shrub oak vegetation at the low'er elevations. For modeling purposes, Figure 1 shows the watershed channels segmented into four drainage areas with associated channels:

(1) $\quad 1.15$-mi channel length initiating at $7300 \mathrm{ft}$ along the main channel near L.ANL fa. cility' TA-59 and terminating at $7100 \mathrm{ft}$ at the junction of the first tributary channel draining the TA-50 site. This channel has a slope of about 0.046 and drains ap. proximately 246 acres. The drainage area has an approximate slope of 0.07 . Vegetation is ponderosa pine torest and has about $10 \%$ of its surtace impermeable due to rock outcrops. A shallow aquifer without an alluvial plain is included (Baltz 1963). 
TABLE 1. Listing of BIOTRAN Subroutines and Their Functions

Subroutine

AIRAC

CLIMAT

WATFLX

GEOFI... ${ }^{*}$

RUNOFF*

EROSION*

AQUIFER*

PLTGRO

FORMAN

FORCUT

UPTAKE

ZOOGRO

ANIMAL

HUMTRN

\section{Function}

Simulates chronic and acute air contamination events

Simulates daily temperature, solar radlation, precipitation amounts and pattern, potential evapotranspiration, and other climatic variables.

Simulates moisture movement through the rooting zone of plants, evapotranspiration processes, and irrigation events.

Simulates the coordination of runoff and erosion events from specific regions of a watershed to respective channels.

Simulates the amount of runoff as a function of antecedent soil moisture and precipitation amount; and the simulation of immediate moisture infiltration into the rooting zone of plants.

Simulates the differential removal of soil or alluvial particles as a function of particle diameter.

Simulates the infiltration and movement of alluvial ground water from one channel segment to another.

Simulates the growth of plants as a function of plant type, solar radiation, ambient temperature, nutrients, frost-free period, and other environmental factors.

Simulates the growth of forest stands by diameter classification and other forest characteristics such as tree height and bole diameter.

Simulates tree harvesting operations and forest fires in conjunction with the FORMAN subroutine.

Simulates the contamination of plants by root uptake and surficial deposition as the result of resuspension and fallout mechanisms.

Simulates the food supply of herbivores, omnivores, carnivores and humans in conjunction with PL.TGRO and UPTAKE subroutinise Both internal and external contamination of plants and animal $\| s:$ ues for consumption are estimated for different diet preferences.

Simulates the growth of mammals iricluding beef and dairy cattle, deer, and rodents. The biological transport of contaminants through the foodchain is also modeled. In addition, an insect model is included to simulate a diet item for insectivorus rodents.

Simulates the growth of male and temale human populations by age group and foodchain transport of contaminants from specific diets. 
TABLE 1. (cont)

Subroutine

AQUAT

BIOPLT

BIOPL............
Simulates the functioning of a lake ecosystem including phytoplankion and zooplankton, and lake chemical and thermal dynamics in conjunction with the CLIMAT subroutine.

Model-wide variable selector for graphical display modes.

"New subroutines documented in this report.

0.46-mi channel length initiating at about $7200 \mathrm{ft}$ near TA-55 and terminating at $7100 \mathrm{ft}$ at its junction with the main channel. This channel has a slope of about 0.08 and drains approximately 72 acres. The drainage area has an ap roximate slope of 0.10 . Vegetation is ponderosa pine forest and has about $10 \%$ of its surface impermeable due to rock outcrops and human pavement. A shallow aquifer without an alluvial plain is included.

(3) $\quad 0.79-\mathrm{mi}$ channel length initiating at $7100-\mathrm{ft}$ elevation along the main channel at its junction with chanriel (2) and terminating down-channel at about 6900-it elevation. This channel has a slope of about 0.05 and drains approximately 116 acres. The drainage area has an approximate slope of 0.10 . Vegetation is predominantly ponderosa pine forest with some admixture of pinyon pine and about $10 \%$ impermeable surface due to rock outcrops. An alluvial plain of about 3.2 acres occurs along the length of the channel coincident with the surlace area of the shallow aquifer underlying the channel.

(4) $0.49-\mathrm{mi}$ channel length initiating at about $6900-$ ft elevation along the main channel at the terminus of channel (3) and terminating down-channel at about $6800-\mathrm{ft}$ elevation. This channel has a slope of about 0.04 and drains approximately 63 acres. The drainage area has an approximate slope of 0.10 . Vegetation is predominanily ponderosa pine forest with an admixture of pinyon pine and juniper and about $10 \%$ impermeable surface due to rock outcrops. An alluvial plain of about 6.9 acres runs along the length of the channel coincident with the surtace area of the shallow aquifer underlying the channel.

The information presented above was estimated from LANL topography maps of Mortandad Canyon and from information obtained by Onishl (1982) in his watershed study of the canyon. A substantial amount of information concerning the vegetation, radionuclide inventory and move. ment, soils, and hydrology of Mortandad Canyon has been documented by a number of investiga. tors (Hakonson 1973. Nyhan 1976, and Purtymun 1974), and the reader is reterred to these documents for more detail. 


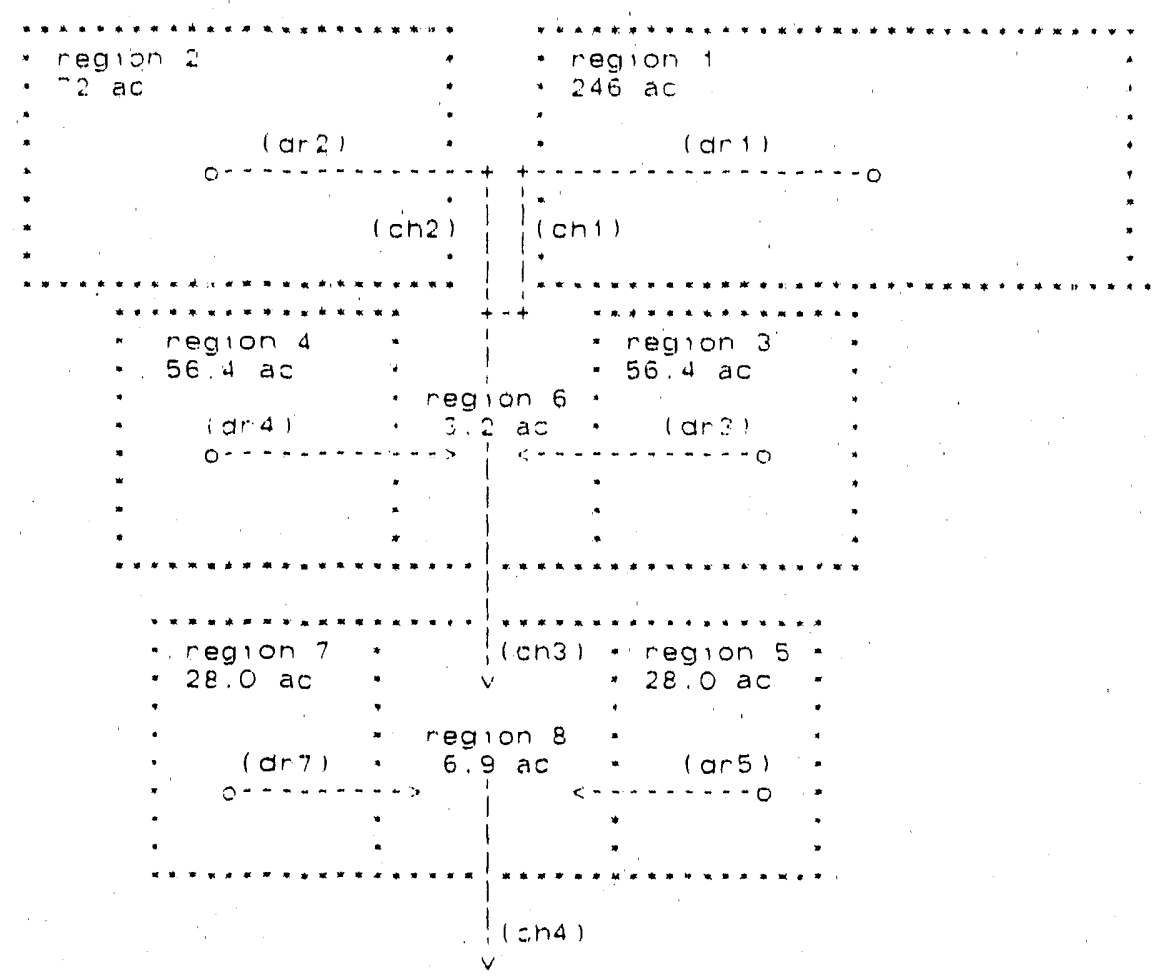

Expianation of Symbols

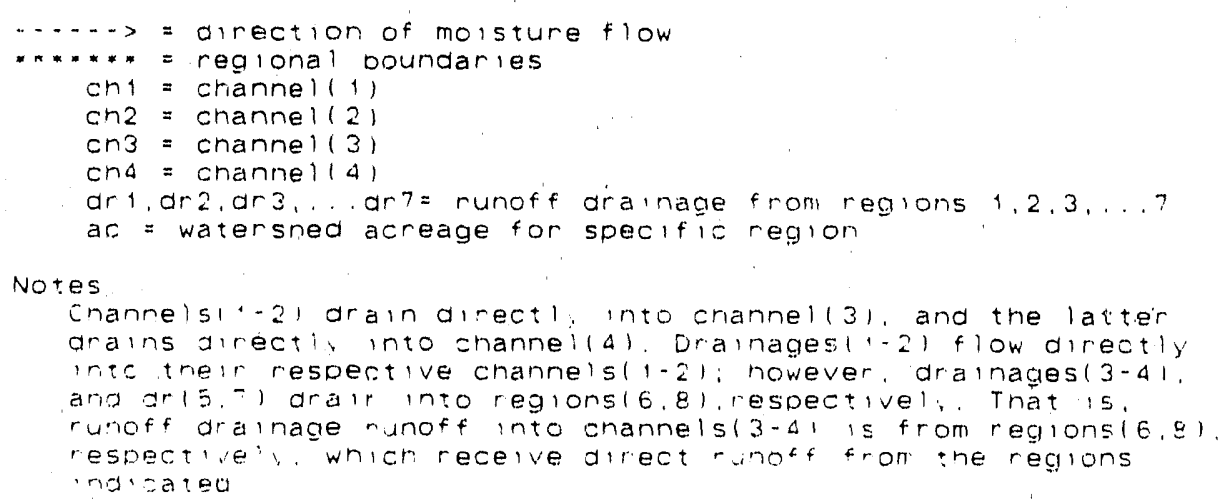

Fig. 1. Sketch of Mortandad Canyon model. 
2. Watershed Aquifer and Alluvial Plain. A shallow aquifer continuous throughout the main and tributary channels in question is included in the scenario. The aquifer is approximated as a series of connected trapezoidal solids with a slope parallel to the corresponding channel slope: the down-channel trapezoidal face has a greater depth and width than the face of the anterior end. The aquifer coincldes with the four channel segments described previously with the posterior faces of anterior segments becoming the anterior faces of posterior channels. The slope of the channel is also taken into account in estimating the aquifer volume. Figure 1 shows the top of the four aquifers beneath each channel. The dimensions of the four aquifers below each channel are estimated from observed values (Baltz 1963) as described below:

(1) Aquifer underlying channel segment 1. This aquifer is estimated to be $6072 \mathrm{ft}$ long with surface slope of 0.046 . The anterior trapezoldal face has estimated dimensions of 3.0, 1.5, and $2.0 \mathrm{ft}$ for upper base, lower base, and height, respectively. The posterior trapezoidal face has dimensions of $24.0,14.0$, and $6.0 \mathrm{ft}$ for upper base, lower base, and height, respectively. An alluvial plain is not included for this channel segment.

(2) Aquifer underlying channel segment 2. This aquifer is estimated to be $2429 \mathrm{ft}$ long with a surface slope 0.08 . The anterior trapezoidal face has estimated dimensions of $3.0,1.5$, and $2.0 \mathrm{ft}$ for upper base, lower base, and height; respectively. The posterior trapezoidal face has dimensions of 24.0, 14.0 and $6.0 \mathrm{ft}$ for upper base, lower base, and height, respectively. An alluvial plain is not included for this channel segment.

(3) Aquifer underlying channel segment 3. This aquifer is estimated to be $4171 \mathrm{ft}$ long with a surface slope of 0.05 . The anterior trapezoidal face has estimated dimensions of 24.0,14.0, and $6.0 \mathrm{ft}$ for upper base, lower base, and height, respectively. The posterior trapezoidal face has dimensions of $43.0,21.0$, and 15.0 It for upper base, lower base, and height, respectively. An alluvial plain is included for this channel segment with a surface area equal to 3.2 acres as described earlier. Other characteristics of this plain are presented later in this report.

(4) Aquifer underlying channel segment 4. This aquifer is estimated to be $2587 \mathrm{ft}$ long with a surface slope of 0.04 . The anterior trapezoidal face has estimated dimensions of $43.0,21.0$, and $15.0 \mathrm{H}$ for upper base, lower base, and height, respectively. The posterior trapezoidal face has dimensions of 191.0, 46.0, and $36.0 \mathrm{ft}$ for upper base, lower base, and height, respectively. An alluvial plain is included for this channel segment with a surtace area equal to 6.9 acres.

In summary, aquifer and channel segments 1 and 2 enter aquifer and channel 3, which then enters aquifer and channel 4 . Alluvial plains are modeled for the last two channel segrnents ( 3 and 4 ). 
C. Regions. Eight coiltributing areas and their associated plant communities that have been defined to model the upland portion of Mortandad Canyon are described below. Figure 1 shows the regions, channels, and underlying outline of the shallow aquifers.

1. This region coincides with the drainage area (canyon walls and watershed) preserited for channel $i$ and its description: 7100- to 7300-ft elevation, 246 acres, with ponderosa pine, oak shrub, and cool-season annual and perennial grasses as the predominant vegetation.

2. This region coincides with the drainage area (canyon walls and watershed) presented for channel 2 and its description: 7200- to 7100-ft elevation, 72 acres, with ponderosa pine, oak shrub, and cool-season annual and perennial grasses as the predominant vegetation.

3 \& 4. These canyon wall watershed regions connect to region 6 parallel to channel 3 . They are located at 6900- to 7100 -ft elevation and are divided equally into two 56.4-acre tracts (for modeling purposes). The predominant vegetation is ponderosa pine, oak shrub, and cool-season grasses.

5,7 . These canyon wall watershed regions connect to region 7 parallel to channel 4 . They are located at 6680- to 6900-it elevation and are divided equally into two 28.0-acre tracts (for modeling purposes). The predominant vegetation is ponderosa pine, oak shrub, and cool-season grasses with some pinyon pine and warmi-season annual and perennial grasses.

6. This region coincides with the alluvial plain for channel 3 as described previously except that it incorporates the aquifer and extends beyond the aquifer area at the surface. It is lociated at an elevation of about $7000 \mathrm{ft}$ with an area of 3.2 acres and a riparian plant community consisting of ponderosa pine, deciduous trees and shrubs, and warm- and cool-season grasses. Channel 3 flows through the center of this region throughout its length.

8. The region coincides with the alluvial plain for channel 4 as described previously except that it incorporates the aquifer and extends beyond the aquifer area at the surface. It is located at an elevation of about $6850 \mathrm{ft}$ with an area of 6.9 acres and a riparian plant community consisting of ponderosa pine, deciduous trees and shrubs, and warm- and cool-season grasses as the predominant vegetation along with an admixture of pinyon pine.

A more detailed description of these simulated regions will be presented when in put/output structures are considered later in this report. 


\section{MODEL STRUCTURE}

The BIOTRAN subrol'ines WATFLX, RUNOFF, GEOFLX, and EROSON will be the primary focus of this section. Subroutine CLIMAT will be discussed in relation to evapotranspiration input into WA.TFLX, and the latter will receive attention with regard to interfacing the newly developed subroutines mentioned above. Other subroutines involved in the watershed simulation using BIOTRAN will receive indirect attention when input requirements are described. The reader is referred to other references for information on BIOTRAN as a whole and specifically for other subroutines not considered here (Gallegos 1980, Gallegos 1984, Wenzel 1985).

\section{A. Subroutine CLIMAT}

This subroutine is a stochastic climate simulator of regional temperature, precipitation, and precipitation pattern. CLIMAT also simulates solar radiation intensity, snowiall, snowmelt, and potential evapotranspiration for a given site (Gallegos 1984).

Potential evapotranspiration, $\mathrm{mm} / \mathrm{day}$, for a given region is estimated with the following FORTRAN algorithms:

$$
P E T=(1.28 * D E L T T * H O) /(D E L T T+A P S Y C),
$$

where DELTT is the slope of psychrometric saturation line, mbars $/{ }^{\circ} \mathrm{C}$;

$$
\operatorname{DELTT}=5304 /(T+273) * * 2 * \operatorname{EXP}(21.255-5304 /(T+273)),
$$

where $\mathrm{T}$ is the average daily temperature, ${ }^{\circ} \mathrm{C}$. APSYC is the psychrometric constant, mbars $/{ }^{\circ} \mathrm{C}$,

$$
\text { APSYC }=0.0006595 * \text { PMBAR, }
$$

where PMBAR is the barometric pressure, mbars;

$$
\text { PMBAR } \approx=1013 .-0.1152 *(0.3048 * \mathrm{G} 1+5.44 \mathrm{E}-06 *(0.3048 * \mathrm{G} 1) *(0.3048 * \mathrm{G} 1)) \text {, }
$$

where $\mathrm{G} 1$ is the site elevation in feet above sea level, $\mathrm{HO}$ is the net daily solar radiation, Langelys;

$$
H O=(1-A L B D) * S O L R A D / 58.3
$$

where ALBD is the albedo (set to 0.2 ), and SOLRAD is the daily energy insolation, Langelys.

The major difference between this estimate of PET and that obtained using the CREAMS model (Knisel 1980) is that the psychrometric constant is a function of estimated barometric pressure based on site elevation. This PET estimate is used later in the WATFLX subroutine to initially es. timate surface water losses and set the upper boundary for transpiration losses from successive rooting soil layers. 
Snowfall and snowmelt are bounded to an average daily temperature of $2^{\circ} \mathrm{C}$ above zero which snowmelt occurs; otherwise, snow accumulation is simulated. This temperature was estimated from turing of the algorithm to give the best representation of snow accumulation at LoS Alamos. At average daily temperatures exceeding $2^{\circ} \mathrm{C}$, snowmelt, $\mathrm{SNM}, \mathrm{mm} /$ day, is estimated as

$$
\text { SNM }=11.28 * T M X+1.128
$$

where $T M X$ is the maximum daily temperature, ${ }^{\circ} \mathrm{C}$;

$$
T M X=T+0.53 * A B S(T+1) \text {, }
$$

where $\mathrm{T}$ is the average daily temperature, ${ }^{\circ} \mathrm{C}$. Ten inches of snow is assumed equivalent to $1 \mathrm{in}$. of precipitation on the average.

\section{R. Subroutine WATFLX}

This subroutine contains a substantial portion of the soil hydrology modeling incluaring soil physical properties; nuclide, chemical, and nytrient composition; extent of root penetration into the soil horizon; transpiration by plants; evaporation from the soil surface; and irrigation strategies. WATFLX integrates with other subroutines used in modeling runoff and erosion as well. Transpiration, evaporation, and an abbreviated discussion of soil moisture movement will be described in this report; other modeling efforts within this subroutine were discussed elsewhere (Wenzel 1987, Gallegos et al. 1990).

Plant transpiration is estimated as the total amount of water evaporated from successive soil layers of a given plant type (each type, such as cool-season grass or ponderosa pine, is simulated separately for each layer) from a given region where $T P_{i}$ is the transpiration from the ith soil layer, $\mathrm{mm} /$ day, $\mathrm{i}=2,3, \ldots, \mathrm{n}$;

$$
T P_{i}=\left(\left(W A_{i}-W 1_{j}\right) /\left(H_{i}-W 1_{i}\right)\right) *\left(W A_{i}-W 1_{i}\right) * Z F F_{i} * T L A I,
$$

where $W A_{i}$ is the ith soil layer soil moisture content, $m m ; H_{i}$ is the ith soil layer moisture content at holding capacity (moisture in total pore space), $m m_{;} W_{1}$ is the ith soil layer moisture content at wilting point; $m m, Z F F_{i}$ is the ith soil layer root penetration fraction; and TLAl is the plant leaf/needle area index, $\mathrm{m}^{2} / \mathrm{m}^{2}$. The $T P_{t}$ is the total daily transpiration from the plant rooting zone, $\mathrm{mm} / \mathrm{day}$ :

$$
T P_{t}=T P 1+T P 2+T P 3+\ldots+T P n
$$

The upper boundary for TP $\mathrm{f}_{\mathrm{t}}$ set by PET, Eq. (1), and moisture is removed from each successive layer until PET is reached or until the last layer is reached, whichever is reaized first. If a given layer cannot satisfy demand, then the excess demand is removed from the next layer. Also, a moisture withdrawal boundary from any soil layer is set by the amount of moisture in excess of the moisture content at wilting point. Root penetration is set at twice the estimated actual 
fraction of a soil layer occupied by plant roots at any simulated time, but it is not allowed to ex. ceed 1.0 for that layer. The actual rate of root penetration varies with plant types: annuals, perennials, woody, herbaceous, time of year,..., etc. (Wenzel and Gallegos 1987).

The leat area index, TLAI, of a specific plant type based on its leat biomass, is modeled to have a significant impact in affecting moisture withdrawals from unsaturated soils. In the current BIOTRAN model, TLAl is based on live (green) leat biomass, WND in $\mathrm{g} / \mathrm{m}^{2}$ dry weight; for each plant type:

$$
T L A I=0.013 * \text { WND. }
$$

For plant type-specific surficial dust deposition modeling in BIOTRAN, TLAI includes both live (WND) and dead standing leat biomass (WD1) (Wenzel and Gallegos 1987).

Evaporation of moisture from the soil surface is modeled to affect the top $20-\mathrm{mm}$ thick soil layer exclusively. This layer is also used for resuspension and deposition modeling of particulates in the same manner. Evaporation in $\mathrm{mm} / \mathrm{day}$ from the soil surface is modeled from the top soil layer as

$$
\text { EVAP }=0.5 * W A V * \operatorname{EXP}(-0.4 * T L A I)
$$

where WAV is the potential moisture withdrawal from top layer, mm/day;

$$
\text { WAV }=(P E T-T P n)
$$

The amount of potential moisture withdrawal from the top layer. WAV, is bounded by that in ex. cess of $5 \%$ volumetric wetness and also by transpiration. $T P_{i}$, losses which are allocated betore hand. The strategy is similar to that of the CREAMS model except for the boundary conditions imposed and the order of allocation. This adjustment is required because BIOTRAN structures more than one soil layer for moisture aliocation and because of the steen moisture gradient cre ated at the surface by evaporation (Hillel 1976). Finally, the leat area index in the soil evapora. tion calculation uses only the green leat biomass densities mentioned previously.

Soil moisture remaining after adjustment for evaporation, transpiration, and surface runoff losses is modeitu as initiitraiion moisture, betore modeling of unsaturated soil moisture movement within the soil profile with an approximation of Darcy's equation (Hillel 1976). Both surface runoff and infiltration will be considered iater in this report along with subsurface return flow The rela. ::onship used to estimate Darcinian soil moisture movement is modeled separately tor the top layer as

$$
M F L X 1=C Z 1+0.5 * C Z 1 * Y M 2
$$

where MFLX1 is the soil moisture movemert from the top layer, $\mathrm{mm}$ water/mm soil per day, CZ1 is the weighted soil water conductivity, $\mathrm{mm}$ water/mm soil per day, based on sand, silt, or clay soil 
composition for the top soil layer; and YM2 is the weighted matric potential, $\mathrm{mm} / \mathrm{mm}$ soil for the second soil layer (matric potential at the surface of the soil is assumed to be zero). Note that units are consistent with Hillel's definition when multiplied by soil layer depth in $\mathrm{mm}$. The relationship for soil moisture movement, MFLX $X_{j}$, in the ith layer, $\mathrm{mm}$ water/mm soil per day, is represented as

$$
M F L X_{i}=C Z_{i}+0.5 * C Z_{i}^{*}\left(Y M_{i}+i-Y M_{i}-1\right)
$$

where $C Z_{i}$ is the weighted soil conductivity, $\mathrm{mm}$ water/mm soil per day, for ith soil layer; $Y M_{i}+1$ is the weighted matric potential, $\mathrm{mm} / \mathrm{mm}$ soil for the ith +1 soil layer; and $Y \mathrm{M}_{\mathrm{i}}-1$ is the weighted matric potential, $\mathrm{mm} / \mathrm{mm}$ soil for the ith - 1 soil layer.

Moisture movement direction is determined as downward (MFLX $>0$ ) or upward $\left(M F L X_{i}<0\right)$ within a given soil layer. Both soil moisture conductivity and matric potential are estirnated by regression analysis $(p=.01, r>9)$ as power functions of volumetric wetness from information for sand, silt, and clay soil columns provided by Hillel (1976). The values of MFLX $X_{i}$ are maximum es:itimates which assume adequate soil moisture is present in a given soil layer. Beginning with thie top layer and proceeding to the bottorn layer, a cumulative boundary moisture flux is estimatec' for each layer, and moisture ilux is adjusted to lower values if inadequate moisture limits the maximum flux estimates. Also, moisture flux is adjusted to prevent any but the top soil layer from exceeding the holding capacity of that layer; this adjustment is accomplished by sequentially downward adjustment of moisture fluxes beginning with the bottom soil layer and proceeding toward the second layer. Lower-limit boundaries are set at $5 \%$ volumetric wetness for all soil layers, and moisture exports are adjusted to disallow soil moisture excursions below this value. A final adjustment is made on upward moisiure fluxes (WATAKU) described previously if the addition of moisture to an upper layer from this source results in a volumetric wetness. which exceeds the adjacent lower layer. In such cases, the export flux is redıced to balance volumetric altogether wetness in both layers or is excluded altogether. The latter was determined by tuning of experiments to stabilize model operation when relatively large volumetric wetness differences exist between adjacent soil layers.

The loss of moisture from the soil protile below the rooting zone is set at $0.5 \%$ of the bottom-layer available moisture daily; however, when subsurface return flow is operational in BIOTRAN, this loss is set to 0.0 . The former loss is modeled as a sink, whereas the subsequent return flow process is integrated with channel hydrology simulations to be described in a subse. quent section of this report.

\section{Subroutine RUNOFF}

This subroutine deals with both surface runoff and infiltration modeling events as a result of precipitation. The infiltration modeling is primarily a mass-balance accounting of residual moisture. This approach is made necessary by lack of precipitation duration information required for this purpose and the consequent necessity of having to model surface runoff on the basis of total precipitation for a given event independent of its intensity (Knisel 1980, Branson 1981, Haan 
1982). Surface runoff is estimated by use of "curve numbers," a technique which takes into account soil type, plant cover, vegetative type, and antecedent soil moisture (Branson 1981). The data presented by Branson were used to formulate regression equations $\left(p=.01, R^{2} \sim .8\right)$ to estimate CNII, the normal soil moisture condition curve number:

$$
C N I I=A C N 2-B C N 2 * A K O N D-B C N 3 * H F A V,
$$

where $A C N 2$ is the plant crown cover tactor:

$$
\mathrm{ACN} 2=96-16 * \mathrm{CCVV}
$$

and

$$
\mathrm{BCN} 2=9.0+5.9 * \mathrm{CCVV}
$$

where CCVV is the plant crown cover fraction, BCN2 is the plant crown cover-conductivity interaction, and BCN 3 is the plant crown cover-vegetation type interaction:

$$
\mathrm{BCN} 3=0.8+0.04 * \mathrm{CCVV}
$$

AKOND is the moisture infiltration rate, in./h, and HFAV is the mean lifespan of vegetation type in years.

Mean lifespans for specific plant types are estimated in BIOTRAN as are daily crown cover values. Moisture infiltration rates are supplied as input to the model. Also, plant types with mean lifespans less than or equal to $15 \mathrm{yr}$ are treated as $15-\mathrm{yr}$ mean lifespans. This strategy places all annual and perennial grasses and herbs into one category, all shrubs into a second category, all shorter-lived trees into a third category, and all long-lived trees into a fourth vegetation-type category. More study of these relationships is suggested to obtain a more accurate formulation of the curve number.

An estimate, CNI, of the dry antecedent soil moisture condition curve number trom the normal soil moisture condition was obtained from the CREAMS model:

$$
C N I=-16.91+1.348 * C N 11-0.01379 * C N 11 * * 2+0.0001177 * C N 11 * * 3 .
$$

This curve number is further corrected tor the presence of impervious material such as exposed bedrock or pavement by the relationship (Lane 1985)

$$
C N I=(100 * C N I *(1-B D R K)+99 * B D R K * 100) / 100
$$

where BDRK is the fraction of slte covered by impervious material.

The corrected dry antecedent soil moisture curve number is used to estimate a maximum soil moisture retention parameter, SMX, in $\mathrm{mm}$ : 
The estimated soll moisture retention parameter SIRn over $n$ soll layers for a given day al a given site for a given vegetation type is estimated as

$$
S I R n=S I R i_{i}-1+S M X * W I S_{i} *\left(\left(U L_{i}-S W_{j}\right) / U L_{. j}\right) \text { for } i=2, \ldots, n \text {, }
$$

where uIRn is the th cumulative moisture parameter for a given soll layer and $W I S_{j}$ is the ith solllayer weighting factor for $i=1,2, \ldots, n$ :

$$
W I S_{i}=C W I S * \operatorname{EXP}(-4.16 * S L C I / S D P T H,
$$

where CWIS is a constant such that the sum of all WIS 's equals 1.0; SDPTH is the depth of soil profile, $\mathrm{mm} ; \mathrm{SLC}_{i}$ is the ratio of depth to bottom of the ith layer to the bottom of the soil profile or nth layer; $U L_{i}$ is the soil moisture content at holding capacity for ith soil layer; and $S W_{i}$ is the daily estimated soil moisture content of ith soil layer.

The SPUR model (Wight 1984) criteria were used for estimating the soil-layer moisture weighting factors as well as the algorithm for estimating the weighted soil moisture parameter (SIRn).

If precipitation exceeds $20 \%$ of the weighted soil moisture, then daily surface runoff, RNOFD, $\mathrm{mm}$ (Soil Conservation Services, SCS), is estimated as

$$
R N O F D=(P R C P-0.2 * S I R n) * * 2 /(P R C P+0.8 * S I R n)
$$

where PRCP is the precipitation event, $\mathrm{mm} /$ day.

The difference between precipitation and surface runotf is treated as infiltration moisture, $\mathrm{mm}$ :

$$
W S R P=(P C R P-R N O F D)
$$

Beginning with the upper soil layer, each successive soil layer is increased to holding capacity until WSRP is totally accounted for. "Ponding" occurs when the soil moisture content of the lop layer is increased above holding capacity should lower layers become saturated to the holding capacity betore WSRP is accounted for. Ponding is treated as surface runoff on the following day

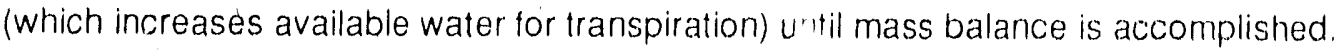

\section{Subroutine GEOFLX}

This subroutine is primarily an interface between surface runoff, return or subsurtace flow, particle erosion, and channel and aquifer flows in BIOTRAN. All of the data input required for execution of these processes is located in this subroutine, and regional integration is also included for sperif; ; land areas and channels. 
Subsurface or return flow is modeled for each watershed region specified on a dally basis by use of a modification of. Darcy's equation. Only those soll layers with the soll moisture content equallng or exceeding the fleld capacity for that soll type will contribute to return flow from a given vegetation type of a given region:

$$
R F L W V=R F L W p-1+W A T V A p
$$

RFLWV is the integral average subsurface return flow, $\mathrm{tt}^{3} /$ day, from all layers (greater than or equal to field capacity) for all vegetation types $(v)$ of a given region, where $p=2, \ldots, v$. WATVAp is the total daily flow, $\mathrm{ft}^{3}$, from the pth vegetation type along the receiving channel:

$$
\text { WATVAP }=2.0 * A R R X p * A K O N D * 0.1
$$

where AKOND is the soll conductivity, in./h, for the region. ARRXp is the weighted cross-secthonal area, $\mathrm{ft}^{3}$, of the pth vegetation type along the recelving channel into which regional return flow enters:

$$
\text { ARRXP }=5280 * S C V R p * D P X * X C H A N
$$

where XCHAN is the length of receiving channel, mi, receiving regional return flow and DPX is the thickness of the soll horizon, $\mathrm{ft}$. SCVRp is the fraction of total crown cover due to the pth velgetation type. A. mean slope of 0.1 is assumed from the center of the mesa tops to the channel segment in question.

BIOTRAN models soll hydrology for all vegetation types in a given region. Each region generally exhibits different water use patterns and may have different soil characteristics (edaphic); hence, return flow is weighted to reflect the vegetation composition of the region as described above. Finally, the upper boundary for RFLWV is set by the cumulative sum of each conducting soil layer for each vegetation type of a given region:

$$
\text { WATVXV }=\text { WATVXP-1+(SWI-FCi)*ARAXp. }
$$

WATVXV is the avallable soil moisture above field capacity for all conducting soil layers of all vegetation types in a given region; $F C i$ is the moisture holding capacity, $\mathrm{ft}$, of ith soil layer at field

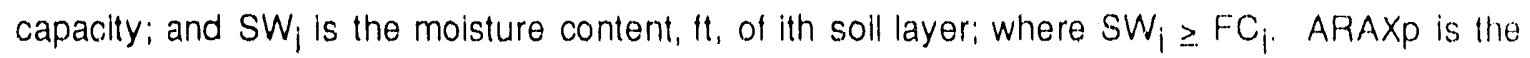
area of pth vegetation type, $\mathrm{ft}^{2}$ :

$$
\text { ARXp = SCVRp } * \text { RAREA } * 43564
$$

where RAREA is the surface area of the region, acres.

After the flow of moisture from each region by surface runolf and relurn flow has been established, the next process modeled in GEOFLX is a channelization of this moisture to an ap. propriate drainage system. The assignment of drainage from a given region to a specific channel 
or from an upper to another lower region is supplled as input to the model. The corresponding interconnectlons of speciflc channels or channel segments to form the drainage pattern are also supplied as input in GEOFLX. If a glven lower reglon is recelving surface runoff from another up. per region(s), then the water runoff increment to the lower region is treated as additional precipi. t. tion and processed by the RUNOFF subroutine described earlier. Although this regional apportionment appears awkward from the mass-balance perspective, the code appears to operate properly. Similarly, return flow water increments are addad to the soll layers (from bottom to top) below speclfic vegetation types in proportion to the number of vegetation types in the receiving lower region. Each consecutive soil layer incremented in this mannel is allowed to reach the holding capacity before allowing molsture to enter the upper layers within the same profile. Residual molsture remalning, after all soll layers for each vegetation type are at holding capacity, is allocated to the surface layers proportionately and are allowed to exceed holding capacity or to "pond" as described earlier. Other parameter estimates such as mean temperature, mean precipitation, and total area of combined regions are also determined in this section of the subroutine.

The volume of water entering specific atlannels from specific regions, other channels, or channel segments must be adjusted for transmission losses before downslope channels or channel segments are incremented. The outflow volume of water, VTRND, from a specific channel or channel MCtd segment is modeled after Lane (1985) as

$$
\text { VTRND }=\text { ATRN } * 43654+B T R N * V T R N X+F T R N * V L A T X / X C H A N
$$

where BTRN is the regression slope, day, and WCHAN is the width of channel, $f t$.

$$
B T R N=\operatorname{EXP}(-A, K D C F * X C H A N * W C H A N),
$$

ADKCF is the decay factor for transmission loss, mi/ft,

$$
A D K C F=-1.09 * n(1-A L N C)
$$

where ALNC is the decay factor coefficient, in./acre-ft,

$$
\text { ALNC }=0.00545 * \text { AKOND*DUHR/(VMEAN*RAREA/12), }
$$

DUHR is the duration of a given runoff event, $h$ :

$$
\text { DUHR }=\text { C1HR*(RAREA } 640) * *(C 2 H R),
$$

where C1HR and C2HR are constants supplied as input or default values.

VMEAN is the potential mean runoff volume into channel, in.

$$
\text { VMEAN }=0.05 *(\text { RAREA } 640) *(-0.2)
$$


ATRN is the regression intercept, acre-ft,

$$
\text { ATRN }=(A \cup C l /(1-B C T R)) *(1-B T R N),
$$

where BCTR is the unit channel regression slope for transmission loss,

$$
B C T R=E X P(-A K D C F)
$$

$\mathrm{AUCl}$ is the unit channel intercept for transmission loss, acre-ft:

$$
A \cup C l=-0.00465 * A L O N D * D U H R .
$$

FTRN is the lateral flow parameter for transmission, acre-tt:

$$
F T R N=(1-B T R N) /(A K D C F * W C H A N)
$$

VTRNX is the total volume of water, $\mathrm{ft}^{3} /$ day, added to channel from other channels, channel icemelt, arid the aquifer, if present. VL.ATAX is the total volume water, $\mathrm{ft}^{3} / \mathrm{day}$, added to channel from surface runoff. Subsurface return flow is included if an aquifer is not modeled below the channel bed ( $A Q U G A T=0.0$ ).

The upper boundary for moisture flow [(VTRND, Eq. (31)] is set by the total inflow from all sources. If an aquifer is present below the specific channel, then the moisture surplus (VTRNX+VLATX-VTRND) is added to the aquifer; otherwise, it is lost to a sink. Finally; mean channel drainage, daily average temperatures, and average precipitation amount per event are estimated as described previously for interconnecting regions.

In the event that an ephemeral or perennial flow of moisture enters a given channel, then ice formation deletions and icemelt additions to channel flow must be taken into consideration. If the average daily temperature is less than or equal to zero, then ice formation occurs:

$$
A I C E=A I C P+(\text { VTRNDP/CHAREX }) * 12 * 25.4
$$

where AICE is the ice thickness, mm, as water above the channel bed, and AICP is the previous ice thickness, mm, as water. VTRNDP is the daily water increment to channel, $\mathrm{ft}^{3 /} \mathrm{day}$; and CHAREX is the area of aquifer surlace specified for ice deposition, $\mathrm{ft}^{\text {? }}$.

$$
\text { CHAREX }=0.5 *(T C H+T B C H) * X C H A N * 5280,
$$

where $\mathrm{TCH}$ is the width of the proximal end of the aquifer, $f$; and $\mathrm{TBCH}$ is the width of distal end of aquifer, $\mathrm{ft}$. Similarly, icemelt is modeled at average daily temperatures above zero as

$$
\text { AMEL.T }=(11.28 * T C H A N+1.11280) * C H A R E X /(25.4 * 12),
$$


where AMEL.T is the maximum molsture production from ice, $\mathrm{ft}^{3} /$ day, and TCHAN is the mean channel drainage temperature, ${ }^{\circ} \mathrm{C}$.

The actual amount melted is bounded by the avallable ice on a given day:

AVMLT $=$ AICE*CHAREX/(25.4*12),

where AVMLT is the moisture, $\mathrm{tt}^{3}$, in ice thickness above the channel

The moisture resulting from icemelt is used to increment VTRNX of a specific channel: as the magnitude of VTRNDP Increases, the model becomes less accurate as not all molsture would be expected to be retained as ice; a fraction of such flow would then be required for this process.

Other modelling aspects of GEOFLX will be discussed in conjunction with subroutines AQUIFER and EROSON.

\section{E. Subroutine AQUIFER}

This subroutine models the flow of moisture into a confined alluvial aquifer(s) from transmission losses of the overlying channel and gains from up-slope subsurface return flow through vertical cross sections. All of the dimensions for constructing the specified aquifers are supplied as input to BIOTRAN in subroutine GEOFLX together with articulation instructions. The aquifers are all specilied as trapezoidal solids incorporating two trapezoldal vertical cross sections at the proximal and distal ends that are connected by the channel segment length, XCHAN, described previously. Furthermore, each aquifer is tilted from the proximal to distal ends at a specified inclination. Consequently, it is modeled as a "tipped-bucket" volume into upper and lower portions to accommodate height variations at both ends due to channel slope. Also, it is possible to model a riparian plant communlty by specifying as input a riparlan region on the non-channel portion of the upper aquifer lateral surface. This surtace is then modeled to intercept drainage into its soll layers before the water enters the associated channel. It is important to note that the specifled channel width is not generally of the same magnitude as are the specified dimensions of the up. per lateral surface of the aquifer, which makes the modeling of a riparian or other terrestrial plant community on this surface possible.

The total volume of a specific aquifer (transverse slice method) is estimated as

$$
\text { VAQT }=A 1 C * h p x * * 3+\wedge 2 C * h p x+2+A 3 C * h p x,
$$

where VAQT is the maximum volume of aquifer, $\mathrm{ft}^{3}$; and $\mathrm{hpx}$ is the maximum linear distance connecting the bottom portions of the aquiter, $\mathrm{ft}^{3}$ :

$$
H P X=(H O H * * 2+h \times h * * 2)^{1 / 2}
$$


where $\mathrm{HOH}$. is the vertical height to the bottom of the aquifer at the proximal end of the aquifer, $1 \mathrm{f}$, relative to the bottom of the aquifer at the distal end, $\mathrm{HXH}$ is the quadratic coefficient, $\mathrm{ft}$, and $\mathrm{A} 1 \mathrm{C}$ is the perpendicular distance between the distal and proximal ends at the aquifer segment, $f t:$

$$
A 1 C=((T B C H-T C H) *(H B T-H T P)+(B B C H-B C H) *(H B T-H T P) /(€ .0 * h p x * * 2),
$$

where TCH and TBCH are the widths of the top of the aquifer at the proximal and distal ends, $I f$, respectively; $\mathrm{BCH}$ and $\mathrm{BBCH}$ are the widths of bottom of aquifer at the proximal and distal ends, $\mathrm{ft}$, respectively; and HTP and HBT the vertlcal helghts, $f t$, at the aquiler segment at the proximal and distal ends, respectively. Further,

$$
\begin{aligned}
& \mathrm{A} 2 \mathrm{C}=(\mathrm{HBT} *(\mathrm{TCH}+\mathrm{BCH}-2.0 *(\mathrm{BBCH}+\mathrm{TbCH}))+\mathrm{HTP} *(\mathrm{TBCH}+\mathrm{BBCH})) / \\
& (4.0 * \mathrm{HPX}) .
\end{aligned}
$$

$A 3 C$ is the coefflcient

$$
\mathrm{A} 3 \mathrm{C}=(\mathrm{TBCH}+\mathrm{BBCH}) * \mathrm{HBT} / 2.0 .
$$

VAQf is the total volume of a specific (vertical slice method) of aquifer at a given height above the bottom, tt:

$$
V A Q f=A 1 C C * H P X * H T X * * 2+A 2 C C * H P X * H T X
$$

where HTX is the helght, feet of water above aquifer bottom,

$$
\begin{aligned}
& \mathrm{A} 1 \mathrm{CC}=(\mathrm{TBCH}-\mathrm{BBCH}) /(4.0 * \mathrm{HBT})+(\mathrm{TCH}-\mathrm{BCH}) /(4.0 * \mathrm{HTP}), \\
& \mathrm{A} 2 \mathrm{CC}=(\mathrm{BBCH}+\mathrm{BCH}) / 2.0,
\end{aligned}
$$

and

$$
H T X=H T X n,
$$

where HTXn is the iterated height determined by Newton's approximation method.

The total volume of water in the aquifer before adjustment for daily loss through its distal vertical cross section is estimated as

$$
V A Q F=V A Q F P+V T R N X+V L A T X-V T R N D+V L O S S P+V R F L X,
$$

where VAQF is the aquifer water content, $\mathrm{tt}^{3}$; VAQFP is the previous day volume, $\mathrm{tt}^{3}$; VLOSSP is the water increment from the up-slope aquiter, $1 t^{3}$; and VRFLX is the return flow water increment from the region drained. 
The distal vertical cross section through which molsture exits depends on the aquller porosity (currently set at 0.25 ), the maximurn vertical cross sectlon itself, and the estlmated moisture volume within. If the water volume in the aqulfer after adjustment for porosity does not exceed VAQT, then Newton's approximation method is applied to Eq. (46) to obtain the height of the fluld in the bottom portlon contained within VAQT, where HTX $X_{b}$ is the height of fluid at the distal vertlcal aquifer cross sectlon:

$$
\begin{aligned}
& H T X_{n}=H T X_{n} \cdot F X X / F X D, \\
& F F X=A 1 C C * H P X * H T X_{n} * * 2+A 2 C C * H P X * H T X n * V A Q F,
\end{aligned}
$$

and

$$
F X D=2.0 * A 2 C C * H F X * H T X_{n}+A 2 C C * H P X
$$

$H_{T X}$ is the helght estimate of the distal vertical cross section, $\hat{i}_{1}$ from Newton's approximation algorithm when the aquifer volume $\leq V A Q T$. This routine is repeated unitil convergence to HTX is approximated.

If the : olume of fluld adjusted for aqulter porosity $\theta x c e e d s$ VAQT, then surplus moisture is added to runoff as shown below, and

$$
\begin{aligned}
& \text { VAQF }=A 1 C C * H P X * H T X b * * 2+A 2 C C * H P X * H T X b ; \\
& H T X_{b}=H T X_{n}
\end{aligned}
$$

after convergence.

Surplus moisture above the aquifer will occur when the unadjusted fluid volume estimate including aquifer porosity exceeds the total volume [VAQT, Eq. (45)]. This model treats them as separate processes:

$$
\operatorname{VQDX} 1=0.25 *(4.0 * V A Q F-V A Q T)
$$

where VQDX1 is the surplus water above aquifer, $\mathrm{ft}$, due to moisture exceeding the maximum aquifer volume (VAQT):

$$
\text { VAQF }=\text { VAQT }
$$

When a region is modeled above the aquifer's lateral surface, then the surplus moisture from the regions is converted to a depth in mm over the surface and is added sequentially to each layer, beginning at the bottom until its soil moisture reaches holding capacity. Then, the next upper layer is incremented and so on until all surplus moisture is used, or until all soil layers are saturated. The residual remaining after all soll layers are saturated is used to increment moisture 
loss from the aquifer itself in the down-slope direction. All of the surplus moisture is used to increment moisture loss from the aquiter if a region has not been modeled above the aquifer.

The loss of molsture from the distal verical cross section VLOSS, in $\mathrm{tt}^{3} /$ day, is estimated by a modification of Darcy's equation described previously through the cross-sectional area:

$$
\text { VLOSS }=2.0 * A T X * A K O N D * S L O P X
$$

$$
A T X=H T X b *(B B C H+W T X) / 2 \text {, }
$$

where ATX is the cross-sectional area, $\mathbb{t}^{2}$, of the distal vertical cross section of aquiter, and SLOPX is the slope of the channel to the distal end of the segment. WTX is the width of the aquifer, $H_{1}$ at water level in the aquiler:

$$
W T X=B B C H+((T B C H-B B C H) /(H B T * H T X b) .
$$

The modeling strategy for construction of the aquifer volumes was taken from the work of Baliz (1963) at Mortandad Canyon to be descri zed later in this report.

\section{F. Subroutine EROSON}

This subroutine models the transport of sediment particles from regions using surface water runotf as a vector. The strategies employed in the SPUR model (Wight 1984) for estimating total sediment yield (lbs/acre, etc.) from a given land surface as a result of surface runoff are couplod with the differential erosion rate strategies as a function of particle diameter developed by Lane (1985) to produce the overall modeling of particle movernent into channels. The movement of particles within and between channels, channel segments, and regions are also adaptations from Lane. This subroutine is highly integrated with the other subroutines described previously, and hence is vory sensitive to intormation flow from these sources, particularly with respect to sunface runoff volume estimates determined in the RUNOFF subroutine.

The peak discharge rates from channels and regional surface moisture llows are estimated as

$$
C^{\circ} S^{\circ} D=(C 5 H R / C 1 H R) * Q F L O W *(\text { RAREA } 640) * *(1-C 2 H R)
$$

for regions where CFSPD is the peak discharge rate of surface runoff from a given region or channel, $t^{3} / \mathrm{s}$,

$$
\text { CFSPD }=\text { C5HR*QFLOW/DUHR }
$$

for channets, where C5HR is the peak discharge coefficient supplied as input or as a defautt yalue to regions and channels. OFLOW is the surface runoff, in./day, from a specific region,

$$
\text { QFLOW = RNOFD/25.4, }
$$

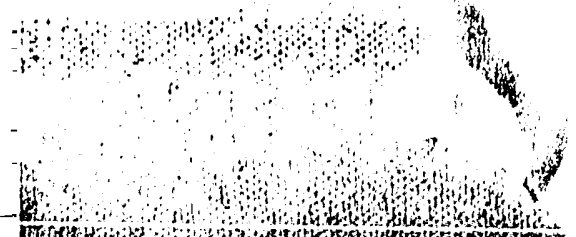


and QFLOW is the transmitted volume, $\mathrm{ft}^{3}$, from a specific channel,

$$
\text { QFLOW }=\text { VTRND }
$$

Regional erosion is modeled as a function of peak discinarge and the MUSLE equation of the Agricultural Research Service (ARS) as

$$
\text { TONFLW }=95 *((Q F L O W * C F S P D) * * 0.56) * K * C * P * L S * S C V R,
$$

where TONFLW is the weight of sediment eroded from a specific region for a given surface runoff event, ton/acre/day, for a given vegetation type. The depth of surface runoff flow from a given region or channel, $\mathrm{ft}$, is given as

$$
\text { DCHAN }=\text { QFLOW/12 }
$$

for regions and

$$
\text { DCHAN }=\text { QFLOW/(12.*DUHR } * 3600)
$$

for channels.

Similarly, the wioth of surface flow for a given region or channel, $\mathrm{ft}$, is estimated as

$$
\text { WCHAN }=\text { XCHAN } * 5280
$$

for regions and

$$
\text { WCHAN }=2.17 *(\text { CFSPD }) / 3) * * 0.5
$$

for channels it not supplied as input.

The mean velocity of surface flow, $\mathrm{ft} / \mathrm{s}$, for both regions and channels is estimated as

$$
\text { VCHAN }=(1.49 / \mathrm{RCHAN}) *(\mathrm{SCHAN} * * 0.5) *(\mathrm{RHYRC} * *(0.66)
$$

where PCHAN is the roughness or Manning coefficient, dimensionless, for regions and channels, which is supplied as input or estimated as

$$
\text { RCHAN }=0.0301 *(\text { CFSPD } / 3) * *(-0.05)
$$
mated as

SCHAN is the regional and channel slope, fraction, which is supplied as input or esti-

$$
\text { SCHAN }=0.000771 *(C F S P D / 3) * *(-0.3)
$$


RHYRC is the hydraulic radius of surface moisture flow for regions and channels, $\mathrm{ft}$ :

$$
\text { RHYRC }=\text { WCHAN } * \text { DCHAN } /(W C H A N+2 * D C H A N)
$$

The hydraulic roughness of the fluid bed for channels and regions is estimated as

$$
\begin{aligned}
& \text { RCHANB }=(\text { RCHAN } * *(0.66)+(2 * \text { DCHAN/WCHAN }) *(\operatorname{RCHAN} * *(1.5)-1.2 * \\
& \text { RCHAN**1.5))**0.66, }
\end{aligned}
$$

where RCHANB $\geq 0.63 *$ RCHAN and RCHANB $\leq$ RCHAN*((WCHAN $+4 * D C H A N) /(4 *$ DCHAN $))$ $* *(0.66)$. The upper boundary is estimated to be the roughness coefficient of the area of the channel perpendicular to the direction of fluid flow.

The hydraulic radius for resic ince of particles on the surface of regions or channels is estimated as

$$
\text { RHYRG }=\text { RHYRB } *(\text { RCHANG/RCHANB }) * * 1.5,
$$

where RHYRB is the hydraulic radius for bed resistance, $\mathrm{ft}$,

$$
\text { RHYRB }=\text { RHYRC } *(\text { RCHANB/RCHAN }) * * 1.5
$$

and RCHANG is the grain or particle resistance coefficient,

$$
\text { RCHANG }=0.132 * D 50 * *(0.166)
$$

where D50 is the median particle diameter, $\mathrm{mm}$, supplied as input.

The shear stress, SSTRES in $\mathrm{lbs} / \mathrm{ft}^{2}$, for sediment transport associated with surface runoff from regions and channel beds is estimated as

$$
\text { SSTRES }=62.43 * \text { RHYRG } * \text { SCHAN. }
$$

The model developed by Lane (1985) for differential erosion of particles as a function of diameter size is based on the assumption that the sum of the transport capacities of the different particle size fractions is equal to the transport capacity estirnated by using the median particle diameter size (D50). The transport capacity for the median particle diameter size, $\mathrm{mm}$, is estimated as

$$
\text { GSBD50 = BSD50*SSTRESS } *(\text { SSTRES-SSTR50), }
$$

where GSBD50 is the particle transport capacity per unit width of channel or region, for median particle diameter (D50), lbs./s ft. BSD50 is the particle transport coefficient for median particle diameter, cubic $\mathrm{ft}^{3} / \mathrm{b}-\mathrm{s}$, of a given channel or regional surface:

$$
\mathrm{BSD} 50=40 / \mathrm{D} 50 * * 1.5
$$


SSTR50 is the critical shear stress for median particle diameter of a given channel or regional surface, $\mathrm{lbs} / \mathrm{ft}^{2}$ :

$$
\begin{aligned}
& \text { SSTR50 }=0.0022+0.01 * D 50, \text { when D } 50<1.0 \mathrm{~mm} \\
& \text { SSTR50 }=-0.0078+0.02 * D 50, \text { when D } 50 \geq 1.0 \mathrm{~mm} .
\end{aligned}
$$

The model of Lane also discriminates between whether the particles are carried along the surface (bed load) or whether the particles are carried in the fluid (suspended load). Particles less than $0.063 \mathrm{~mm}$ in diameter are assumed to be suspended; all other particles are considered bed load. An estimate of the suspended load transport capacity is given as

$$
\text { GSBDS }=2 * \text { DSFS } * \text { SSTRES } * \text { VCHAN } * 2
$$

where GSBDS is the particle transport capacity per unit width of channel or region, for particles less than $0.063 \mathrm{~mm}$ in diameter, $\mathrm{lbs} / \mathrm{s}-\mathrm{ft}$; and DSFS is the mass fraction of particles in that diameter class.

The transport capacities of all pther diameter classes in the soil or channel alluvium is presented as

$$
\text { GSBDI }=\text { DSF } 1 * B S D I * S S T R E S *(S S T R E S-S S T R I),
$$

where GSBDI is the particle transport capacity per urit width of channel or region, the for ith particle in bed load, Ibs/s-tt, $i=2, \ldots, n$, and DSFI is the mass fraction of particles in ith diameter class.

$\mathrm{BSDI}$ is the sediment transport coefficient for ith diameter class, cubic $\mathrm{ft}^{3} / \mathrm{lb}-\mathrm{s}$ :

$$
B S D I=40 / D S 1 * * 1.5
$$

where DSI is the specific diameter of ith particle class, mm. SSTRI is the critical shear stress for ith particle size class, $\mathrm{lbs} / \mathrm{ft}^{2}$ :

$$
\begin{aligned}
& \text { SSTRI }=0.0022+0.01 * D S I \text {, when DSI }<1.0 \mathrm{~mm} ; \\
& \text { SSTRI }=-0.0078+0.02 * D S I, \text { when DSI }>1.0 \mathrm{~mm} \text {. }
\end{aligned}
$$

The sum of all particle transport capacities, GSBDI, is identified as GSBDT, or the total bed load particle iranspori capacity over all diameter classes greater than $0.063 \mathrm{~mm}$. The effective particle transport capacity for each diameter class in this range is estimated by a constant which will make GSBDT equal to GSBD50:

$$
\text { GSBDI }=\text { GSBDI } *(G S B D 50 / G S B D T)
$$


In estimation of particle erosion from a regional surface, the estimates of sediment yield by particle diameter are initially made by "strapping" overall sediment yield for a runoff event, TONFLW, for a given vegetation type with a weighting factor and then summing over all vegetation types; for channels the process is straightforward. Both events are estimated as

$$
\text { GSBDWI }=2000 * \text { TONFLW*RAREA*GSBDI/(GSBD50+GSBDS) }
$$

for a given vegetation type of a speclfic region and

$$
\text { GSBDWI }=3600 * \text { GSBDI } * \text { DUHR } * \text { WCHAN }
$$

for a given channel, where GSBDWI is the weighted sediment yield, Ibs/day, for the ith particle diameter class, $l=2, \ldots, n$, for a given channel or vegetation type (bedload).

GSBDWS is the weighted sediment yleld, lbs/day, for the suspended load particle diameter class from a given region of a specific vegetation type or specific charnel (suspended load):

$$
\text { GSBDWS }=2000 * \text { TONFLW } * \text { RAREA } * \text { GSBDS } /(G S B D 50+\text { GSBDS })
$$

for a given vegetation type of a specific region and

$$
\text { GSBDWS }=3600 * \text { GSBDS } * \text { DUHR } * \text { WCHAN }
$$

for a given channel. The total inventory for a given particle diameter is adjusted for erosion losses:

$$
D S M S I=D S M S P \cdot D S M I
$$

where DSMSI is the soil inventory of channel or region for suspended and bed load particles of the ith diameter class, assuming a 20-mm thickness for regions and 200-mm thickness for channels, pounds, $I=1,2, \ldots, n$; where DSMSP is the previous-day soil inventory, lbs, for the ith diameter class, and DSMI is the cumulative daily regional removal from all vegetation types, or daily channel removal, lbs, of the ith diameter class.

A total soil loss over all particle diameters is also inventoried, DSMT, by summation of the losses [see Eq. (92)] and subtraction from the total soil mass inventory, SEDMNS.

The nuclide content of specific diameter classes and the overall diameter class is obtained in a similar manner by use of the specific activity of each particle diameter class:

$$
\text { DSMAI = DSMAIP }- \text { DSACl }
$$


where DSMAl is the soil Inventory of channel or region for suspended and bed.load particle nucllde content of the ith diameter class, assuming a $20-\mathrm{mm}$ thickness for regions and a $200-\mathrm{mm}$ thickness for channels, $\mu \mathrm{g}, \mathrm{pCl}$, etc. DSMAIP is the previous-day activity inventory, $\mu \mathrm{g}, \mathrm{pCi}$, etc., for the th dlameter class. DSACl is the cumulative daily regional removal from all vegetation types or daily channel removal, $\mu \mathrm{g}, \mathrm{pCi}$, etc., of the ith diarneter class:

$$
D S A C I=G S B D W S * D Z A S \mid * 454
$$

for suspended load particles and

$$
\mathrm{DSACl}=\mathrm{GSBDW}|* \mathrm{DZAS}| * 454
$$

for bed load particles, where DZASI is the nuclide concentration or activity, ppm, pCi/g, etc., of the ith particle diameter.

A total activity inventory, SDMNSA, is maintained for a given region or channel by subtraction of Eq. (91) for each diameter class specified, and the specific activity of the surface soil or alluvium is obtained by the ratio

$$
\text { SDMNCT }=\text { SDMNSA/SEDMNS*454, }
$$

where SDMNCT is the specific activity, $\mu \mathrm{g} / \mathrm{g}$, act $/ \mathrm{g}$, etc., for surface soil over all diameter classes for channel surface alluvium or regional surface soil.

The specific activity for any channel or regional surface may be affected by the deposition of soil particles from another channel or region as the model may specify in its interconnections. Hence, a new value of the nuclide concentration, DZASI, must be estimated whenever an erosion event occurs that may in fact reflect both deposition of soil particles from another channel or region and a scouring of particles from the region or channel in question.

\section{INPUT STRUCTURE}

Three scenarios were developed as input for testing the hydrological simulations:

1. Mortandad Canyon with only warm- and cool-season annual and perennial grass growth in all 8 regions (10-yr simulation called Sc1).

2. Mortandad Canyon with ponderosa and/or pinyon-juniper, shrubs, and associated annual and perennial grasses in all 8 regions $(10-y r$ simulation called sc2).

3. Same as (2) above, but extended to 100-yr simulation called sc3.

The first scenario (sc1) was used to test and verify subroutine interfacing and economize on computer time required for tuning and debugging of the newly developed subroutines. $B 1 O$. TRAN simulates the serial development of vegetation through the climax stage and also places 
plants with similar growth strategles into niche competition for avallable soil moisture. Consequently, the first scenario can reach climatic cllmax within 4 to $10 \mathrm{yr}$ if the advanced succession strategy, ADSUC, is employrid. However, between 80 and $120 \mathrm{yr}$ of simulation time were required to reach climax when ponderosa and/or pinyon-juniper tree simulations are included. The first scenario also serves as a runoff and erosion comparison between forested and nontorested reglons in the canyon watershed of interest. Other minor differences between scenario input specifications will be noted later in this report. Input requirements logether with variable identifications are presented in Tables $2-3$ for the three scenarios. However, the description to follow will address sc1 onlv in Table 2; input for the second and third scenarios (sc2. and sc3) will be discussed insofar as they differ from sc.1. Further detail on scenario setup and input is described in the BIOTRAN Users Manual (Gallegos 1990).

\section{A. Input to MAIN}

1. SC1: The number of simulation years (y2) was set to 10. "Two elements and four chemical compounds are modeled (anz): uranium, nitrate-nitrogen, ammonla-nitrogen, labile phosphate, soluble phosphate, and potassium. The four chemical compounds and potassium are obligatory nutrients necessary for plant simulation to the model in all simulations. Additional nonobligatory elements and chemicals can be Included in addition to potassium if desired. Eight land regions (apx) and four vegetation types $(a p \mid=4$ ) are modeled as described previously. Optional subroutines accessed by MAIN are BIOPLT $(p b x=1)$, and WATFLX (watX $=1$ ); calls to CLIMAT and PLTGRO are obligatory to MAIN.

2. SC2 and SC3: Input to the main subroutine is identical to input for sc1 with one exception: the value of the simulation time $\left(y_{2}=100\right)$ for sc3 is the only difference in input for the three simu!ations.

\section{B. Input to CLIMAT}

1. SC1: Input for separate regions $(a p x=8)$ is entered sequentially, beginning with region 1 and terminating with region 8 . Minimum $(t 1=270)$ and maximum $(t 2=723)$ insolation together with the lag to maximum $(11=90)$ are entered with minimum and maximum $(t 4=68.4)$ temperature and lag-to-maximum temperature $(12=120)$. Included is the monthly temperature standard deviation ( $\operatorname{tmxv}=2$ ) and the precipitation event coefficient of variation for each region $(\mathrm{prcv}=2)$. The elevation (relv $=7000$ ) and the temperature lapse rate (alpsr $=0.005$ ) for each site is entered next as.well as the number of precipitation events for each month (tre). Also, the fractions of annual rainfall $(x)$ for each month are specified together with the annual precipitation $(r=18)$, reference elevation $(g 1=7000)$, and latitude correction $(1=0)$ for the site. The frost-free period ( $f \mathrm{fp}=138$ ) and latitude of the region (alatd $=37$ ) are also entered. A reference site is re. quired if climatic data are not available for the regions in question. Finally, a random number (randn $=136)$, day $(d \bmod =0)$, and year $(y \bmod =0)$ modules are entered. The random number resets the random number generator to produce a different set of numbers for a given run. The day and year moduli are required for CLIMAT output purposes (a value of 0 for either module negates output from that subroutine). The climatic data for all eight regions of sc1 are identical. 
TABLE 2. Scenario 1 Input Description

\begin{tabular}{llllllll}
10. & 0.0 & 8.0 & 0.0 & 0.0 & 0.0 & 1.0 & \\
$Y 2$ & ANZ & AFX & $200 X$ & ANIY & HUMX & BPX & \\
4.0 & 4.0 & 4.0 & 4.0 & 4.0 & 4.0 & 4.0 & 4.0 APL \\
0.0 & 0.0 & 0.0 & 0.0 & 0.0 & 0.0 & 0.0 & 0.0 AIRX \\
1.0 & 1.0 & 1.0 & 1.0 & 1.0 & 1.0 & 1.0 & 1.0 WAIX \\
0.0 & 0.0 & 0.0 & 0.0 & 0.0 & 0.0 & 0.0 & 0.0 FRMNX \\
0.0 & 0.0 & 0.0 & 0.0 & 0.0 & 0.0 & 0.0 & 0.0 AQUAX \\
& & & & & & & MAIN \\
\hline
\end{tabular}

\begin{tabular}{|c|c|c|c|c|c|c|c|}
\hline 0.0 & 0.0 & 0.0 & 0.0 & 0.0 & 0.0 & 0.0 & $\begin{array}{l}\text { CLIMAT } \\
O .0 \text { CLM }\end{array}$ \\
\hline 270 & $\begin{array}{r}7.4 * \\
793\end{array}$ & $9 * * *$ & & & & 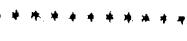 & $1+x+1$ \\
\hline Ti & $T 2$ & $\begin{array}{l}90 . \\
L_{1}\end{array}$ & $\begin{array}{l}33: 9 \\
T 3\end{array}$ & $\begin{array}{l}68.4 \\
T 4\end{array}$ & $\begin{array}{l}120 . \\
12\end{array}$ & & \\
\hline 2.0 & .2 & 7000. & $\begin{array}{l}13 \\
.005\end{array}$ & $\begin{array}{l}T 4 \\
136 .\end{array}$ & $\begin{array}{l}\mathrm{L} 2 \\
0.0\end{array}$ & 0.0 & \\
\hline$T M X V$ & PRCV & RELLV & ALPSR & $\begin{array}{l}136 \\
\text { RANDN }\end{array}$ & $\begin{array}{l}0.0 \\
\text { DMOD }\end{array}$ & YMOD & \\
\hline 4.0 & 4.0 & 4.0 & 4.0 & 4.0 & 3.0 & 8.0 & 9.0 \\
\hline $\operatorname{TRE}(1,1)$ & $\operatorname{TRE}(2,1)$ & TRE $(3,1)$ & $\operatorname{TRE}(4,1)$ & TRE $(5,1)$ & TRE $(6,1)$ & TRE $(7,1)$ & TRE $(8,1)$ \\
\hline $\begin{array}{ll}4.0 \\
T R E(9-1)\end{array}$ & $\begin{array}{l}4.0 \\
\text { TRE }(10,1)\end{array}$ & $\begin{array}{l}3.0 \\
\operatorname{TRE}(11,1)\end{array}$ & $\begin{array}{l}\text { 4.O } \\
\text { TRE }(12,1)\end{array}$ & & & & \\
\hline $\begin{array}{l}\text { TRE }(9,1) \\
.046\end{array}$ & $\begin{array}{l}\text { TRE }(10,1) \\
.038\end{array}$ & .062 & .046 & .004 & .059 & 178 & .216 \\
\hline$x(1,1)$ & $\dot{x}(2,1)$ & $x(3,1)$ & $x(4,1)$ & $x(5,1)$ & $x(6,1)$ & $x(7,1)$ & $x(8,1)$ \\
\hline $\begin{array}{l}.094 \\
\times(9,1)\end{array}$ & .085 & $\begin{array}{l}.053 \\
x(11,1)\end{array}$ & $\begin{array}{l}.058 \\
\times(12,1)\end{array}$ & & & & \\
\hline $\begin{array}{l}18.11 \\
18 .\end{array}$ & $\begin{array}{l}x_{1}(10,1) \\
7000 .\end{array}$ & 0.0 & 138. & 37 & & & REGION 1 \\
\hline $\mathrm{R}$ & $G_{1}$ & L3 & FFP & ALATD & & & \\
\hline$* * * * * * * * *$ & $* * * *+*$ & $* * * * * *$ & $* * 4 * * * * * * *$ & $* * * *+4$ & $*+* *+*$ & +* & $+\cdots+\ldots+\cdots$ \\
\hline 270 & 723. & 90. & 33.9 & 68.4 & 120 & & \\
\hline $\begin{array}{l}2.0 \\
4.0\end{array}$ & $\dot{4}^{2}$ & 7000 & .005 & 136. & 0.0 & 0.0 & \\
\hline 4.0 & $\begin{array}{l}4.0 \\
4.0\end{array}$ & $\begin{array}{l}4.0 \\
3.0\end{array}$ & $\begin{array}{l}4.0 \\
4.0\end{array}$ & 4.0 & 3.0 & 8.0 & 9.0 \\
\hline .046 & .038 & .062 & .046 & & & & \\
\hline .094 & .085 & .053 & .058 & .064 & .059 & .178 & .216 \\
\hline & 7000. & 0.0 & 138. & 37. & & & REGION 2 \\
\hline$* * * * * *$ & $* *+\cdots$ & $+\cdots * * * *+\cdots * *$ & $* * \cdots * *$ & … & $+4+\cdots$ & & KETIJON \\
\hline 270 & 723. & 90. & 33.9 & 68.4 & 120 & & \\
\hline 2.0 & .2 & 7000 & .005 & 136. & 0.0 & 0.0 & \\
\hline 4.0 & 4.0 & 4.0 & 4.0 & 4.0 & 3.0 & 8.0 & 9.0 \\
\hline 4.0 & 4.0 & 3.0 & 4.0 & & & & \\
\hline .046 & $.0,38$ & .062 & .046 & .064 & .059 & 178 & .216 \\
\hline .094 & .085 & .053 & .058 & & & & \\
\hline 18 & 7000 & 0.0 & 138 & 37 & & & REGION 3 \\
\hline $\begin{array}{l}* * * * \\
270\end{array}$ & $* * * * * *$ & $* * * * * *$ & $* * * * *$ & $*+\cdots * *$ & $* *+4 * *$ & 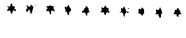 & $+* * * \cdots *$ \\
\hline 270 & 723. & 90. & 33.9 & 68,4 & 120 & & \\
\hline 2.0 & .2 & 7000 & .005 & 136 & 0.0 & 0.0 & \\
\hline 4.0 & 4.0 & 4.0 & 4.0 & 4.0 & 3.0 & 8.0 & 9.0 \\
\hline 4.0 & 4.0 & 3.0 & 4.0 & & & .178 & .210 \\
\hline .046 & .038 & .062 & $\begin{array}{l}.046 \\
.058\end{array}$ & .064 & .059 & .178 & \\
\hline .094 & .085 & .053 & .058 & & & & CFC: $10 \mathrm{~N} A$ \\
\hline 18 & 7000 & $\begin{array}{l}0.0 \\
* * * * * * * 1\end{array}$ & $\begin{array}{l}138 \\
4 * \ldots * * * *\end{array}$ & 37. & $n+\cdots+$ & & (1.. \\
\hline$* * * * * *$ & $* * *+* * * * * * *$ & $\begin{array}{l}* * * * * * * * \\
90 .\end{array}$ & 33.9 & $\begin{array}{l}* * * 4 \\
68.4\end{array}$ & 120 & & $* * *$ \\
\hline $\begin{array}{l}270 . \\
2.0\end{array}$ & $\begin{array}{l}723 . \\
2\end{array}$ & $\begin{array}{l}90 . \\
7000 .\end{array}$ & .005 & $\begin{array}{l}68.4 \\
136\end{array}$ & 0.0 & 0.0 & \\
\hline 4.0 & 4.0 & 4.0 & 4.0 & 4.0 & 3.0 & 8.0 & 9.0 \\
\hline 4.0 & 4.0 & 3.0 & 4.0 & & & & \\
\hline .046 & .038 & .002 & .046 & .064 & .059 & 178 & 216 \\
\hline .094 & .085 & .053 & 058 & & & & \\
\hline 18. & 7000 & 0.0 & 138 & 37. & & & REGION 5 \\
\hline$*+* * *$ & $* * * \ldots * *$ & $* *+\cdots+$ & $* * 1 * * 1$ & $x^{-1}$ & $x^{2}$ & * & $* * * * \ldots * * *$ \\
\hline 270. & 723. & 90. & 33.9 & 68.4 & 120. & & \\
\hline 2.0 & .2 & 7000 & .005 & 136. & 0.0 & 0.0 & \\
\hline 4.0 & 4.0 & 4.0 & 4.0 & $4: 0$ & 3.0 & 8.0 & 9.0 \\
\hline 4.0 & 4.0 & 3.0 & 4.0 & & & & \\
\hline .046 & .038 & .062 & .046 & .064 & .059 & .178 & .216 \\
\hline .094 & .085 & .053 & .058 & & & & \\
\hline 18. & 7000 & 0.0 & $13 \%$ & $3 \%$ & & & KEGION G \\
\hline $\begin{array}{l}* * * *+* \\
270 .\end{array}$ & 723 & & & & 120 & $* *+\cdots+\cdots$ & $+*++*+*+*+$ \\
\hline $\begin{array}{l}270 . \\
2.0\end{array}$ & $.22^{3}$ & $\begin{array}{l}90 . \\
7000 .\end{array}$ & $\begin{array}{l}33.9 \\
.005\end{array}$ & $\begin{array}{l}68.4 \\
136 .\end{array}$ & 0.0 & 0.0 & \\
\hline 4.0 & 4.0 & 4.0 & 4.0 & 4.0 & 3.0 & 8.0 & 9.0 \\
\hline 4.0 & 4.0 & 3.0 & 4.0 & & & & \\
\hline & .085 & .053 & & & & & \\
\hline
\end{tabular}


TABLE 2. (cont)

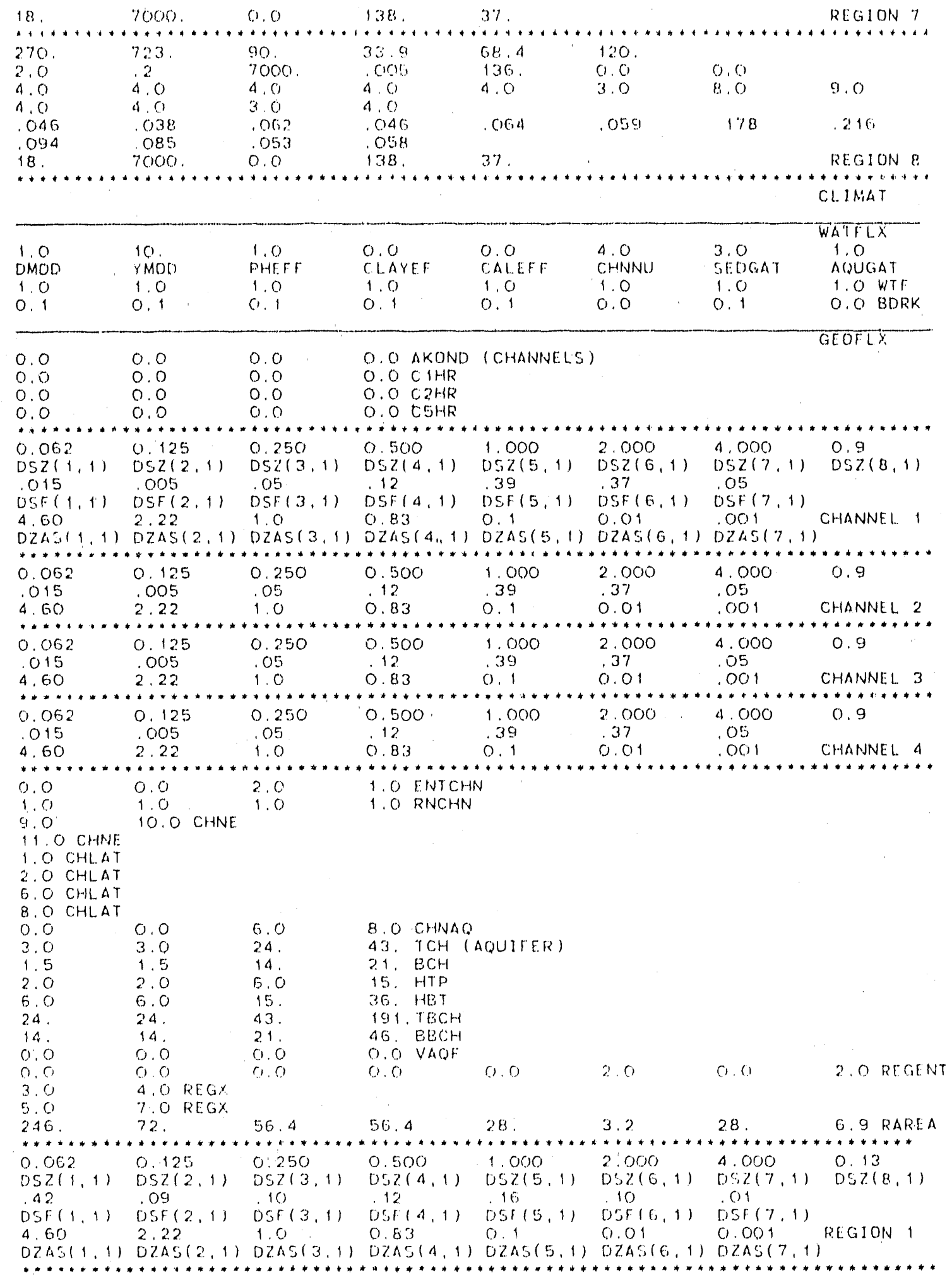


TABLE 2. (cont)

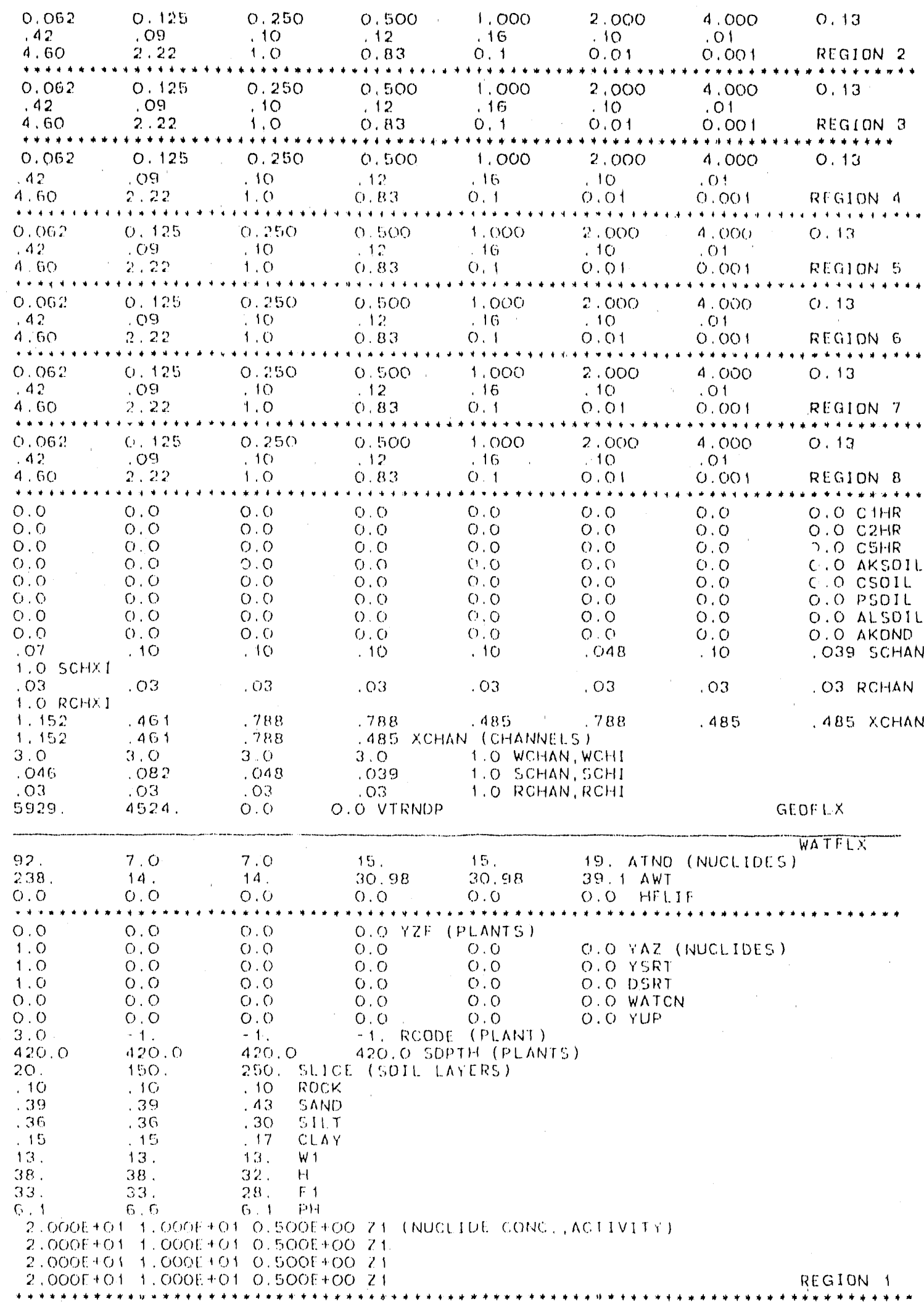


TABLE 2. (cont)

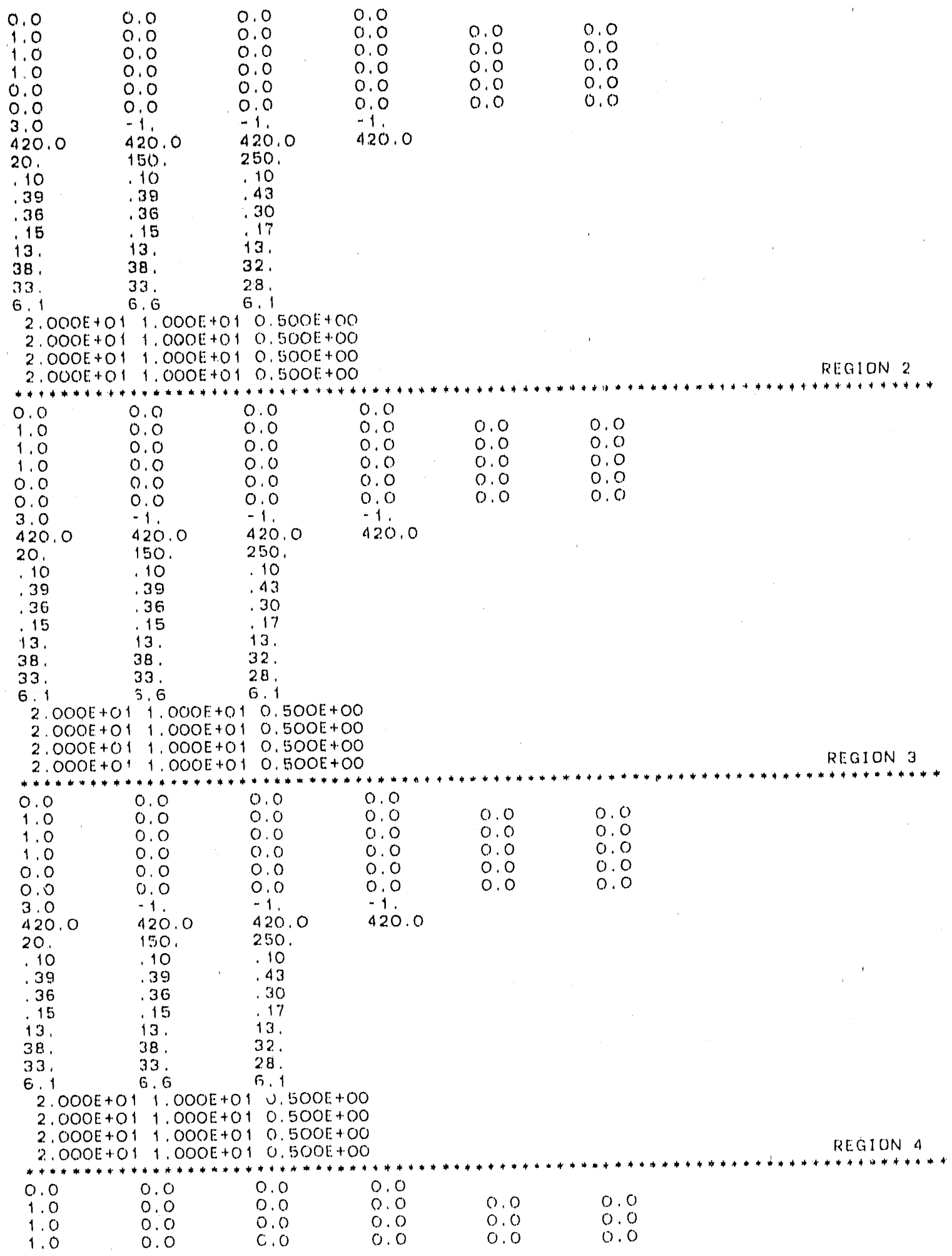


TABLE 2. (cont)

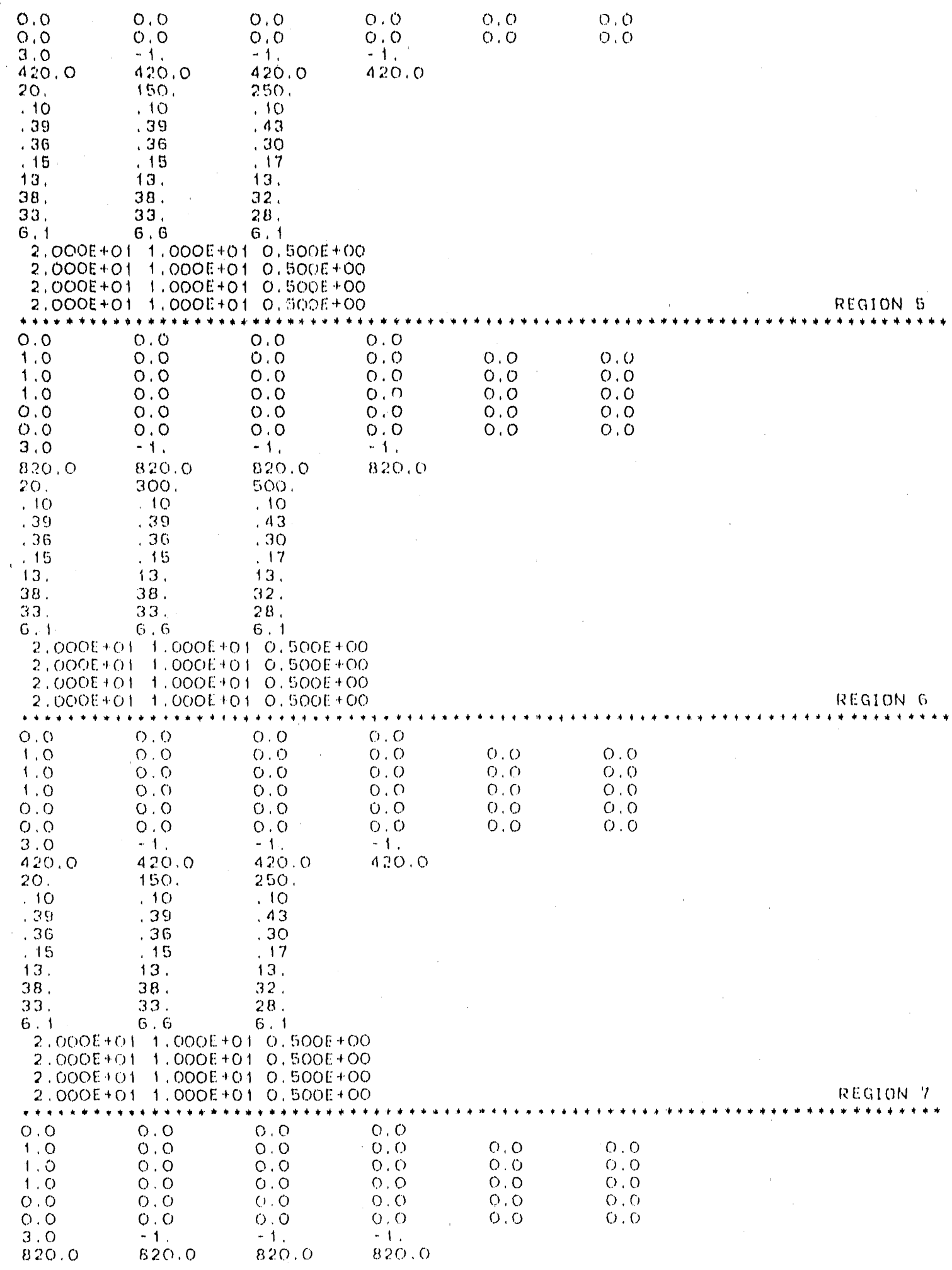


TABLE 2, (cont)

$\begin{array}{lll}20 & 300 & 600 \\ 10 & .10 & .10 \\ 39 & .39 & .43 \\ 36 & .36 & .30 \\ 15 & 15 & 17 \\ 13 . & 13 . & 13 . \\ 38 . & 38 . & 32 . \\ 33 . & 33 . & 28 . \\ 6.1 & 6.6 & 6.1\end{array}$

$2.000 E+011.000 E+010.500 E+00$

$2.000 E+011.000 E+010.500 E+00$

2.000E+01 1.000E+01 $0.500 E+00$

$2,000 E+01$ 1. OOOE+01 0.500E+00

REGION 8

WATrLx

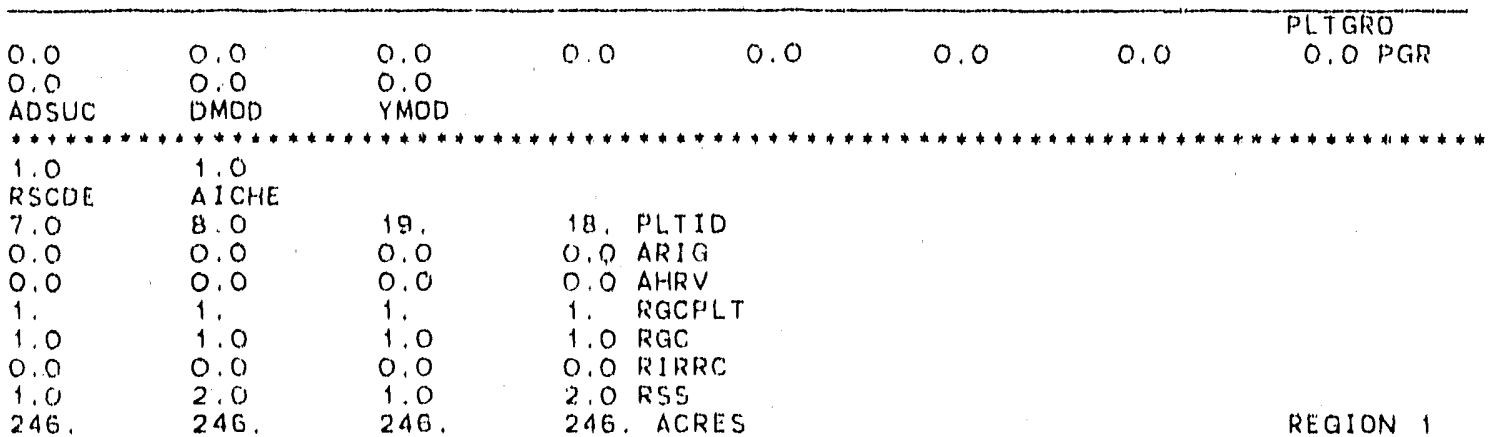

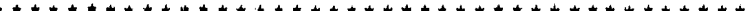

$\begin{array}{cccc}1.0 & 1.0 & & \\ 7.0 & 8.0 & 10 . & 18 . \\ 0.0 & 0.0 & 0.0 & 0.0 \\ 0.0 & 0.0 & 0.0 & 0.0 \\ 1.0 & 1.0 & 1.0 & 1.0 \\ 1.0 & 1.0 & 1.0 & 1.0 \\ 0.0 & 0.0 & 0.0 & 0.0 \\ 1.0 & 2.0 & 1.0 & 2.0 \\ 72 . & 72 . & 72 . & 72 .\end{array}$

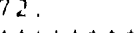

$\begin{array}{llll}1.0 & 1.0 & & \\ 3.0 & 8.0 & 19 . & 18 . \\ 0.0 & 0.0 & 0.0 & 0.0 \\ 0.0 & 0.0 & 1.0 & 0.0 \\ 1.0 & 1.0 & 1.0 & 1.0 \\ 1.0 & 1.0 & 1.0 & 1.0 \\ 0.0 & 0.0 & 0.0 & 0.0 \\ 1.0 & 2.0 & 1.0 & 2.0 \\ 56.4 & 56.4 & 56.4 & 56.4\end{array}$

REGION 3

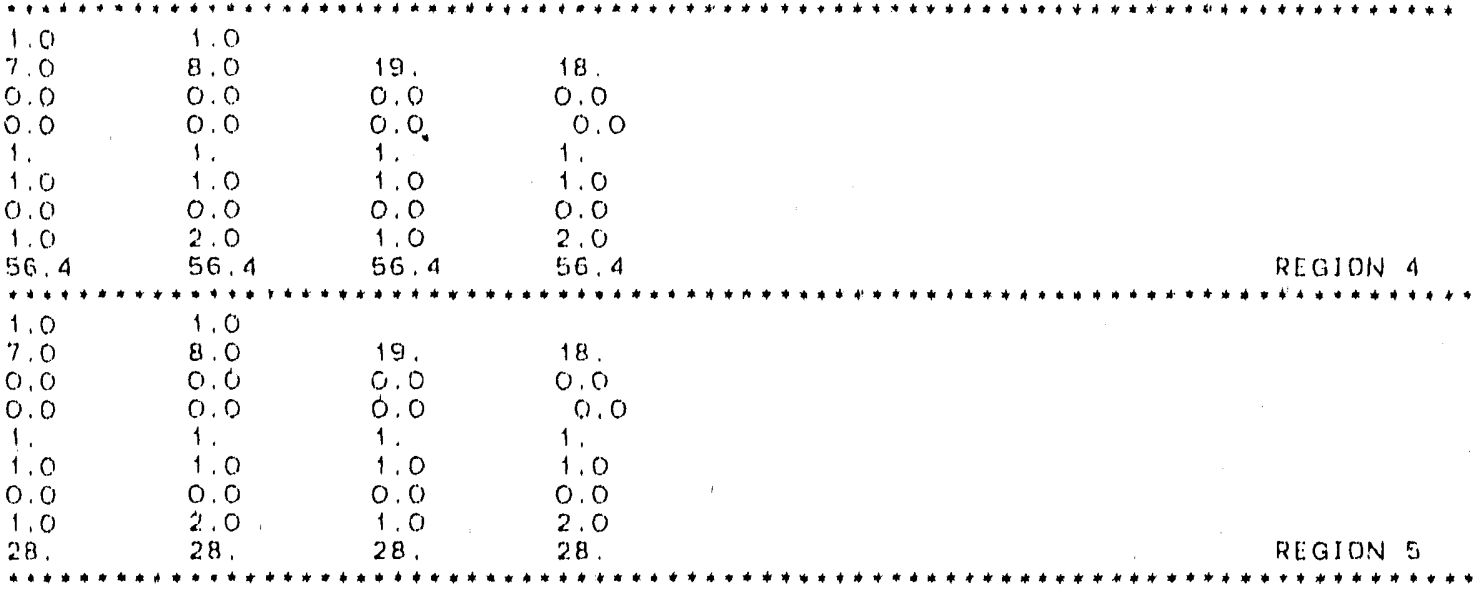


TABLE 2, (cont)

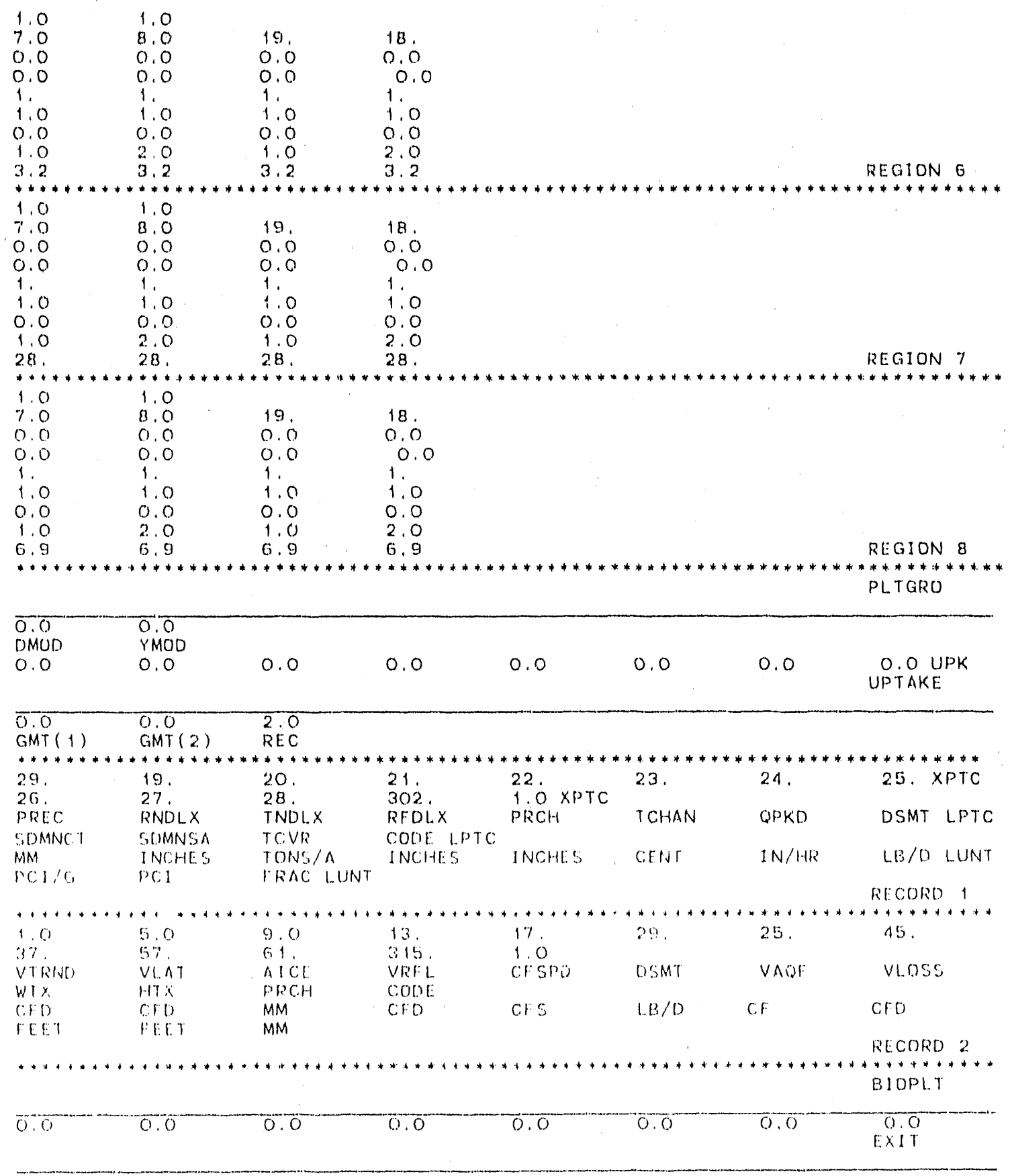


TABLE 3. Scenarios 2 \& 3 Input Description

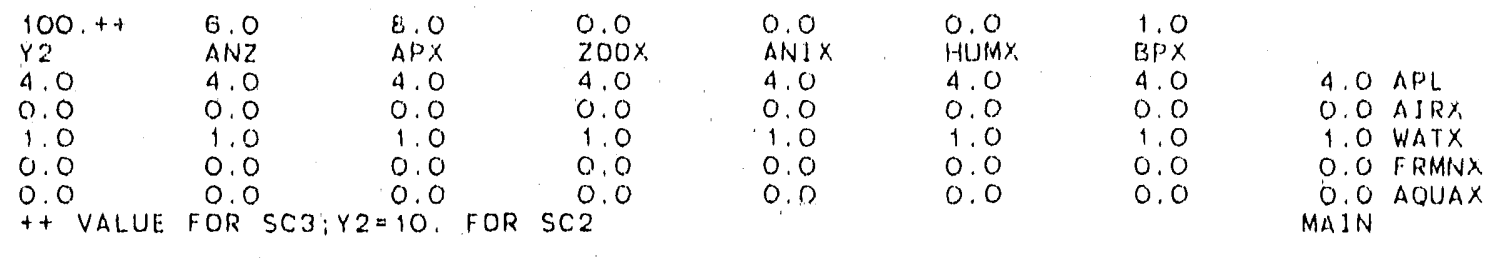

\begin{tabular}{|c|c|c|c|c|c|c|c|}
\hline 0.0 & 0.0 & 0.0 & 0.0 & 0.0 & 0.0 & 0.0 & $\begin{array}{l}\text { CLIMAT } \\
0.0 \mathrm{CLM} \\
0.0\end{array}$ \\
\hline $2 * * *$ & $\begin{array}{r}* * * * * \\
7.23 .\end{array}$ & क०*. & $\begin{array}{l}* * * * * * * * * * * \\
33.9\end{array}$ & $68 * 4 * * *$ & $\begin{array}{l}* 4 * * * * * * \\
120\end{array}$ & $\Delta+\cdots+\cdots$ & $+\cdots+\cdots+\cdots$ \\
\hline T 1 . & T2 & LI & T3 & TA & 12 & & \\
\hline $\begin{array}{l}2.0 \\
\text { TMXV }\end{array}$ & $\dot{P}^{2}$ & $\begin{array}{l}7200 . \\
\text { RELV }\end{array}$ & $\begin{array}{l}\text { OOS } \\
\text { ALPSR }\end{array}$ & $\begin{array}{l}136 \\
\text { RANDN }\end{array}$ & $\begin{array}{l}0.0 \\
D M O D\end{array}$ & $\begin{array}{l}0.0 \\
\text { YMOD }\end{array}$ & \\
\hline 4.0 & 4.0 & 4.0 & 4.0 & 4.0 & 3.0 & 8.0 & 9.0 \\
\hline $\operatorname{TRE}(1,1)$ & $\operatorname{TRE}(2,1)$ & $\operatorname{TRE}(3,1)$ & $\operatorname{TRE}(4,1)$ & $\operatorname{TRE}(5,1)$ & $\operatorname{TRE}(6,1)$ & $\operatorname{TRE}(7,1)$ & $\operatorname{TRE}(8.1)$ \\
\hline 4.0 & $A, O$ & 3.0 & 4.0 & & & & \\
\hline TRE $(9,1)$ & $\operatorname{TRE}(10,1)$ & TRE $(11,1)$ & $\operatorname{TRE}(12,1)$ & & & & \\
\hline .046 & .038 & .062 & .046 & .064 & .059 & .178 & .216 \\
\hline $\begin{array}{l}x(1,1) \\
.094\end{array}$ & $\begin{array}{l}X(2,1) \\
.085\end{array}$ & $\begin{array}{l}x(3,1) \\
053\end{array}$ & $\begin{array}{l}\times(4,1) \\
.058\end{array}$ & $x(5,1)$ & $\dot{x}(6,1)$ & $x(7,1)$ & $\dot{x}(8,1)$ \\
\hline$x(9,1)$ & $x(10,1)$ & $x(11,1)$ & $x(12,1)$ & & & & \\
\hline$R^{18 .}$ & $\begin{array}{l}7000 \\
\text { G1 }\end{array}$ & $\begin{array}{l}0.0 \\
13\end{array}$ & $\begin{array}{l}138 \\
F F P\end{array}$ & $\begin{array}{l}37 \\
\text { ALATD }\end{array}$ & & & REGION 1 \\
\hline$* * * * * *$ & $* \cdots * * *$ & $* \cdots * * * 1$ & $* * \cdots * * * *$ & & $* * * *$ & $* *$ & \\
\hline 270 & 723. & 90. & 33.9 & 68.4 & 120 & & \\
\hline 2.0 & .2 & 7150. & .005 & 136 & 0.0 & 0.0 & \\
\hline 4.0 & 4.0 & 4.0 & 4.0 & 4.0 & 3.0 & 8.0 & 9.0 \\
\hline 4.0 & 4.0 & 3.0 & 4.0 & & & & \\
\hline .046 & .038 & .062 & .046 & .064 & .059 & .178 & .216 \\
\hline .094 & .085 & .053 & .058 & & & & \\
\hline & 7000 & 0.0 & 138. & 37. & & & REGION 2 \\
\hline$* * * * * *$ & $* \ldots \ldots *$ & $\cdots * * * * \cdots+* *$ & $* * * \ldots * * * * *$ & $* * \ldots+\cdots * *$ & $* * * \cdots *$ & $\ldots+\ldots+\ldots+$ & $\ldots+\ldots \ldots \ldots$ \\
\hline 270. & 723. & 90. & 33.9 & 68.4 & 120. & & \\
\hline 2.0 & 2 & 7000. & .005 & 136 & 0.0 & 0.0 & \\
\hline 4.0 & 4.0 & 4.0 & 4.0 & 4.0 & 3.0 & 8.0 & 9.0 \\
\hline 4.0 & 4.0 & 3.0 & 4.0 & & & & \\
\hline .046 & .038 & .062 & .046 & .064 & .059 & .178 & .216 \\
\hline .794 & .085 & .053 & .058 & & & & \\
\hline 18. & 7000 & 0.0 & 143. & 37. & & & REG1ON 3 \\
\hline & & & & & & & \\
\hline 270. & 723 & 90. & 33.9 & 68.4 & .120 & & \\
\hline 2.0 & 2 & 7000. & .005 & 136 & 0.0 & 0.0 & \\
\hline 4.0 & 4.0 & 4.0 & 4.0 & 4.0 & 3.0 & 8.0 & 9.0 \\
\hline 4.0 & 4.0 & 3.0 & 4.0 & & & & \\
\hline .046 & .038 & .062 & .046 & .064 & .059 & .178 & .216 \\
\hline .094 & .085 & .053 & .058 & & & & \\
\hline $1 \%$ & 7000 & 0.0 & 143. & 37. & & & REGION 4 \\
\hline$* * *$ & $700 \mathrm{c}$ & $\because n$ & $4 * 4 * *$ & $* \cdots *$ & & & \\
\hline 270. & 723. & 90. & 33.9 & 68.4 & 120. & & \\
\hline 2.0 & 2 & 6850. & .005 & $13 E$ & 0.0 & 0.0 & \\
\hline 4.0 & 4.0 & 4.0 & 4.0 & 4.0 & 3.0 & 8.0 & 9.0 \\
\hline 1.0 & 4.0 & 3.0 & 4.0 & & & & \\
\hline .046 & 0.38 & .062 & .046 & .064 & .059 & .178 & .216 \\
\hline .094 & .085 & .053 & .058 & & & & \\
\hline 16. & 7000. & 0.0 & 150 & 37. & & & REGION 5 \\
\hline$* \ldots$ & $* \cdots$ & $\ldots$ & & & & & 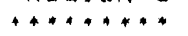 \\
\hline 270 & 723. & 90. & 33.9 & 683.4 & 120. & & \\
\hline 2.0 & .2 & 7000 & .005 & 136 & 0.0 & 0.0 & \\
\hline 4.0 & 4. 0 & 4.0 & 4.0 & 4.0 & 3.0 & 8.0 & 9.0 \\
\hline 4.0 & 4.0 & 3.0 & 4.0 & & & & \\
\hline .046 & .038 & .062 & .046 & .064 & .059 & $.17 \mathrm{E}$ & .216 \\
\hline .094 & 085 & .053 & .058 & & & & \\
\hline 17. & 7000. & 0.0 & 143 & 37. & & & REGION G \\
\hline & & & & & & & \\
\hline 270. & 723. & 90. & 33,9 & 68.4 & 120 & & \\
\hline 2.0 & .2 & 6850 & .005 & 136 & 0.0 & 0.0 & \\
\hline 4.0 & 4.0 & 4.0 & 4.0 & 4.0 & 3.0 & 8.0 & 9.0 \\
\hline 4.0 & 4.0 & 3.0 & 4.0 & & & & \\
\hline .046 & .038 & .062 & .016 & .064 & .059 & .178 & .216 \\
\hline .094 & .085 & .053 & .058 & & & & \\
\hline
\end{tabular}


TABLE 3. (cont)

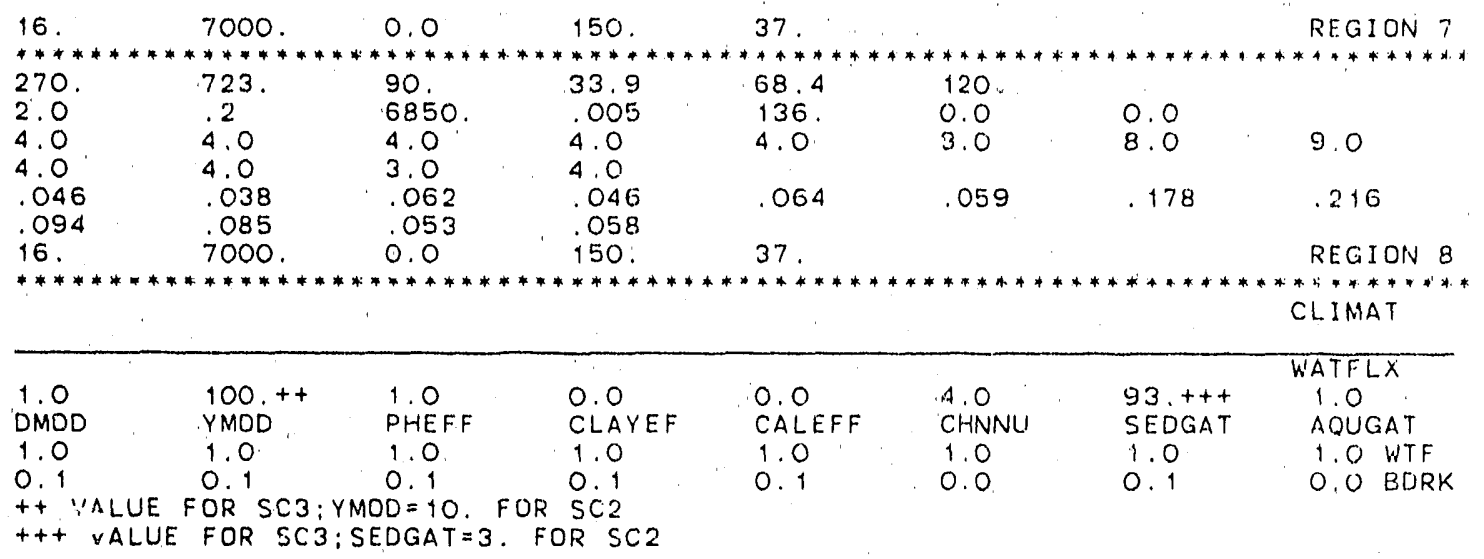

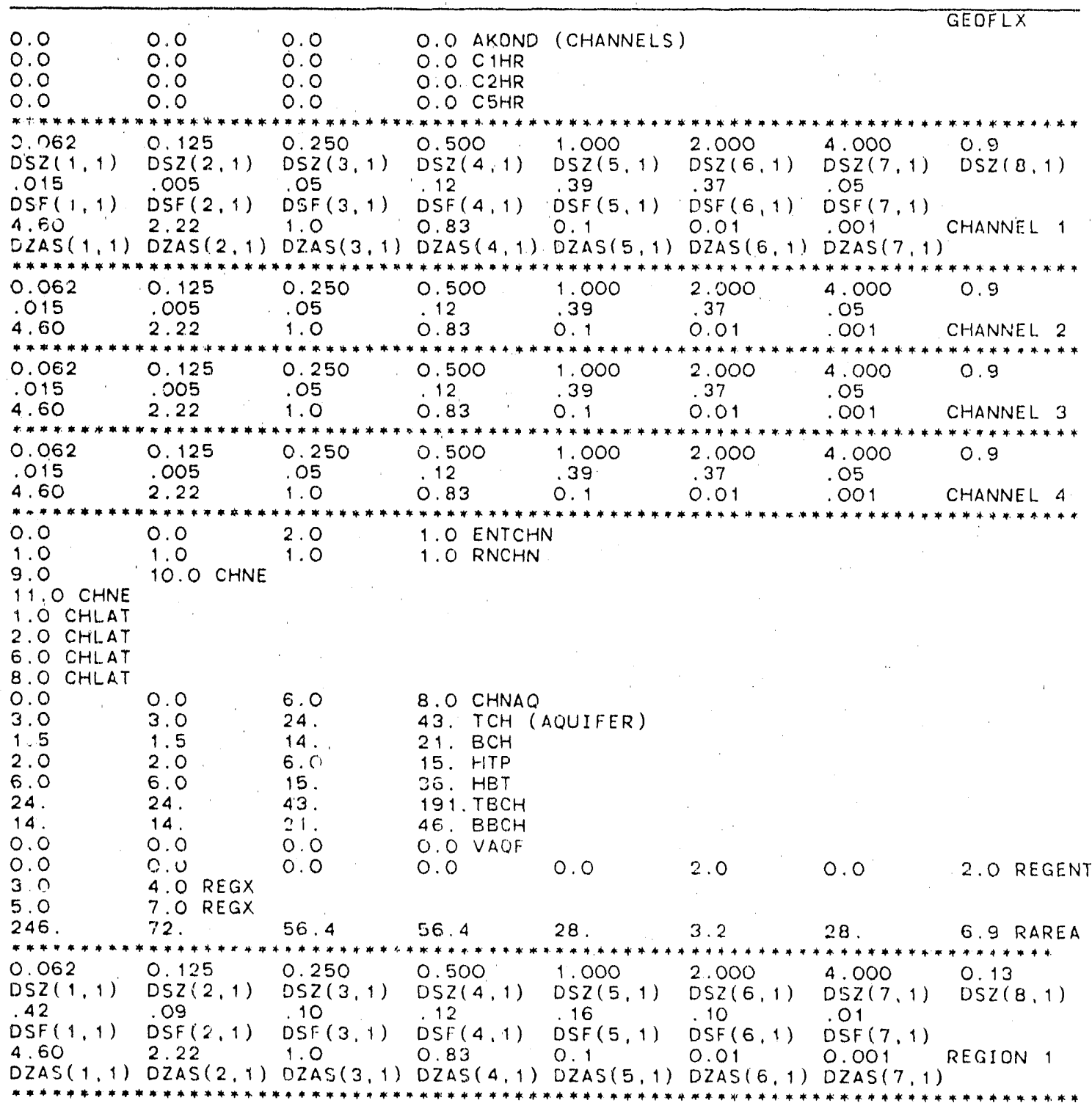


TABLE 3. (cont)

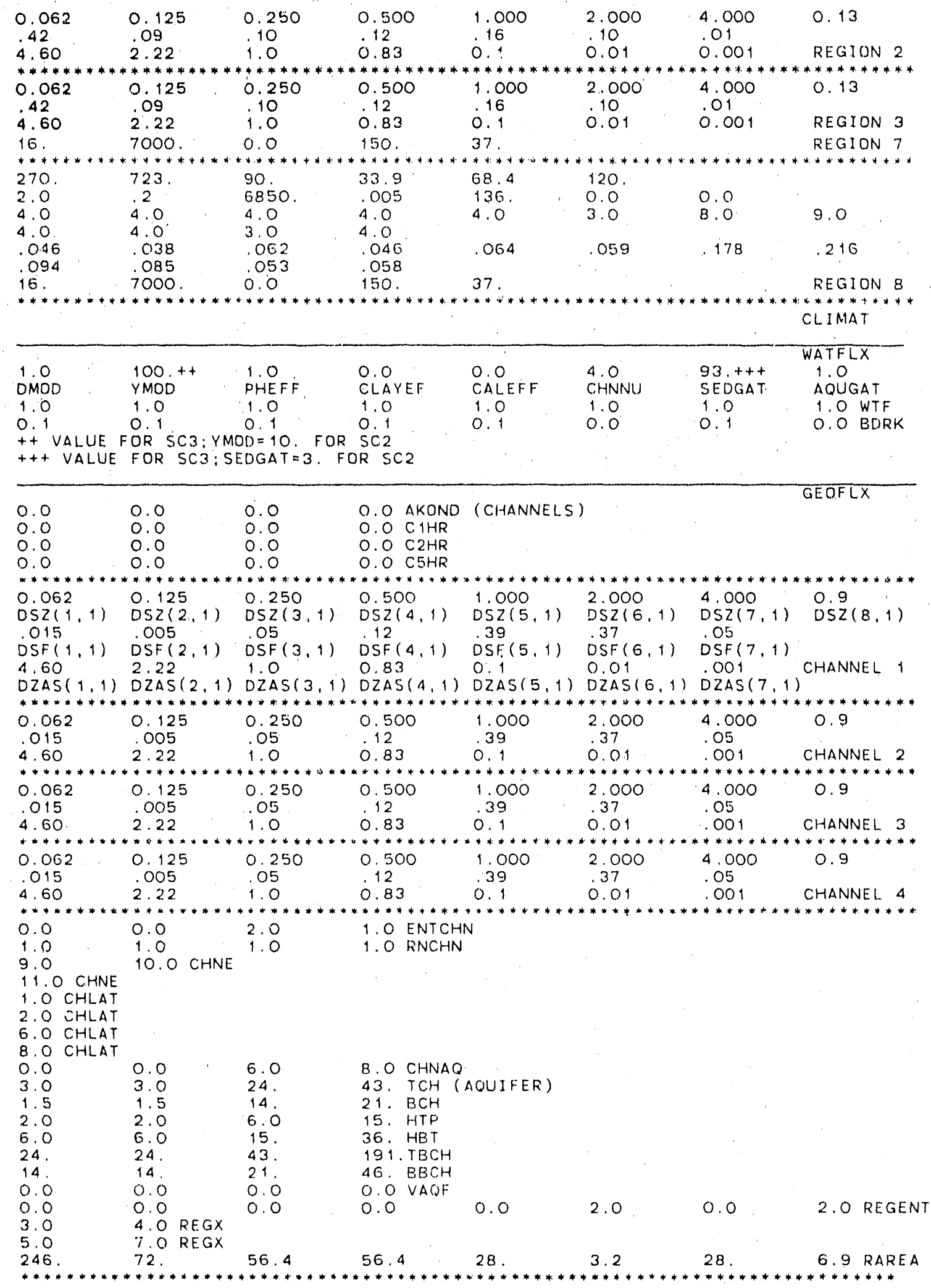


TABLE 3. (cont)

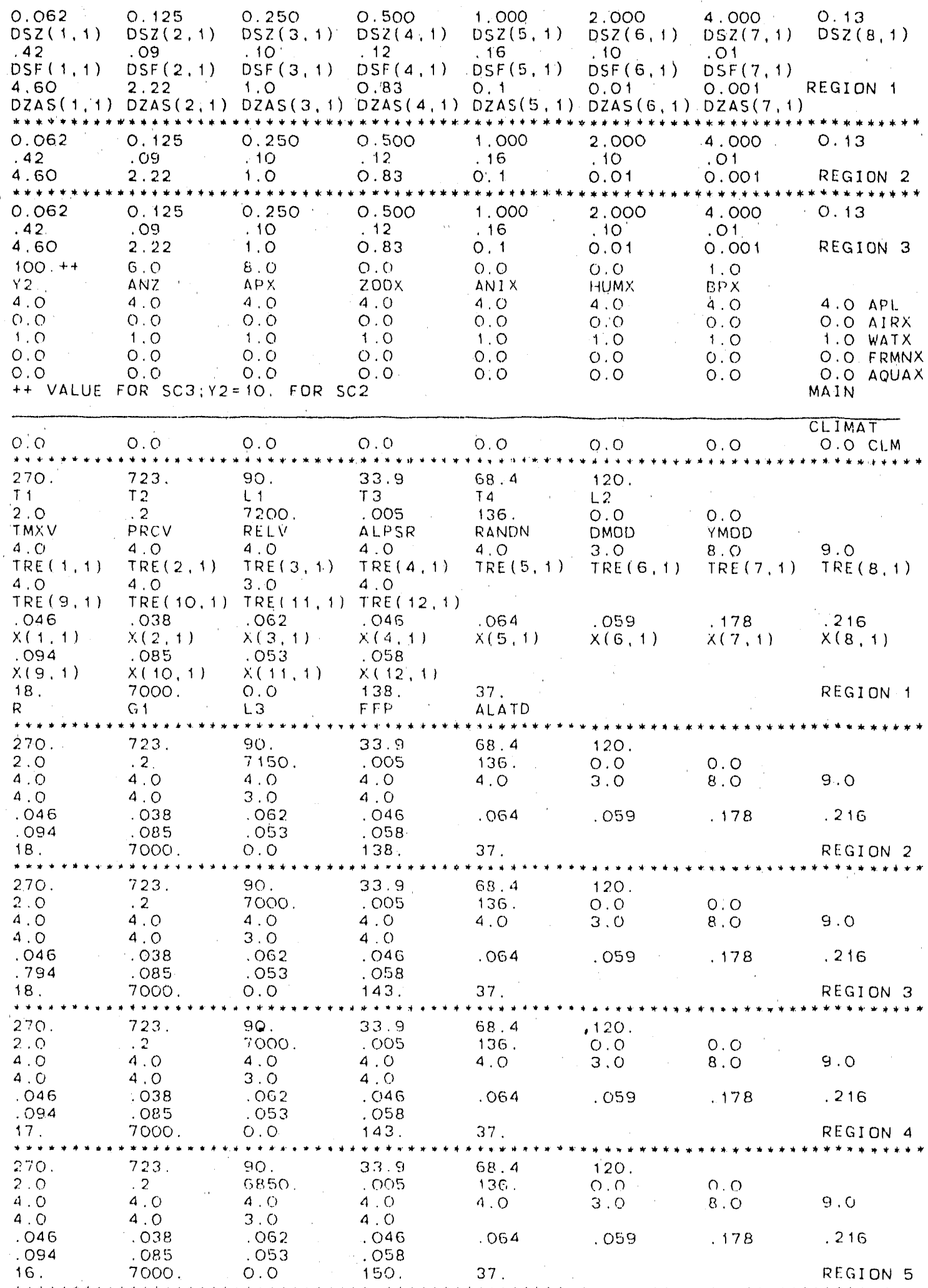


TABLE 3. (cont)

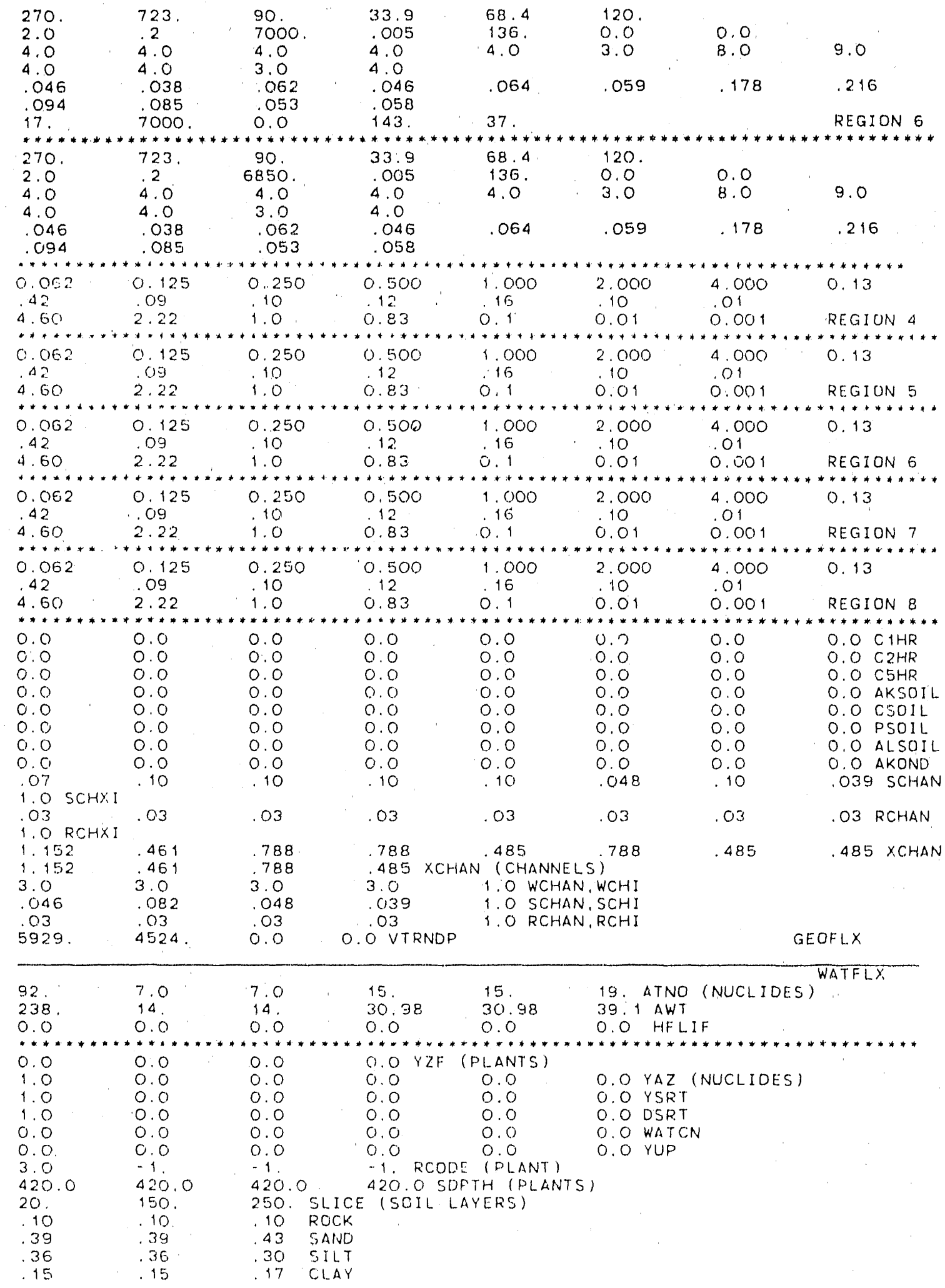


TABLE 3. (cont)

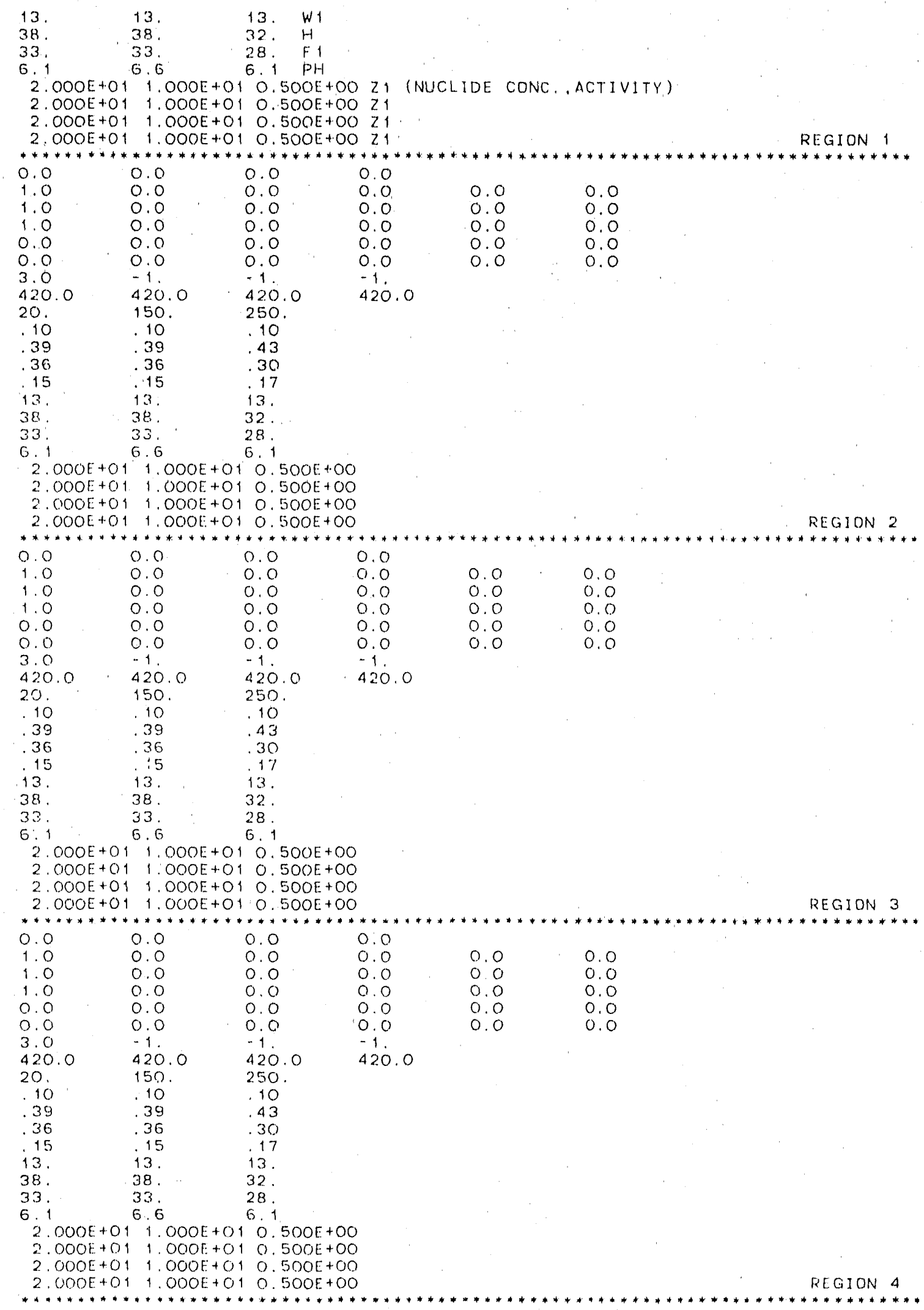


TABLE 3. (cont)

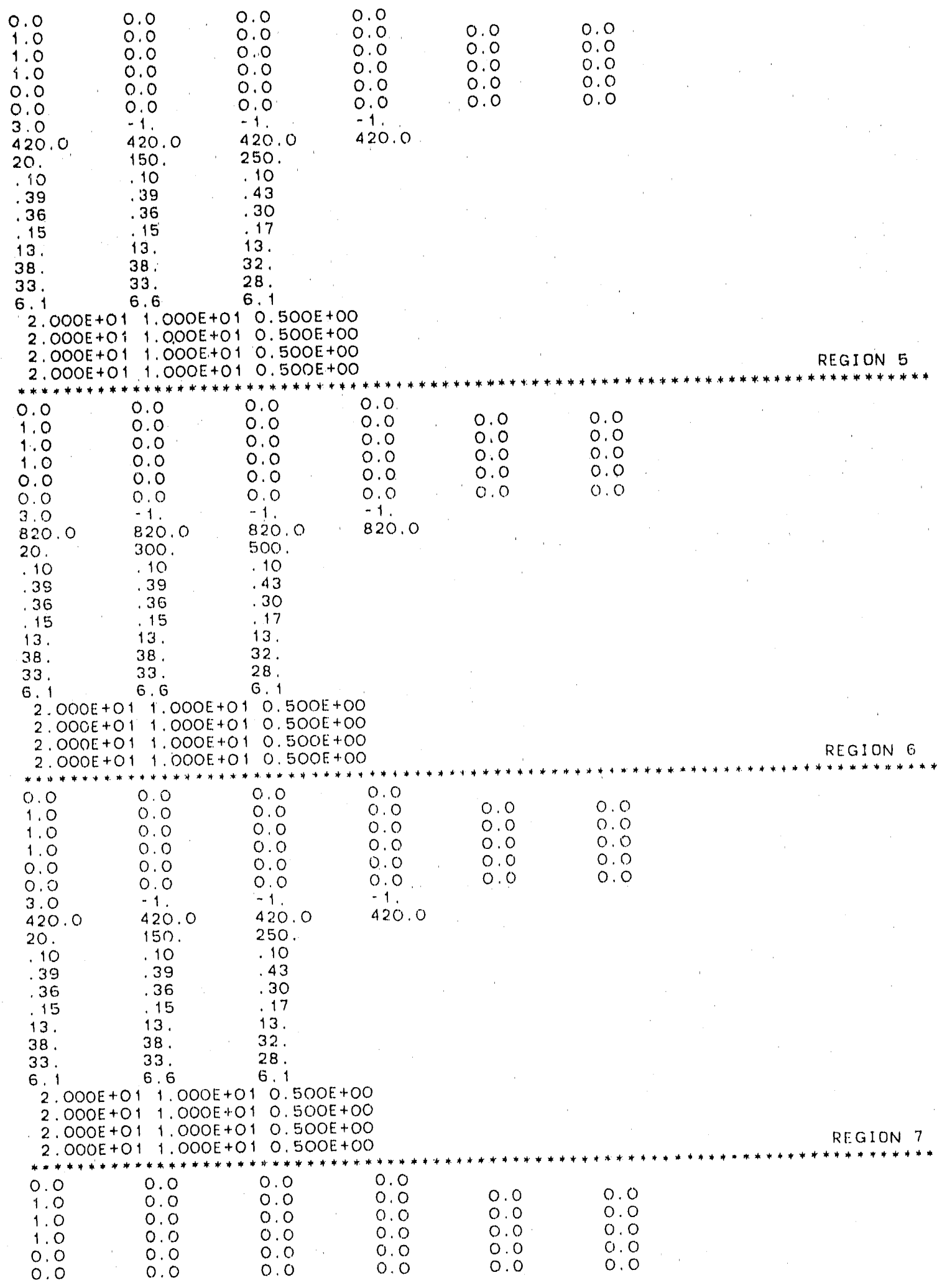


TABLE 3. (cont)

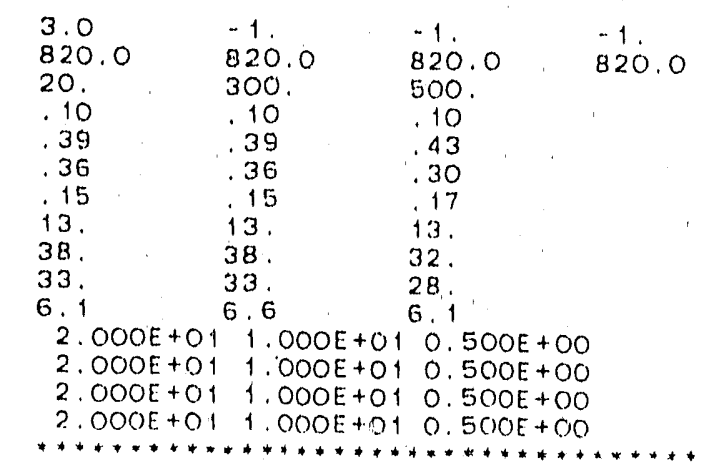

REGION 8

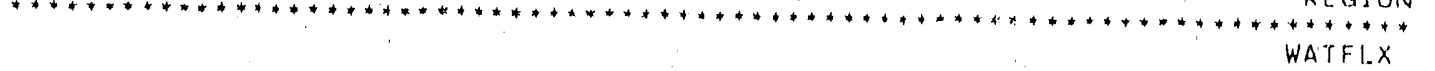

\begin{tabular}{|c|c|c|c|c|c|c|c|}
\hline $\begin{array}{l}0.0 \\
O .0 \\
\text { DMOD }\end{array}$ & $\begin{array}{l}0.0 \\
0.0 \\
Y M O D \\
*^{* * *}\end{array}$ & 0.0 & 0.0 & 0.0 & 0.0 & 0.0 & $\begin{array}{l}\text { PLTGRO } \\
0.0 \mathrm{PGR}\end{array}$ \\
\hline
\end{tabular}

RSCDE AICHE ADSUC

$\begin{array}{llll}15 . & 16 . & 18 . & 19 . \text { PL.TID } \\ 0.0 & 0.0 & 0.0 & 0.0 \text { ARIG }\end{array}$

$0.0 \quad 0.0 \quad 0.0 \quad 0$ ARIG

$\begin{array}{lllll}0.0 & 0.0 & 0.0 & 0.0 \text { AHRV } & \\ 1.0 & 1.0 & 1.0 & 1.0 \text { RGCPLT PONDEROSA-OAK-GRASS } \\ 2.0 & 1.0 & 1.0 & 1.0 \text { RGC } & \\ 0.0 & 0.0 & 0.0 & 0.0 \text { RIRRC }\end{array}$

$0.0 \quad 0.0 \quad 0.0 \quad 0.0$ RSS

246.246 .246 . ACRES 246. REGION 1

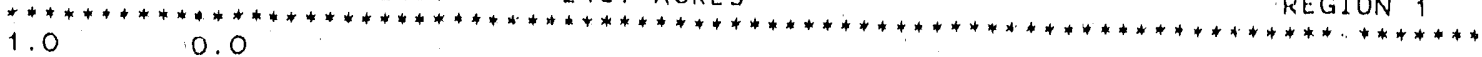

15.018 .019

$\begin{array}{llll}0.0 & 0.0 & 0.0 & 0.0\end{array}$

$\begin{array}{lll}0.0 & 0.0 \quad 0.0 & 0.0\end{array}$

$\begin{array}{llll}1.0 & 1.0 & 1.0 & 1.0\end{array}$

$\begin{array}{llll}0.0 & 0.0 & 0.0 & 1.0 \\ 0.0 & 0.0 & 0.0 & 0.0\end{array}$

$\begin{array}{llll}0.0 & 0.0 & 0.0 & 0.0\end{array}$

$\ldots \ldots \ldots+\ldots+\ldots \ldots+\ldots+\ldots \ldots+72 \ldots \ldots$ REGION 2

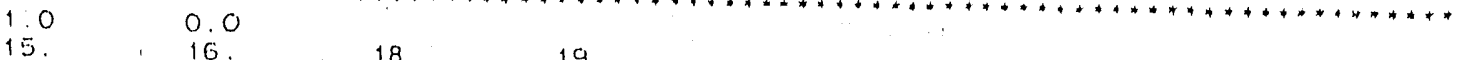

$15.16,19$

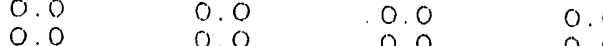

$\begin{array}{llll}0.0 & 0.0 & 0.0 & 0.0\end{array}$

$\begin{array}{llll}2.0 & 1.0 & 1.0 & 1.0\end{array}$

$\begin{array}{llll}0.0 & 0.0 & 0.0 & 0.0 \\ 0.0 & 0.0 & 0.0 & 0.0\end{array}$

$56.4 \quad 56.4 \quad 56.4 \quad 56.4$

REGION 3

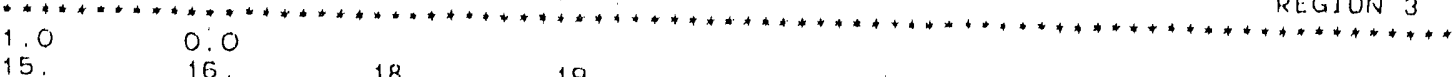

$15 . \quad 16$.

$0.0 \quad 0.0 \quad 18.0 .0019$

$0.0 \quad 0.0 \quad 0.0, \quad$ PONDEROSA-OAK - GRASS

$\begin{array}{llll}1.0 & 1.0 & 1.0 & 1.0\end{array}$

$0.0 \quad 1.0 \quad 1.0 .0$

$\begin{array}{llll}0.0 & 0.0 & 0.0 & 0.0 \\ 56.4 & 0.0 & 0.0\end{array}$

$56.4 \quad 56.4 \quad 56.4 \quad 56.4$

REGION 4

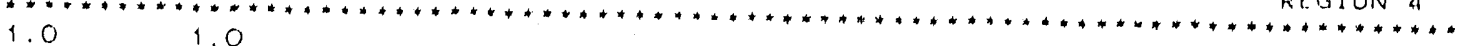

$\begin{array}{llll}5.0 & 8.0 & 15 . & 18\end{array}$

$0.0 \quad 0.0 \quad 0.0$

$\begin{array}{lll}0.0 & 0.0 & 0.0\end{array}$

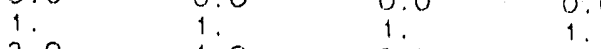

2. $021.0 \quad 2.0 \quad 1.0$

$0.0 \quad 0.0 \quad 0.0$

$\begin{array}{llll}1.0 & 2.0 & 1.0 & 2.0\end{array}$

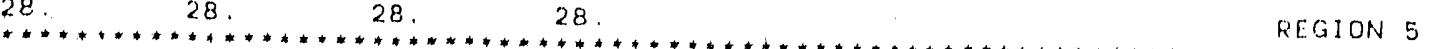


TABLE 3. (cortit)

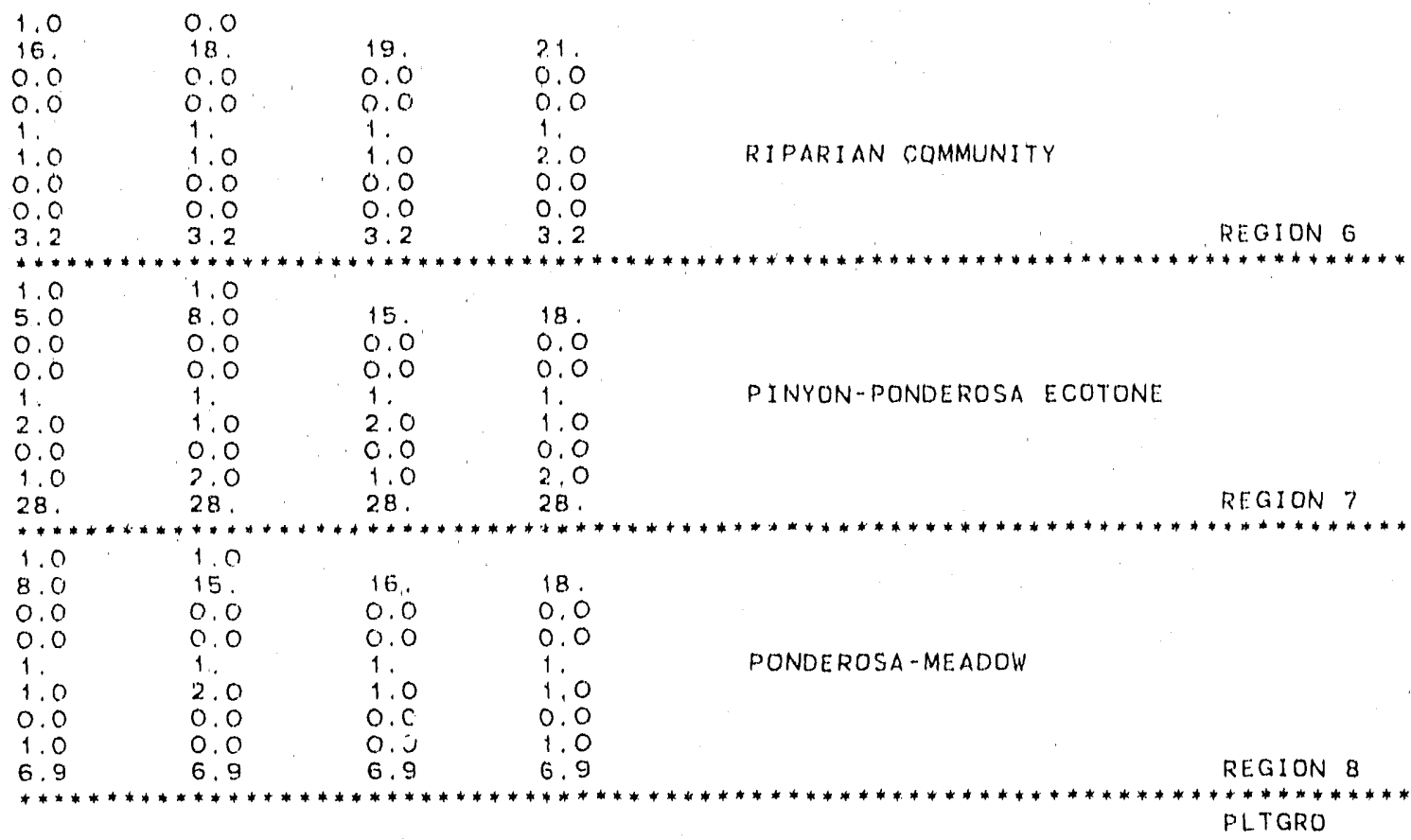

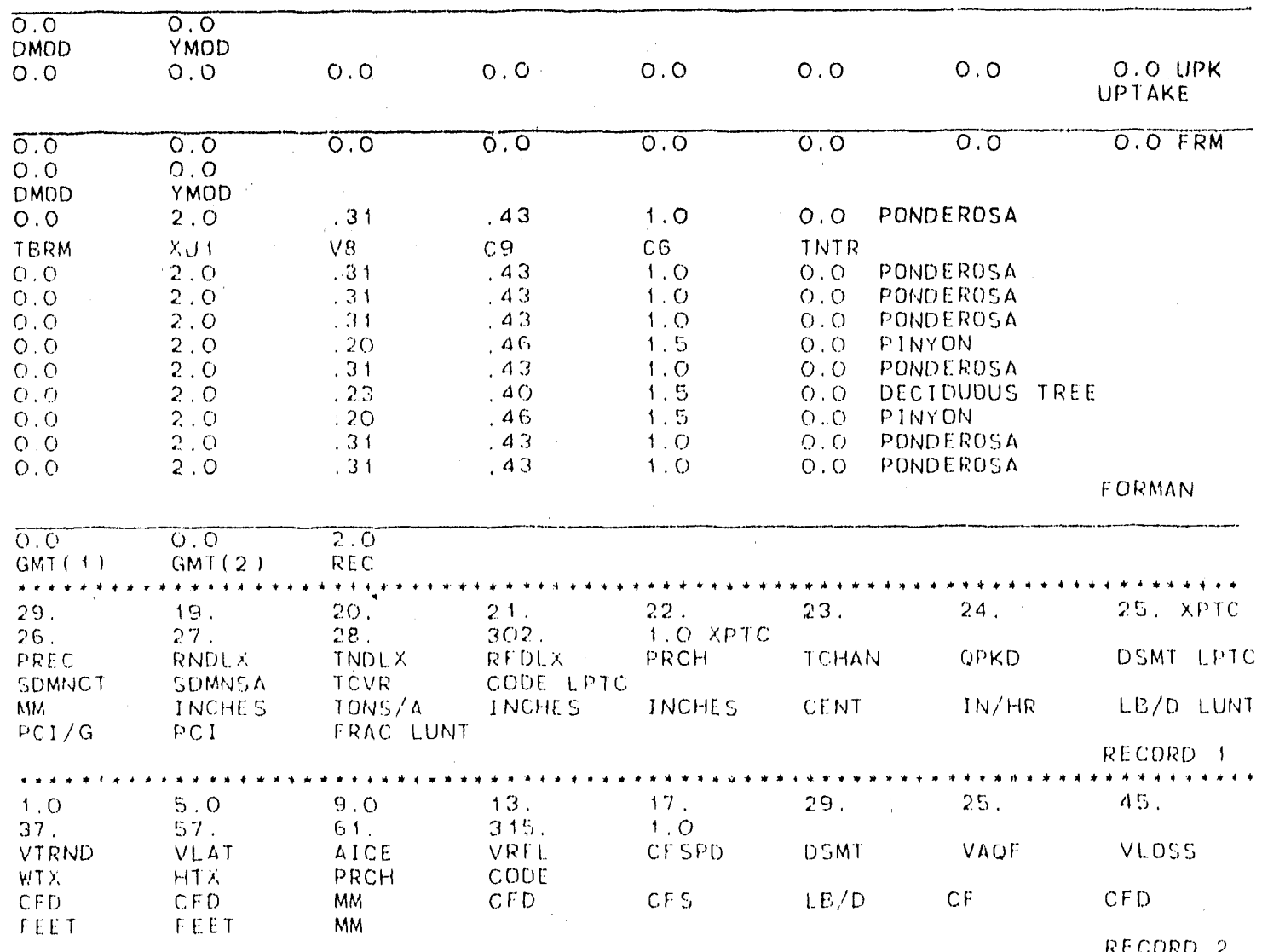


TABLE 3. (cont)

\begin{tabular}{|c|c|c|c|c|c|c|c|}
\hline 0.0 & 0.0 & 0.0 & 0.0 & 0.0 & 0.0 & 0.0 & $\begin{array}{r}0.0 \\
E \times 17\end{array}$ \\
\hline
\end{tabular}


2. SC2 and SC3: Input to subroutine CLIMAT for SC1, SC2, and SC3 are identloal with three exceptlons. The first difference is in the assignment of site elevation (relv $=7200,7150$, $7000,7000,6850,7000,6850$, and 6850 for reglons $1,2, \ldots, 8)$ of each reglon in sc3. The annual precipltation amounts for all reglons included in sc1 are set at $18 \mathrm{In}$., whereas sc2 and sci3 are rot all equal $(18,18,18,17,16,17,16$, and $16 \mathrm{in}$. for reglons 1 to 8 , respectlvely. The third dirler. ence is the frost-free perlod (ffp $=138,138,144,143,150,143,150$, and 150 for regions 1 , $2, \ldots, 8)$ assignments for each region. These last values are estirnated for these reglons.

\section{Input to WATFLX}

1. $S C 1$ : The first line of input concerns the day (dmod $=1$ ) and year (yrnod $=4$ ) moduli, the effects of $\mathrm{pH}($ pheff $=1$ ) and clay (clayef $=0$ ) on the uptake of uranium by plants $(0=$ no ef . fect simulated), the number of channels (chnnu $=4$ ), erosion Initlation year (sedgat $=3$ ), and a gate for aqulfer operation (aqugat $=1$ ) (a zero does not allow operation). The second line of input is a selection gate for output from a given reglon ( $w \mid x=1$ for all; a zero cllsallows), whereas the third line specifles the fraction of each regional surtace overlain by moisture impervious material (bdrk $=0.1$ for reglons $1,2,3,4,5$, and $7 ;$ bdrk $=0$ for regions 6 and 8 ). If the watershed model is being used (chnnu $>0$ ), then subroutine GEOFLX is accessed for Input (to be described under that heading) before returning to line 4 of WATFLX input. Shot line enters the atomic numbers (atno) for uranium, nitrate-nltrogen, ammonla-nitrogen, labile phosphorus, soluble phosphorus, and potassium in that order, followed by the respective atomic weights (awt) and half-lives (hflit) of these ruclldes in lines 5 to 6 ; the larter is set to zero for stable elements.

Beginning with line 7, and continuing until the end of WATFLX input, eight sets of WAT. FLX input corresponding to the regions simulated (apX) are entered in sequence intil completed. Line input $(y z t=0)$ is a gate for selectively entering root fractions in each soll layer for each veg. etation type (a value of 0 causes default values to be calculated internally). Line 8 input (yaz $=1$ for uranium; yaz $=0$ for all other nuclides) determines whether nucllde concentrations in soll lay. ers are entered (yaz $>0$, yaz $<3$ ), or calculated internally (yaz $=0$, or yaz $=3$ ). Furthermore, when yaz $=3$, soll nuclide concentrations for all soll layers are set equal to the concentration in the top layer. If the half-life (hillif) of specilfic nuclide is greater than zero, then the specific activity of $\mathrm{pCl} / \mathrm{g}$ dry weight of soil is calculated. If yaz $=1$, then the soll concentrations entered as $\mu \mathrm{g} / \mathrm{g}$ soll are converted internally to specific activity units (hilif $>0$ ). Finally, values of yaz $=2,3$ will atlow soil concentrations to retain the same concentration units either from input or internally calculated estimates of a given element or radionuclide. Ultimately, all element (non-radioactive nu. clide) concentrations entered as $\mu \mathrm{g} / \mathrm{g}$ are converted to $\mathrm{g} / \mathrm{g}$ internally.

Lines 8 and 9 determine what year (ysit $=1$ for uranium; ysit $=0$ for all other radionuclides) and what day (dsrt $=1$ for uraniumli dsrt $=0$ for all other nuclides) soil concentrations of specific nuclides will enter the simulation (a value of 0 defaults to all years and days it the simulation). Line 10 enters the concentration (watch $=0$ ) of irrigation water for cultivated plant types; if is not used in sc1. Line 11 is a gate $(y u p=0)$ for entering plant/soll concentration factors for a given nuclide (a value of 0 defaults to internal calculation). 
The remaining input in WATF $L X$ specifies soll characleristics relating to plant growith and nuclide uptake by plants. Line 12. enters the number of soll layers (rcode $: 3$ ) for all plant types in a given reglon. When - 1 is entered as inpul, il designates that a specifle plant has the same soll characterlstios as the first plant designated. All plant types in all reglons are set to have identical soll characteristlos with the excuplion of soll depth. Line 13 onters spuctic soll depthe (sdpth = $420 \mathrm{~mm}$ for regions $1,2,3,4,5$, and 7 ; and $\mathrm{sdpth}=820 \mathrm{~mm}$ for reglons 6 and 7 ) for all plants of a glven region. The soll layer thicknesses (slice $=20,150,250 \mathrm{~mm}$ for reglons $1,2,3,4,5$, ancl 7: slloe $=20,300,500$ lor reglons 6 and 8 ) for all plants of a glven region are presented in line 14 . Lines 15 to 18 enter stone (rock $:=0.1$ ), sand (sand $:=0.39,0.43$ ), sill (silt $=0.36,0.30$ ), and clay (clay $=0.15,0.17$ ) fractions in each soll layer described for a givgn region; the second value in each set of pareritheses represents the fractlons in the innermost scill layer. I. ines 191022 ontor wllting polrits $(w 1=0.15,0.17)$, holding capacity $(n=38 \%, 32 \%)$, field capacily $(11=33 \%, 28 \%)$, and $\mathrm{pH}(\mathrm{ph}=6.1$ for layers 1,$3 ; \mathrm{ph}=6.6$ for layer 2 ) of each soll layer; the second value in each set of parentheses for $w 1, h$, and $t 1$ represents values for the irnermost soll layer. Finally, lines 23 to 26 enter the soll concentratlon for uranium $(z 1=2,1,0.5 \mathrm{pCi} / \mathrm{g}$ for layers 1,2, and 3$)$ for each plant type of each reglon; all are identical.

2. SC2 and SC3: Input to subroutine WATFLX for sc3 dilfers from that of Sc1 in mod. ules assignment (ymod $=100$ ) and Initial access to the hydrological portion of the model (sedgal $=93)$.

\section{Input to GEOFLX}

1. SC1: Input from subrouthe GEOFLX is accessed from subroutine WATFI.X when chnnu $>0$, as mentioned previously. However, all Input requirements required for operation of EROSON and AQUIFER are included in this subroutine. Line 1 enters the hydraulic conductivity (akond $=0$ ) of the channel beds. A default value of 0 sets the conductivity internally to $3 \mathrm{in} . \mathrm{h}$. Lines 2 to 4 enter the constants required for estimating runoff flow duratlon (c1hr $=0$, c2 $\mathrm{hr}=0$ ), and peak flow (c5hr $=0$ ). Default values used when the input is zero are c1hr $=2.53, \mathrm{c} 2 \mathrm{hr}=0.2$, and $\mathrm{c} 5 \mathrm{hr}=4.82$ ).

Lines 5 to 7 enter the channel bed alluvium dlameter distributions (ds $z=0.062,0.125$, $0.500,1.000,2.000,4.000$, and $0.9 \mathrm{~mm})$, the mass fractions for each particle dameter category (dst $=0.015,0.005,0.05,0.12,0.39,0.37$, and $0.05 \mathrm{~mm}$ ), and particle uranilum speclific activity $(4.6,2.22,1.0,0.83,0.1,0.01$, and $0.001 \mathrm{pCi} / \mathrm{g})$ for the first channel. Input fic all other channels (lines 8 to 16) are identical to channel $1 \mathrm{in} \mathrm{sc1.} \mathrm{The} \mathrm{eighth} \mathrm{value} \mathrm{of} \mathrm{dsz} \mathrm{(0.9)} \mathrm{is} \mathrm{the} \mathrm{mass} \mathrm{median}$ diameter of the alluvial particles. Line 18 enters the number of tributary channels (entchn $=0,0$, 2, 1 for channels 1, 2, 3, and 4) to a specitic channel. Line 19 enters the number of laterals (rnchn $=1$ for all channels) or regions draining directly into each channel. Lines 20 and 21 enter specific tributarles (chne $=1.2$ into channel $3 ;$ chne $=3$ into channel 4). The tributary can also in. clude a portion or segment of the same channel (channels 3 and 4 are segments of the same channel). Also, the channel numbers are identified $(9,10,11$, and 12) with values commensurate to the regions in the scenario $(1,2,3, \ldots$ apx $)$ because regions and chanrels share some common arrays or varlables in the model and are processed similarly. L.ines 22 to 25 enter the direct lat erals or regions (chlat $=1,2,6,8$ into channels $1,2,3$, and 4) draining into a speciflc channel. 
L.Ine 26 enters the reglon overlying an aciulfer (chnag $=0,0,6,8$ for channols $1,2,3$, and 4) and its assoclated channel. A value equal to 0 indicales that a channal does not have an alluval plain or reglon through which the channel flows. In sc1 channels 3 and 4 have alluvial platins (regions 6 and 8 ), whereas they are not modeled in channels 1 and 2 .

L.Ines 27 to 32 enter the aquiler dimenslons beneath each aqulter upstream and down. stream. Sectlons are modeled as trapezolds connected to lorm the aquiler volume. Line 27 enters the top dimenslons (ich = 3, 3,24, 43 If lor channels 1, 2, 3, and 4) for the upstream portion of each aquifer. LIne 28 enters the bottom dimensions of the trapezolds for the upstream portion (bch $=1,5,1,5,14,21 \mathrm{tt}$ for channels 1, 2, 3, and 4). Line 2.9 enters the depth of the acjulfer of the upstream portion (htp $=2,2,6,15 \mathrm{ft}$ for channels $1,2,3$, and 4 ); line 30 enters the downstream or distal depth of the aquller ( $\mathrm{hbt}=6,6,15,36 \mathrm{ft}$ for channels $1,2,3$, and 4). Line 31 enters the top dimensions (bboh $24,24,43,191 \mathrm{ft}$ for channels $1,2,3$, and 4 ) at the distal or downstream end of each aquifer; line 32 enteis the bottom dimenslons (bbch $=14,14,21,46$ if for channels 1 . 2,3 , and 4) at the downstream end of each aquiler. Finally, line 33 enters the Inillal aquiter vol. ume (vacif $=0,0,0,0$ for channels $1,2,3$, and 4$)$.

Line 34 enters the number of reglons which transport surface runoff, subsurface return flow, and sediment into another reglon (regent $=0$ tor reglons $1,2,3,4,5$, arid 7 ; regerlt $=2$ for reglons 6 and 8). A value of 0 indicates that a glven reglon does not receive such transport. Lines 35 and 36 enter the speclif reglons which contrlbute rurioff, return flow, and sediment 10 a speciflo region (regx $=3,4$ regions to reglon 6 ; regx $=5,7$ regions to region 8 ). Reglons 6 and 8 are thus modeled is alluvial plains recelving these materlals from adjacent reglons normal to the channel segment. The surface areas of all reglons (rarea $=246,72,56.4,56.4,28,3.2,28,6.9$ acres for reglons $1,2, \ldots, 8$ ) are entered in line 37.

As described earller for channels, the top $20 \mathrm{~mm}$ of soll of each, region is sized and quall. fled, starting with region 1. Lines 38 to 61 enter these characteristlcs; however, they are identical for each reglon modeled in sc1. Herice, llnes 38 to 40 will describe all reglons. Line 38 enters the partlcle soll dlameter ( $d s z=0.062,0.125,0.250,0.500,1,2,4,0.13 \mathrm{~mm}$ ), line 39 enters the mass fraction of each particle size $(d s f=0.42,0.09,0.10,0.12,0.16,0.10,0.01)$, and line 40 ertters the uranlum specific activity (dzas $=4.6,2.22,1,0.83,0.1,0.01,0.001$ ) for each particle size. The elghth value of dsz $(0.13)$ is the mass median diameter for the soll particles described.

Liries 62 to 64 enter the runoff duration and peak flow coefticients $(\mathrm{c} 1 \mathrm{hr}=0, \mathrm{c} 2 \mathrm{hr}=0$, $\mathrm{c} 5 \mathrm{hr}=0$, for all reglons). The default values $(0)$ for those coefficlents are c1hr $=3.3, \mathrm{c} 2 \mathrm{hr}=0.25$, and $c 5 \mathrm{hr}=4.84$. Lines 65 to 69 enter the MUSLE soll elosion coefficients (aksoil $=0$, csoll $=0$, psoll $=0$, and alsoll $=0$ for all reglons. The default values $(0)$ for these parameters are aksoil $=$ 0.2 , scoll $=0.1$, psoll $=1.0$, and alsoll =1,0. Line 70 enters the slope of each region (schan $=0.07$, $0.1,0.1,0.1,0.1,0.048,0.1$, and 0.039 for reglons $1,2, \ldots, a p x$, schxi $=1$ ). Line 71 enters the Manning roughness coefflclent for each region (rchan $=0.03$ for all reglons, rchx| $=1$ ). L.ine 72 enters the length of each reglon parallel to its associated channel (xchan $=1.152,0.461,0.788$, 0.485 , and $0.485 \mathrm{mi}$ for reglons $1,2, \ldots, \mathrm{apx})$. Line 73 enters the channel length $(1.152,0.461$, $0.788,0.485 \mathrm{ml}$ for channels $1,2,3$, and 4 ). Line 74 enters the width of each channol (wohan $=3$ It for all channels, wchl $\Rightarrow 1$ ). Line 75 enters the slope of each channel (schan $=0.046,0.082$, 
$0.048,0.039$ for channels $1,2,3$, and 4, schi $= \pm 1$, and line 76 enters the Manning coefflelents of tho channels (rchan $=0.03$ for all channels, rchi $=1$ ). When the parameters schxi, rchxi, wchi, schil, and rethl, are equal to 1, they preserve the input value for the respectlve parameters during the entire simulation. A value of 0 for these parameters actlvates internal calculation of thern whenever surface runoff and/or stream flow occur in the simulation. Finally, llne 77 enters the perennlal additlon of water to a given channel (virndp $=5929,4524,0,0 \mathrm{ft}^{3} \mathrm{k}$ day for channels 1,2 , 3 , and 4).

2. SC2 and SC3: Input requitrements for GEOFLX are Identical to those of SC1.

\section{E. Input to PLTGRO}

1. SC1: Line 1 of input for this subroutine enters the output selector for eacil region (pgr $=0$ for all regions). A value of 0 does not allow output from thls subroutlne through BIOPLT. LIne 2 defaults the advanced successlon mode (adsuc $=0$ ), and the day and year modull (dmod $=0$, $y$ mod $=0$ ). A value of 0 for adsuc does not allow the advanced-successlon strategy to operate.

L.Ines 31075 enter plant growth parameters for all elght regions simulated In sc1: however, the input, with one exceptlon, is identical for all regions. Hence, input for reglon 1 (lines is to 12) will be representatlve of input lor all regions in PLTGRO. Line 3 enters the successior mode option ( $r s d c e=1$ ), and the niche computition mode optlon $(a \operatorname{ch} e=1$ ) for the simulation. A value of 0 for these optlons does not allow their operation in the simulatlon. Line 4 enters the plant types simulated in the given region (plitd $=7,8,19,18$ ). These values correspond to warm-season annuals (7) and perennlal grasses (8) and cool-season annual (19) and perennlal grasses (18). Line 5 enters the irrigation input specification for a given plant (arig $=0$ for all plants). An input value of 0 specifles that Irrigation is not simulated. Line 6 enters the number of harvests for a speciflc plant of a given reglon (ahrv $=0$ for all reglons). The latter varlable applies primlarily to cultlvated plants. Line 7 enters the printing option for a glven plant in a reglon (rgcplt $=1$ for all reglons). A value of 0 does not allow input from BIOPL.T for a given plant type. Line 8 enters the forest management mode for a given plant in a region (rgc $=1$ for all plants). A value of 1 does not allow operation of the mode, a value of 2 allows operatlon of the mode on a yearly basis, and a value of 3 allows operation on a dally basis. Ordinarlly, tree growth accesses the forest management model FORMAN on a yearly basis $(\mathrm{rgc}=2)$. The use of dally access to FORMAN is sometimes desirable to structure the growth of Irrigated crops such as corn. Daily access to FORMAN for tree growth is not recommended because it is wasteful of computer execution time.

Line 9 enters the Irrigation mode optlon for each plant (rirrc $=0$ for all plants). A value of 0 does not allow irrigation and harvesting Input for a given plant of a given region. Line 10 enters the niche competition mode (rss $=1$ for plants 1 and $3, r s s=2$ for plants 2 and 4 ). Plant types with matching iss numbers are placed into niche competition. Finally, line 11 specifles the surface area for each crop type (acres $=246$ acres for all plants in region 1). Acreage for other roglons (acres $=72,56.4,56.4,28,3.2,28,6.9$ acres for region $2,3, \ldots$ apx ) is the only exception to identical input from PLRGRO tor each sile. 
2. SC2 and SC3: The input requirements for SC2 and sc3 differ with respect to several parameters of sc1 input: accsss to the niche competition model (aiche $=0$ for reglons $1,2,3,4$, and 6 ; alche $=1$ for reglons 5,7 , and 8 ) and in plant type assignments described bolow. Plant types (pltid $=15,16,18,19$ for reglons $1,2,3$, and 4 ; pltid $=5.8,15,18$ for regions 5 and $7 ;$ pltid $=16,18,19,21$ for region 6 ; pltid $=8,15,16,18$ for region 8 ) are entered to specify a ponderosa. oak forest, pinyon-ponderosa ecotone, a riparian community, and a ponderosa-meadow, respectively, for the reglons. simulated. Pinyon and ponderosa are set Into niche competition in regions 5 and 7, as are cool- and warm-season perennlal grasses. In regien 8, only warm- and cool-sea. son grasses are sel into niche compelition. The advanced-succession strategy (adsuc $=1$ ) is entered for all regions. Plant identiflcations for the regions are pinyon (5), warm-season perennial grasses (8), ponderosa pine (15), cool-season deciduous shrubs (16), warm-season perennial grasses (18), cool-season annual grasses and herbs (19), and cool-season deciduous trees (21).

\section{F. Input to UPTAKE}

1. SC1: There are only two lines of input in this subroutine. Line 1 enters the day (dmod $=0$ ), and year (ymod $=0$ ) moduli for subroutine output selection (a value of 0 omits output). Line 2 contains a regional output option (upk $=0$ for all reglons): a value of 0 negates output for a given region. There is no output from this subroutine in sc1.

2. SC2 and SC3: Input requirements for UPTAKE are identical to those of SC1.

\section{G. Input to BIOPLT}

1. SC1: Input to this subroutine determines the specific output variables selected for output from any or all subroutines involved in the simulation. Input to line 1 determines whether specific information $[(\mathrm{gmt}(1)=0)]$ from each subroutine accessed by BIOPLT will be specified as output; general Information [(gmt(2) $=0)]$ is not used. When a value of 0 is entered in each case, it disallows formatted output in the output file. Generally, formatted output is not selected because output from BIOPLT is utilized for computer graphics analysis.

Lines 2 to 13 enter output specifications for two records of output (as mariy as 10 records may be specified for output). Lines 2 to 7 enter input for one record: lines 2 and 3 enter the speciflc variables $(x p t c=29,19,20,21,30,23,24,25,26,27,28 ; k=302,1)$. The first 11 parameters identify specific variables selected for output (prec, mdix, tndlx, tddx, b1t, tchan, qpkd, dsmt, sdmnct, samnsa, and tcvr); the last two parameters identify the subroutine $(302=$ WATFI.X) from which output originates (all 300 series values identify WATFL.X output) and whether time units will be in years (1) or days (0). Lines 4 and 5 identify the variables entered in lines 2 and 3 , and lines 6 and 7 enter the units for these variables. The second output specifications from WATFL.X (315) are entered in lines 8 to 13. The variables selected as output are virnd, viat, aice, vrll, cfspd, dsmt, vaqt, vloss, $w t x, h t z$, and prch. All of the variables specified have been discussed previously except for b1t in the first record. This variable represents the total live standing biomass due to all plant types in a given region on a given day. This and all other variables in these records will be discussed further in the next section of this document Finally, the last line in the 
input file terminates execution (0) of BIOTRAN. A value other than zero, will cause BIOTRAN to initiate amother simulation for a different scenario.

2. SC2 and SC3: Input requirements for BIOPLT are identical to those of Sc1.

\section{RESULTS}

This section of the report will focus on a ciescription of selected output for purposes of documenting model operation. Output for channels and regions of the watershed are presented in Figs. 2a-c through 18a-c, where the subscripts $a, b, c$, refer to scenarios $s c 1, s c 2$, and sc3, respectively, A schematic of the watershed area together with its channel network is presented in Fig. 1, as described previously. Finally, input data described previously will be summarized as needed for clarity.

\section{A. Regions, Precipitation}

Precipitation events for the 10th simulation year (sc1 and sc2), and the 100th simulation year (sc3) are presented in Figs. 2a-c for all eight regions of the watershed. Precipitation patterns $(4,4,4,4,4,3,8,9,4,4,3$, and 4 rain events per month from January-December, respectively) are the same for all scenarios. The variations observed on the graphs (rain-event day number and amount of precipitation) are due in part to differences in annual precipitation input. A significant difference is due to the uniform and standard distribution generators in subroutine CLIMAT, which select event day number and precipitation variance for each event, respectively. Most of the precipitation amounts simulated in all scenarios are generally below 0.6 in., however, a small number of events exceeded $1.5 \mathrm{in}$. with a maximum value of about $2.0 \mathrm{in}$. simulated on the $100 \mathrm{th}$ year of sc3. It should be noted that the simulated annual precipitation amount may be greater or less than that entered as input because of the stochastic nature of the simulation.

\section{B. Regions, Mean Daily Temperature}

Annual variation of regional mean daily temperature are presented in Figs. 3a-c for sc1. $s c 2$, and $s c 3$, respectively. Only one pattern is observed for all regions in a given scenario, but each scenario has a unique pattern. The significant fluctuations observed are due to modeled temperature variations on a monthly basis using the normal distribution generator. The minimum $\left(33.9^{\circ} \mathrm{C}\right)$ and maximum $\left(68.4^{\circ} \mathrm{C}\right)$ mean daily temperatures as well as the monthly coefficient of variation (0.2) are entered for all regions of a given scenario. Regional differences in elevation are modeled to affect daily temperatures through the use of the lapse rate $\left(0.005^{\circ} \mathrm{F} / \mathrm{ft}\right.$ for all regions) in sc2 and sc3; however, the range in mean elevation (6850-7200 ft above sea level) com. pared with the reference elevation (7000 ft) was not large enough to produce any significant differences in the pattern. Of particular interest for each scenario are the effects of temperature on snowiall and snowmelt and on the formation of ice on channel surfaces. The effect on snowmelt can be observed in the surface runoff plots toyether with the effect on channel ice formation to be described later in this report. 


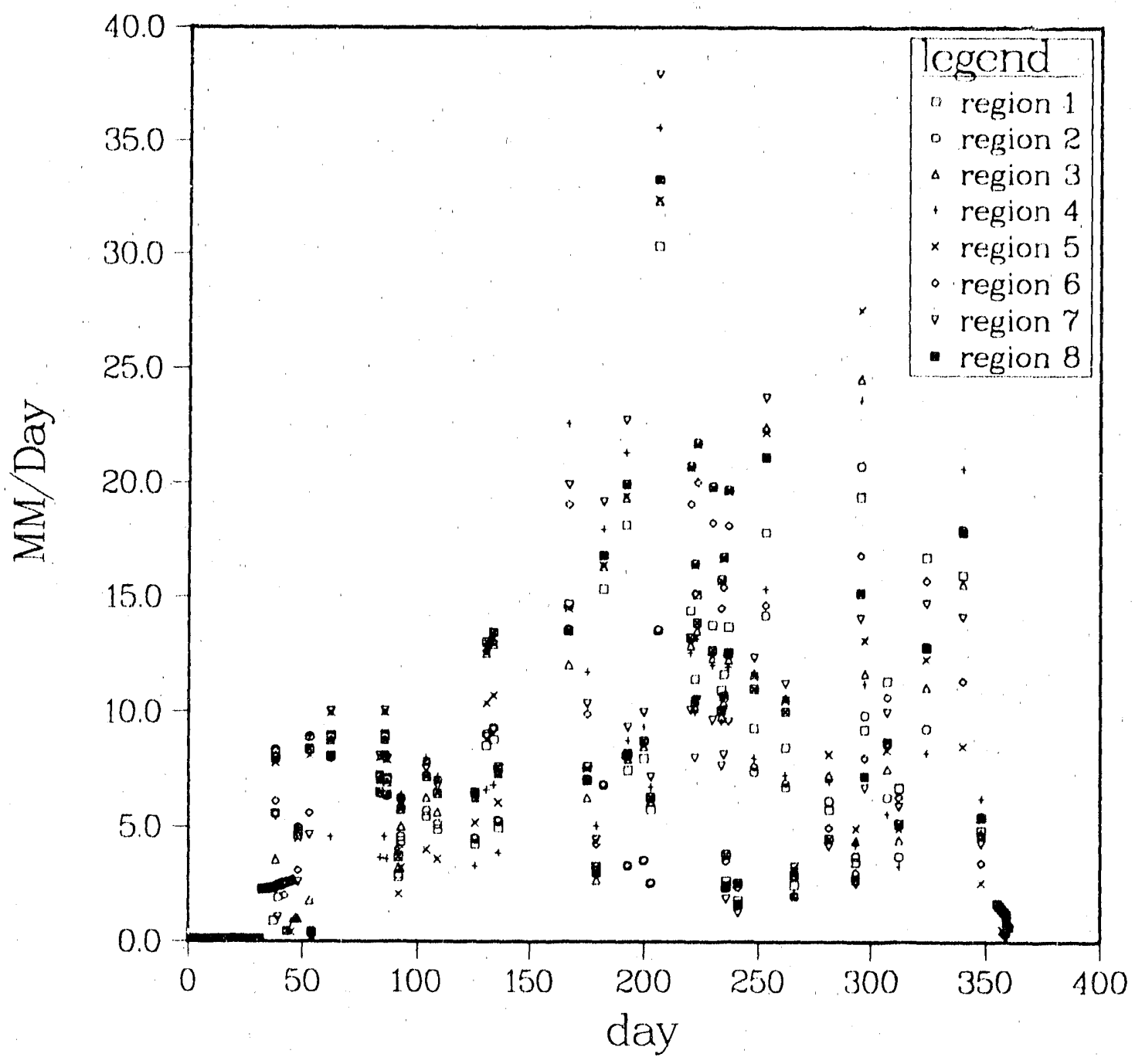

Fig. 2a. Precipitation events for the 10th simulation year for scenario 1, sc1. 


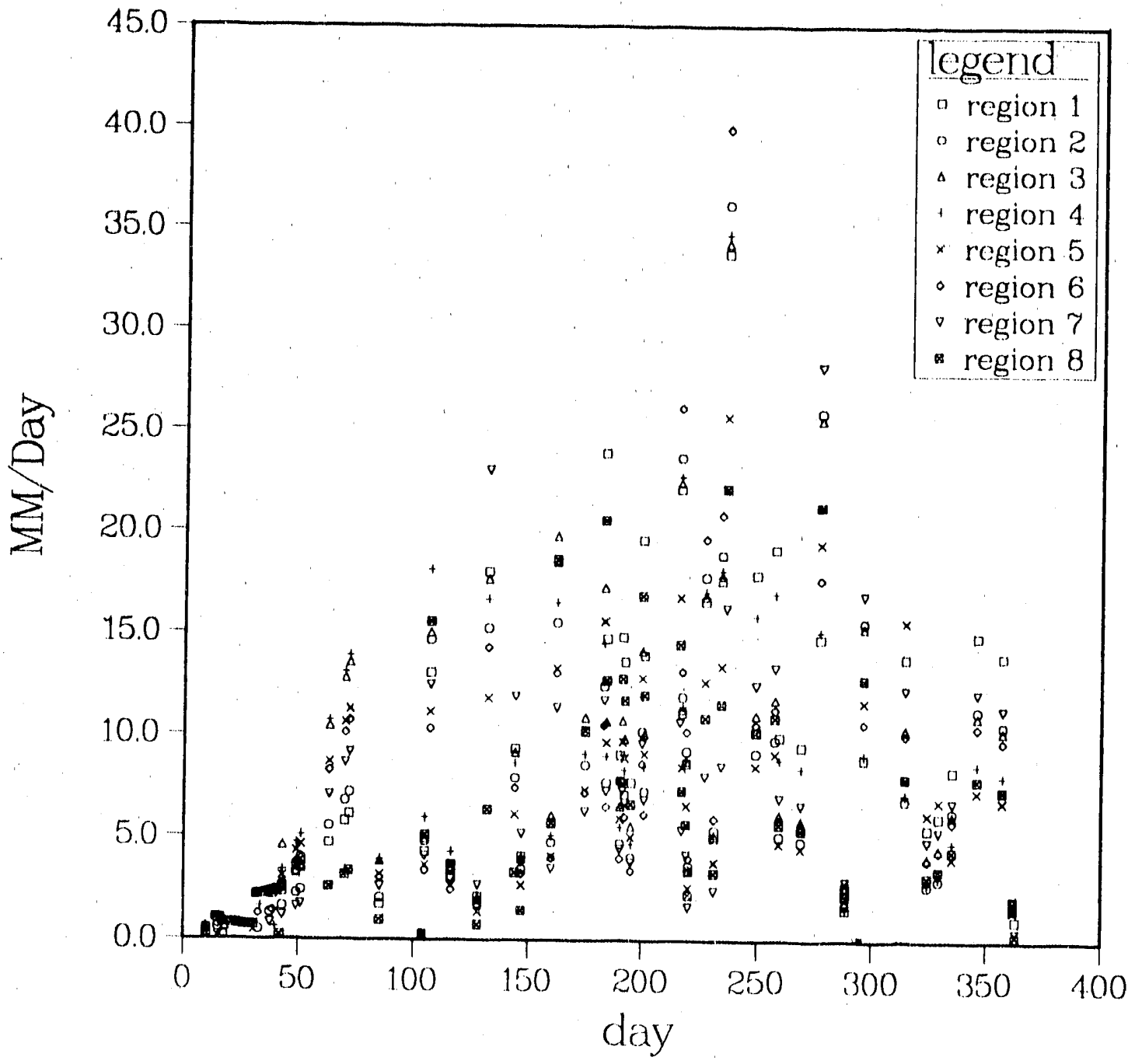

Fig. 2b. Precipitation events for the 10th simulation year for scenario 2, sc2. 


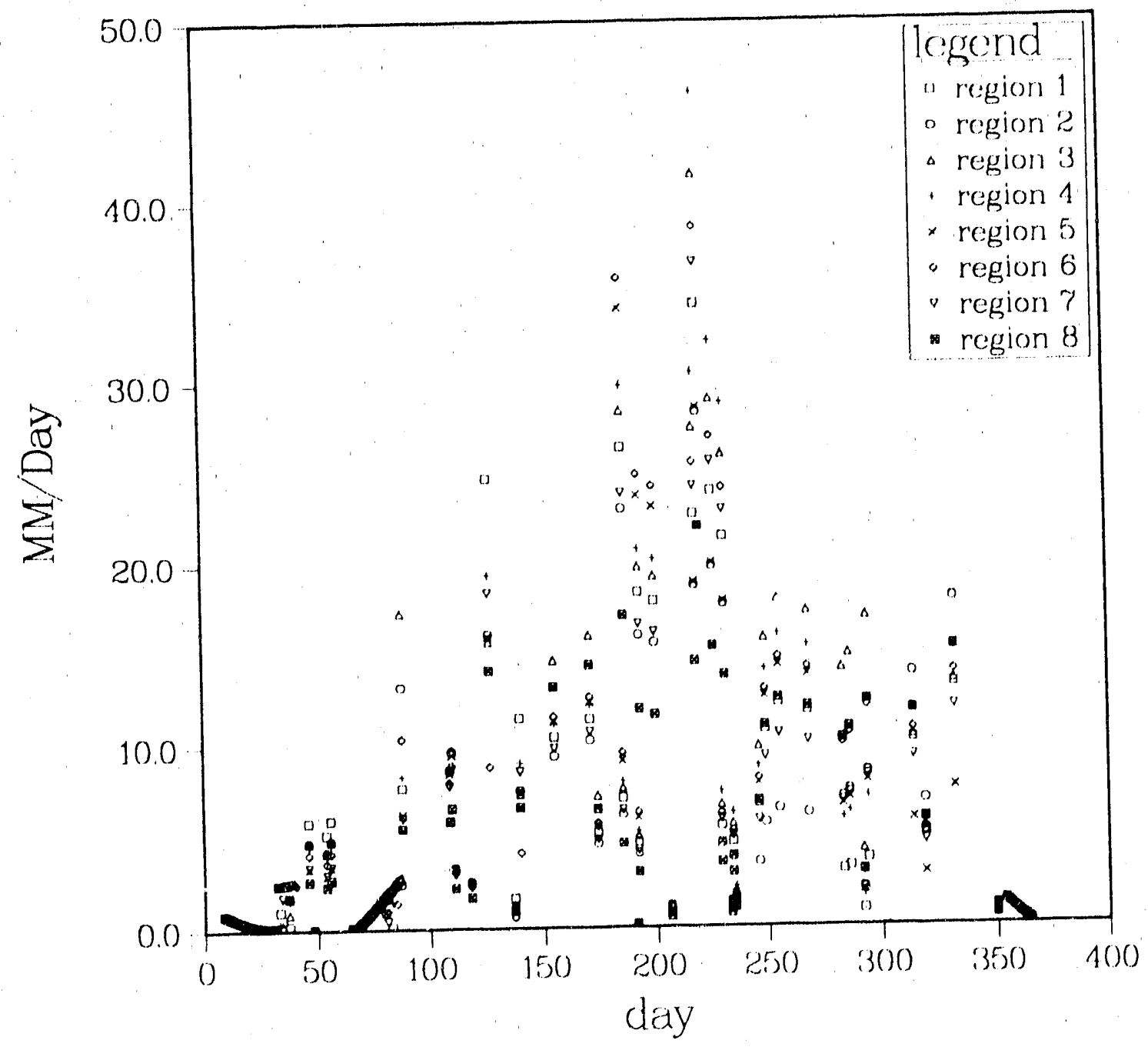

Fig. 2c. Precipitation events for the 100 th simulation year for scenario 3, sc3. 


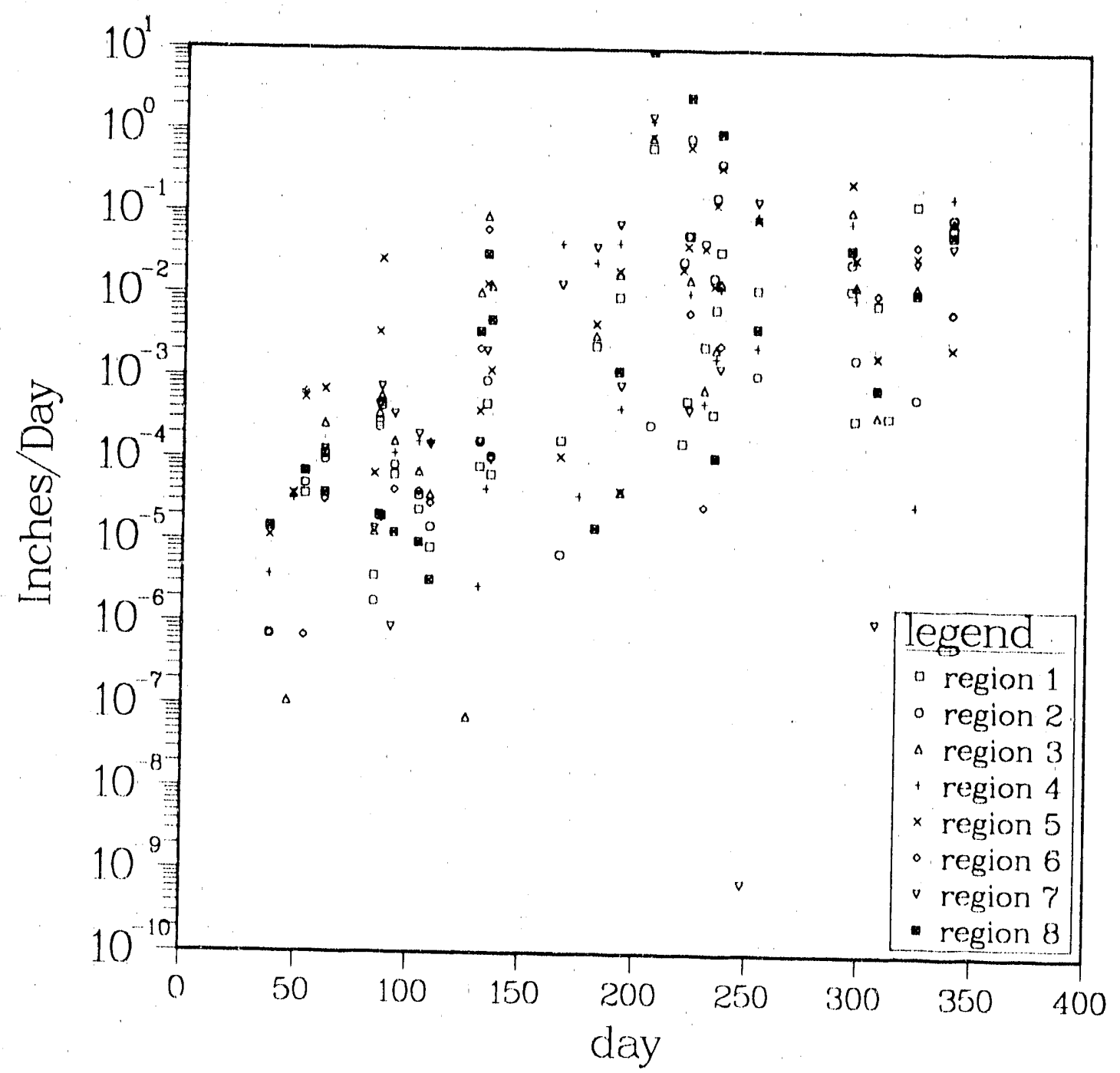

Fig. 3a. Mean daily temperature for the 10th simulation year for scenario 1, sc1. 


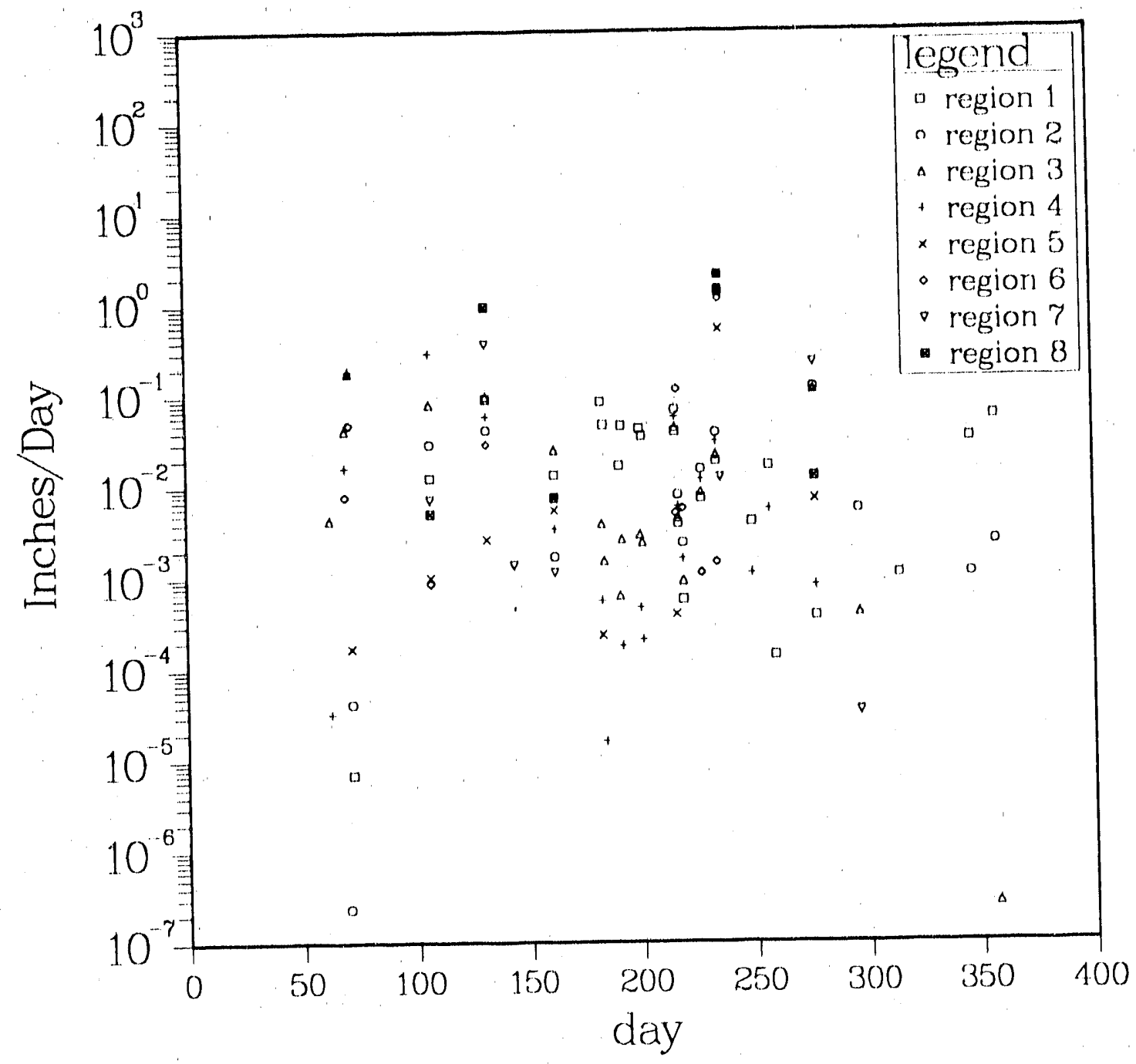

Fig 3b. Mean daily temperature for the 10 th simulation year for scenario $2, \operatorname{sc2}$. 


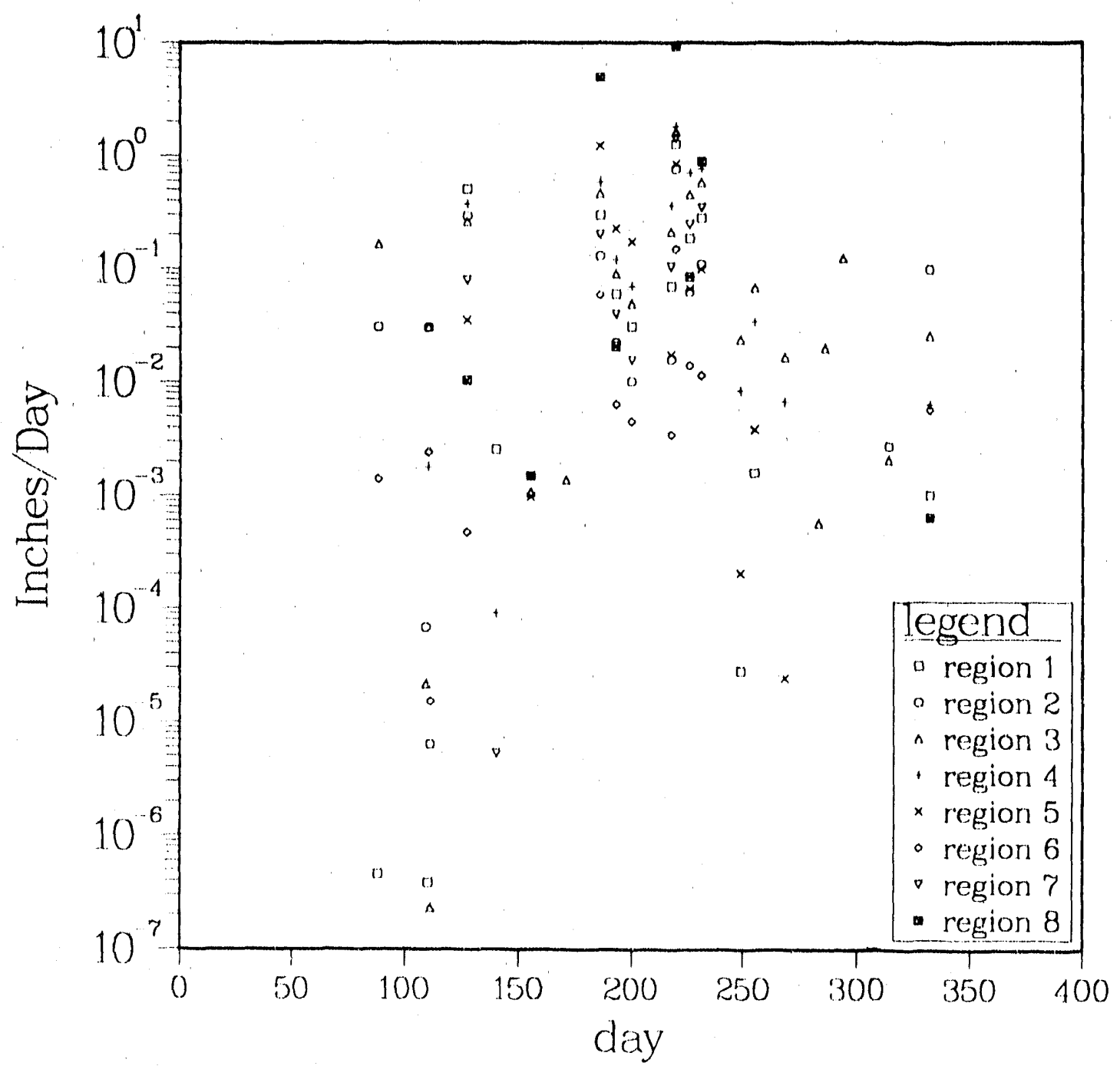

Fig. 3c. Mean daily temperature for the 100th simulation year for scenario 3, sc.3. 


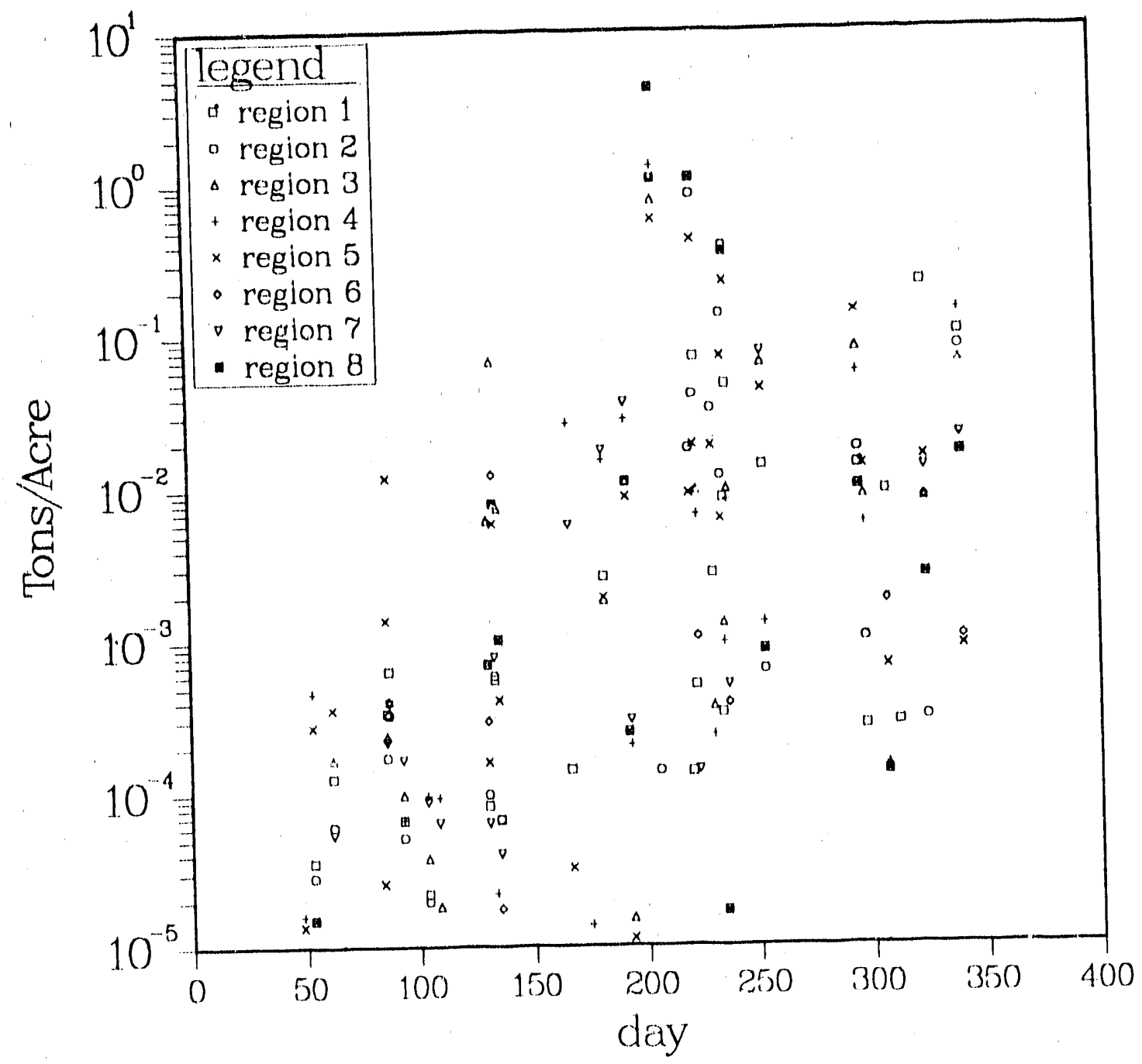

Fig. 4a. Total above ground llve blomass for scenarlo 1, sc1, for annual and perennial grasses and herbs on the 10th simulation year. 


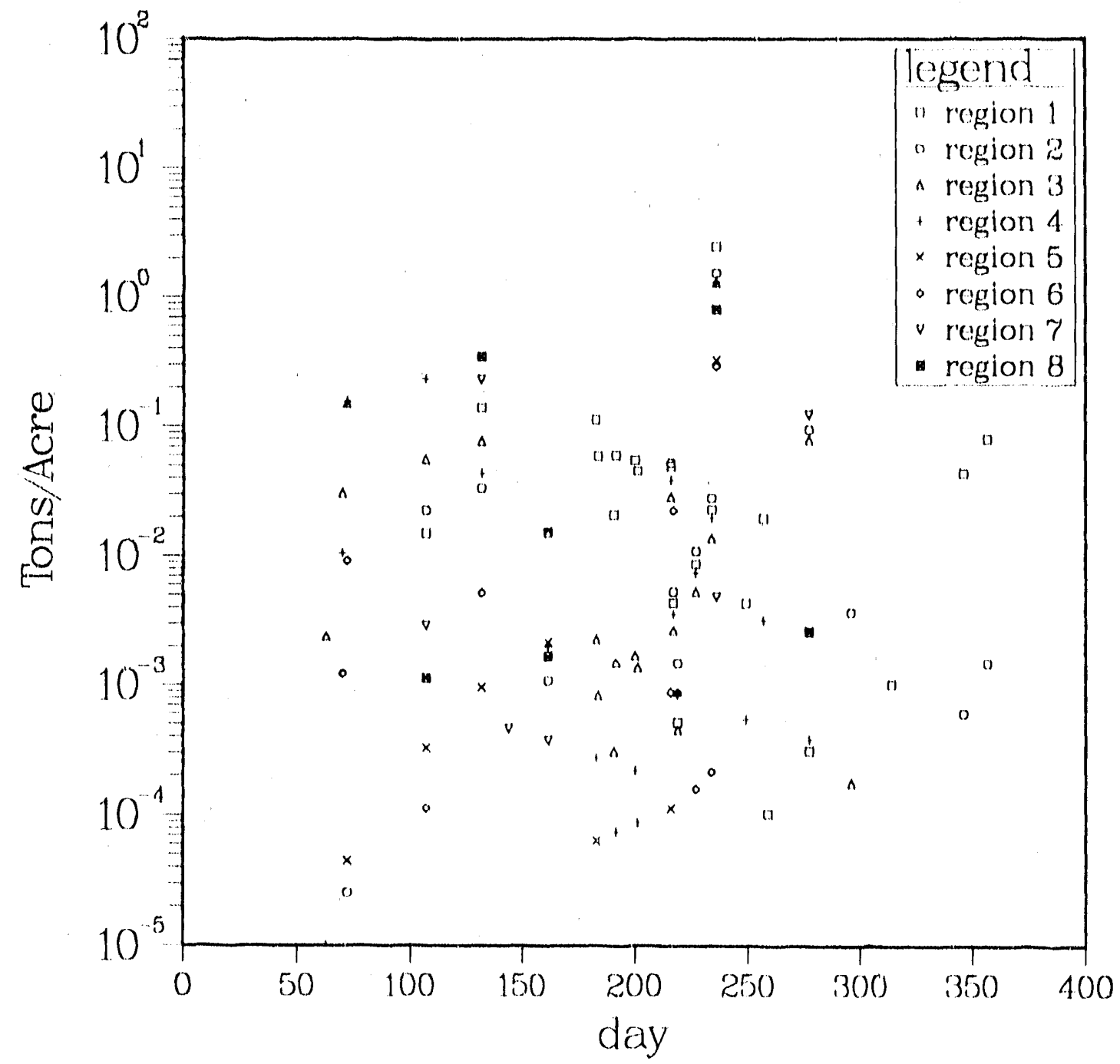

Fig. 4b. Total above ground llve blomass for scenario 2, sc2, for grasses, shrubs, and trees in niche competition and succession on the 10th simulation year. 


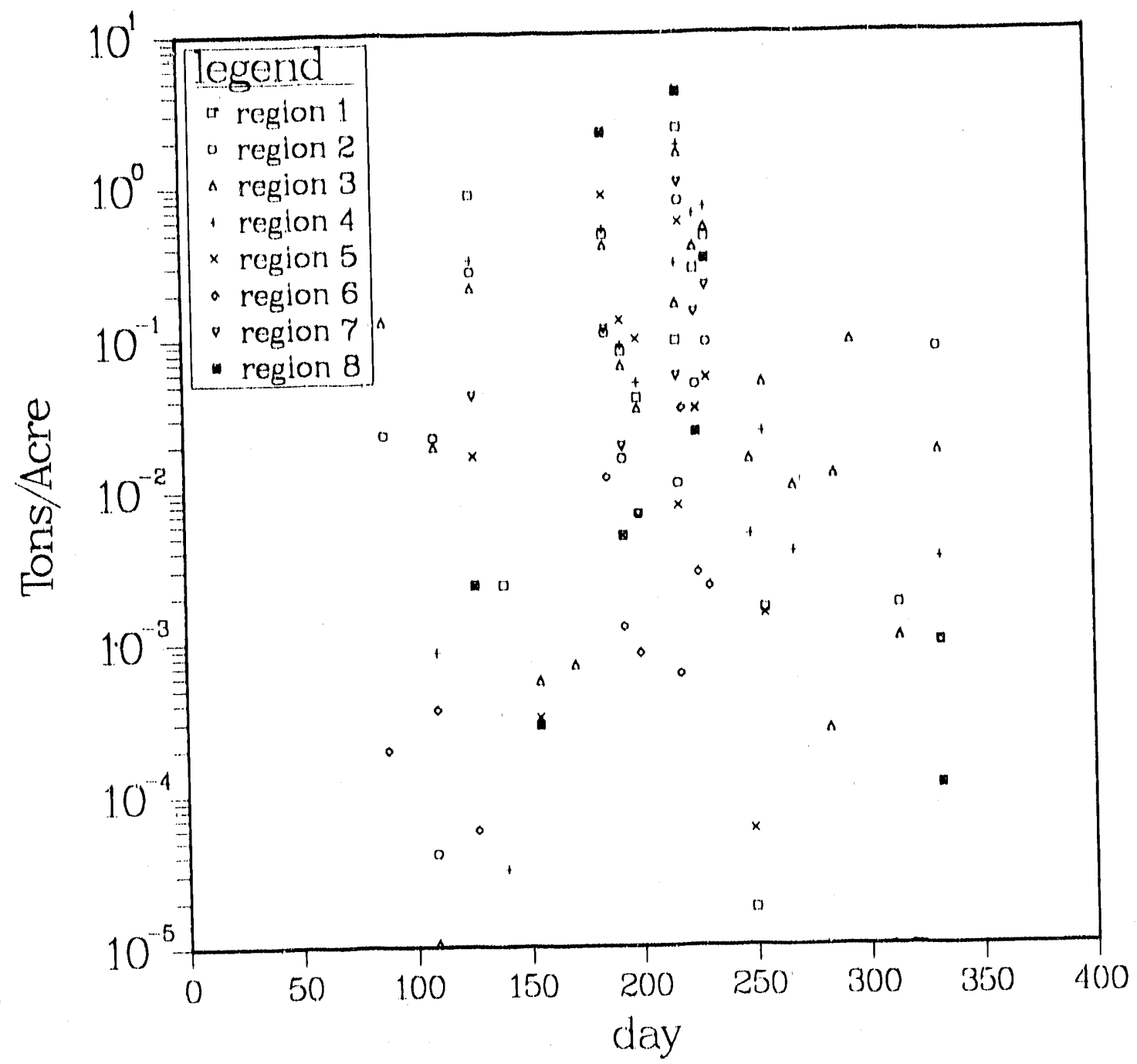

Fig. 4c. Total above ground live blomass for scenario 3, sc3, for grasses, shrubs, and trees in niche competition and succession on the 100 th simulation year. 


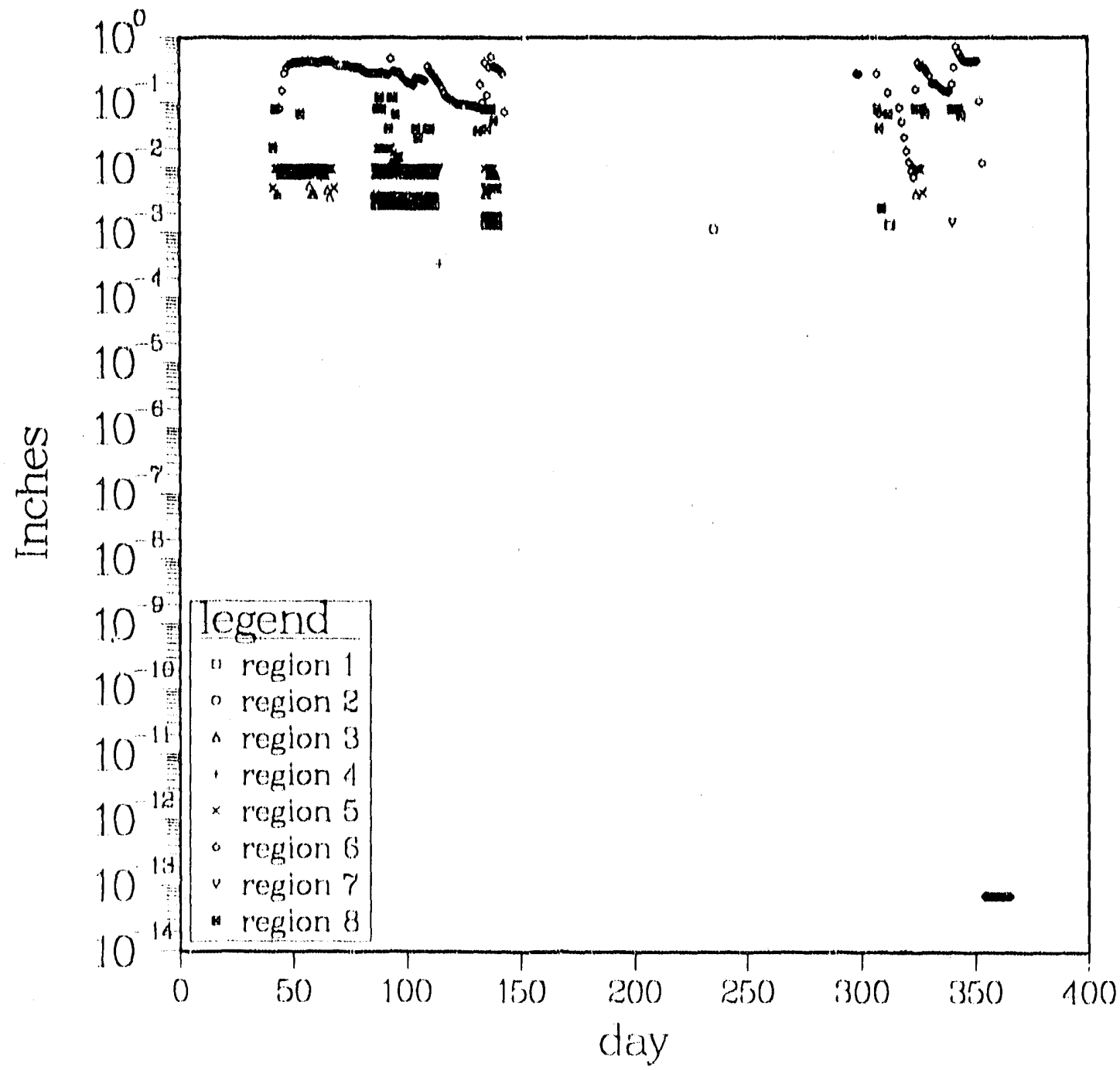

Fig. 5a. Reglonal surface runoff events for the 10th simulation year in scenario $1, \mathrm{sc} 1$. Compare with Fig. 2a. 


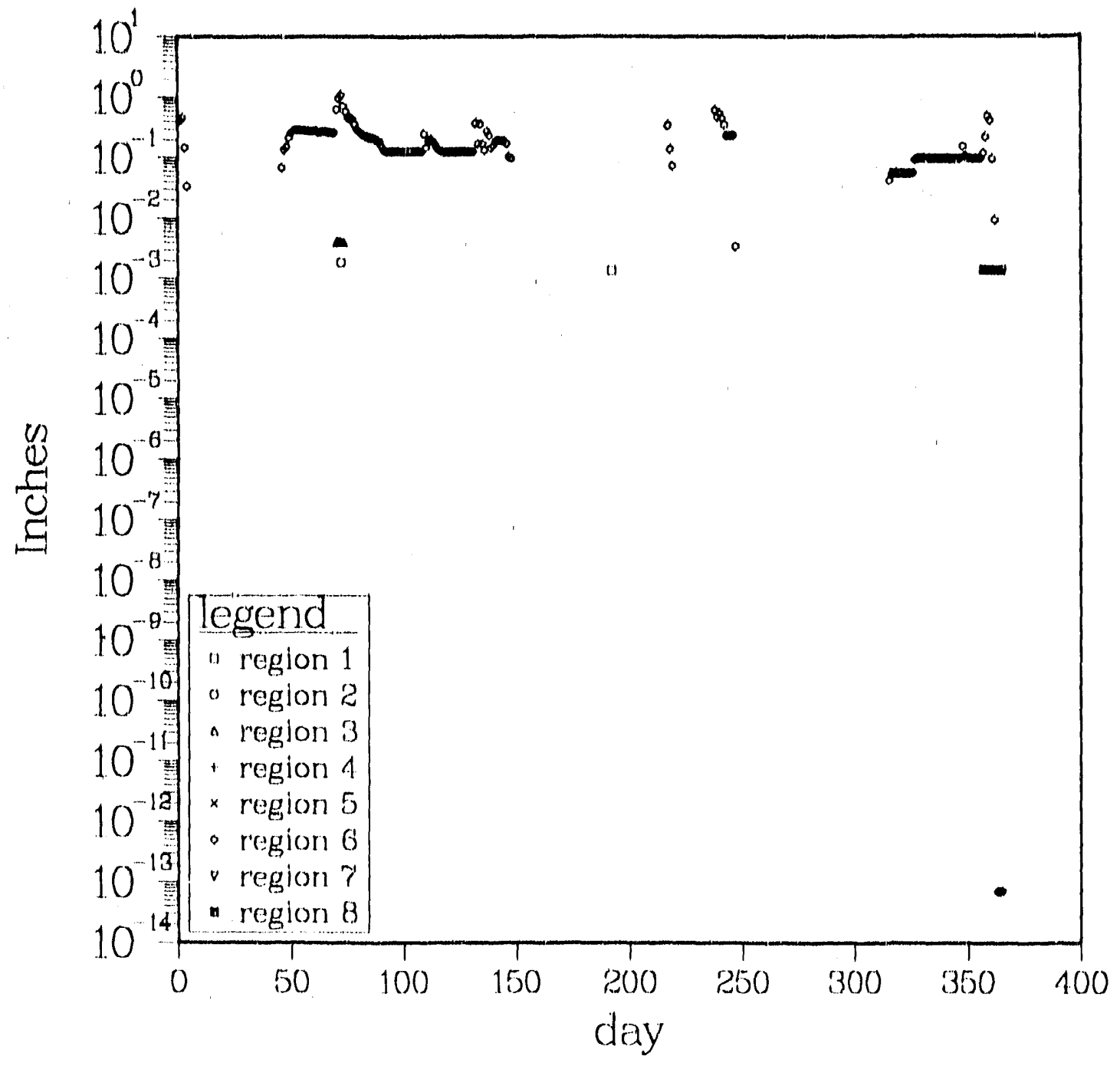

Fig. 5b. Regional surface runoff events for the 10 th simulation year in scenario 2, sc2. Compare with Flg. 2b. 


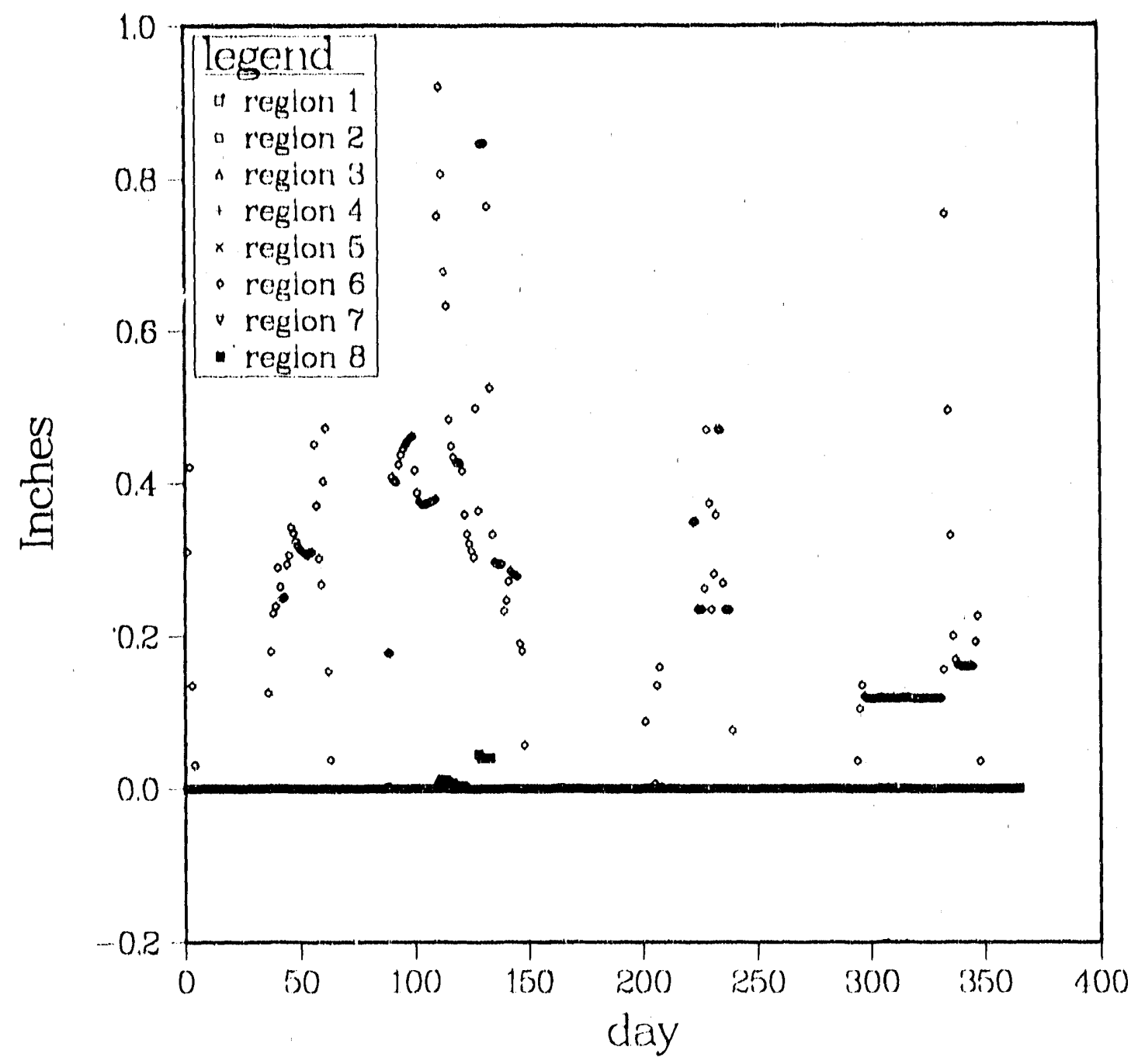

Fig. 5c. Regional surface runoff events for the 100th simulation year in scenario 3, sc3. Compare with Fig. 2c. 


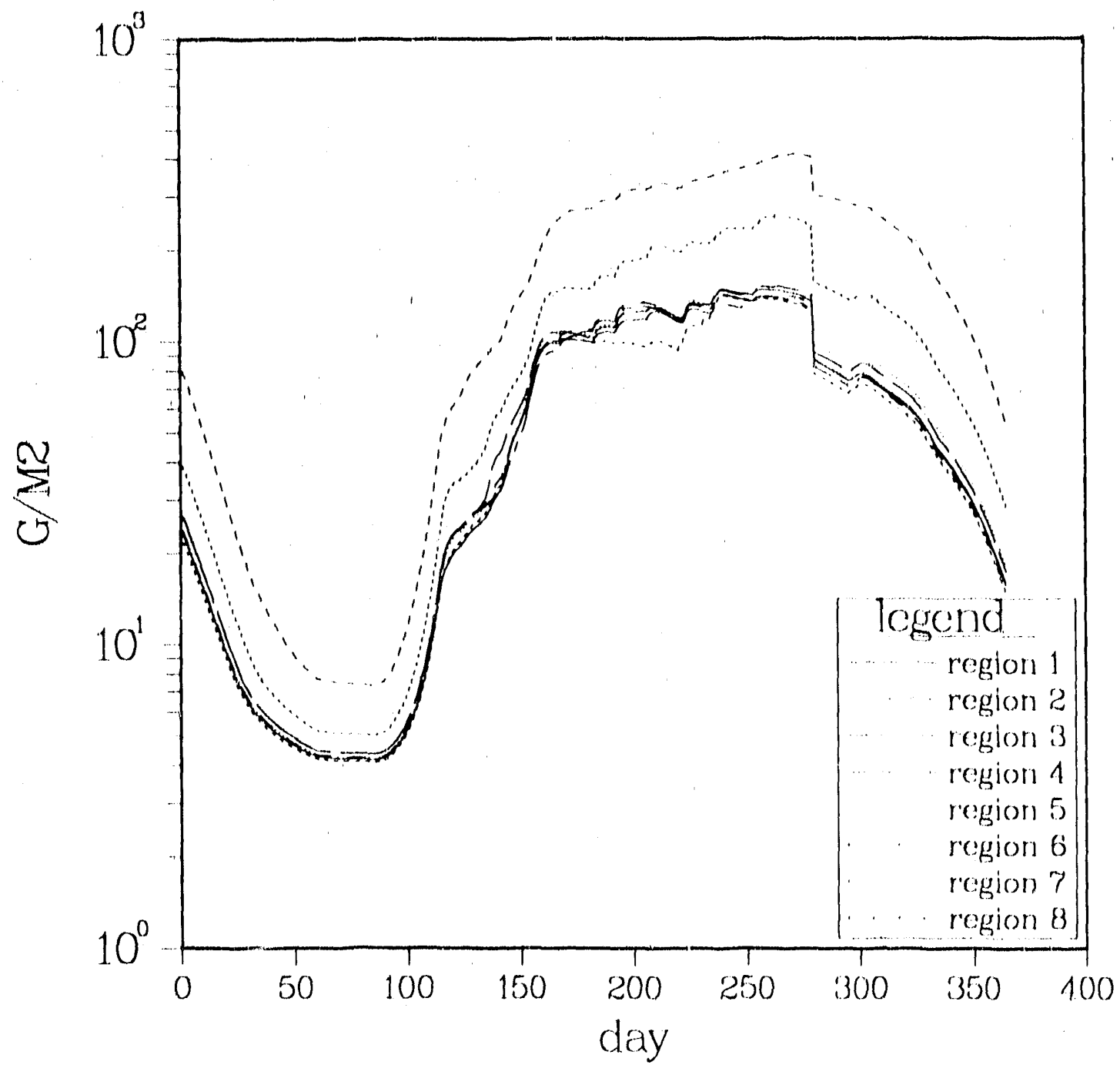

Fig. 6a. Subsurface return flow for the 10th simulation year for scenario 1, sc1. 


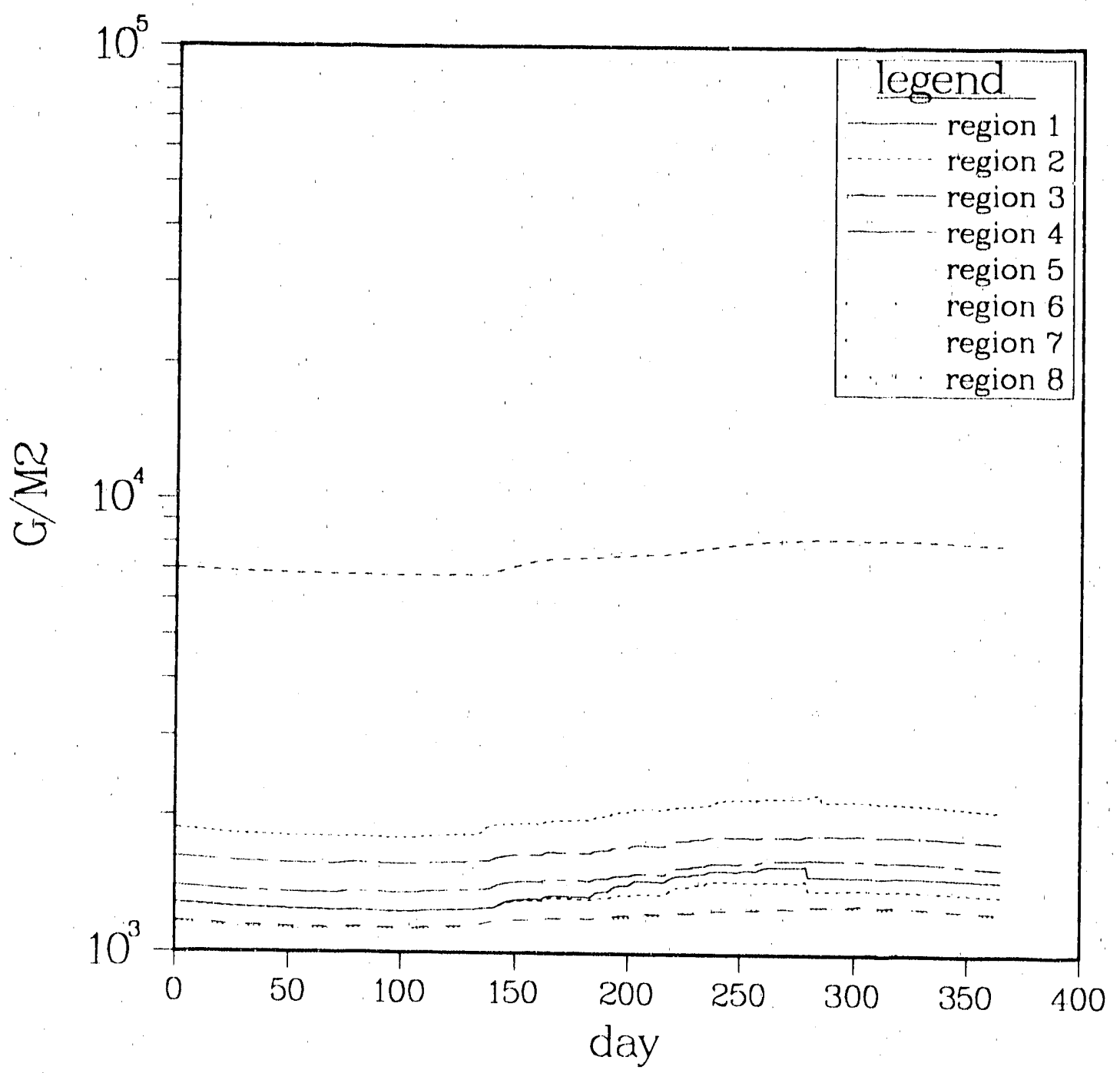

Fig. 6b. Subsurface return flow for the 10th simulation year for scenario 2, sc2. 


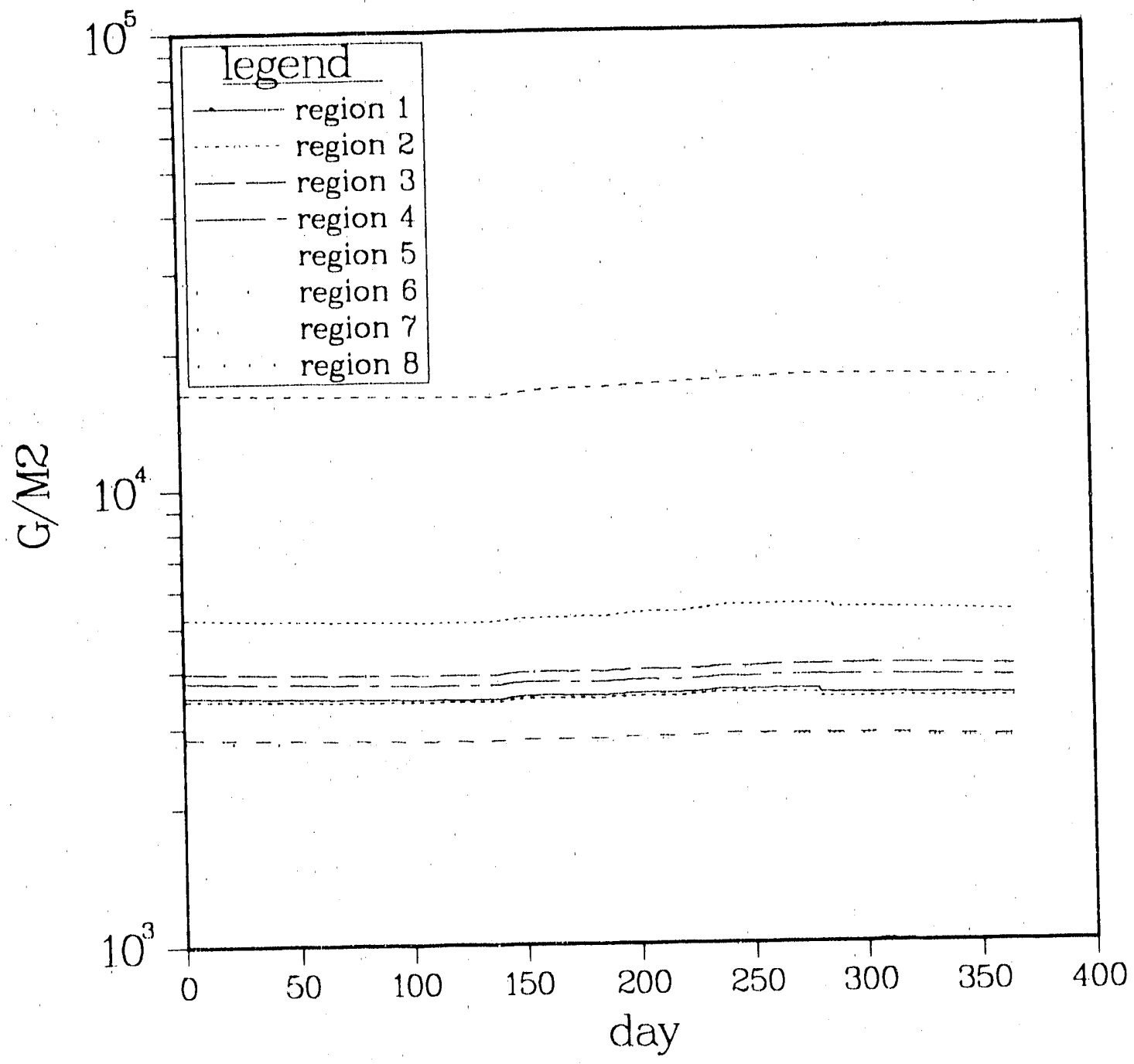

Fig. 6c. Subsurface return flow for the 100th simulation year for scenario $3, \operatorname{sc} 3$. 


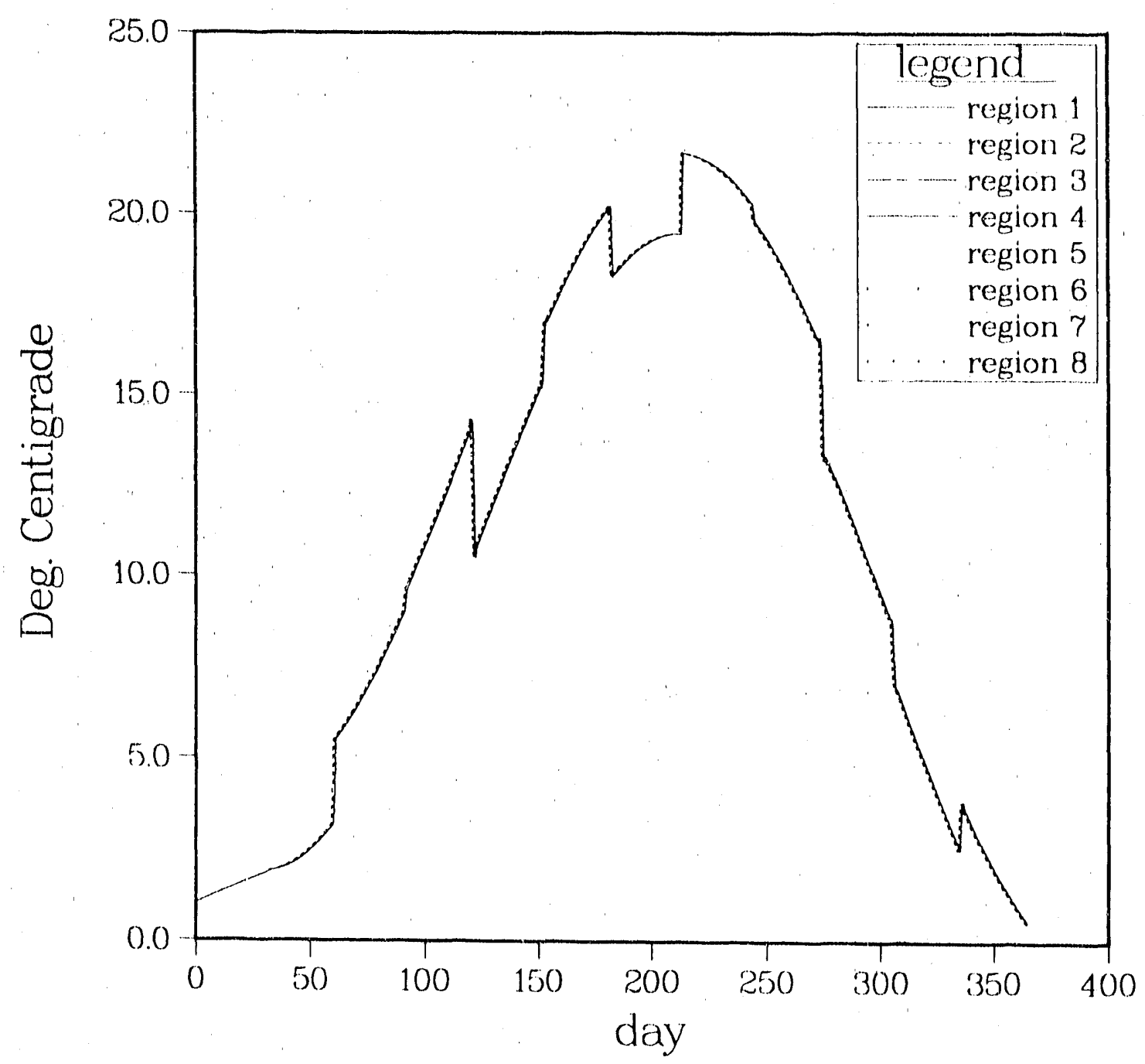

Fig. 7a. Regional soil erosion for the 10 th simulation year in scenario 1, sc1. 


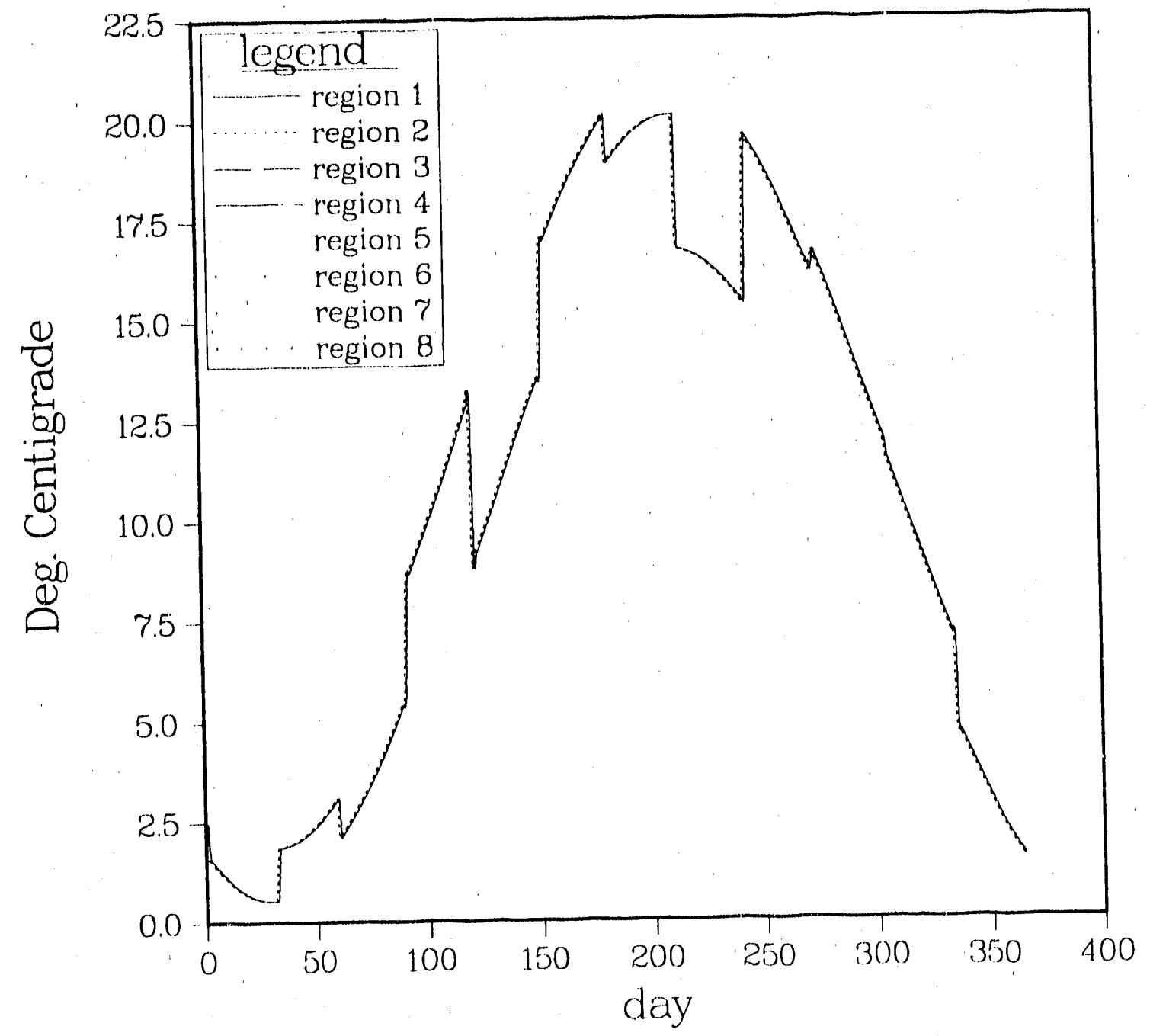

Fig. 7b. Regional soil erosion for the 10th simulation year in scenario 2, sc2. 


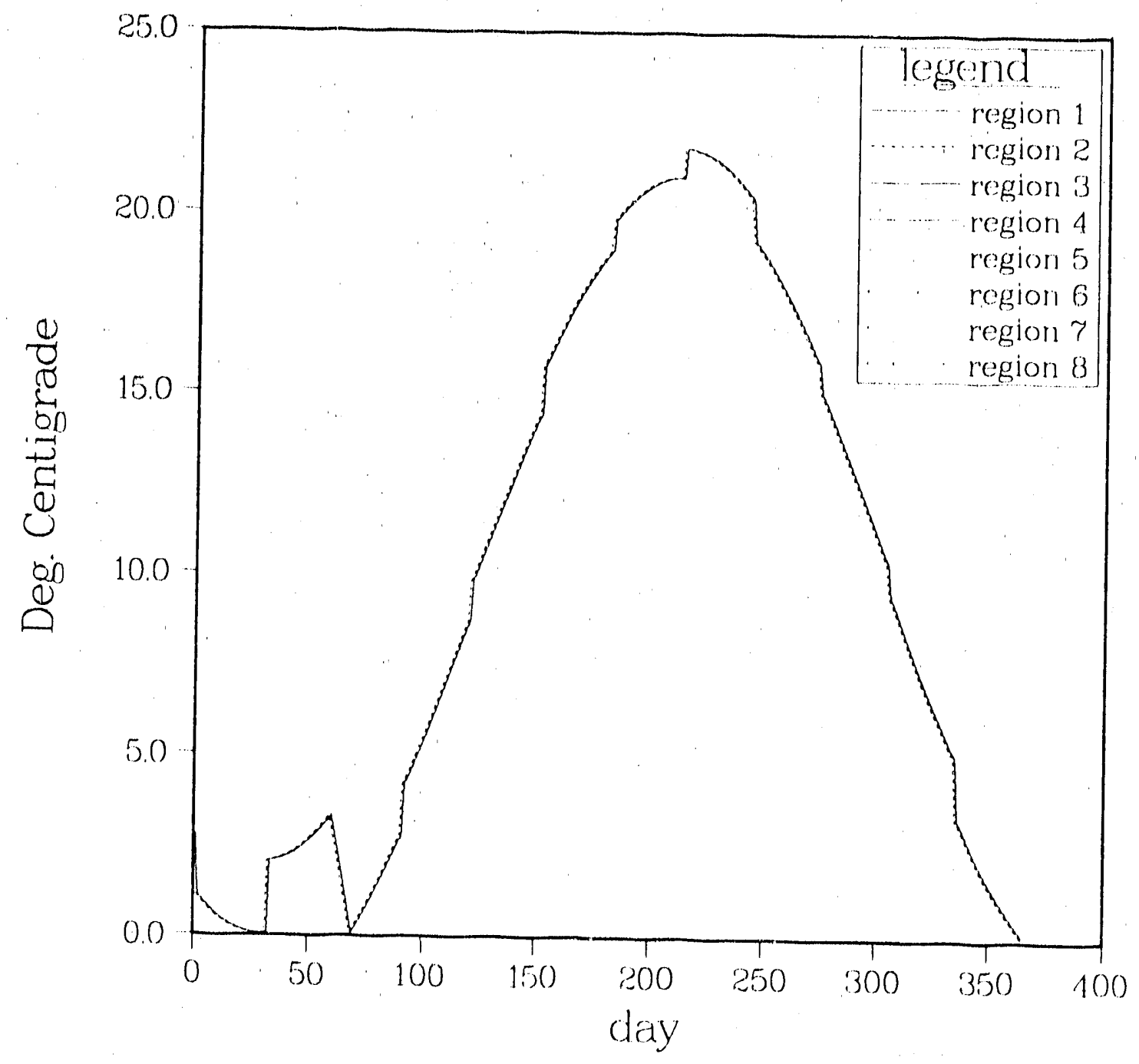

Fig. 7c. Regional soil erosion for the 100 th simulation year in scenario $3,5 \mathrm{c} 3$. 


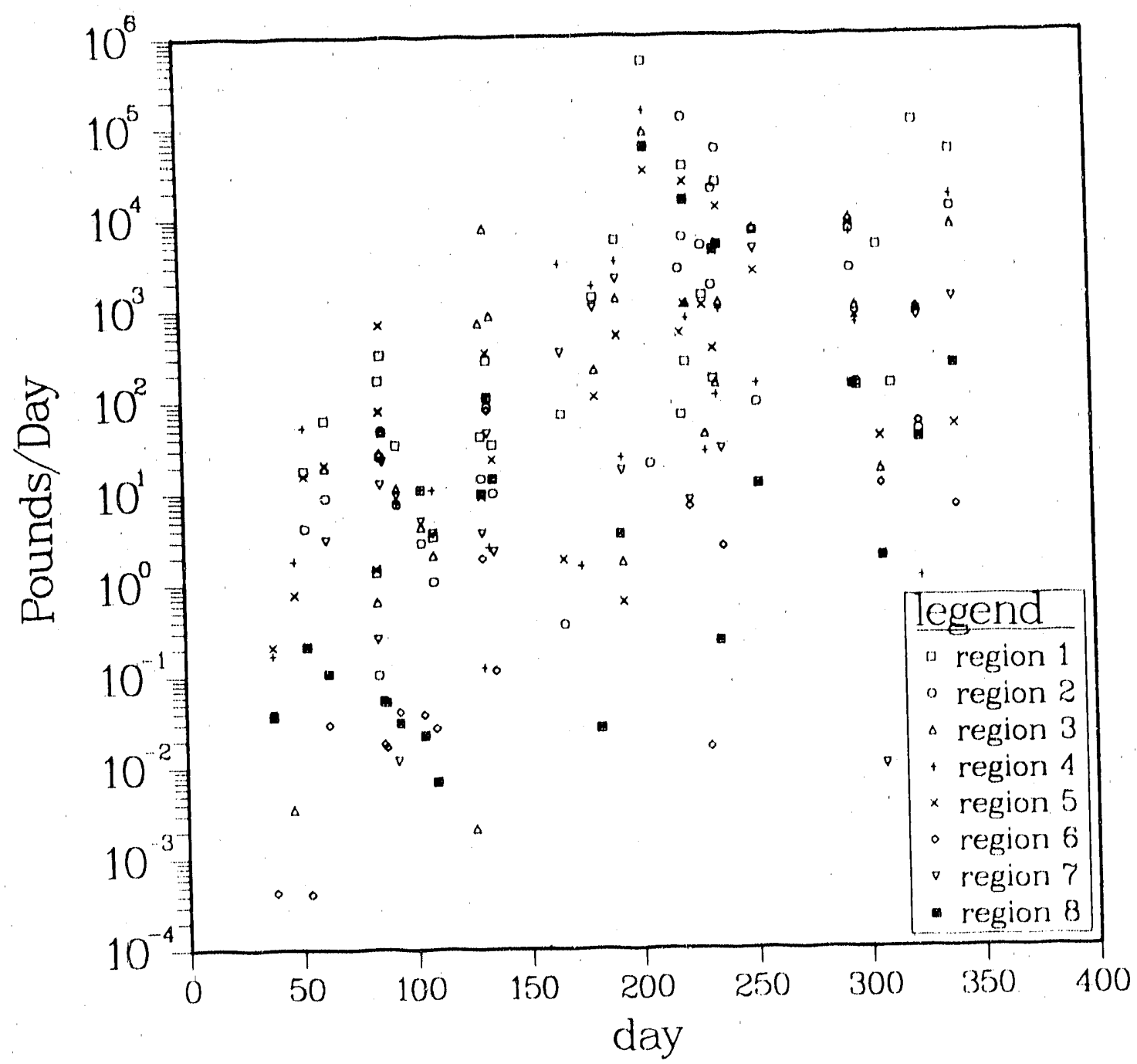

Fig. 8a. Mass of soil removed by erosion from regions in 10 th simulation year for scenario 1 , sc1. 


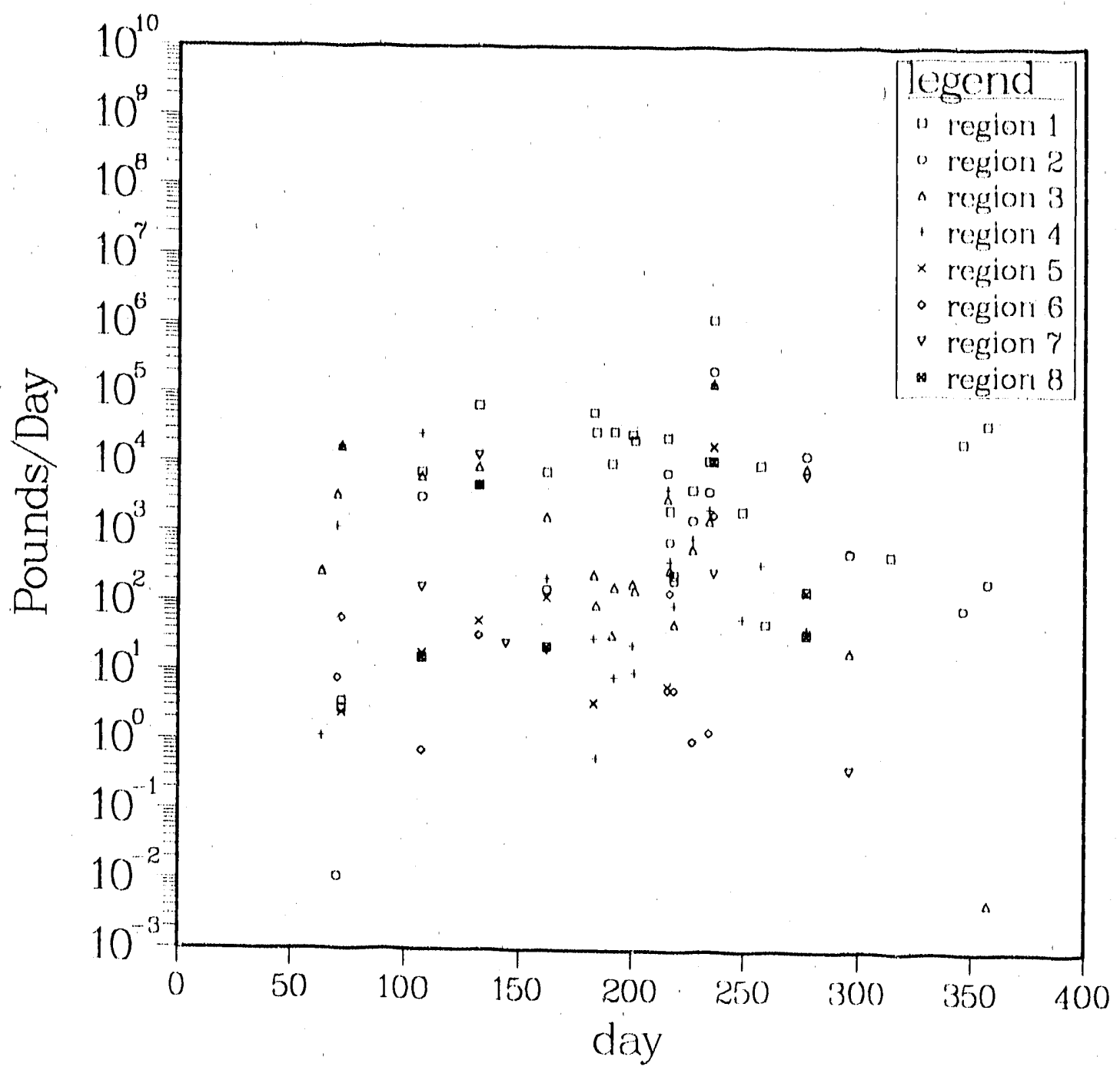

Fig. 8b. Mass of soil rernoved by erosion from regions in 10 th simulation year for scenario 2, sc2. 


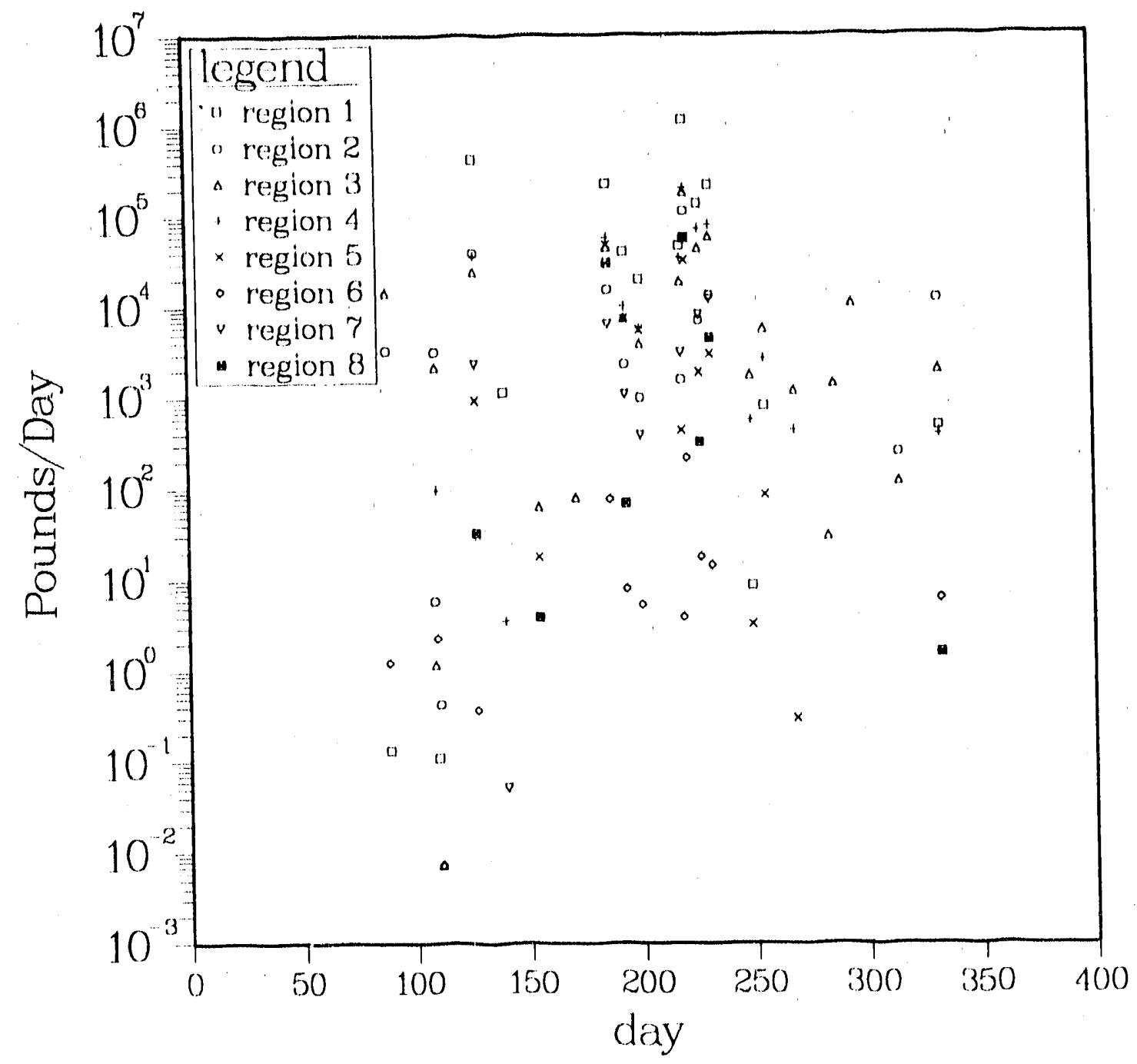

Fig. 8c. Mass of soll removed by erosion from regions in 100 th simulation year for scenario 3 , sc3. 


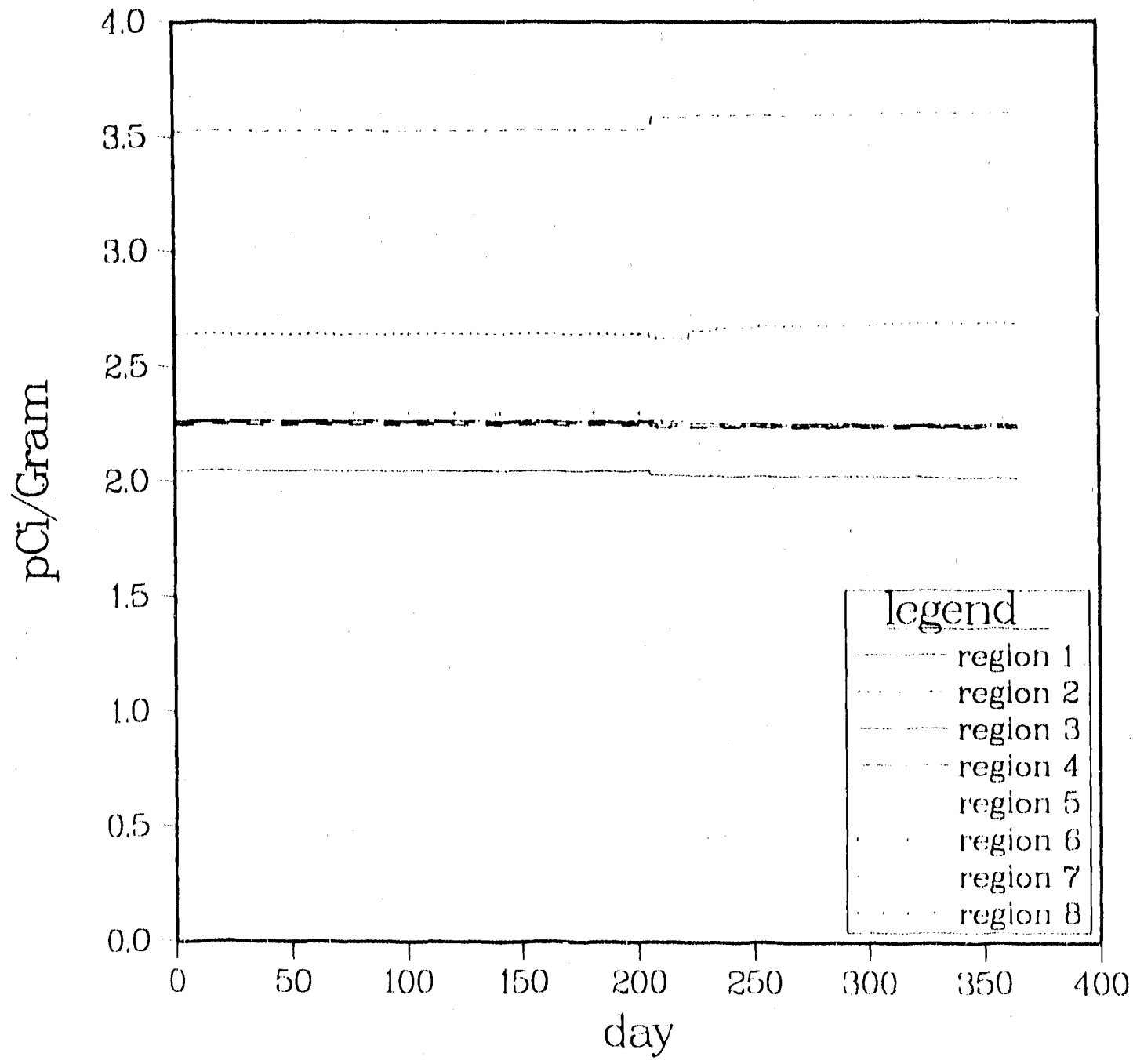

Fig. 9a. Regional soll uranium specific radloactivlty for 10 th simulatlon year in scenario 1 , sc1. 


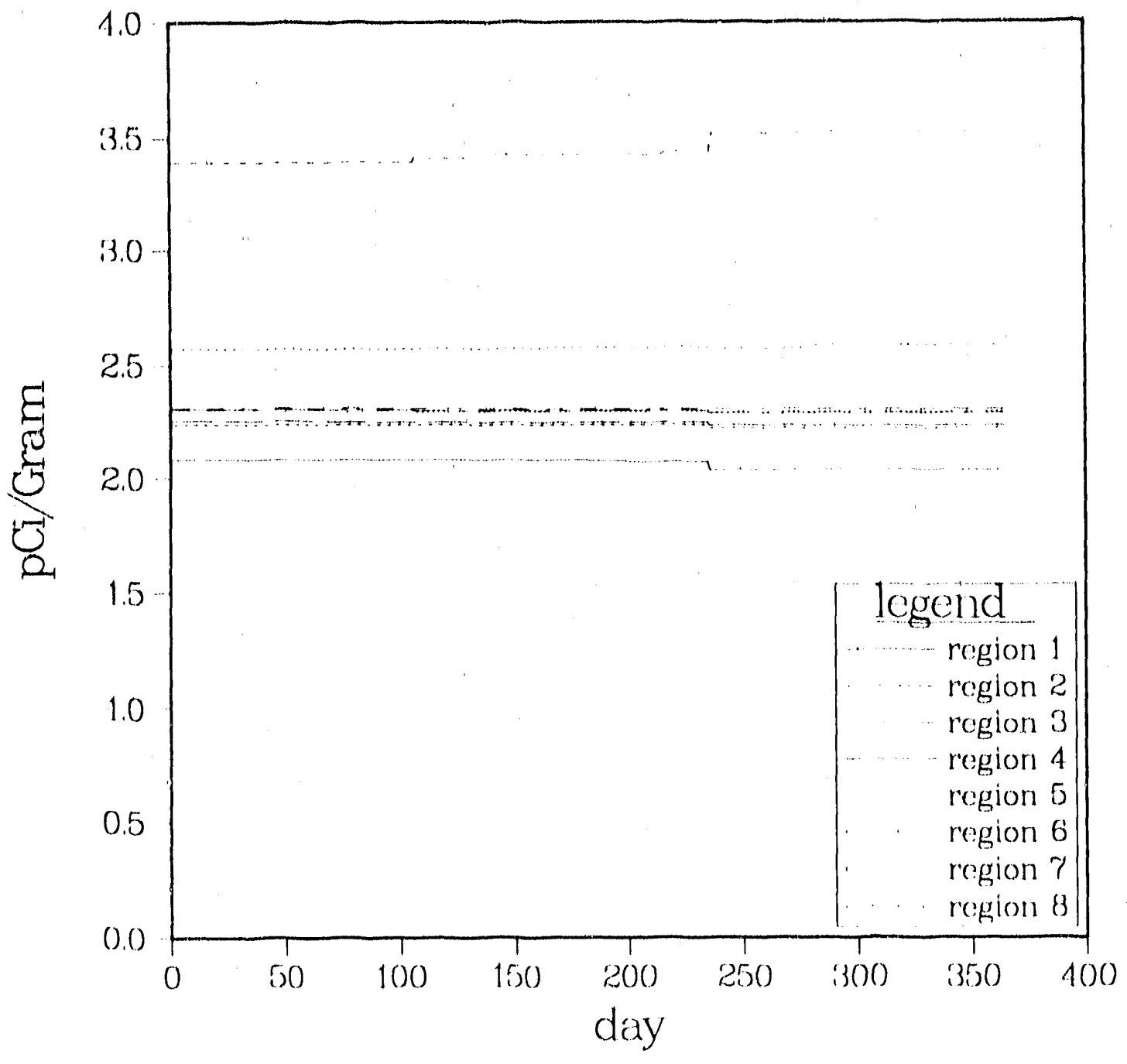

Fig. 9b. Regional soil uranium speciflc radloactlvity for 10 th simulation year in scenario 2, sc2. 


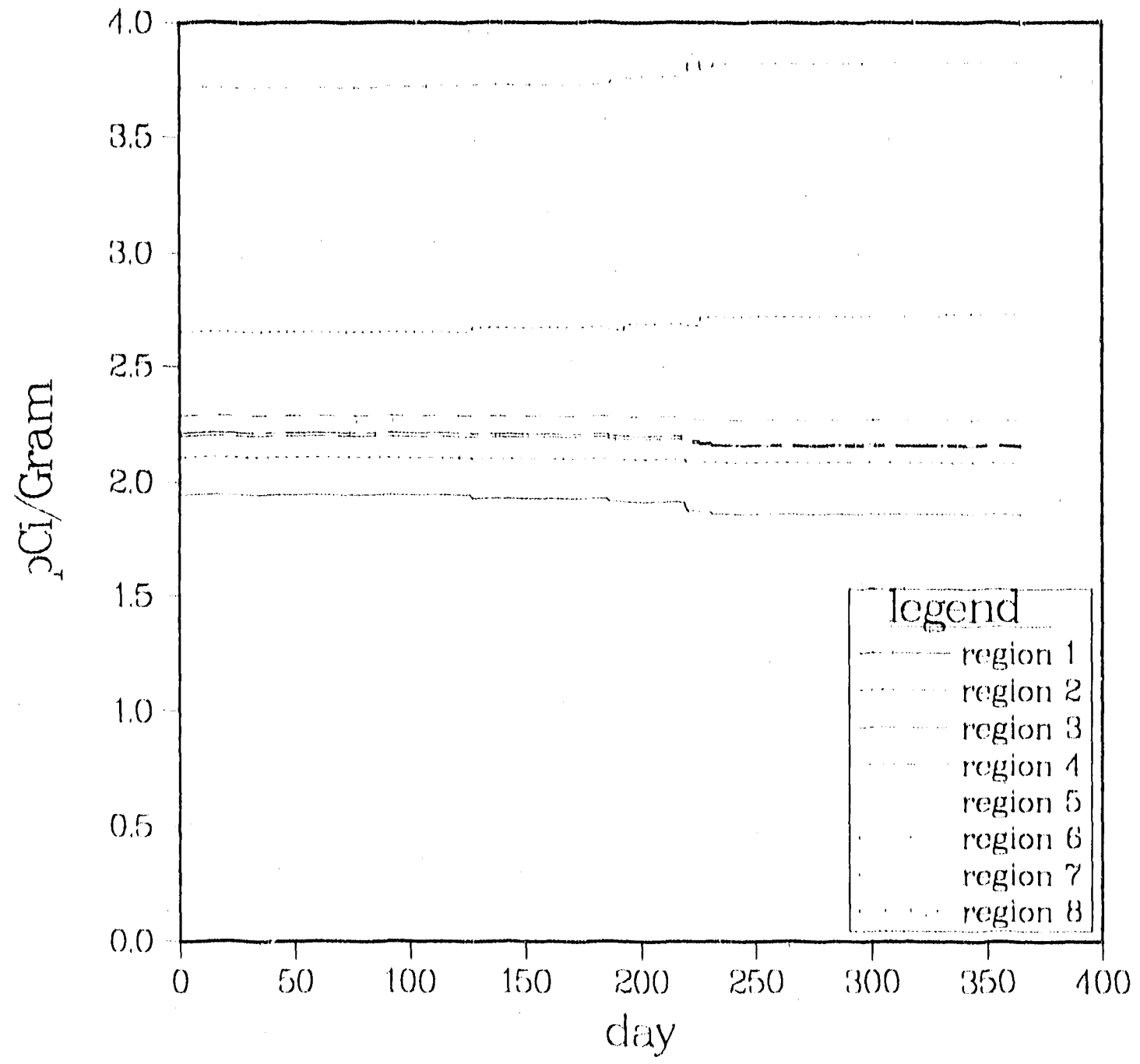

Fig. 9c. Reglonal soll urarium specific radioactivity for the 100 th simulation year in scenarlo 3 , SC3. 


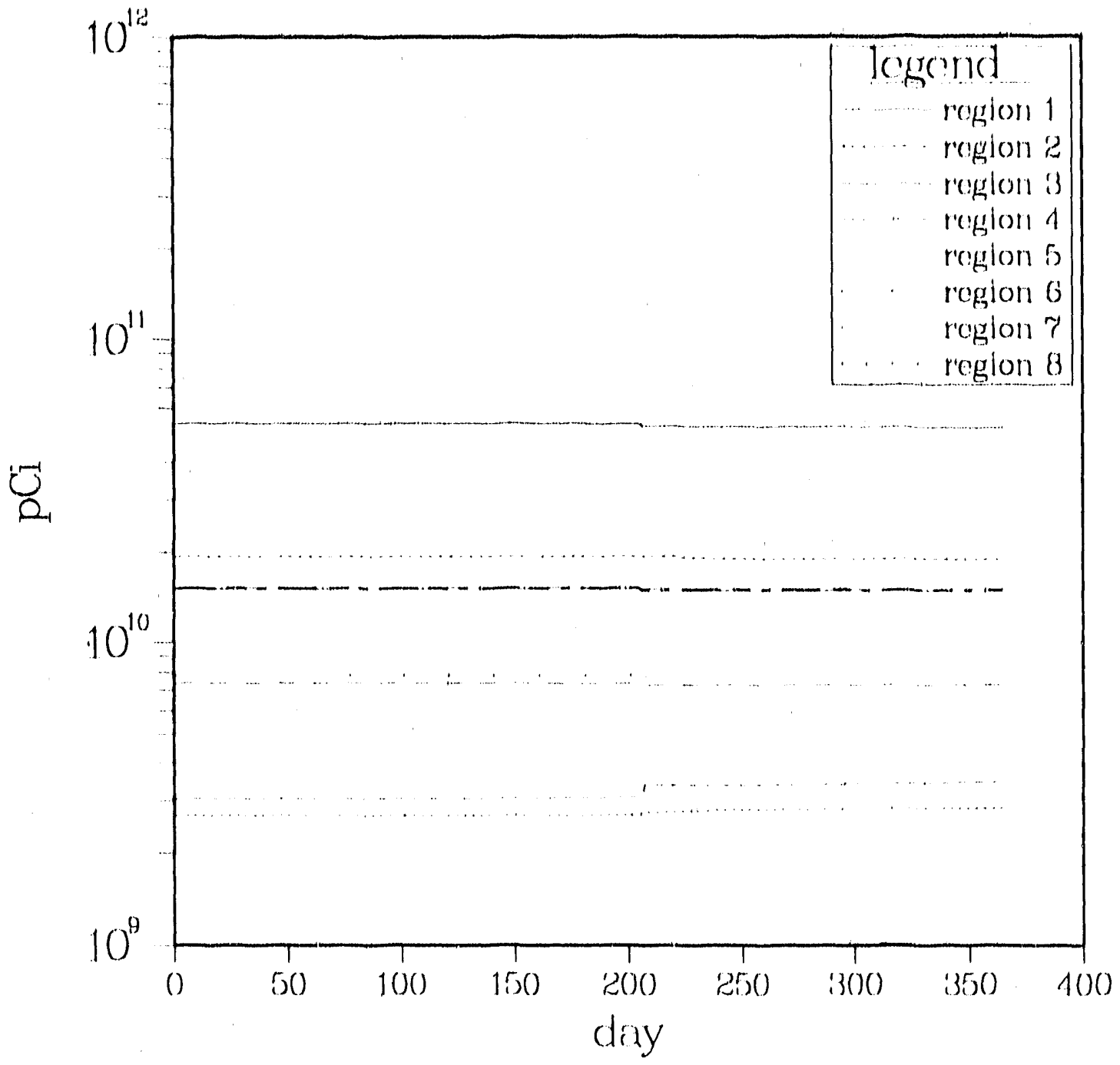

Fig. 10a. Regional total soll uranlum radioactivity for 10 th simulation year for scenario 1 , sct. 


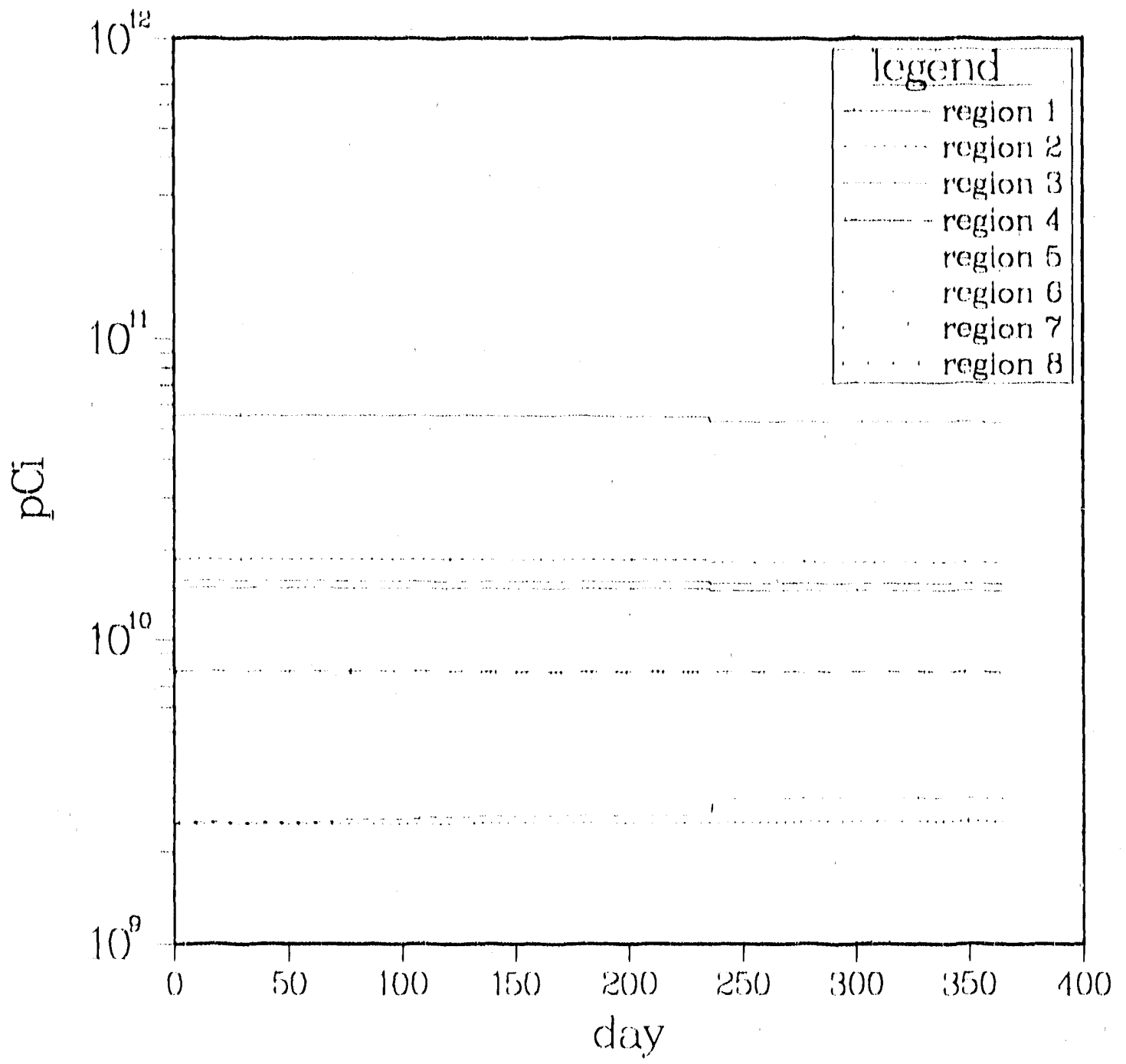

Fig. 10b. Regional total soll radioactlvity for 10 th simulation year for scenario 2, sc2. 


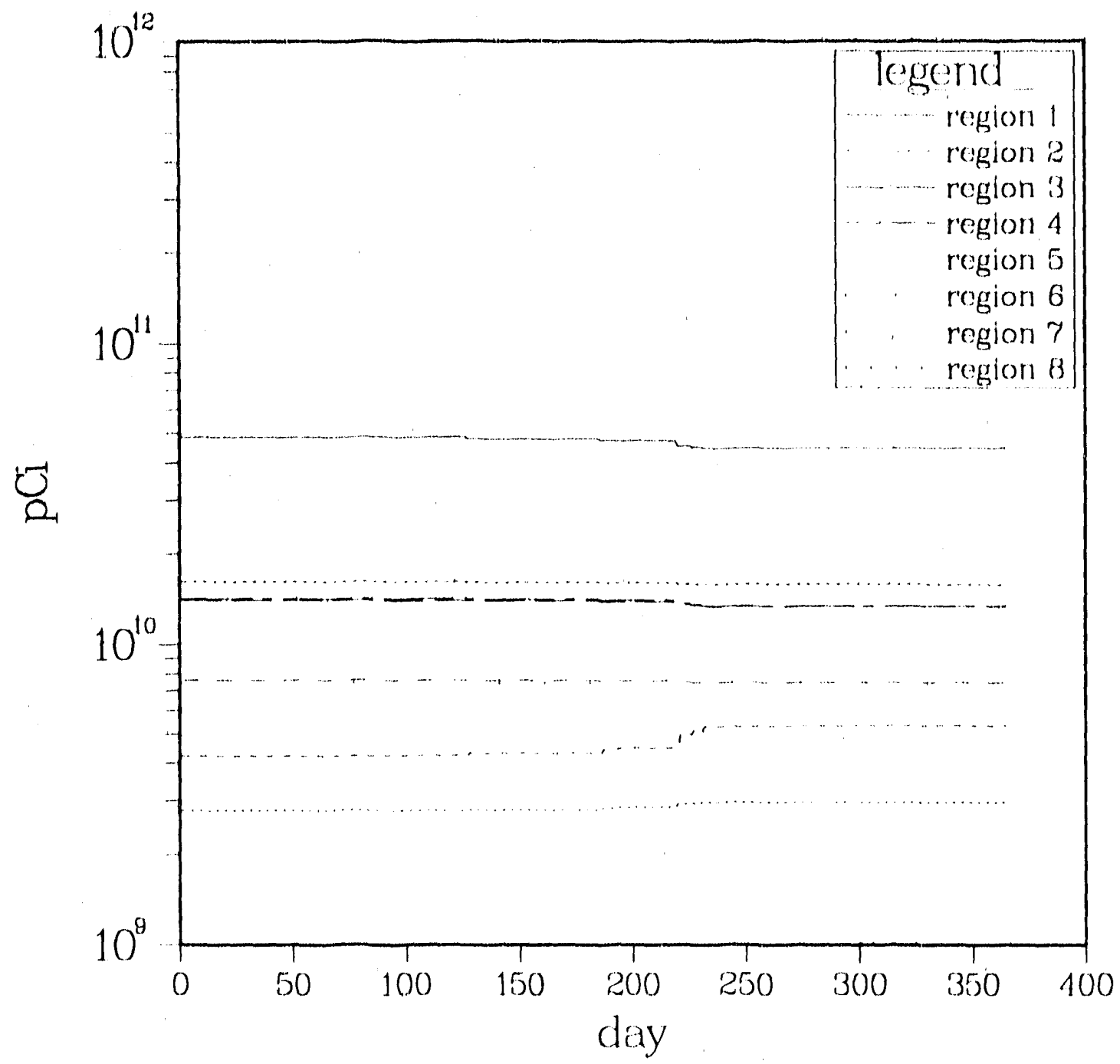

Fig. 10c. Reglonal total soll uranium radioactlvity for 100 th simulation year for scenario 3, sc3. 


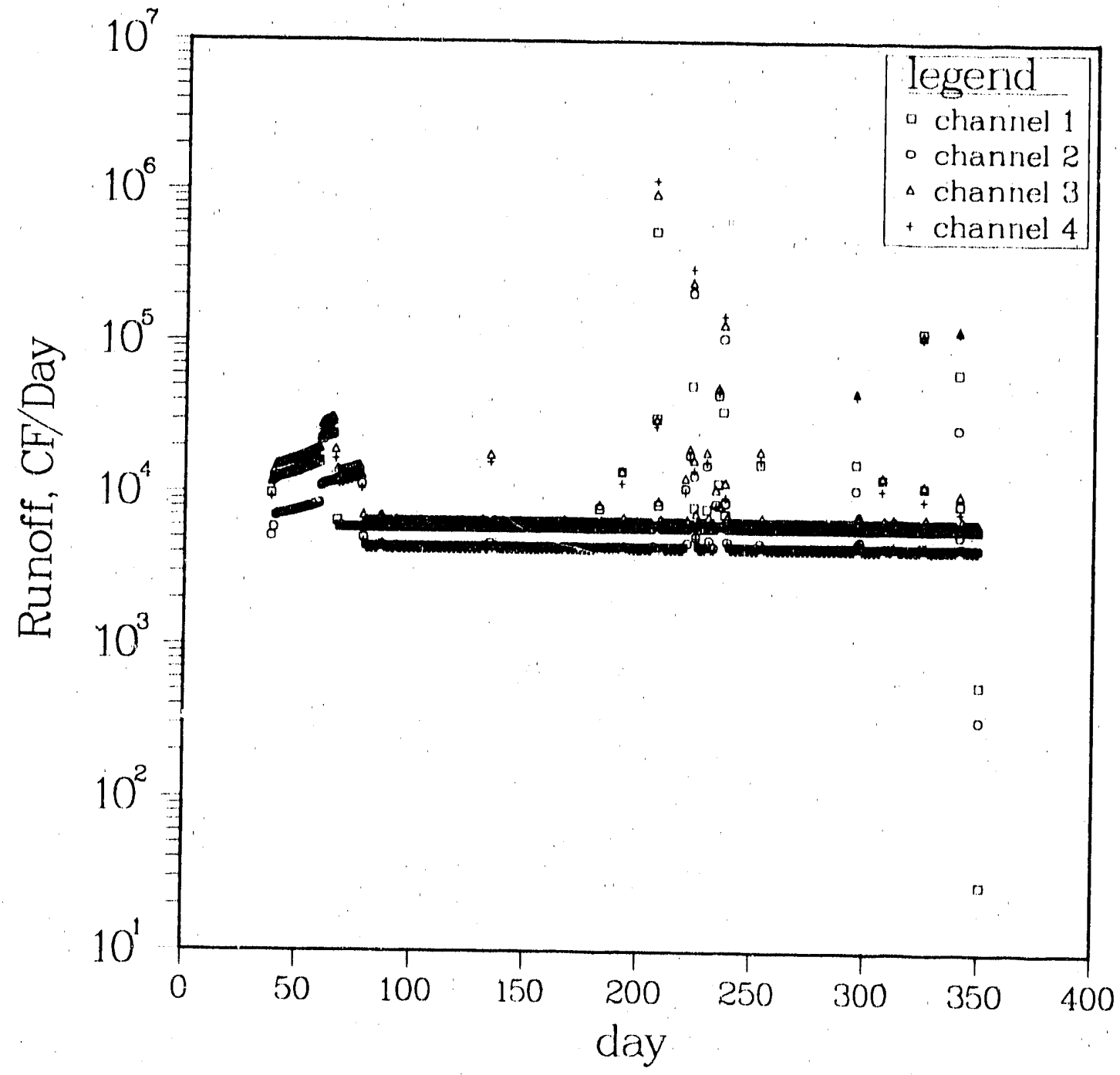

Fig. 11a. Lateral runoff into channels from adjacent regions for 10 th simulation year for scenario $1, \mathrm{sc} 1$. 


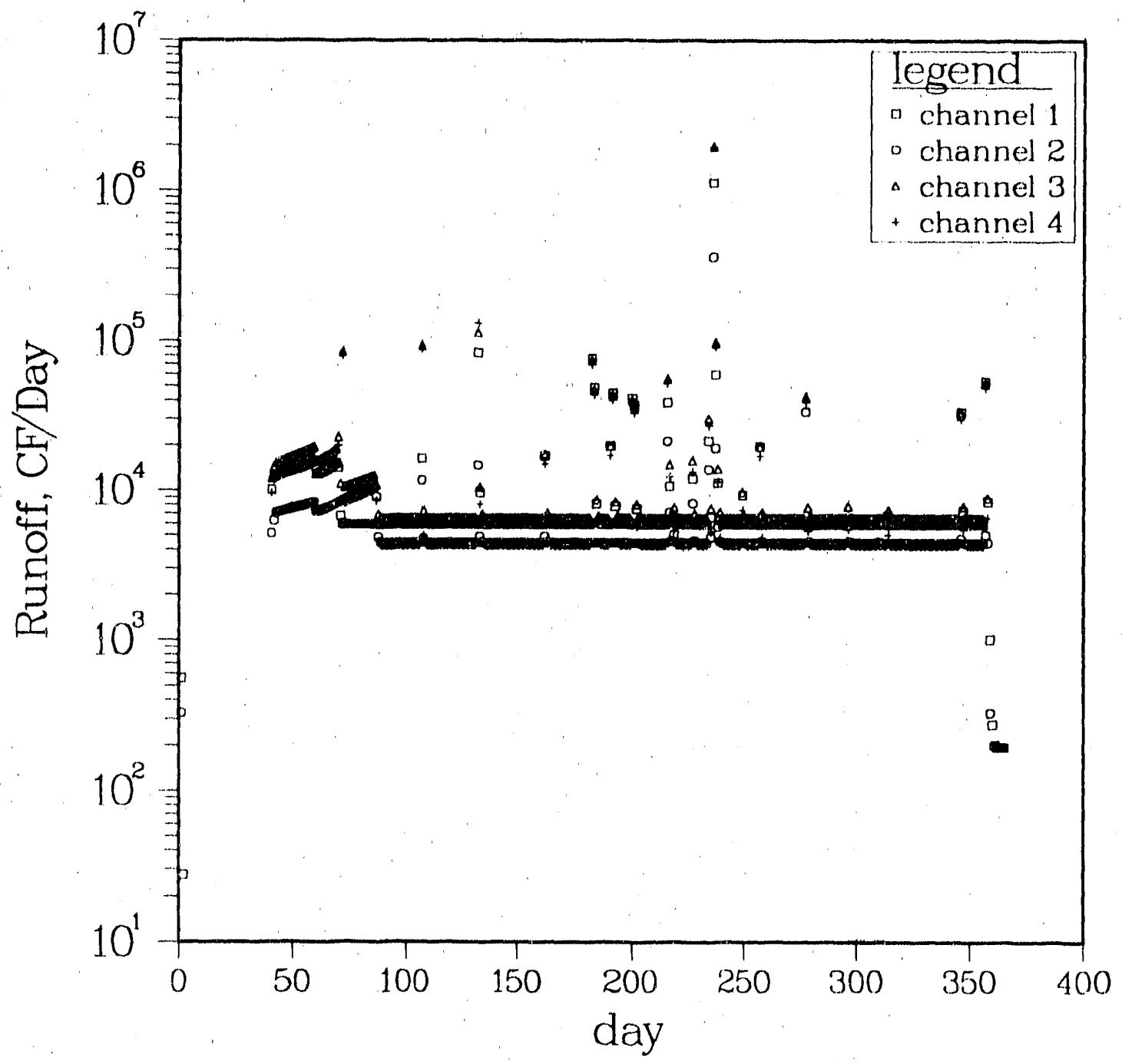

Fig. 11b. Lateral runoff into channels from adjacent regions for 10 th simulation year for scenario 2, sc2. 


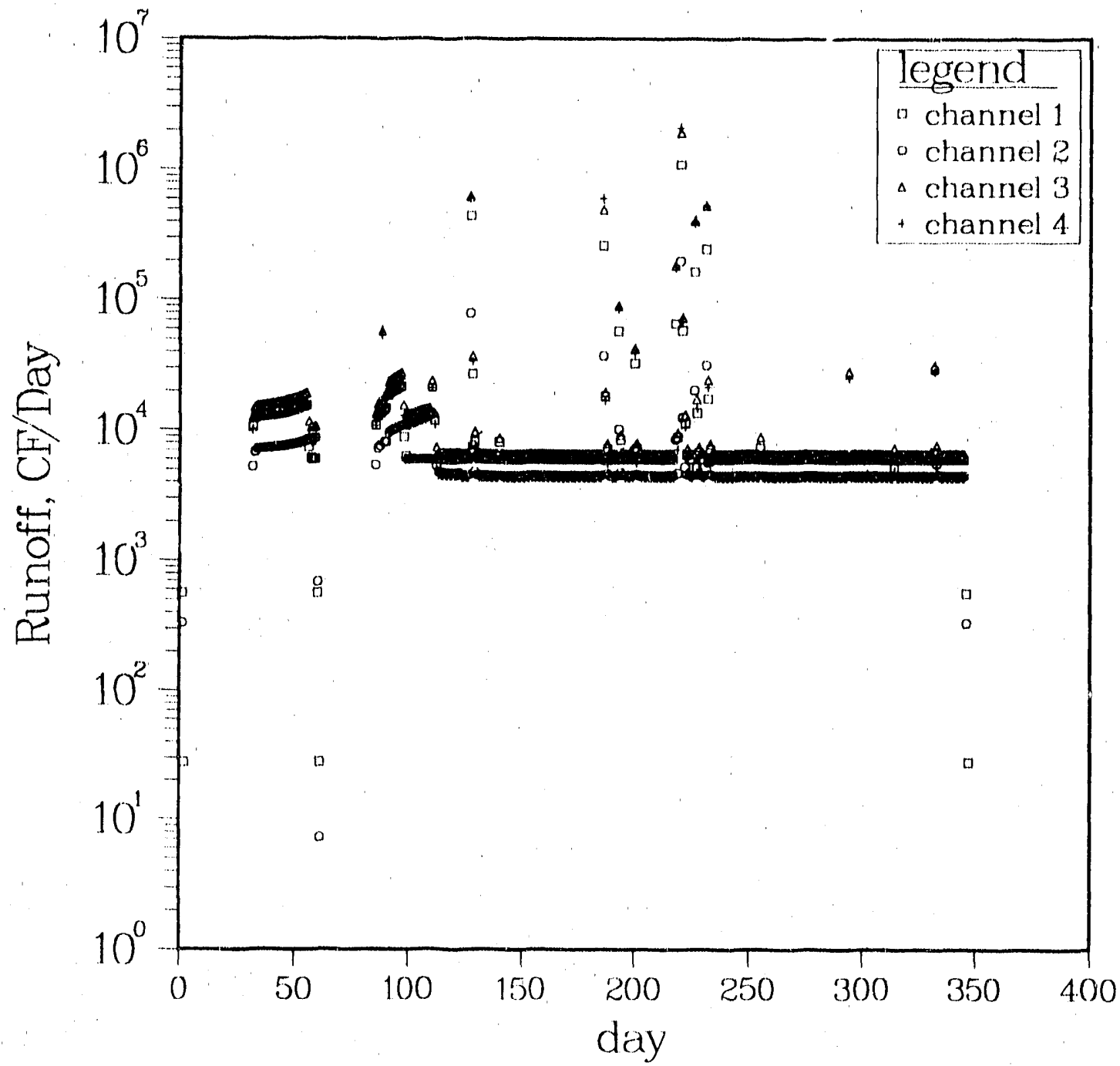

Fig. 11c. Lateral runoff into channels from adjacent regions for 100 th simulation year for scenario $3,5 c 3$. 


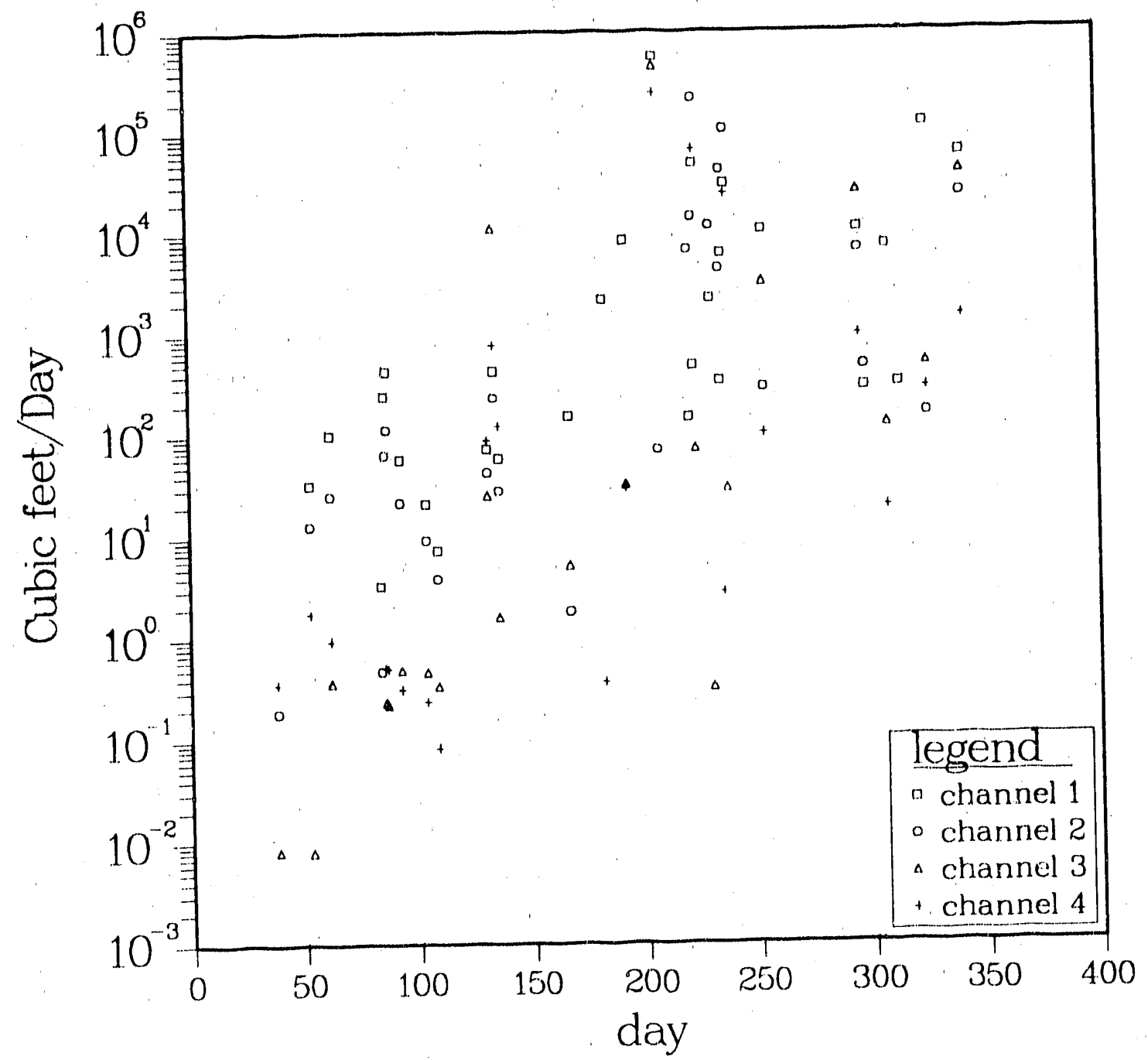

Fig. 12a. Water transmission at end of channel on 10th simulation year for scenario 1 , sc1. 


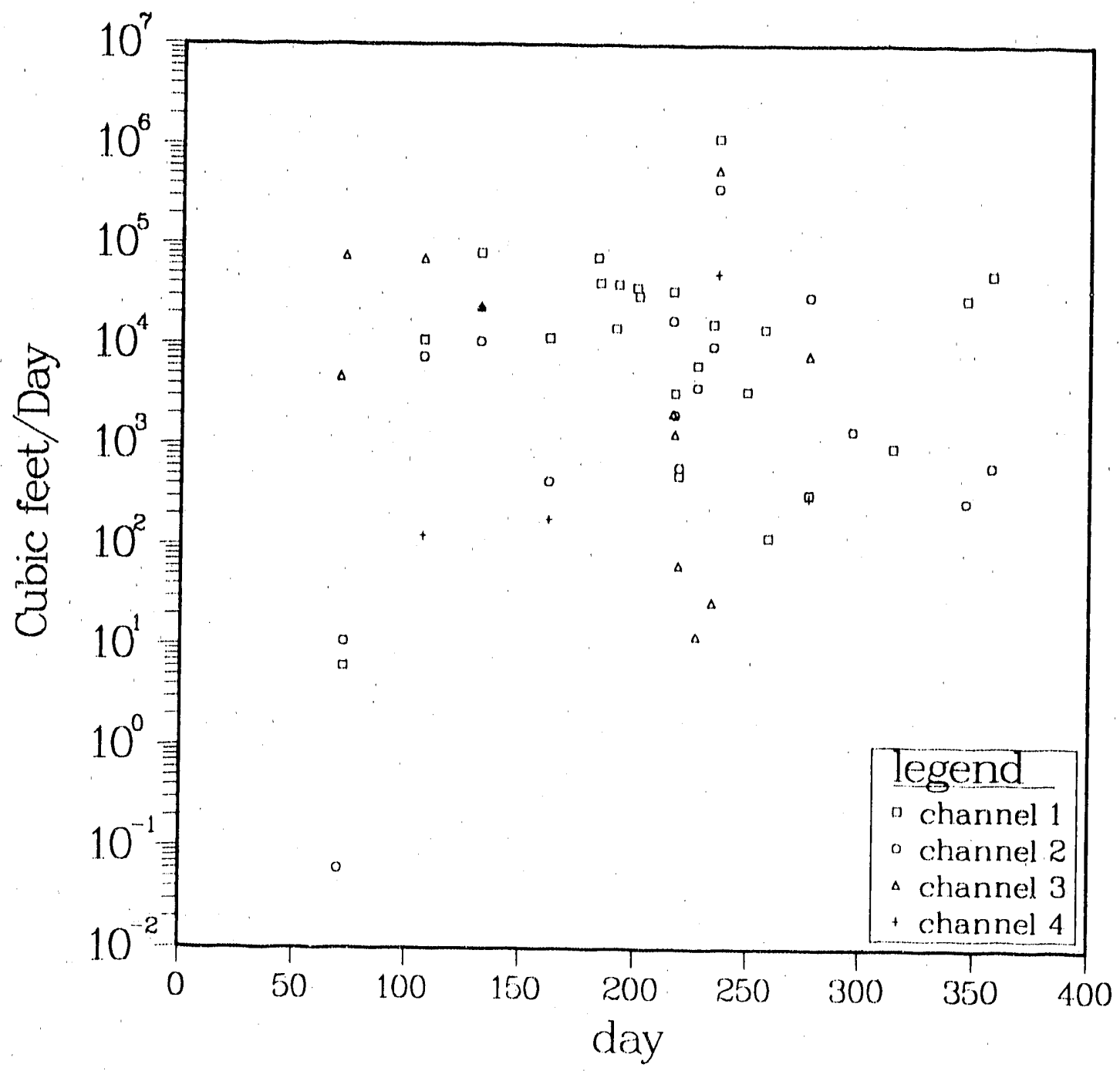

Fig. 12b. Water transmission at end of channel on 10 th simulation year for scenario $2, \mathrm{sc2}$. 


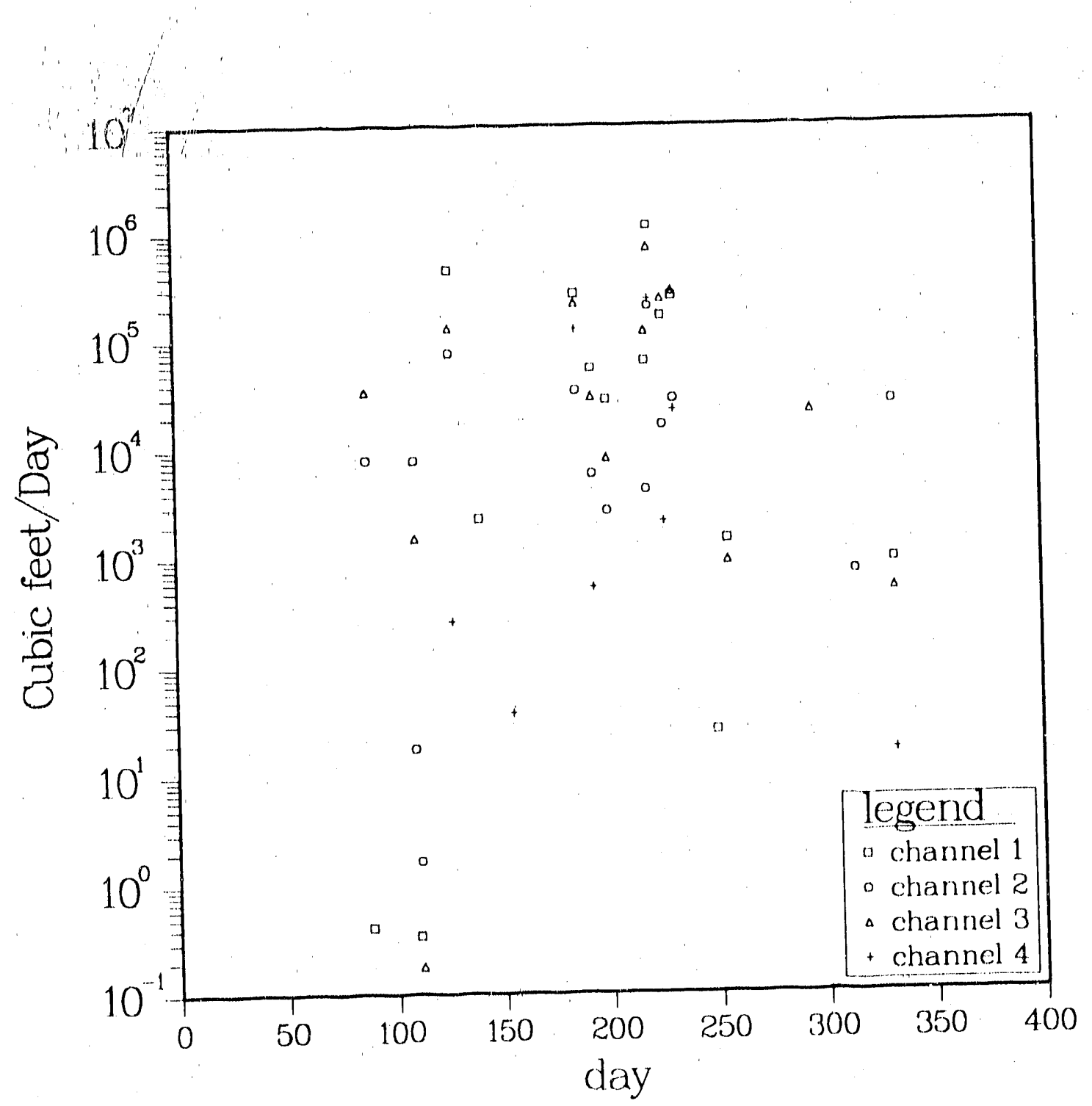

Fig. 12c. Water transmission at end of channel on 100 th simulation year for scenario $3, \mathrm{sc3}$. 


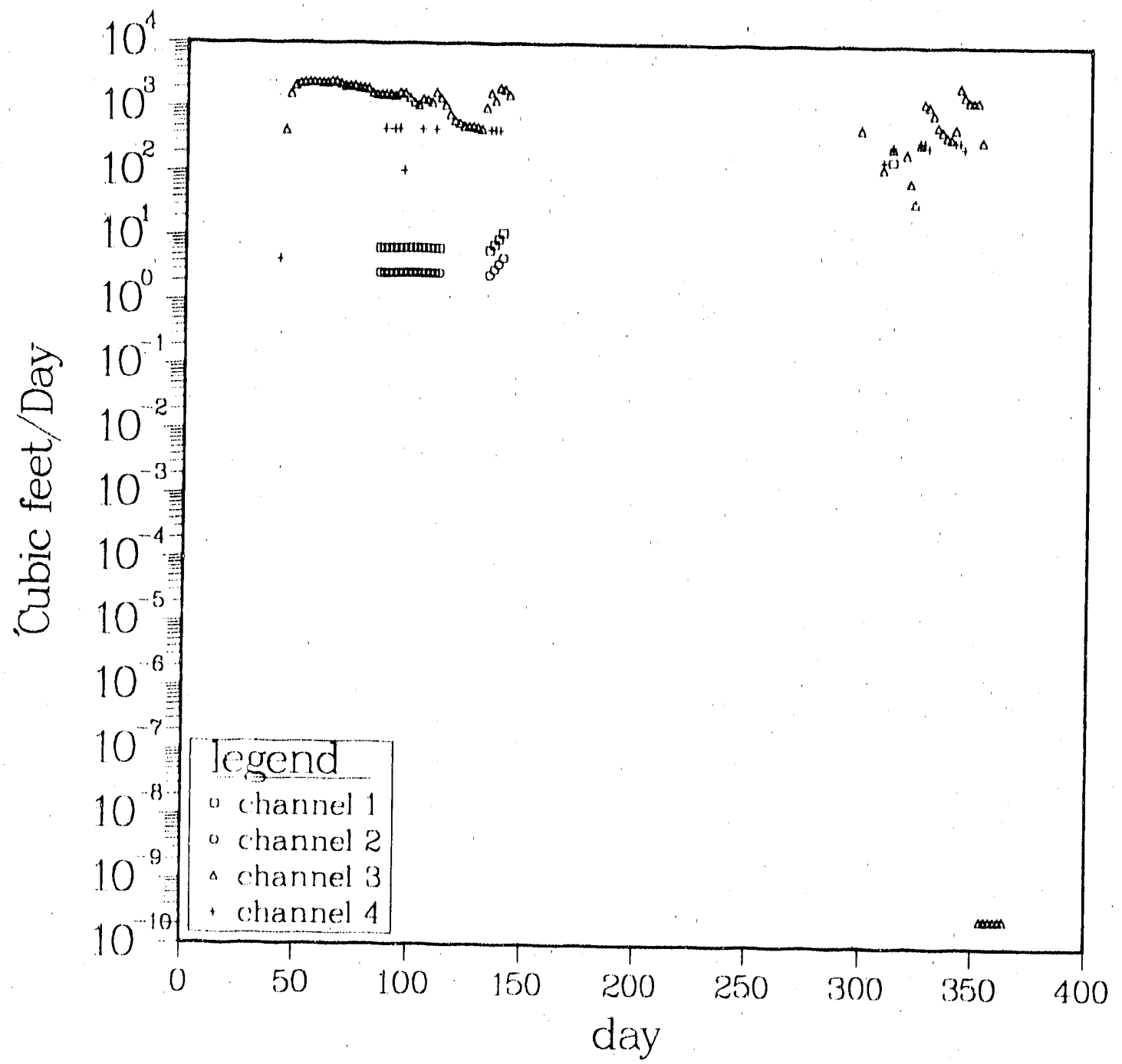

Fig. 13a. Peak channel discharge rates for runoff events in 10th simulation year in scenario 1 , Sc1. 


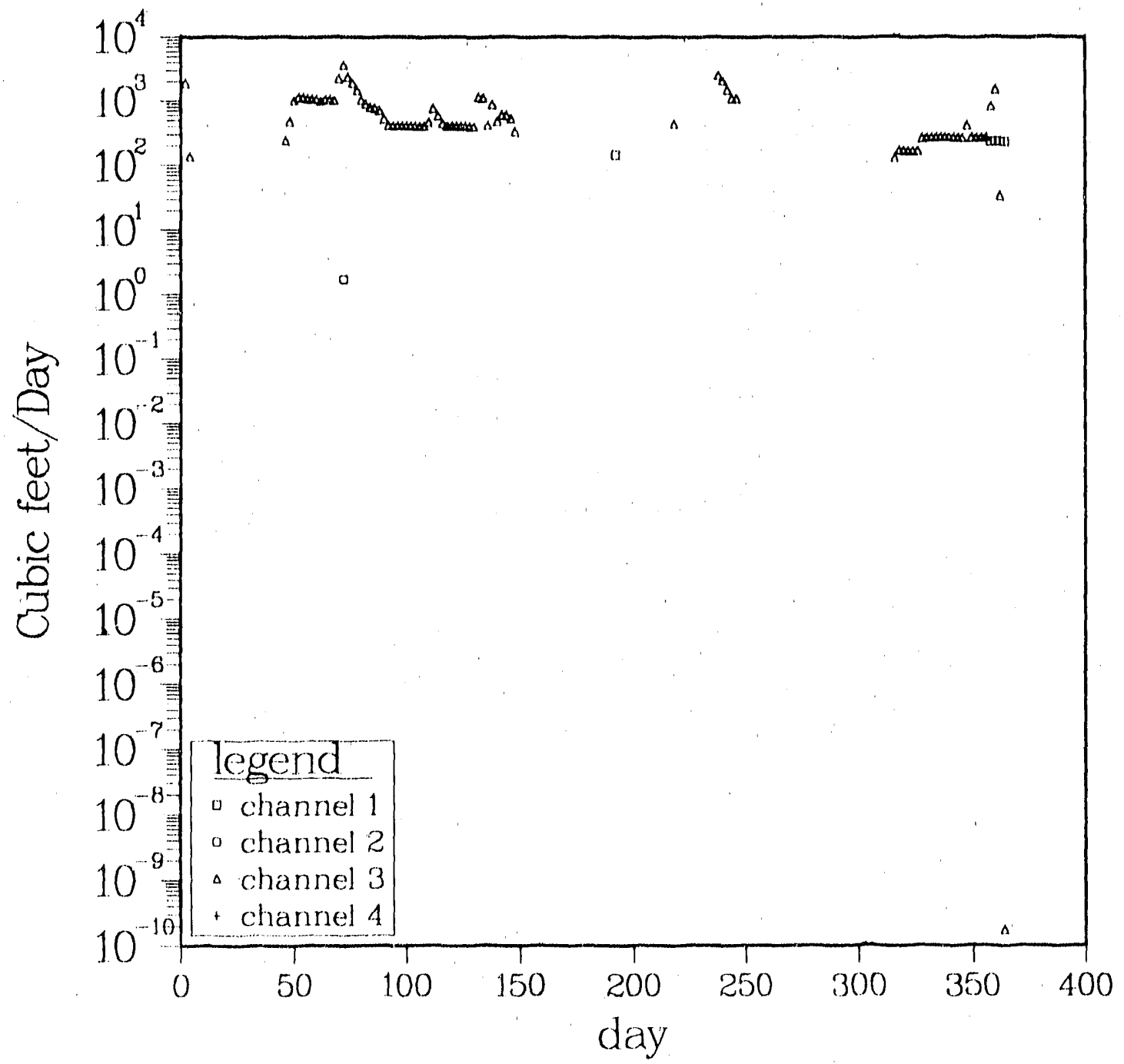

Fig. 13b. Peak channel discharge rates for rurioff events in 10 th simulation year in scenario 2 , sc2. 


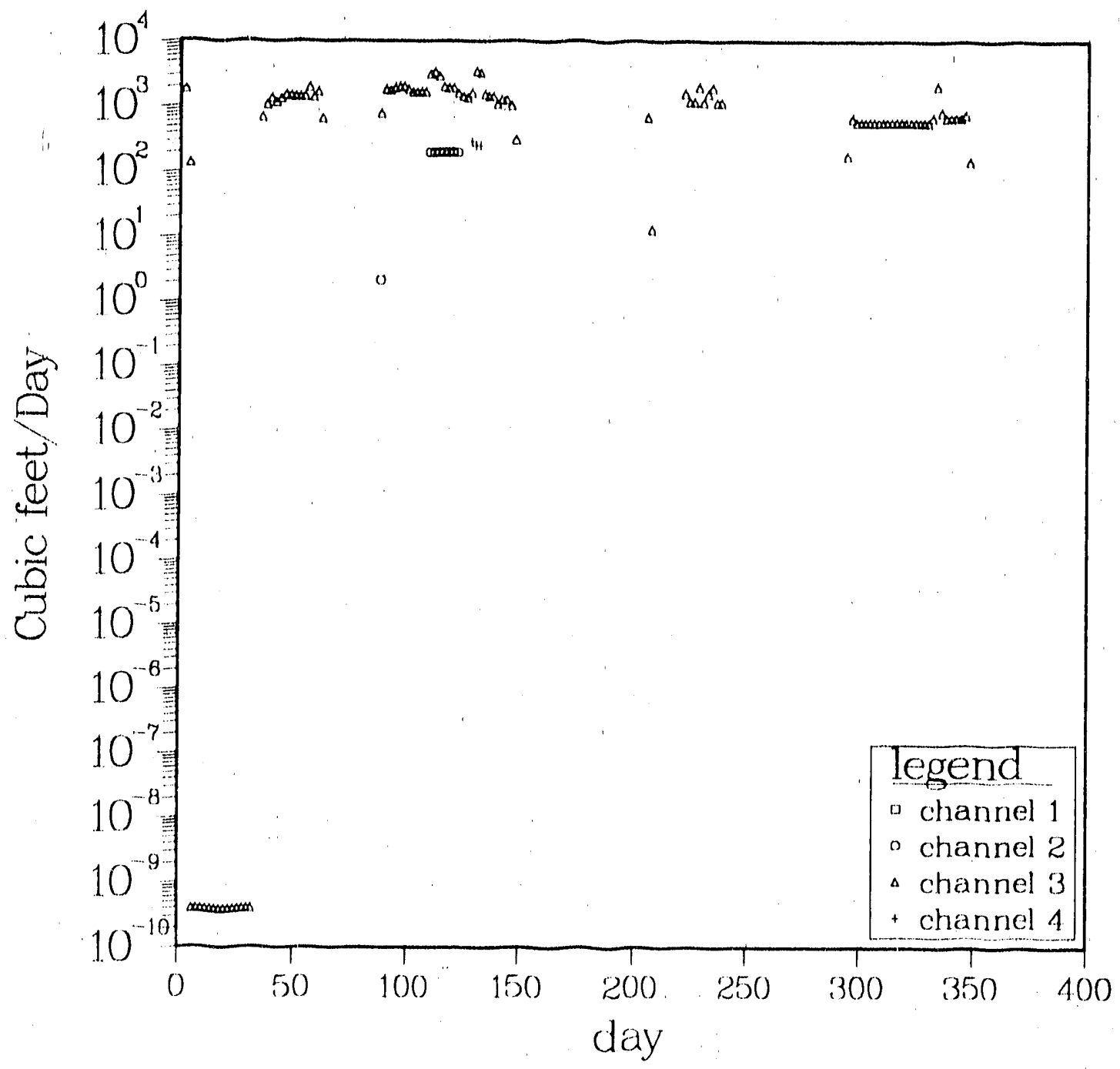

Fig. 13c. Peak channel discharge rates for runoff events in 100 th simulation year in scenario $3, \mathrm{sc} 3$. 


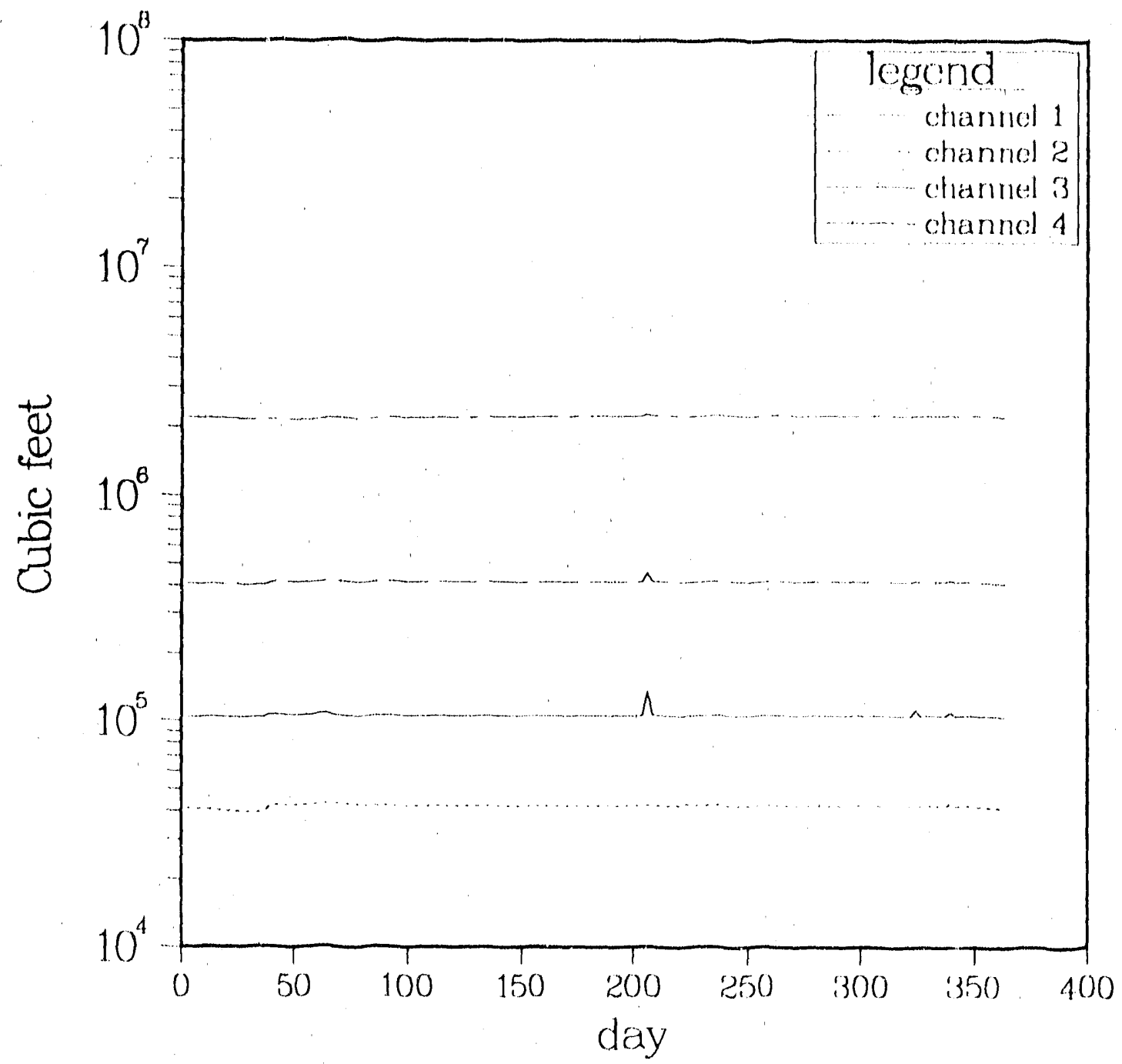

Fig. 14a. Return flow volume entering a channel from adjacent regions on 10th simulation year for scenario 1, sc1. 


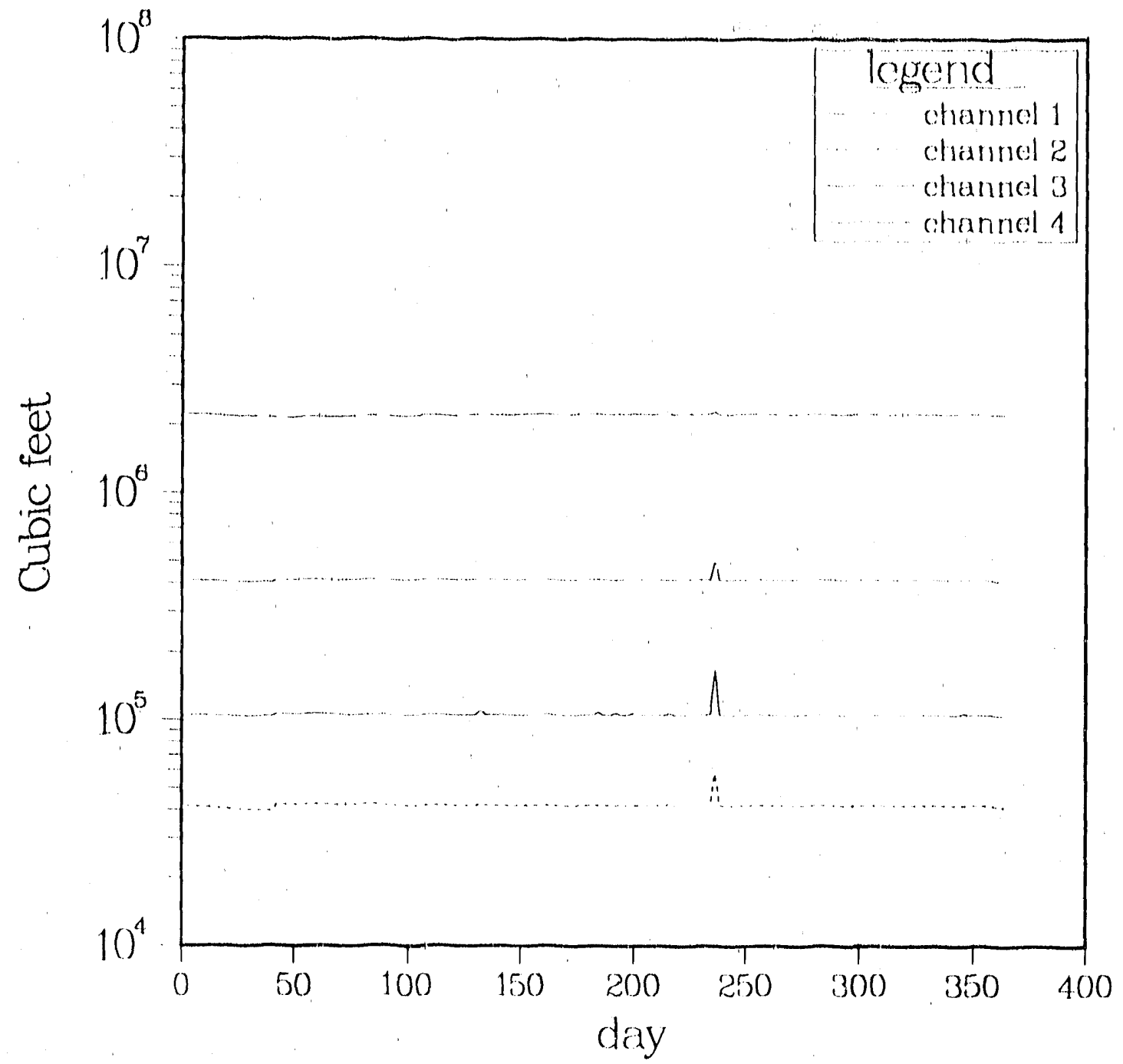

Fig. 14b. Return flow volume entering a channel from adjacent regions on 10th simulation year for scenario $2, \mathrm{sc} 2$. 


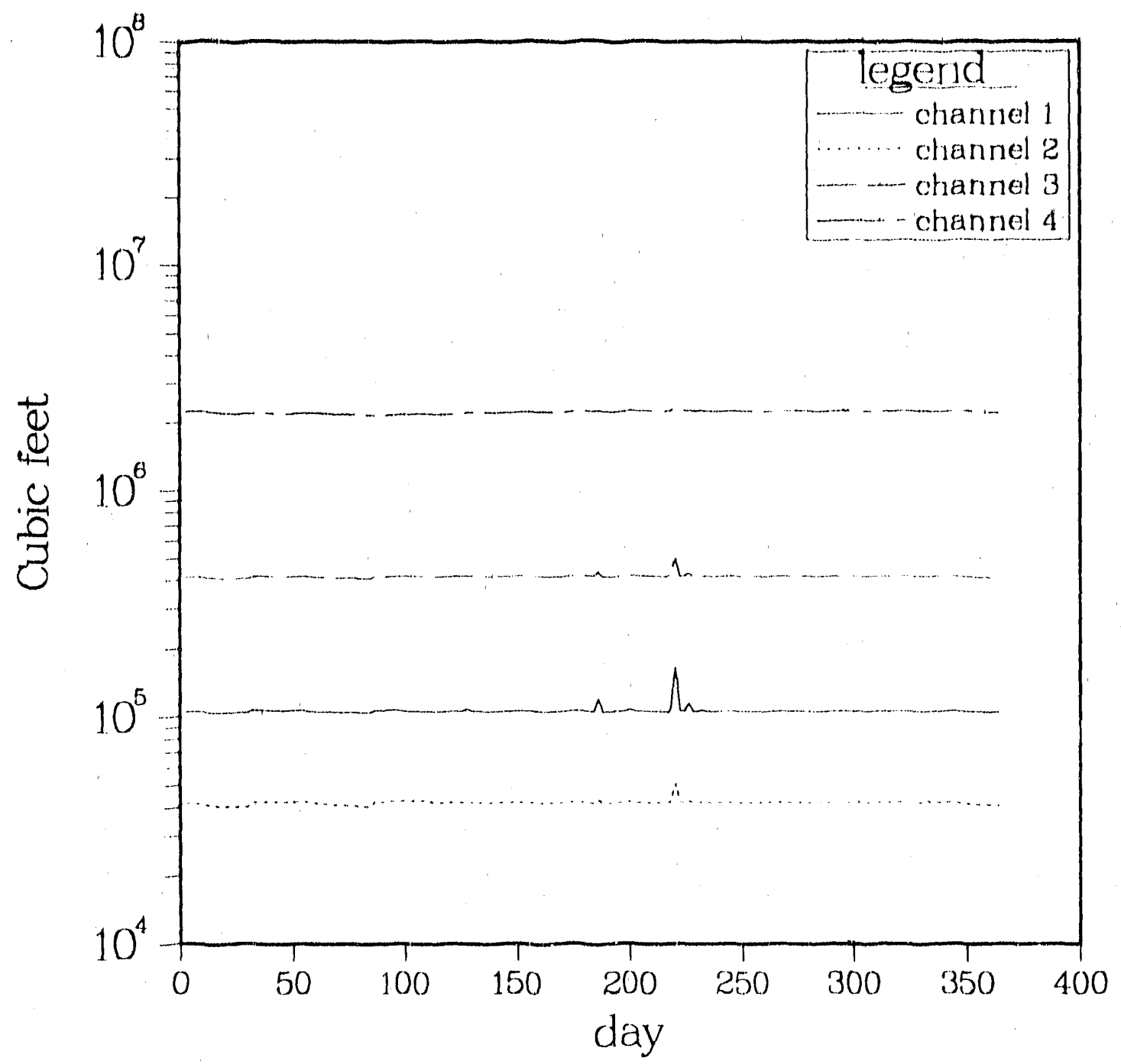

Fig. 14c. Return flow volume entering a channel from adjacent regions on 100th simulation year for scenario $3, \mathrm{sc} 3$. 


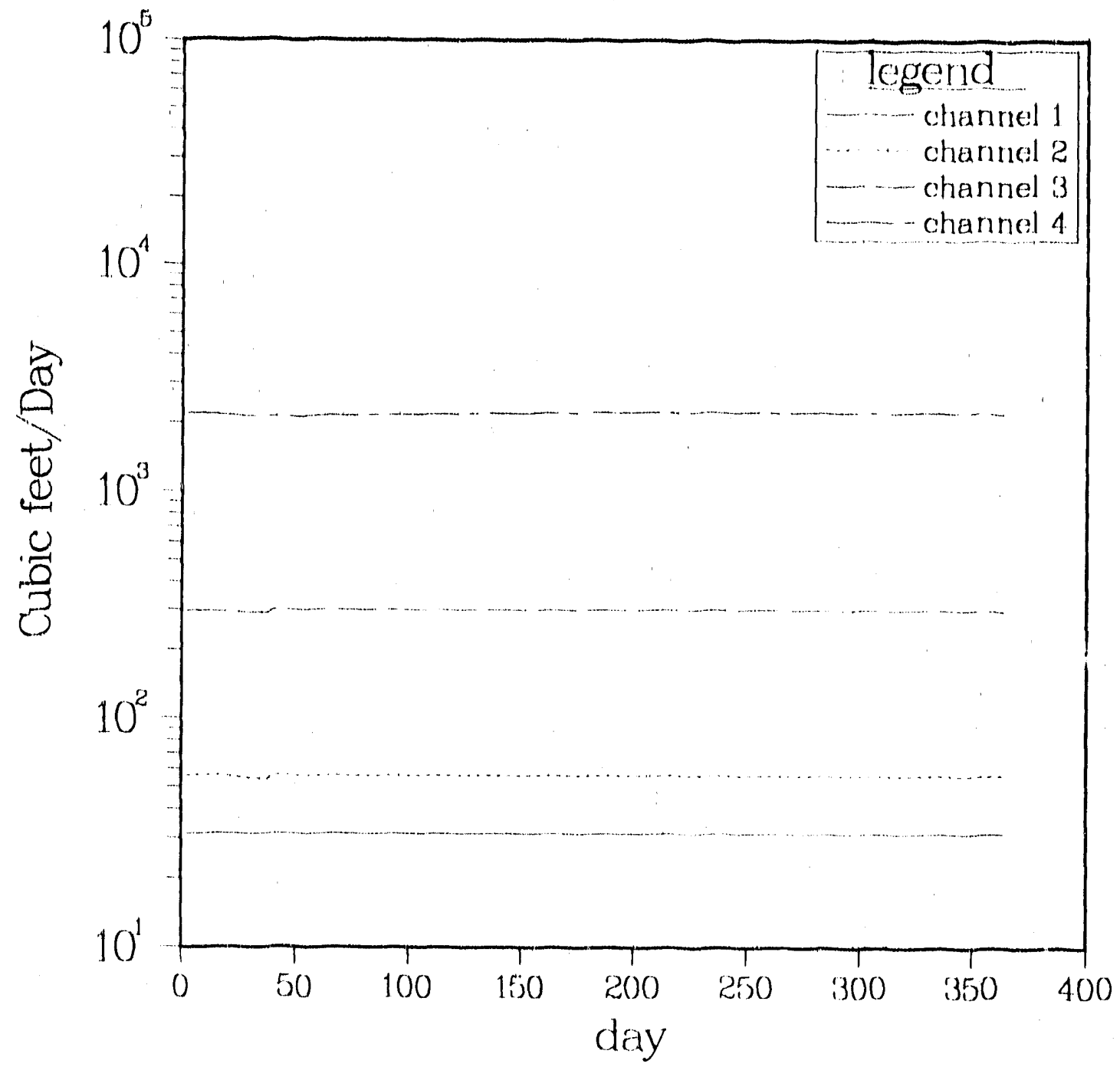

Fig. 15a. Aquifer transport losses at distal face below channels for 10th simulation year for scenario 1, sc1. 


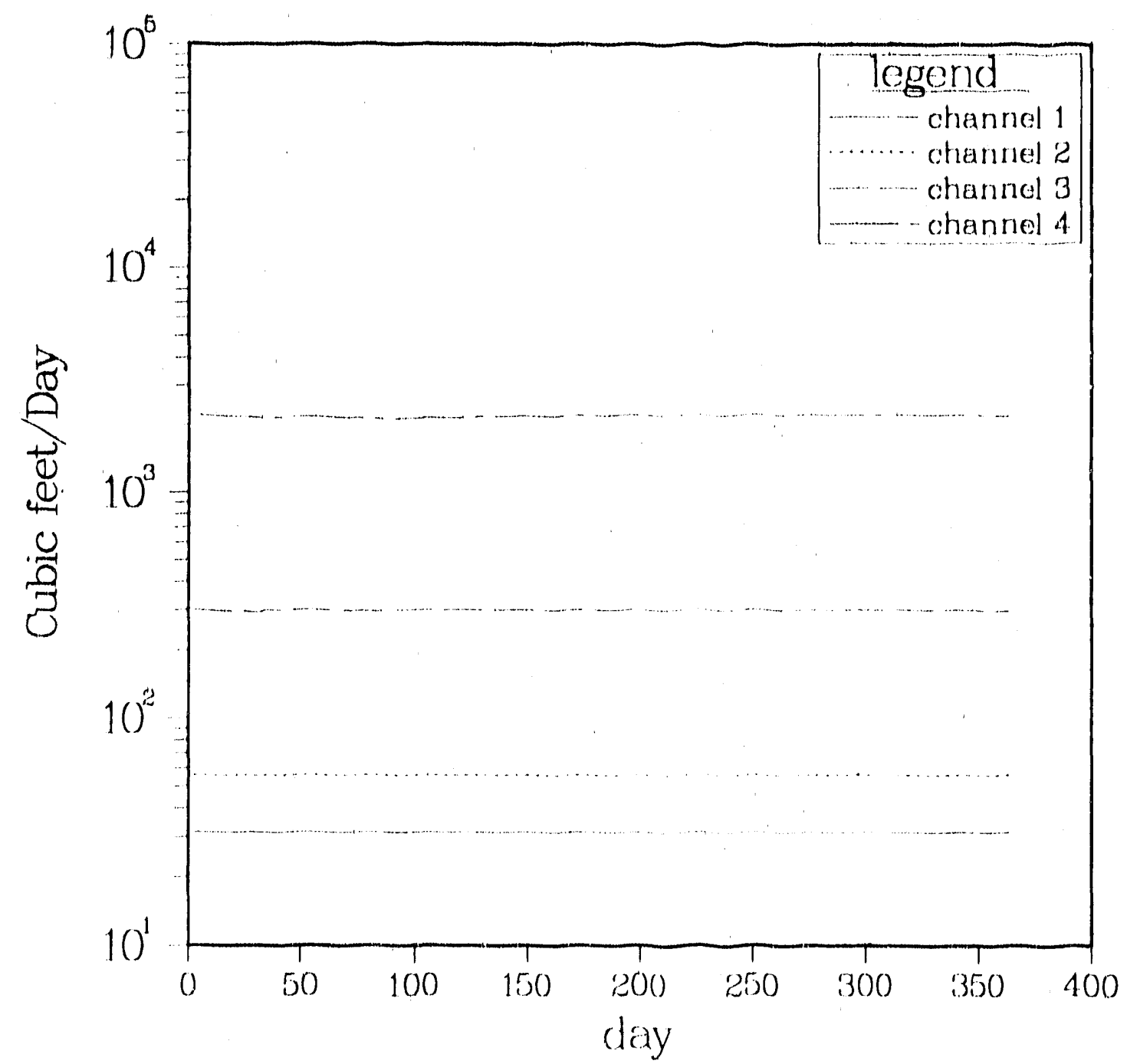

Fig. 15c. Aquiler transport losses at distal face below channels for 100th simulation year for scenario 3, sc3. 


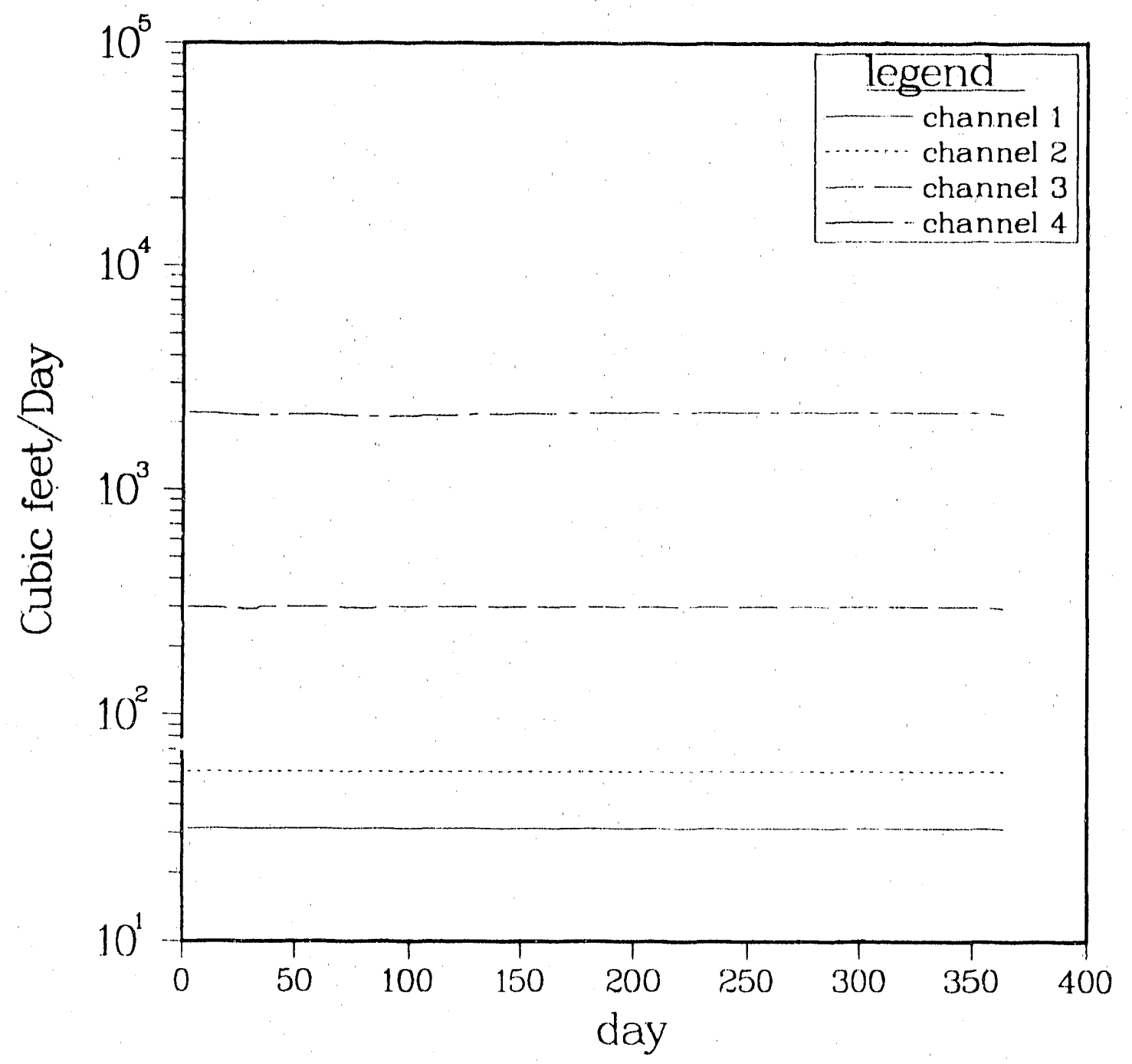

Fig. 15c. Aquifer transport losses at cistal face below channels for 100th simulation year for scenario 3, sc3. 


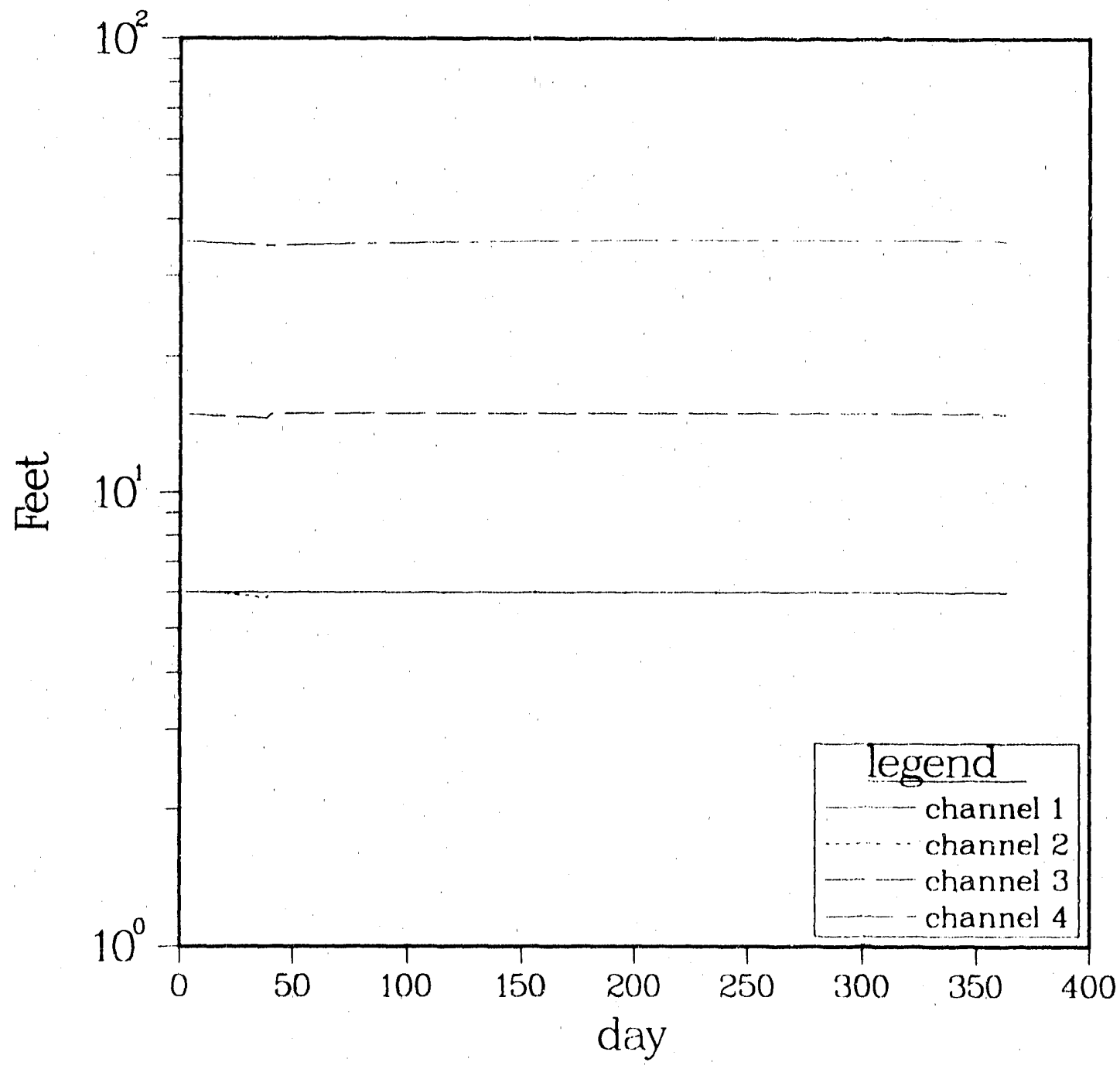

Fig. 16a. Aquifer height below channel for 10th simulation year for scenario 1, sc1: 


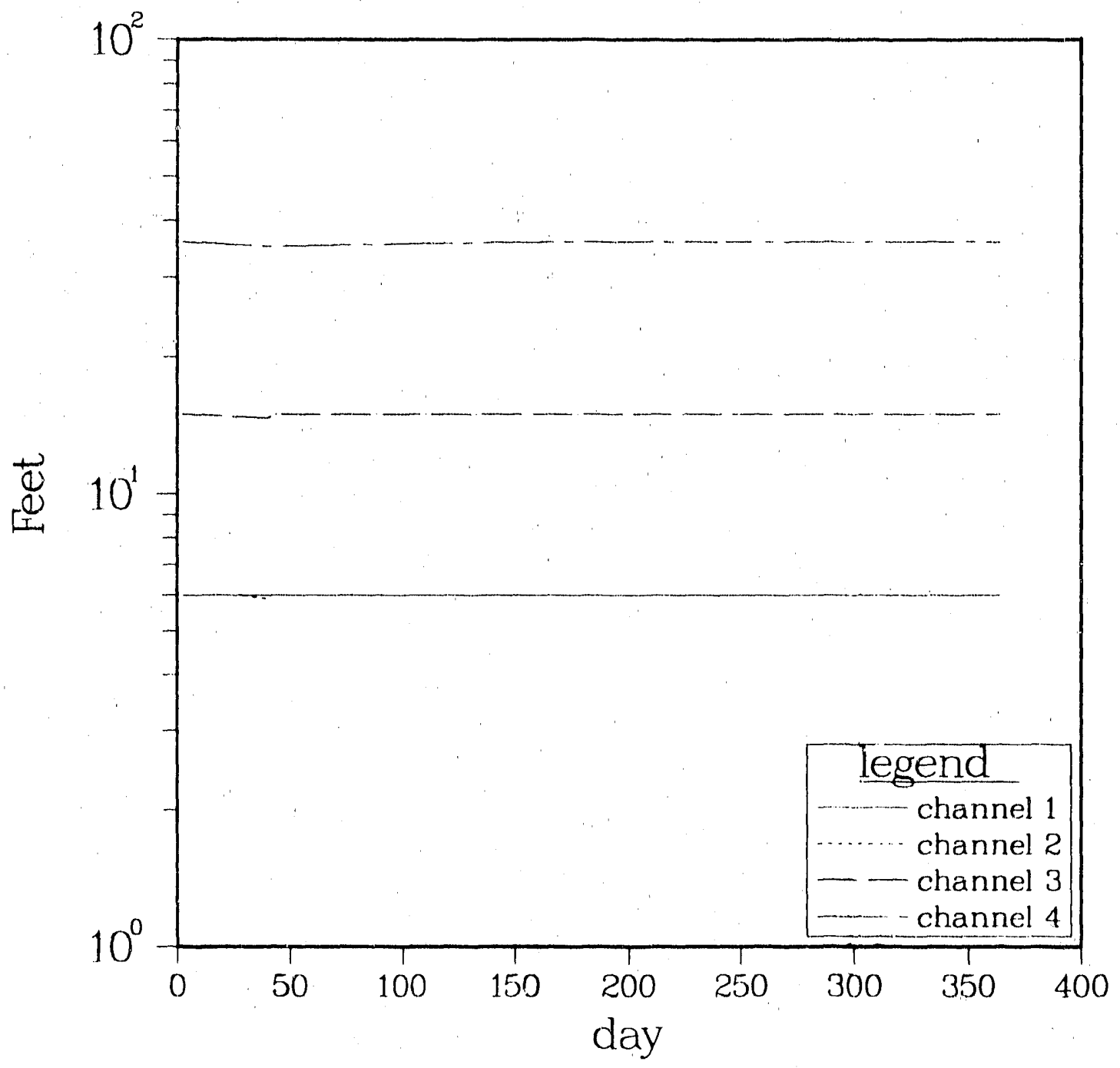

Fic. 16b. Aquifer height below channel for 10 th simulation year for scenario 2, sc2. 


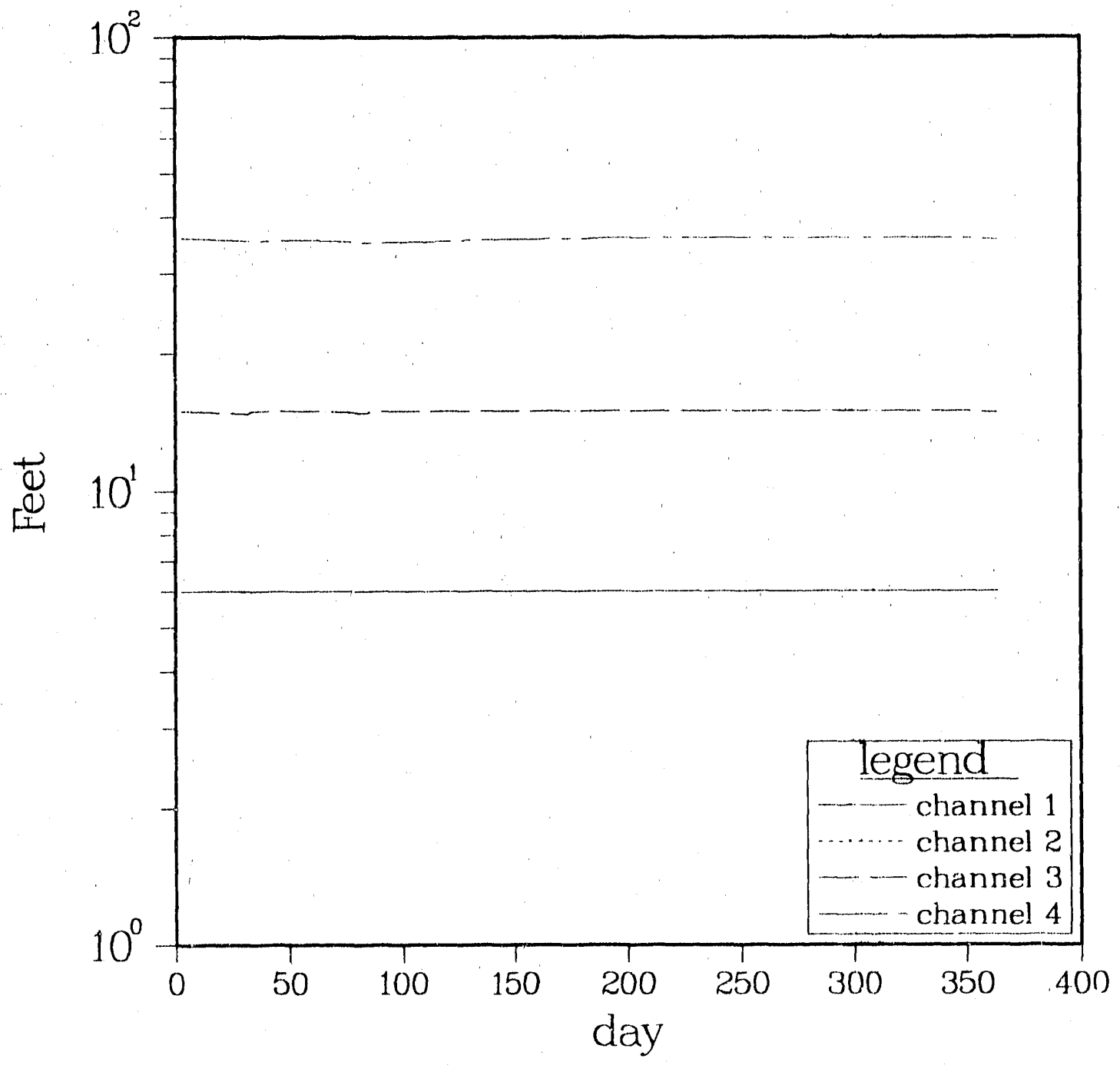

Fig. 16c. Aquifer height below channel for 100th simulation year for scenario 3, sc3. 


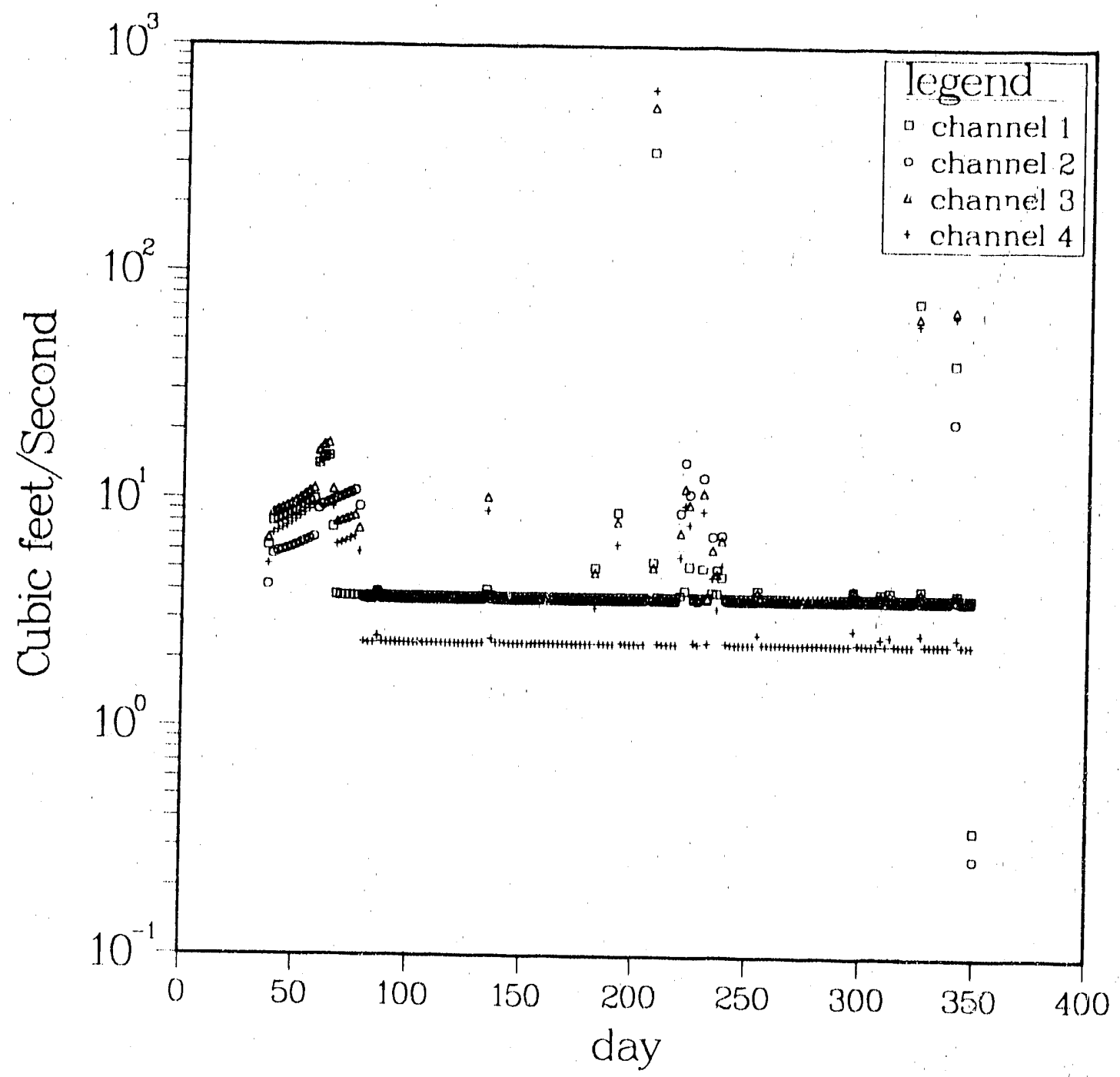

Fig. 17a. Alluvial aquifer volume for 10th simulation year for scenario 1, sci. 


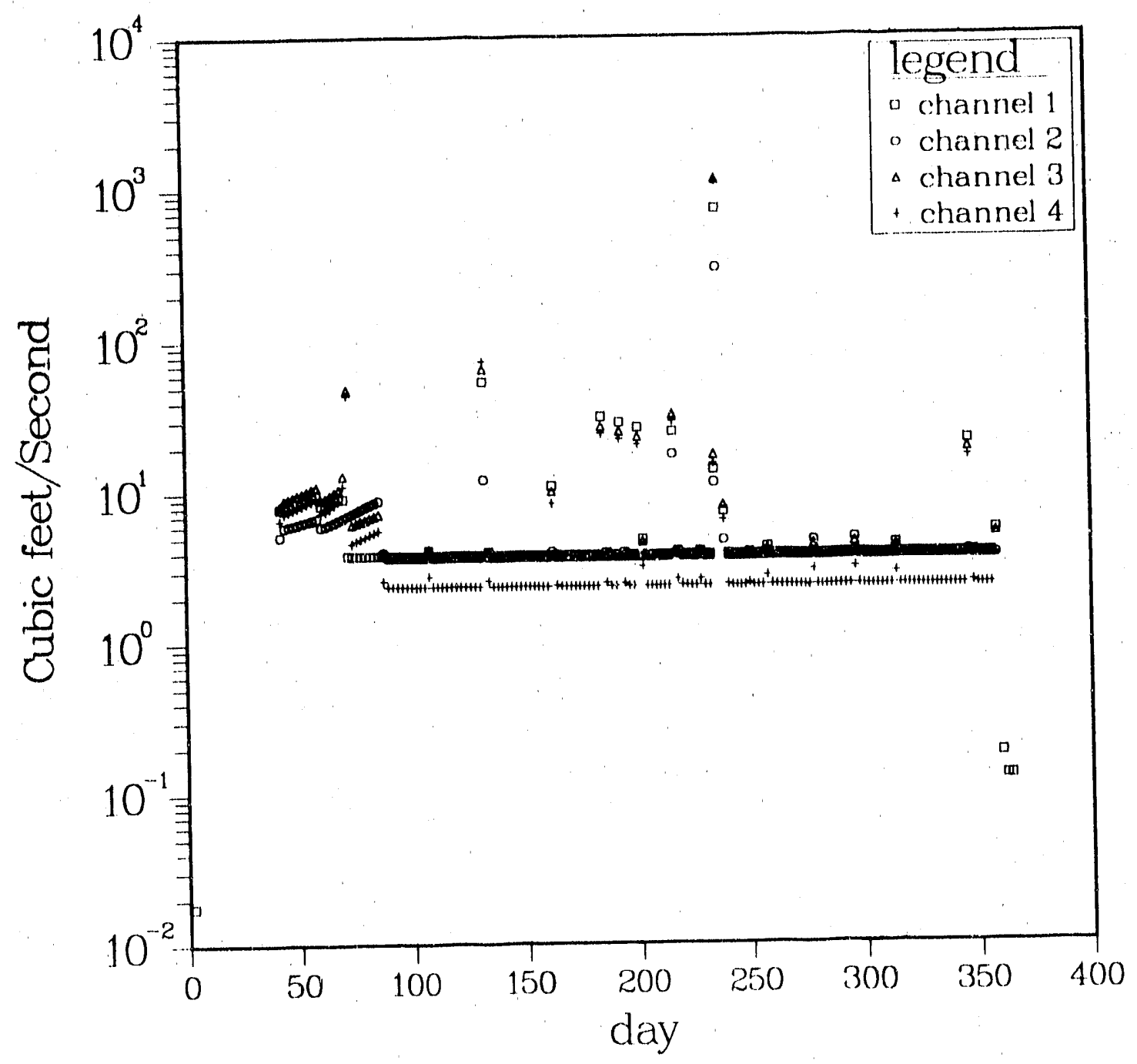

Fig. 17b. Alluvial aquifer volume for 10 th simulation year for scenario $2, \operatorname{sc2}$. 


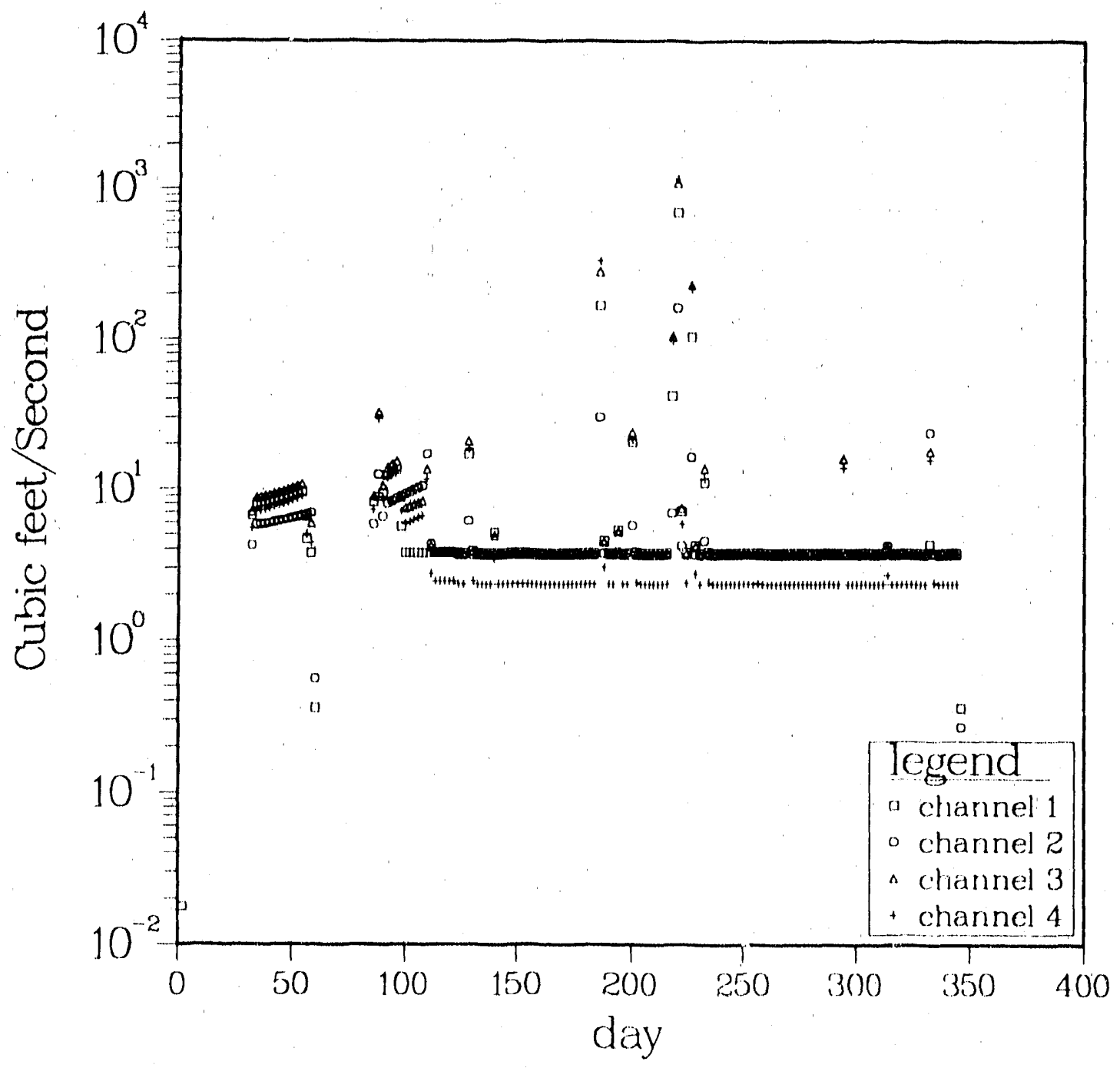

Fig. 17c. Alluvial aquifer volume for 100 th simulation year for scenario 3, sc3. 


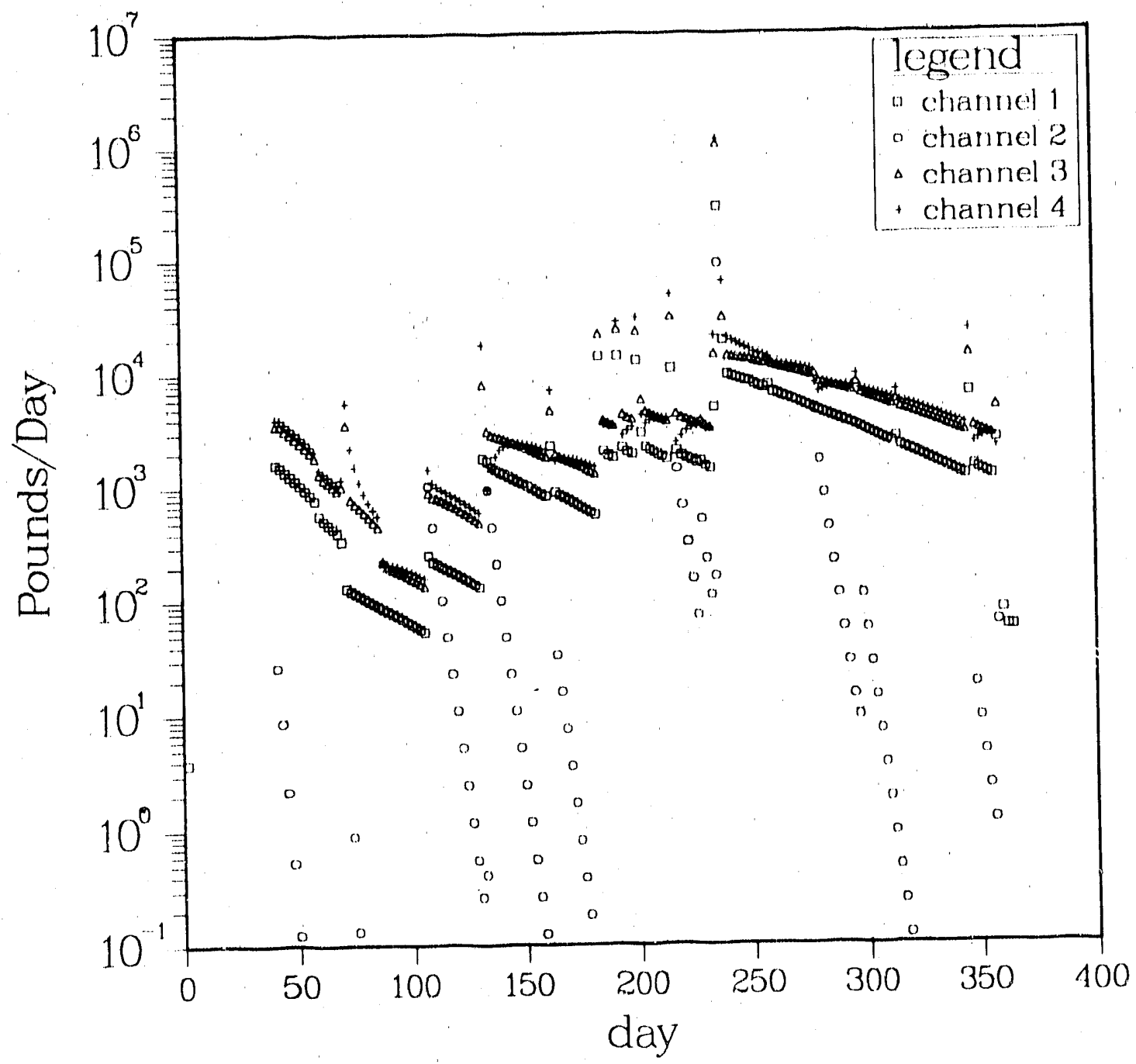

Fig. 18a. Sediment discharge from channels in 10 th simulation year for scenario $1, \mathrm{sc1}$. 


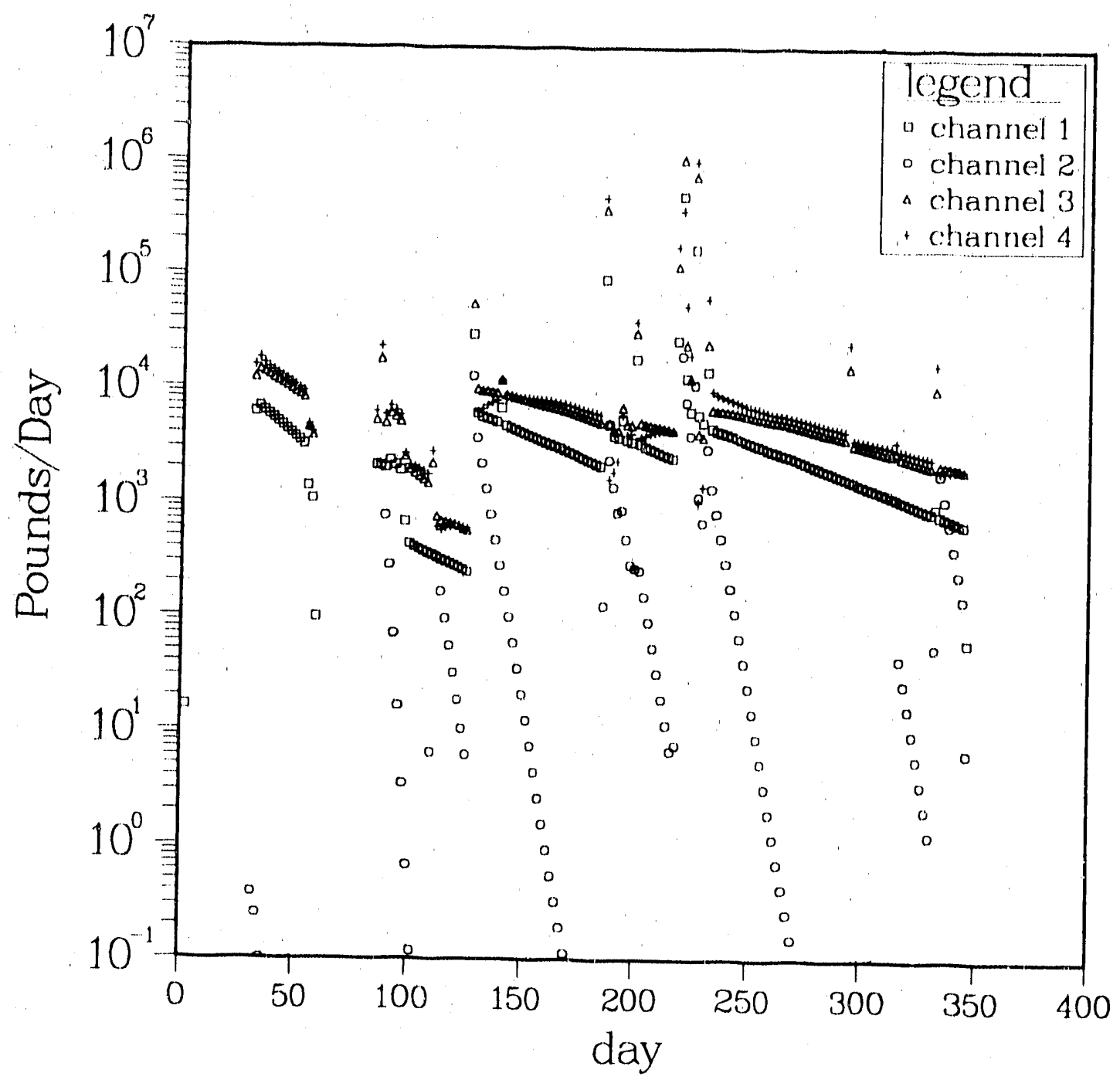

Fig. 18b. Sediment discharge from channels in 10th simulation year for scenario $2, \mathrm{sc2}$. 


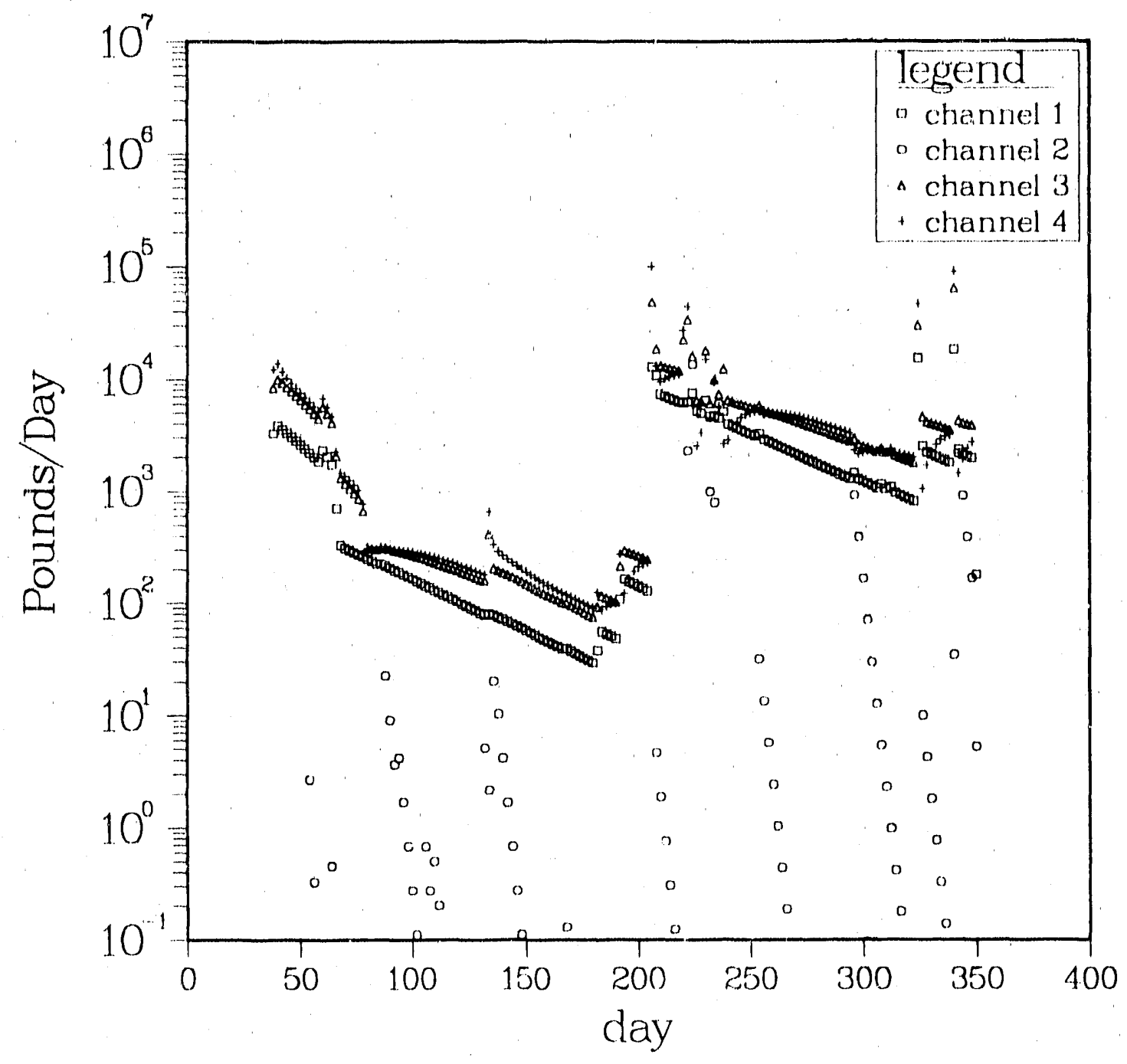

Fig. 18c. Sediment discharge from channels in 100 th simulation year for scenario $3, \operatorname{sc3}$. 


\section{Regions, Total Above Ground Blomass}

Annual variations of regional above-ground biomass for a glven year are presented in Figs, 4a-c for sc1, sc2, and sc3, respectively. Only annual and perennial grasses and herbs are simulated in sc1, and the blomass variation is more pronounced than in sc2 or sc3, where trees and shrubs predominate. The rapid drop in blomass at the end of the growing season due to the death of annuals is clearly visible (Flg. $4 a$ ). With the exception of regions 6 and 8 , all regions show a similar growth pattern and magnitude with a maximum above-ground biomass of about $100 \mathrm{~g} / \mathrm{m}^{2}$ during midseason. The inclusion of a riparian community in the scenario receiving both runoff from adjacent land surfaces into an alluvial plain and the addition of simulated outfall water from TA-50 and TA-48 increases the avallable soll moisture for the growth of plants. This is reflected by a maximum biomass of almost $300 \mathrm{~g} / \mathrm{m}^{2}$ during midseason for region 6 . A smaller but significant effect is noted for an alluvial plain with larger surface area in region 8 , where a maximum biomass of about $200 \mathrm{~g} / \mathrm{m}^{2}$ is observed in the 10 -yr simulation. The latter simulations were performed with the advanced secondary succession strategy in BIOTRAN, which assigns primary resource advantage to perennial grasses. The same strategy applled to grasses, shrubs, and trees in sc2; sc3 assigns primary resource advantage to climatic climax trees in the simulation. The simulation of sc2 (Fig. 4b) shows only a very small effect of annual grasses on the overall biomass density because most vegetation is associated with woody tissue which persists from year to year. The significantly larger biomass density of about $8000 \mathrm{~g} / \mathrm{m}^{2}$ for the riparian community (region 6) clearly illustrates this point of analysis despite the relatively short simulation time $(10 \mathrm{yr})$ for the growth of woody plants. Other regions simulated in sc2 show biomass densities between 1500 and $2000 \mathrm{~g} / \mathrm{m}^{2}$, which are above those observed in sc1, but do not show complete dominance of trees over shrubs and grasses including annuals. It should be noted that the more rapid approach to the climax stage in region 6 is due to the enhanced moisiure availability and to the presence of deciduous trees and shrubs in the simulation for that region.

The advanced succession strategy applied to sc3 (Fig. 4C), which for biomass density simulation is identical to all aspects of $\mathrm{sc} 2$ with the exception of the simulation time $(100 \mathrm{yr})$, serves to illustrate the final climax siage for each regicn. Region 6 simulates the riparian community along channel 3 of the watershed at an equilibrium biomass density of about $17000 \mathrm{~g} / \mathrm{m}^{\text {? }}$, whereas other regions show biomass densities between 3500 and $5500 \mathrm{~g} / \mathrm{m}^{2}$ over the same time period. The degree to which vegetation reached equilibrium biomass density during this simulation period can be approximated by a similar simulation in which a plant type (ponderosa pine) has no competitors for resources. A simulation of this type yielded a biomass density of about $5900 \mathrm{~g} / \mathrm{m}^{2}$ for this vegetation type alone after a $100-\mathrm{yr}$ simulation period. Hence, the advanced succession strategy is $80 \%-90 \%$ efficient with regard to the production of a pure stand of this vegetation type without any competition from other kinds of plants. Also, a 100-yr simulation of a pure stand of ponderosa without the limiting effects of nutrients, nitrate and phosphate, yielded about $7000 \mathrm{~g} / \mathrm{m}^{2}$ biomass density. This is important to the analysis because national mean concentrations of these nutrients were used to limit growth in all other scenarios.

With the exception of region 6, equilibrium biomass was not attained in a $100-\mathrm{yr}$ simulation for ponderosa pine forests, and it appears that 120 to $150 \mathrm{yr}$ would be required for this 
to occur. Hence, runoff and associated erosion events were simulated in an early-climatic serial stage (sc2) and two late-climatlc subclimax stages (sc1 and sc3). The grassland scenario (sc1) could also be considered a disclimax stage where shrub and tree growth were prevented by man or the chemical-physical effects of the erivironment (edaphic). This discussion also applles to pinyon forests at L.ANL. Finally, the enhanced blomass accumulation in regions 6 and 8 is also due to the avallability of ground water once the root depth has penetrated the simulated surface of the shallow aquilers below the soll horizons in these regions.

\section{Reglons, Surface Runoff}

Regional surface runoff events for the 10th year (sc1 and sc2), and the 100th year (sc3) are presented in Figs. 5a-c. The grassland scenario (sc1) shows 11 runoff events in excess of $0.1 \mathrm{in.} \mathrm{for} \mathrm{all} \mathrm{regions.} \mathrm{Ten} \mathrm{runoff} \mathrm{events} \mathrm{are} \mathrm{observed} \mathrm{in} \mathrm{sc2,} \mathrm{including} \mathrm{one} \mathrm{evert} \mathrm{in} \mathrm{region} 6$. Thirty-five runoff events are observed for all regions in sc 3 with 4 events involving region 8 and 5 events involving region 4 . The grassland scenario also shows 29 runoff events between 0.095 and $0.1 \mathrm{in}$. The sc1 and the sc2 scenarios show 31 events yielding runoff in this range, whereas scenario sc3 shows 29 events of this magnitude. An appreciable number of events below $0.05 \mathrm{in}$. are observed in all scenarios. The largest runoff event recorded for all regions is about 1 in. occurring in region 8 with relatively few events above 0.4 in. in all scenarios. Events in regions 6 and 8 reflect cumulative runoff from adjacent regions ( 3 and $4 ; 5$ and 7 ), which would tend to magnify runotf depth in some instances due to the large difference in surface area (region $6=3.2$ acres; regions 3 and $4=56.4$ acres each) between region 6 and regions 3 and 4 , which articulate with the former. A similar situation exists between region 8 (6.9 acres) and regions 5 and 7 , which occupy 28 acres each. However, this effect is observed only in response to large simulated raiin events. In summary, between 29 and 31 runoff events less than $0.1 \mathrm{in}$. occurred in the scenarios over all regions, and in most cases less than $2 \mathrm{in.} \mathrm{of} \mathrm{runoff} \mathrm{occurred} \mathrm{over} \mathrm{the} \mathrm{entire}$ year in any one region. An average number of runoff events per region of a given magnitude can be obiained by dividing the observed events by the number of reglons ( 8 ) or by inspecting the graphs. Also, the runoff events include the spring runoff caused by snowmelt in all regions and icemelt in regions 6 and 8 .

\section{E. Regions, Return Flow}

Subsurface return flow for the 10th simulation year (sc1 and sc2), and the 100th simulation year ( $(\mathrm{sc} 3)$ are presented in Figs. 6a-c, respectively. Excluding regions 6 and 8 , which are alluvial plains, daily return flows for all regions were less than $0.1 \mathrm{in}$. with most of it occurring during spring snowmelt; a cumulative total return flow of less than $0.2 \mathrm{in}$. is observed in the simulations for these regions. Region 6 shows numerous return flow events in all scenarios primarily during early spring. A late fall series is observed in sc1, and middle summer events are observed in sc3. A smaller number of events of this type are recorded for region 8 , most of which are observed in sc1 during late spring and early summer; it is observed to occur in both $\mathrm{sc2}$ and sc3 primarily at the end of the growing season. A main source of soil moisture for region 6 is derived from its underlying aquifer below channel 3. The middle-summer paucity of events is caused by evapotranspiration of deciduous trees and shrubs and annual and perennial grasses in 
sc2 and sc3; annual and perennial grasses evapotranspirate water in sc1. A trend of return flow cessation during the growing season is observed for all scenarios, which corresponds with increasing live standing biomass in the regions. Region 8 has an underlying aquifer below channel 4 , but it is unsaturated for the most part and does not contribute significant moisiure to the overlying soil in the simulation. More details on this specific analysis will be presented when aquifers are considered.

\section{F. Regions, Erosion}

Simulated soil erosion from each region for the 10th simulation year (sc1 and sc2), and the 100th simulation year ( $\mathrm{sc} 3$ ) are presented in Figs. 7a-c. Thirty erosion events above 0.03 ton/acre are observed for $\mathrm{sc1}$ with one event involving region 8. Thitty erosion events above 0.03 ton/acre are recorded for sc2, two of which involve regions 6 and 8 . Forty erosion events above 0.03 ton/acre are recorded for $\mathrm{Sc} 3$ with five of these events involving region 1 and four events involving region 6. A total of 2733 erosion events between 0.003 and 0.03 ton/acre are observed for sc1 1 with five of thce events associated with region 5 . Twenty-four erosion events between 0.003 and 0.03 ton/acre are observed for sc2 with six of these events associated with region 1 . Twenty-one erosion events between 0.003 and 0.03 ton/acre are observed for sc3 with two events associated with region 8 and four such events associated with region 6 . Only 4 to 13 erosion events above $U .2$ ton/acre are observed in each scenario with the maximum value between 1 and 2 ton/acre cver all scenarios. In both sc1 and sc2, erosion events are more uniformly distributed throughout the year, whereas larger events in sc3 are clustered primarily within the growing season. Howe:er, events below 0.003 ton/acre, which are the most numerous type for all scenarios, are more uniformly distributed throughout the year with only a small tendency to cluster within the growing season in sc3.

The major erosion events correspond very closely to major runoff events in each region as shown in Figs. 5a-c. The stochastic nature of the precipitation pattern and precipitation amounts may obscure any trends associated with vegetation types simulated and approach the climax stage. However, it does not appear that a decrease in significant erosion events associated with region 6 are observed from grassland (sc1) to early forest stage (sc2) to advanced forest stage (sc3) described previously. Also, it appears that enhanced surface runoff from regions 6 and 8 is the result of higher antecedent soil moisture due to aquifer moisture transport to ve described later in this report.

Using an assumed bulk density for soil of $1.5 \mathrm{~g} / \mathrm{cm}^{3}$, the removal of 1 ton/acre of soil in an erosion event amounts to the removal of approximately $0.15 \cdot \mathrm{mm}$ mean thickness from that surface or about $225 \mathrm{~g} / \mathrm{m}^{2}\left(0.046 \mathrm{lbs} / \mathrm{At}^{2}\right)$. For example, the total weight of soil removed from all regions for scenarios sc1, sc2, and sc3 are presented in Figs. 8a-c, expressed in Ibs/day. The comparatively large differences in soil erosion rates are primarily due to the large range in areas of the regions $(246,72,56,4,56,4,28,3.2,28$, and 6.9 acres for regions 1 to 8 , respectively).

The highest discharge rate was observed to be about $500000 \mathrm{lbs} /$ day in region 1 of sc3. This discharge amounts to the removal of about $0.1-\mathrm{mm}$ thickness from the entire regional surface. 
The latter was observed in response to a simulated 2.0 -in. rainfall event during midsummer of the 100 th year. This rain event was the largest observed in all the scenarios.

\section{G. Regions, Soil Specific Activity}

The specific activity in all regions for $s c 1, s c 2$, and $s c 3$ are presented in Figs. $3 a-c$. The initial specific activity for all regions was set at about $2.35 \mathrm{pCi} / \mathrm{g}$ when averaged over all particle sizes and associated mass fractions. Specific activities in excess of this initial estimate for any region show net sedimentation, whereas those regions with specific activities below the initial value represent net scouring of soil toward channels or alluvial plains. Regions 6 and 8 in all scenarios show net sedimentation based on specific activities between 2.6 and $3.6 \mathrm{pCi} / \mathrm{g}_{\text {; }}$ all other regions in the scenarios represent variably scoured areas ( 2.1 to $2.34 \mathrm{pCi} / \mathrm{g})$ on this basis. An increase of specific activity above $2.35 \mathrm{pCi} / \mathrm{g}$ also indicates a deposition of $0.063-\mathrm{mm}$ diameter particles (suspended load) in a region (specific activity of $0.063-\mathrm{mm}$ particles $=4.60$ $\mathrm{pCi} / \mathrm{g}$ ). The specific activity in all regions is observed to change abruptly, corresponding to major surface runoff everits.

\section{H. Regions, Total Activity Inventory}

The total activity inventory for all regions assuming a $20-\mathrm{mm}$ erosion layer are presented in Figs. 10a-c, for sc1, sc2, and sc3. The initial activity for each region was set at 70.2, 20.5, $16.1,16.1,7.99,0.913,7.99$, and $1.97 \mathrm{mCi}$ for regions 1 to 8 , respectively; the activity was uniformly distributed over the surface. Region 1 in all scenarios showed the greatest loss of activity. Regions $2,3,4,5$, and 7 in all scenarios had significantly lower losses, whereas regions 6 and 8 both registered activity gains with region 6 exhibiting the highest gains in all scenarios of about $270 \%$. Region 8 showed gains of about $150 \%$ in all scenarios; the losses from those regions exhibiting net erosion were generally less than $3 \%$ over 7 yr of cumulative events. Losses of soil involved the suspended particles or "fines," which initially had the largest mass fraction (0.42) and the highest specific activity $(4.6 \mathrm{pCi} / \mathrm{g})$, and accounts for most of the losses of activity from all regions in all scenarios.

The loss or gain patterns for each region showed abrupt changes associated with significant rain events presumably over the 7 simulation years of runoff history for all scenarios The stochastic nature of precipitation events, patterns, and amounts, however, precludes our giving any cause for the observed losses, although similar reductions were observed in all scenarios. Major erosion events from region 1 are observed more frequently as shown in Figs. $8 a-c$.

\section{Channels, Lateral Runoff}

Lateral runoff into all channels from adjacent regions for $\mathrm{sc1}, \mathrm{sc2}$, and $\mathrm{sc} 3$ are presented in Figs. 11a-c. The majority of lateral runoff events for all scenarios range between 100 and $100000 \mathrm{ft}^{3} /$ day with only a few events exceeding $100000 \mathrm{ft}^{3} /$ day, corresponding to major precipitation events. Charnel 1, which receives lateral flow from region 1, had the largest event of this type (sc3) for all scenarios (about $1000000 \mathrm{ft}^{3} /$ day for a 2.0 -in. rain event). In general, the 
number of lateral events decreased from $\mathrm{sc1}$ to $\mathrm{sc} 3$, and a clustering of events within the growing season also followed the same trend. Most of the reduction of events was due to decreased lateral events from channel 1 exclusive of events during summor. Lateral runoff input events to channels 3 and 4 in sc2 and sc3 show significant decreases when compared with sc1, particularly sc3. As hoth channel 3 and channel 4 are situated in alluvial plains, it appears that a riparian community which includes trees and shrubs is more efficient in reducing lateral flow events under these conditions. In contrast, the number of lateral runoff events in channels 1 and 2 were not significantly different for $\mathrm{sc} 1$ and $\mathrm{sc} 2$ but decreased in sc3.

\section{J. Channels, Water Transmission}

The transmission of water past the distal end of each channel for sc1, sc2, and sc.3 are presented in Figs. 12a-c. Channel 1 is modeled to accept $5929 \mathrm{tt}^{3} /$ day from TA-48, and channel 2 receives $4524 \mathrm{ft}^{3} / \mathrm{day}$ from TA -50 . The former channel transmits about $5000 \mathrm{ft}^{3} /$ day and the latter about $4000 \mathrm{ft}^{3} /$ day; the volume difference enters the underlying aquifers. These quantities remain almost constant for all scenarios unless a precipitation event or snow- and ice-melt create additional runoff moisture. The greater transmission traction for channel 2 over channel 1 in all cases for perennial flow from the technical areas is attributed to the larger aquiter volume of channel 1. The transmission of water from the distal end (about $5000 \mathrm{ft}^{3} /$ day) of channel 3 is also perennial but considerably less than at its, anterior end (about $9000 \mathrm{ft}^{3} / \mathrm{day}$ ); these quantities are also increased by watershed runoff events. The distal end of channel 4 in all scenarios is observed to transmit about $3000 \mathrm{ft}^{3} /$ day and also to respond to major runoff events in the entire watershed. The largest single channel runoff events are observed to be in channels 3 and 4 for all scenarios ( 1000000 to $2000000 \mathrm{ft}^{3} /$ day followed by channel 1 , then by channel 2. Most events of significance are between 2000 and $40000 \mathrm{ft}^{3} / \mathrm{day}$ with the majority in the lower portion of the range for all scenarios. The total number of events are also reduced (with the exception of those associated with snow- or icemelt) from sc1 to sc3. The major cause of the latter reduction is the reduction of precipitation generated events in channels 3 and 4 ; this is consistent with the reduction of lateral runoff events described earlier. Events associated with snow- and/or icemelt are observed to be quite variable and may be either lacking ( $(\mathrm{sc} 2)$ or delayed ( $\mathrm{sc} 3$ )

\section{K. Channels, Peak Discharge Rate}

Peak discharge rates for given runoff events for sc1, sc2, and sc3 are presented in Figs 13a-c. The modeling of a peak discharge rate assumes that water passing past a point in a channel will reach a maximum volume discharge rate depending on the total volume involved and on the duration of the event (Lane 1985), which will result in the production of a hydrograph. Discharges from TA-50 into channel 2 meet this criterion, but the duration of the event used in the model would be that which is characteristic of region $2(1.63 \mathrm{hr})$. Hence, the observed peak runoff of about $3.5 \mathrm{ft}^{3} / \mathrm{s}$ in all scenarios is probably a low estimate of this daily zvent. The waste discharge from TA-48 into channel 1 is also estimated with a duration period characteristic of region $1(2.1 \mathrm{hr})$ that results in a high estimate $\left(3.2 \mathrm{ft}^{3} / \mathrm{s}\right)$ assuming continuous flow of $0.043 \mathrm{ft}^{3} / \mathrm{s}$ $\left(4000 \mathrm{ft}^{3} /\right.$ day) as described previously. The peak flow estimate for TA-50- and TA-48-derived outflow channel 3 using 2.34-hr duration of flow yields $2.1 \mathrm{ft}^{3} / \mathrm{s}$; a continuous flow estimate for this channel yields $0.057 \mathrm{tt}^{3} / \mathrm{s}$. Increased discharge volumes resulting from surface runoff events 
including snow- and icemelt are superimposed on technical area discharges, and peak discharges incorporate these volumes in making such estimates. The major peak discharges observed 60 to $250 \mathrm{ft}^{3} / \mathrm{s}$ ) were in response to simulated rainfall events between 1 and $2.0 \mathrm{in}$. in all scenarios. The majority of peak discharge rates in sc1 and sc2 were between 1 and $10 \mathrm{tt}^{3} / \mathrm{s}$, while most observed events in sc3 were between 1 and $60 \mathrm{tt} /$ day; about 8 of the events in sc 3 were between 20 and $60 \mathrm{ft}^{3} / \mathrm{s}$. Only 3 to 11 events in each scenario exceeded $100 \mathrm{ft}^{3} / \mathrm{s}$ with most of them occurring during the same rain event. Finally, the smaller number of peak discharge events, less that $1 \mathrm{ft}^{3} / \mathrm{s}$, were simulated in all three scenarios. Whereas all peak discharge estimates are affected by the daily water discharges from TA-50 and TA-48, the observed events below $3 \cdot \mathrm{ft}^{3} / \mathrm{s}$ are most affected because these efficient volumes are included in making peak discharge determinations.

\section{Channels, Return Flow}

The volume of water entering a channel and/or alluvium through return flow from adjacent regions for sc1, sc2, and sc3 is presented in Figs. 14a-c. With the exception of channel 3 , return flow for all other channels is observed to occur only during middle to late spring in all scenarios: return flow is not observed in channel 4 for sc2 and only three times in sc3. Additionally, there is a general reduction of return flow events for channels 1 and 2 from sc1 to sc 3 and the presence of return flow events only in channel 3 after the beginning of the frost-free period. The volume of such flow for channels 1 and 2 ranges between 9 and $800 \mathrm{ft}^{3}$ /day when it occurs in sc2 and sc3. Return flow volumes for channel 4 in sc1 ranges between 4 and $8 \mathrm{ft}^{3} /$ day, and a maximum of about $2000 \mathrm{fq}^{3} /$ day was observed in channels 2 and 3 during spring.

Return flow events in channel 3 are more numerous and variable in all scenarios because it lies in an alluvial plain which overlies a mostly saturated aquifer to be described later in this report. BIOTRAN models the transport of moisture to the soil above the aquifer if the potential volume exceeds the volume of the "tipped" aquifer. Thus, the soil contains an additional source of moisture for plant evapotranspiration and for "back". return flow when the amourt exceeds soil field capacity in any or all layers modeled. Hence, return flow in channel 3 for all sceriarios varies from a maximum of about $2400 \mathrm{ft}^{3} /$ day (sc3) during minimal plant moisture use to regligible values during the middle of the growing season and other times. There is also an overall reduction in return flow rates to this channel from sc1 to sc3. Soil moisture enhancement from the aquifer is part of the modeling process.

\section{Channels, Aquifer Transport Losses and Aquifer Heights}

Losses of moisture from the distal aquiter cross sections of channels 1 and 4 are presented in Figs. 15a-c. Corresponding aquifer heights from the bottom of each channel segment are presented in Figs. 16a-c. The flow through distal faces of channels 1 and 2 are observed in a given scenario. Aquifer losses from chanriels 3 and 4 show a similar response to ice formation and also remain fairly constant thereafter. The outflow from the aquifer below channel 3 stabilizes at about $300 \mathrm{ft}^{3} /$ day, and the one below channel 4 stabilizes at loss rates 
about 2100 to $2400 \mathrm{ft}^{3} /$ day depending on the magnitude of runoff events. The latter aquifer is observed to be more sensitive to runoff than is the aquifer below cilannel 3 .

The height of the aquifers below channels 3 and 4 follow a similar pattern to aquifer volume losses in being responsive to ice formation and rainfall events but to a lesser degree. The height of the aquifers below channels 1 and 2 stabilize at $6 \mathrm{ft}$, which is the height of the aquifer at the distal ends of these channels. The height of the aquifer below channel 3 stabilizes at about 1.4 to $15 \mathrm{ft}$, while the one below channel 4 stabilizes at about $35 \mathrm{ft}$ above the bottom of the aquifer at its distal end. Hence, the aquifers below channels 1 and 3 are saturated for the most part throughout the year, while the aquifer below channel 4 is always observed to be near saturation because of the $10453 \mathrm{ft}^{3} /$ day water input described previously. The movement of moisture through the total aquifer appears to be underestimated in the model and may require tuning to give more representative aquifer heights at the designated locations.

\section{N. Channels, Aquifer Volumes}

The dynamic volumes of aquifers below channels 1 to 4 for sc1, sc2, and sc3 are piesented in Figs. 17a-c. With the exception of the aquifer below channel 4 , all other aquifers are near or at saturation during most of the year (100000,40000,400 000, and $21000000 \mathrm{ft}^{3}$ for aquifers below channels 1 to 4 , respectively). Short aquifer depletion periods are observed during snow and ice accumulation periods when they occur. Transient increases in volume ar. observed in response to large simulated rain events but are generally balanced with technical area discharges noted earlier, with a discharge of about $90 \%$ of the daily input into the upper channels (10 $453 \mathrm{tt}^{3} /$ day). Evapotranspiration losses appear to account for about $10 \%$ of this input. This estimate can be further verified by specified output of evapotranspiration losses in subroutine BIOPLT. Aquifer volumes appear to be overestimated, and the model may require tuning to give more representative volume estimates. Note that aquiter discharge to the underlying tutf is currently unknown for Mortandad Canyon and is not modeled

\section{O. Charınels, Sediment Discharges}

The loss of sediments from adjoining regions through the channel network and out of the study area are presented for sc1, sc2, and sc3 in Figs. 18a-c. The losses are coincident with snow- and icemelt processes and major runoff events. The largest single-daily loss rate is observed in sc2 in channel 4 ( $1000000 \mathrm{lbs} /$ day); most of the loss events for all scenarios are observed between 100 and $20000 \mathrm{lbs} /$ day with the majority in the lower range. An exponential decrease of varying slope is observed for sediment removal following a major rain event or during snow and icemelt for all scenarios. The perennial flow through the channels selectively removes sediment particles in a continuous process until another major runoff event provides the channel(s) with additional sediment from the drainage area. This effect is more pronounced for 
channel. 1, which has a higher scouring rate and where this rate may vary from 0.1 to 300000 $\mathrm{lbs} /$ day within a very short time period. 'The sediment discharge from channel 4 is of particular interest because this material is lost from the system together with its associated radionuclide content from the entire watershed area ( 496.9 acres).

\section{DISCUSSION}

The primary dependence of hydrological processes and erosion on the modeling of precipitation events makes it important to specify statistical information on such events as accurately as possible, particularly the number of these events in a given month. The fewer the number of events per month coupled with a significant rainfall traction and large siochastic incrernent, the larger the individual precipitation amount. Combinations of this type occurred in the scenarios to produce events of this type (such as the 2.0 -in. rain in sc3). The assumption of a normal distribution ( $C . v .=0.2$ ) may result in a higher frequency. of large precipitation events if the actual distribution is log-normal and skewed to the lower end of the probability curve. A data set developed by Wenzel (1986) called METDAT includes a 35-yr history of precipitation events in the LANL area and possibly could be used to determine precipitation patterns and distributions more accurately. The inclusion of these events directly in a BIOTRAN scenario would also be of value in testing model assumptions. However, the report of Baldwin (1973) on climates of the US is an excellent reference in the absence of more site-specific data for the development of climatic iriput for BIOTRAN, and it was used extensively to develop the scenarios under discussion.

Onishi et al. (1982) utilized BIOTRAN together with hydrological models ARM,DKWAV, and TODAM to model surface and channel runoff and sediment transport in Mortandad Canyon. BIOTRAN was used to simulate the vegetative cover of the site for $100 \mathrm{yr}$ before hydrological application. The model was calibrated by use of actual precipitation and temperature data for stations in proxirnity to the upper reaches of the canyon (OHL, SM-43, and LAMPF). The precipitation events recorded at these three sites are presented in Table 4 as reported by Onishi et al. (1982). A comparison of these observations with simulated runoff events are presented in Table 5 where available.

Although it was not possible in those scenarios to duplicate areal averages of precipitation for the observed rain events, there is general overlap between simulated and observed surface and channel runoff at GS-1; however, the model yields runoff events which are generally higher than those observed. If the LANL effluent contribution (10 $453 \mathrm{ft}^{3} / \mathrm{day}$, which is equivalent to about $0.1 \mathrm{in}$. of surface runoff and $7.4 \mathrm{ft}^{3} / \mathrm{s}$ at the intersection of channels 1 and 2 with channel 3 called GS-1) is added to the runoff total, then better agreement is observed. It is not known how corrections were made for effluent discharges for a specific observed rain everit, but it is conceivable that some events could be confounded by this component depending on the time and duration of the event. A similar argument can be extended to the estimates of peak discharge and channel runoff by the model. Further study of the conditions under which the observed data were recorded should help in determining whether the model needs tuning of the runoff equations used or whether the input parameters should be adjusted to obtain the desired degree of agreement. Finally, the simulation results involving $s c 3$ should be in closer agreement with observed values because the near-climax vegetation simulated compares more closely to 
TABLE 4. Observed Precipitation Near Mortandad Canyon at Three LANL Sites

\begin{tabular}{|c|c|c|c|c|}
\hline \multirow[b]{2}{*}{ Date } & \multirow[b]{2}{*}{ LAMF } & \multicolumn{2}{|c|}{ Precipitation, Inches } & \multirow[b]{2}{*}{ Area Mean } \\
\hline & & $S M-43$ & $\mathrm{OHL}$ & \\
\hline $7 / 12 / 76$ & & & & 0.39 \\
\hline $7 / 14 / 76$ & 1.19 & & 0.72 & 0.72 \\
\hline $7 / 16 / 76$ & & & & 0.72 \\
\hline $7 / 17 / 76$ & 0.22 & & 1.19 & 0.72 \\
\hline $7 / 20 / 76$ & & & & 0.35 \\
\hline $7 / 21 / 76$ & 0.15 & 0.43 & 0.45 & 0.55 \\
\hline $7 / 22 / 76$ & & & & 0.14 \\
\hline $7 / 26 / 76$ & & & & 0.25 \\
\hline $7 / 27 / 76$ & 0.01 & 0.62 & 0.59 & 0.42 \\
\hline $8 / 1 / 76$ & 0.71 & 0.64 & 0.45 & 0.53 \\
\hline $8 / 11 / 76$ & 0.70 & & 0.81 & 0.81 \\
\hline
\end{tabular}

the actual environment of the study area. The annual moisture runoff from both surface and return flow events predicted by the model is shown in Table 6 .

These simulations compare with the data of Dortignac (1956) for different vegetation zones of the Rio Grande Basin in New Mexico. The data indicate a runoff between $5 \%$ and $10 \%$ of the mean annual precipitation between 14 and $19 \mathrm{in.}$. Considering that the model used mean annual precipitation estimates between 16 and $18 \mathrm{in}$., the simulations are in good agreement, particularly scenario sc1. However, the model also predicts higher total runoff for climax vegetation (sc3) when compared with annual and perennial grasslands and immature forest. The increase in runoff of the mature forest when compared with grassland is probably due to a decrease in ground cover of the latter at climax and an increase of leaf litter; the effect of leat litter on runoff rates was not modeled as it was assumed to be included in crown cover effects. Also, the contribution of the stochastic effects of the model on these predictions requires iurther study.

The simulated discharge of sediment from GS-1, GS-2, and from the distal end of the last channel segment (GS-E) modeled (channel length of $0.5 \mathrm{mi}$ trom GS-2) along with other related output variables are presented below in Table 7.

A comparison between model output and observed values of instantaneous discharge vs suspended sediment loading (Hakonson at al 1976) at the GS.2 weir shows reasonable agreement, although only one event was examined by these observers. In this event a range of instantaneous discharge values between 0.06 and $0.4 \mathrm{~m}^{3} / \mathrm{s}$ were observed. corresponding to a range in suspended sedirnent values between about 10 and $800 \mathrm{~kg} / \mathrm{min}$; the amount of precipitation which caused this runotf was not measured. Model output for mean rain events causing oufflow of sediment at GS-2 for sc3 taken from Table 7 is shown in Table 8.

: 1odel output of these parameters for sc1 and sc2. are comparable although there appears to be a general increase of sc3 values at higher levels of precipitation. The variability of model output indicates that sediment loading is dependent not only on instantaneous discharge 


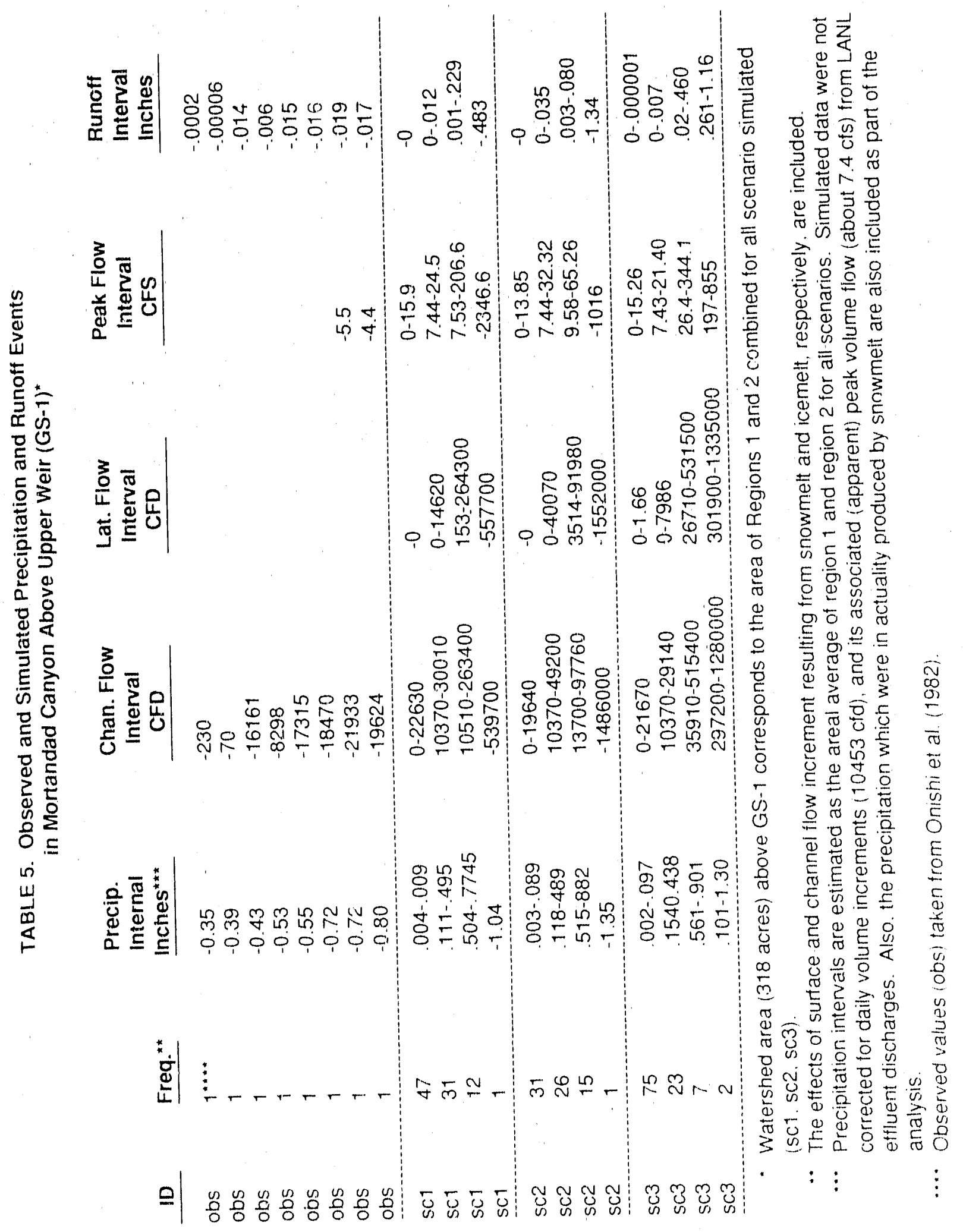


TABLE 6. Simulated Molsture Runoff from Surface and Return Flow Events

\begin{tabular}{|c|c|c|c|}
\hline Scenarlo & Area Used, Acres & Runoff, Inches & Percent \\
\hline sc 1 & $318(17.81)$ & 1.12 & 6.3 \\
\hline sc1 & $434(17.91)$ & 1.22 & 6.8 \\
\hline sct 1 & $497(17.84)$ & 1.31 & 7.3 \\
\hline 502 & $318(19.84)$ & 1.85 & 9.3 \\
\hline$s c 2$ & $434(19.58)$ & 1.88 & 9.6 \\
\hline sc2 & $497(18.87)$ & 1.77 & 9.4 \\
\hline $\operatorname{sc} 3$ & $318(16.26)$ & 2.45 & 15.1 \\
\hline sc3 & $434(17.22)$ & 2.98 & 17.3 \\
\hline $\operatorname{sc} 3$ & $497(16.85)$ & 2.89 & 17.2 \\
\hline
\end{tabular}

"Value in parenthesis is the weighted average precipitation for a watershed above the respective weir.

but also on the avallable amount of suspended sediment available. The modeled sediment discharge rates shown in Figs. 18a-c show an almost continuous discharge, which is expected because of effluent contributions. However, almost six orders of magnitude in discharge are predicted by the model with abrupt increases followed by exponential declines in discharge rates. The abrupt increases are associated with significant runoft events resulting from rainfall, snowmelt, and icemelt.

The mean annual erosion rates for the total watershed area modeled ( 497 acres) are $1.28,1.72$, and 2.74 tons/acre for sc1, sc2, and sc3, respectively. These values are between $25 \%$ and $55 \%$ of the values predicted for "tolerable" croplands ( 5 tons/acre, Branson 1981). The same source reports runoff values for forests of about 1 to 2 tons/acre/yr. If one assumes that row-crop vegetal cover has an average USA erosion rate of abcut 10 tons/acre/yr, then the erosion rates simulated are about $12 \%$ and $28 \%$ of these observations. These simulated erosion rates appear reasonable in that the less mesic climate of Mortandad Canyon might cause higher forest erosion rates when compared with wetter siles having more ground cover. Finally, it should be noted that the model predicts an erosion rate for a near-climax forest of ponderosa pine/pinyon-juniper which is about twice as high as that predicted for the watershed when annual and perennial grasses are the source of ground cover. This predictive outcome deserves further investigation as does sediment loading comparisons between scenarios.

An important goal of this investigation was to predict the movement of surficial deposits of radionuclides into the main channel of Mortandad Canyon and beyond the contines of the most distal outflow models (GS-E). A listing of annual water and sediment budgets leaving this outtlow is presented in Table 9. 


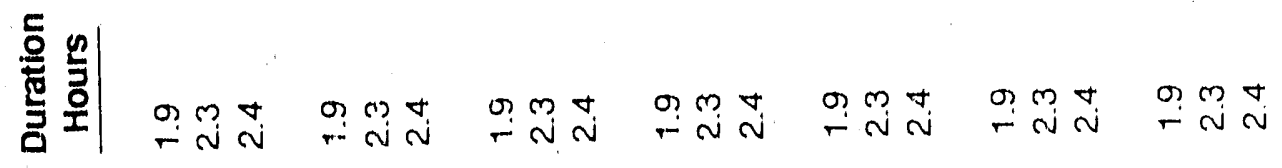

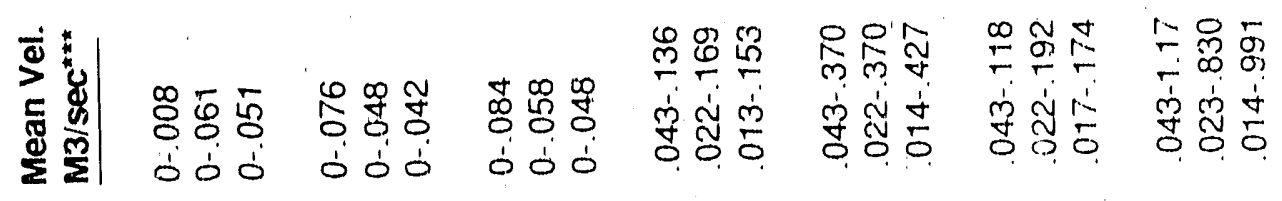

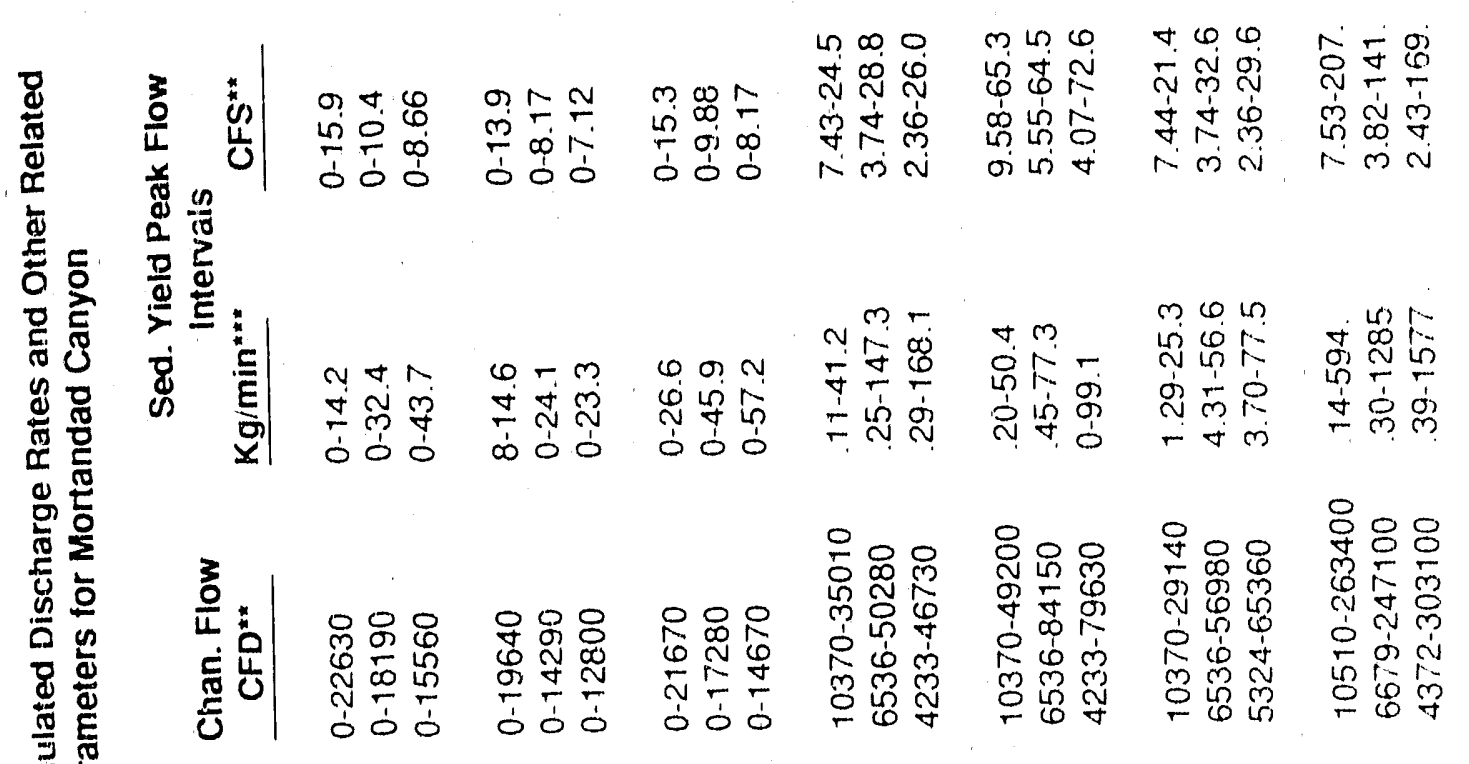

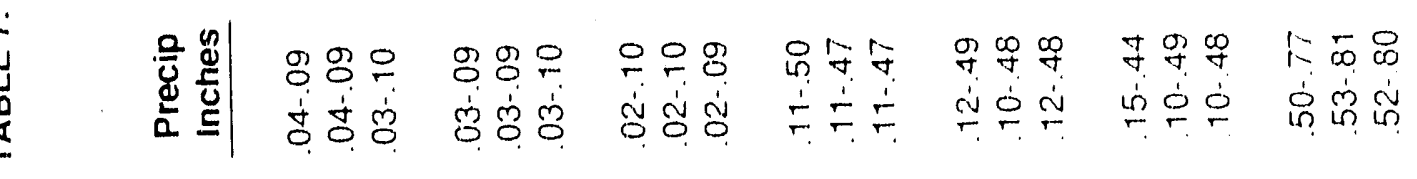

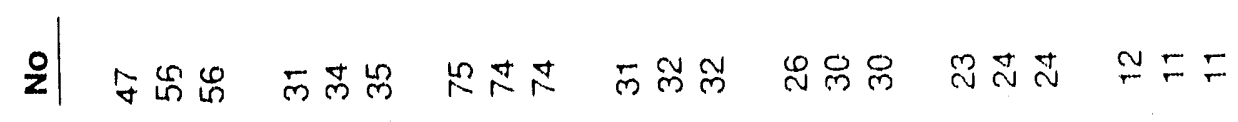

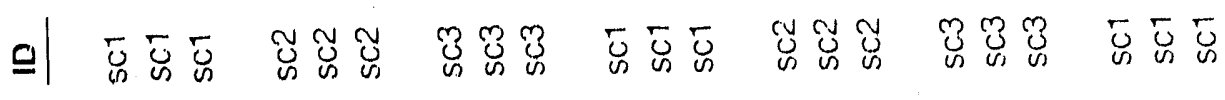

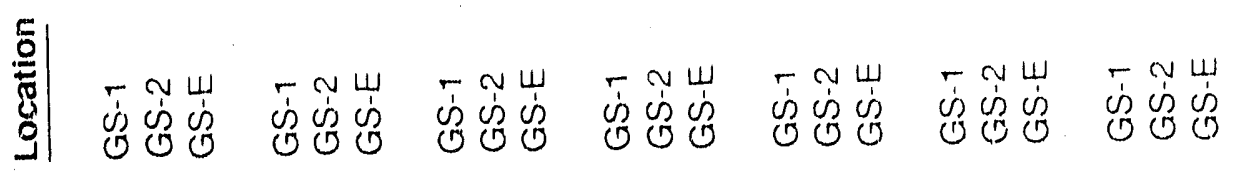




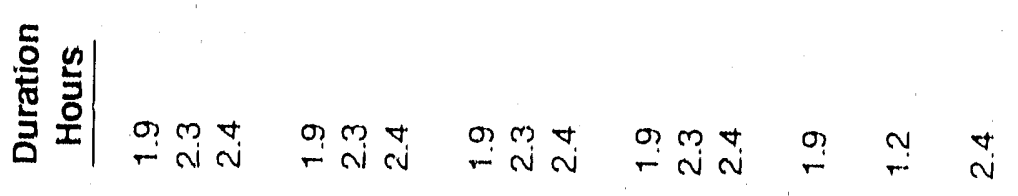

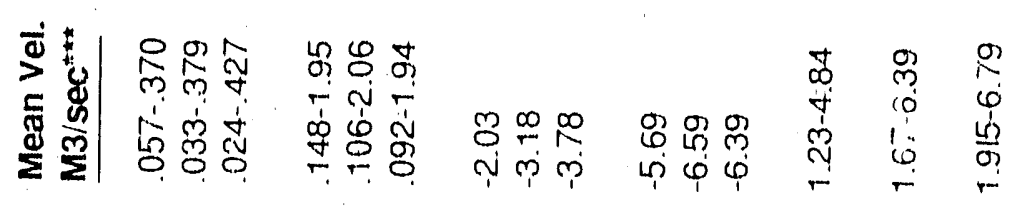

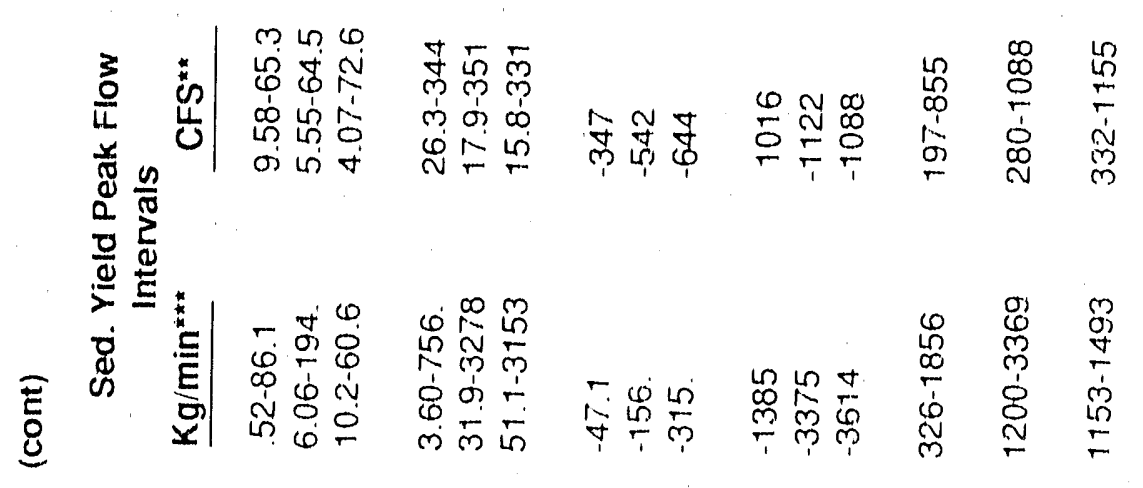

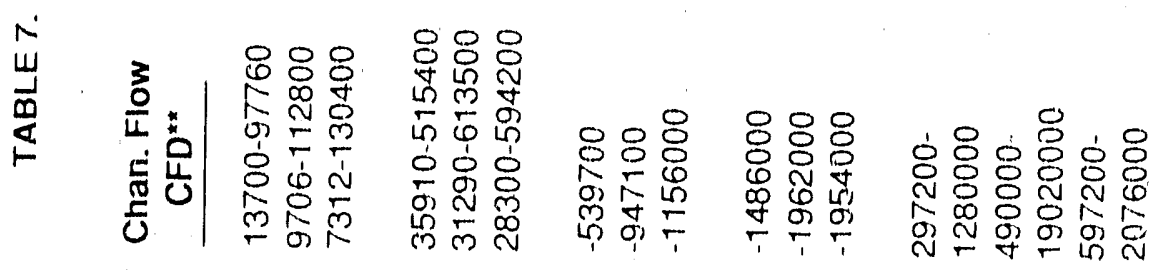

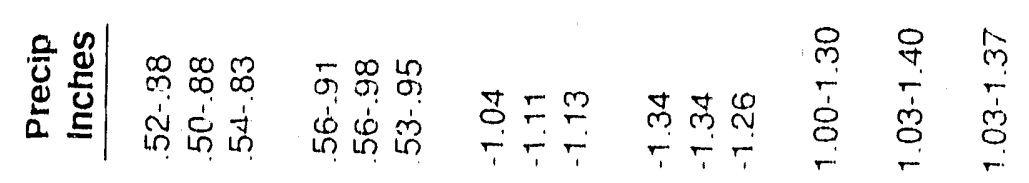

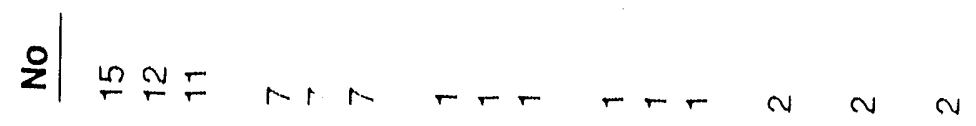

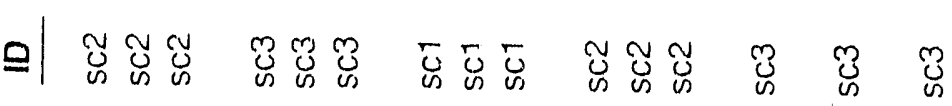

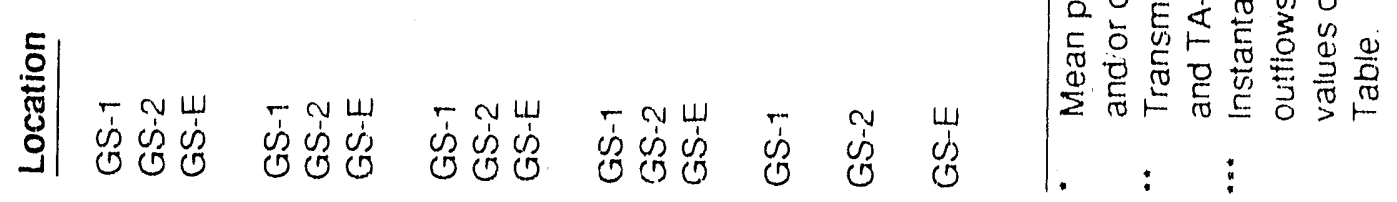


TABLE 8. Simulated Sediment Outflow ai Weir GS*2 for Gcenarlo 3

Mean Precipitation
Inches

$.02-0.1$

$.10 \cdot .49$

$.56-.98$

$1.03-1.40$
Sediment Load

Range

$\mathrm{Kg} / \mathrm{min}$

0.45 .9

$4.31-56.8$

$31.9-2378$

$1200-3369$
Instantaneous Discharge

CMS

0.058

$.022-.192$

$.106-2.06$

$1.67-6.39$

TABLE 9. Annual Water and Sediment Outflows From GS-Z

\begin{tabular}{|c|c|c|c|c|}
\hline $\begin{array}{l}\text { Channel } \\
\text { Loss } \\
\text { CFY }\end{array}$ & $\begin{array}{c}\text { Aquifer } \\
\text { Loss } \\
\text { CFY }\end{array}$ & $\begin{array}{c}\text { Total } \\
\text { Loss } \\
\text { CFY } \\
\end{array}$ & $\begin{array}{c}\text { Adjusted } \\
\text { Loss } \\
\text { CFY* } \\
\end{array}$ & $\begin{array}{c}\text { Sediment } \\
\text { Loss } \\
\text { Lbs/Y }\end{array}$ \\
\hline 2351700 & 766500 & 3118200 & .696800 & 1272320 \\
\hline 2951840 & 766500 & 3718340 & -96660 & 1709680 \\
\hline 4907200 & 766500 & 5673700 & 1858700 & 2723560 \\
\hline
\end{tabular}

"Outflow volume adjusted for TA-50 and TA-48 annual effluent volumie increment of 3815000 cubic leer.

The estimated annual precipitation average based on area for the portion of Mortandad modeled is about 17.84, 18.87, and 16.85 in. for Sc1, sc2, and SC3 (the watershed area modeled equals 496.9 acres), which translates to about 32200000,34000000 , and $30400000 \mathrm{ft}^{3} / \mathrm{yr}$, respectively, for these scenarios. The ratios of the adjusted losses to the latter yleld runoff percentages between $-0.28 \%$ from sc2 to $6.1 \%$ from sc3. Hence, between $94 \%$ and $100 \%$ of precipitation is lost from the watershed as evapotranspiration. However, the model predicts that most if not all of the added effluent volume is lost by both channel and aquiter outflows. Also, the effects of effluent outflow on overall channel transmission of incoming runoff water from the watershed is probably of significance and is worthy of future study.

The mean annual concentration of sediment ranges between 0.54 and $0.58 \mathrm{lbs} / \mathrm{ft}^{3}$. Conservatively assuming that most of the sediment losses are due to the suspended fraction (less than or equal to $63 \mu \mathrm{m}$ ), we can estimate the mean annual radionuclide losses $(4.6 \mathrm{pC} / \mathrm{g} \mathrm{U}$. 238 for this diameter class) to range between 2.66 and $5.53 \mathrm{mCi} / \mathrm{yr}$. The total assumed activity for the entire watershed is modeled to be $141.76 \mathrm{mCl}$; hence, between $1.9 \%$ and $3.9 \%$ of the total inventory of the watershed is predicted to be lost from the system arnually. It should be noted that these losses also assume a homogeneous distribution of U-238 on the soll surface. For radioactive waste sites that concentrate contaminants over much smaller areas of a watershed and where waste is buried below the surtace, one would expect much smaller loss rates. In lact, a great deal of activity dilution would be expected from uncontaminated sediments entering the channel at the same timie. Again, the mature lorest shows the largest simulated losses (sc3). 
The fact that effluent from TA-50 contains radionuclides such as plutonium-239, uranium. 238, americlum-241, and cesium-137 (Hakorison 1973) that enter the drainage channels would warrant the development or Inclusion Into BIOTRAN of radionuclide partitioning between aqueous and sediment phases (partition coefficients). Onishl et al. (1982) used the data of Hakonson (1976) 10 estimate adsorption of Pu-239 on channel sediments, and this information could be incorporated into the miodel for this purpose. The present simulation assumed that the major fraction of U-238 was present in the sediments and solls of Mortandad Canyon with only a small fraction present in the aqueous phase during runoff events.

\section{ACKNOWLEDGMENTS}

Development of the hydrogeological portions for the BIOTRAN model was inspired by the leadership of Wayne R. Hanson. Tom Buhl, and Ken Rea at LANL. Many others assisted in the early conception of a higher resolution model to simulate watersheds for risk assessment purposes. We are indebted to Bill Purtymun for assisting during set up of the Mortandad Canyon input and to Everett Springer for his excellent technical review and guidance. Special thanks go to Gloria Brito for her patient and thorough report preparation and word processing skills.

\section{VII, REFERENCES}

Baldwin, J. L., 1973. Climates of the United States. U.S. Dept. of Commerce, NOAA, Washington, D.C.

Baltz, E. H., J. H. Abrahams, and W. D. Purtymun, 1963. Preliminary Report on the Geology and Hydrology of Mortandad Canyon Near Los Alamos, New Mexico, With Reference to Disposal of Low-Level Radioactive waste. United States Department of the Interior Geological Survey in Cooperation with USAEC and LASL. Open-File Report, Los Alamos, NM.

Branson, F. A., et al., 1981. "Rangeland Hydrology." 2nd ed., Society for Range Management, Denver, Colorado, Kendall/Hunt Publishing Co., Dubuque, lowa.

Cole, G. W., et al., 1976. "ELM: Version 2.0." Colorado State University Range Sciences Department. Science Series 20. Colorado State University, Fort Collins, Colorado.

Dortignac, E. J., 1956. "Watershed Resources and Problems of the Upper Rio Grande Basin. U. S. Forest Service, Rocky Mountain Forest and Range Experimental Station, $107 \mathrm{p}$.

Gallegos, A. F., B. J. Garcia, and C. M. Sutton, 1980. Documentation of TRU Biological Transport Model (BIOTRAN). Los Alamos National Laboratory Report, LA-8213-MS, LoS Alamos National Laboratory, Los Alamos, New Mexico.

Gallegos, A. F., and W. J. Wenzel, 1984. HUMTRN: Documentation and Verification For an ICRP-Based Age and Sex-Specific Human Simulation Model for Radionuclide Dose Assessment. Lus Alamos National Laboratory Report, L.A-99994-MS, L.os Alamos National Laboratory, L.os Alamos, New Mexico. 
Gallegos, A. F., W. J. Wenzel, and M. E. Ennis, 1990. BIOTRAN Users Manual: Los Alamos National Laboratory Report, in preparation.

Gilbert, B. J., 1974. "Range IV Grassland Simulation Model, Reglonal Analysls of Grasslarid Environmental Systems." Colorado State University Report 17-18. Colorado State University, Fort Collins, Colorado.

Hann, C. T., et al., Eds., 1982. "Hydrologic Modeling of Small Watersheds." Amerlcan Soclety of Agricultural Engineers, St. Joseph, Michigan.

Hakonson, T. E., et al., 1973. Ecology Investigation of Radioactive Materials in Waste Discharge Areas. Los Alamos National Laboratory Report, LA-5282-MS, Los Alamos National Laboratory, Los Alamos, New Mexicn.

Hakonson, T. E., et al., 1976. "Accumulation and Transport of Soll Plutonium in Liquild Waste Discharge Areas at Los Alamos." Transuranic Nuclides in the Environment, IAEA, Vienna.

Hillel, D., and C. H. M. Von Bavel, 197€ "Simulation of Profile Water Storage as Related to Soil Hydraulic Properties." Soll Science Journal (40:6), pp 807-815.

Knisel, W. G., Ed., 1980. "CREAMS: A Field-Scale Model for Chemicals, Runoff, and Erosion from Agricultural Management Systems," U.S. Dept. of Agric... Conservation Research Report 26.

Lane, L. J., et al., 1985. New Estimating Procedures for Surface Runolf, Sediment Yield and Contaminant Transpont in Los Alamos County, New Mexico. Los Alamos National Laboratory Report, LA-10335-MS. Los Alamos National Laboratory, Los Alamos, New Mexico.

Nyhan, J. W., et. al., 1980. Soll Plutonium and Cesium in Stream Channels and Banks of Los Alamos Liquid Effluent-Receiving Areas. Los Alamos National Laboratory Document, LA. UR-80-1184. Los Alamos National Laboratory, Los Alamos, New Mexico.

Ohishi, Y., et al., 1982. Development of a Multimedia Radionuclide Exposure Assessment Methodo.jgy for Low-Level Waste Management. Pacific Northwest Laboratory Report, PNL. 3370. Pacific Northwest Laboratory, Richland, Washington.

Purtymun, W. D., 1974. Dispersion and Movement of Tritium in a Shallow Aquifer in Mortandad Canyon at the Los Alamos Scientific Laboratory. Los Alamos National Report, LA-5\%16-MS. Los Alamos National Laboratory, Los Alamos, New Mexico.

Wenzel, W. J., and A. F. Gallegos, 1985. EFFECTS: Documentation and Verification for a BEIR III Cancer Risk Model for BIOTRAN. Los Alamos National Laboratory Report, LA-10371. MS. Los Alamos National Laboratory, Los Alamos, New Mexico. 
Wenzel, W. J., et al., 1987. Cesium-137, Plutonium-239/240, Total Uranium and Scandium in Trees' and Shrubs Growing in Transuranic Waste at Area B. Los Alamos National Laboratory Report, LA-11126-MS. Los Alamos National Laboratory, Los Alamos, New Mexico.

Wenzel, W. J., et al., 1986. METDAT. Los Alamos National Laboratory unpublished data, Los Alamos National Laboratory, Los Alamos, New Mexico.

Wight, J. R., et al., 1982. "SPUR-Simulation of Production and Utilization of Rangelands: A Rangeland Model for Management and Research." U.S. Dept. of Agric., Agricultural Research Service, Miscellaneous Pub. 1431. 

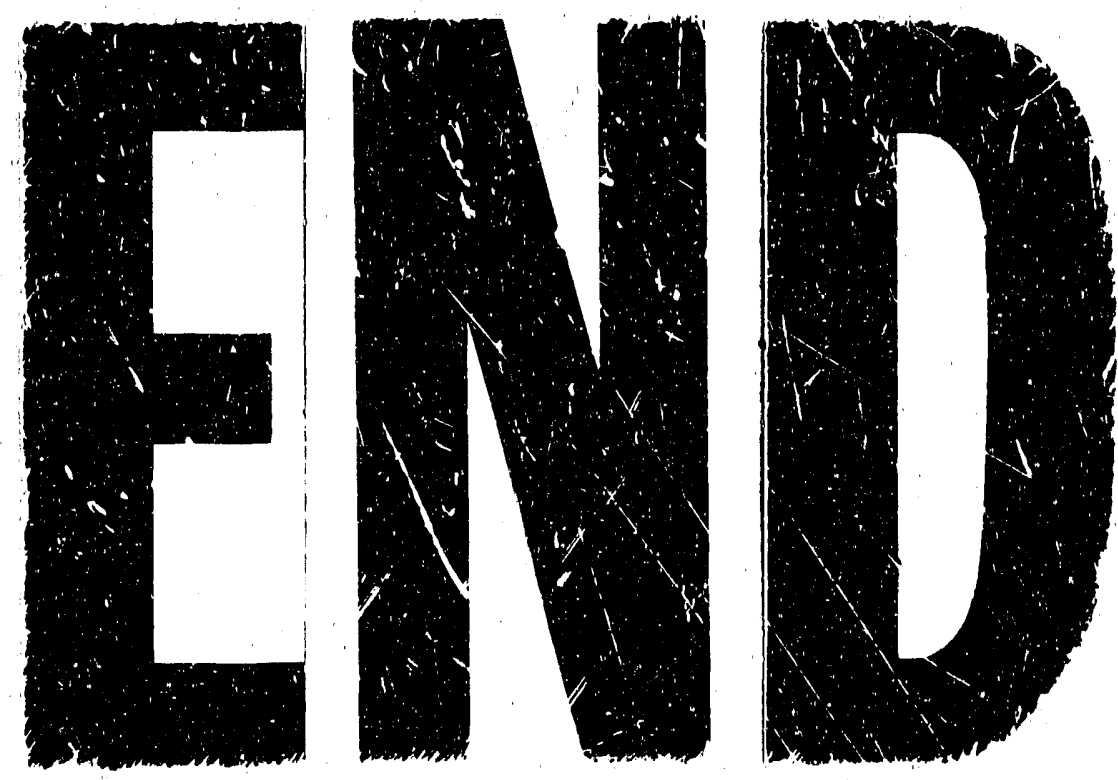

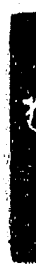
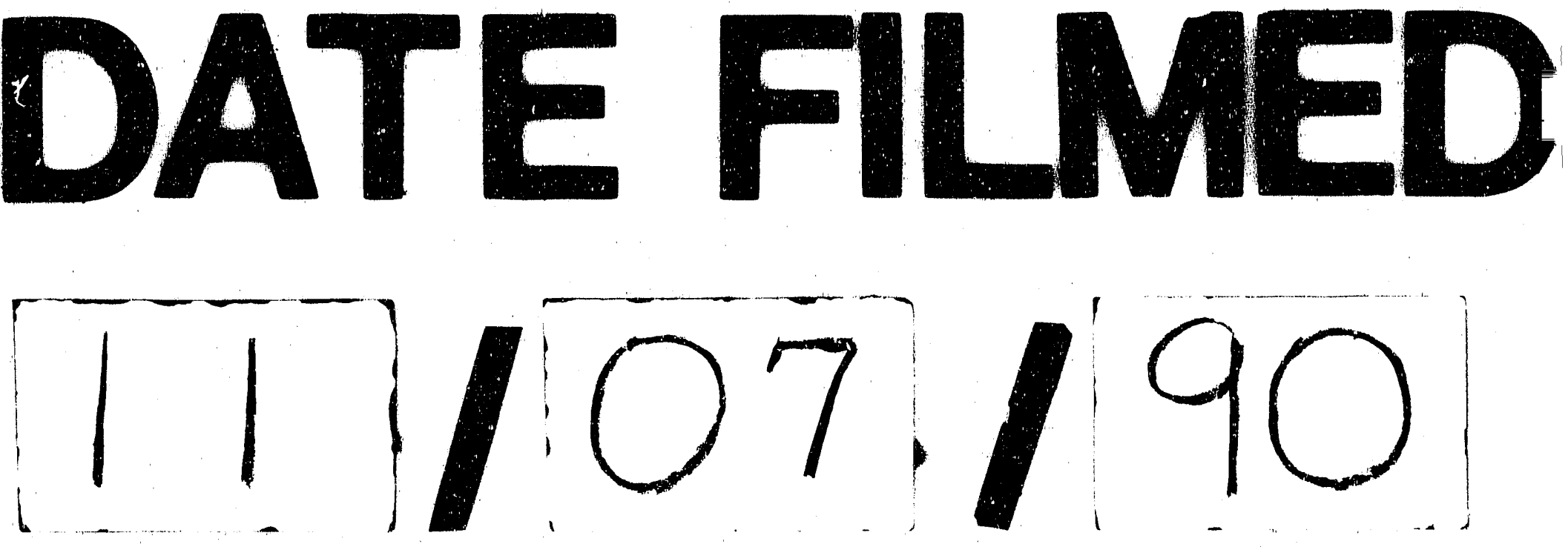
